Fernando Lemos de Mello

\title{
Estudo e Implementação de um Gerador de Tráfego com Dependência de Longa Duração
}

\author{
Dissertação apresentada à Escola \\ Politécnica da Universidade de São \\ Paulo para obtenção do Título de \\ Mestre em Engenharia Elétrica.
}


Fernando Lemos de Mello

\section{Estudo e Implementação de um Gerador de Tráfego com Dependência de Longa \\ Duração}

Dissertação apresentada à Escola

Politécnica da Universidade de São

Paulo para obtenção do Título de

Mestre em Engenharia Elétrica.

Área de concentração:

Sistemas Eletrônicos

Orientador:

Prof. Dr. José Roberto de Almeida Amazonas 


\section{Ficha Catalográfica}

Mello, Fernando Lemos de

Estudo e Implementação de um Gerador de Tráfego com Dependência de Longa Duração. São Paulo, 2006. 144 p.

Dissertação (Mestrado) - Escola Politécnica da Universidade de São Paulo. Departamento de Engenharia de Telecomunicações e Controle.

1. Gerador de tráfego. 2. Wavelets. 3.Auto-similaridade I. Universidade de São Paulo. Escola Politécnica. Departamento de Engenharia de Telecomunicações e Controle. II.t. 


\section{Agradecimentos}

Agradeço a meus pais por todo o suporte ao longo da minha vida. À minha filha, pela alegria que representa. À minha esposa, pelo incentivo, paciência e amor. A todos os amigos que me apoiaram e ajudaram na realização deste trabalho. Em especial a meu orientador, Prof. Dr. José Roberto de A. Amazonas, ao Prof. Dr. Luiz Antonio Baccalá e aos amigos Msc. Alexandre B. de Lima e Marcelo Lipas do Laboratório de Comunicações e Sinais (LCS) da Escola Politécnica da USP. 


\section{Resumo}

Medidas mostraram que o tráfego das redes multisserviço possui propriedades fractais tais como auto-similaridade e memória longa ou dependência de longa duração (LRD). A memória longa é caracterizada pela existência de um pólo na origem da função densidade espectral de potência (formato $1 / f$ ). Também foi constatado que o tráfego pode apresentar dependência de curta duração (SRD) em algumas escalas temporais. A utilização de um gerador de tráfego agregado "realista", que sintetize séries temporais fractais, é fundamental para a validação de algoritmos de controle de tráfego.

Neste trabalho, a síntese de realizações aproximadas de dois tipos de processos aleatórios auto-similares é efetuada via transformada wavelet. O primeiro deles é denominado Ruído Gaussiano Fracionário (fGN) e o segundo Modelo Wavelet Multifractal (MWM).

O método proposto também é capaz de sintetizar séries Gaussianas (fGN) e não-Gaussianas (MWM) com espectros mais genéricos do que $1 / f$, ou seja, séries que também apresentam dependência de curta duração. A geração é feita em dois estágios. O primeiro gera uma realização aproximada do fGN ou do MWM via Transformada Wavelet Discreta (DWT). O segundo estágio introduz SRD através de uma filtragem IIR da saída do primeiro estágio. Efetuou-se uma caracterização detalhada das séries resultantes, utilizando-se nas análises momentos estatísticos de $2^{\underline{a}}, 3^{\underline{a}}$ e $4^{\underline{a}}$ ordens, além de testes estatísticos específicos para séries autosimilares.

Adicionalmente, duas alternativas de conversão são apresentadas para que as séries temporais geradas sejam transformadas em séries de pacotes, que é o formato adequado para transmissão por um módulo gerador de pacotes. As séries de pacotes são novamente analisadas a fim de identificar se o método de conversão introduz distorção nas características auto-similares das séries sintetizadas. Mostra-se que as séries de pacotes auto-similares podem ser utilizadas em softwares simuladores de rede ou, alternativamente, serem utilizadas para injetar pacotes em redes de teste.

Utilizando-se recursos do simulador NS-2, as séries de pacotes sintetizadas foram introduzidas em cenários de simulação adequados. Os resultados (medidas de atraso médio, perda de pacotes para o tráfego de interesse e tamanho da fila) dos cenários com tráfego interferente correspondente às séries de pacotes baseadas em modelos fGN e MWM foram comparados com resultados obtidos em cenários cujo tráfego interferente foi gerado com modelo Poisson. 


\section{Abstract}

Measurements have shown that multiservice network traffic has fractal properties such as self-similarity and long memory or long-range dependence (LRD). Long memory is characterized by the existence of a pole at the origin of the power spectrum density function ( $1 / f$ shape). It was also noticed that traffic may present short-range dependence (SRD) at some time scales. The use of a "realistic" aggregated network traffic generator, one that synthesizes fractal time series, is fundamental to the validation of traffic control algorithms.

In this document, the synthesis of approximate realizations of two kinds of self-similar random process is done via wavelet transform. The first one is named Fractional Gaussian Noise (fGN) and the second Multifractal Wavelet Model (MWM).

The proposed method is also capable of synthesizing Gaussian (fGN) and non-Gaussian (MWM) time series with more generic spectra than $1 / f$, that is, time series that also have short-range dependence. The generation is done in two stages. The first one generates an approximate realization of fGN or MWM via Discrete Wavelet Transform (DWT). The second one introduces SRD through Infinite Impulse Response (IIR) filtering at the output of the first stage. A detailed characterization of the resulting series was done, using statistical moments of first, second, third and forth orders, as well as specific statistical tests for self-similar series.

Additionally, two alternatives for conversion are introduced in order to generate packet series, which is the suitable format for transmission by a packet generator module, from the original synthesized time series. Packet series are also analyzed to find if the conversion method has introduced distortion in the self-similar characteristics of the synthesized series. It is shown that the selfsimilar packet series can be used in network simulator software or, alternatively, be used to inject packets in a testbed network.

Using resources from the NS-2 simulator, the synthesized packet series were introduced in appropriate network simulator scenarios. The results (average delay measurements, packet loss for interest traffic and queue length) from scenarios with interfering traffic corresponding to the packet series based on fGN and MWM models were compared to results from scenarios with interfering traffic generated by Poisson model. 


\section{Sumário}

\section{Lista de Figuras}

\section{Lista de Tabelas}

\section{Lista de Abreviaturas}

1 Introdução 1

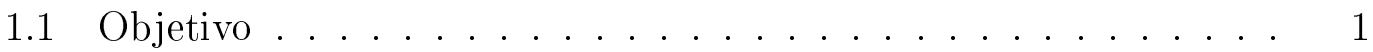

1.2 Organização do Trabalho . . . . . . . . . . . . . . . 2

1.3 Contexto e Motivação . . . . . . . . . . . . . . 2

$\begin{array}{llr}2 & \text { Revisão Teórica } & 7\end{array}$

2.1 Introdução . . . . . . . . . . . . . . . 7

2.2 Geradores de Tráfego . . . . . . . . . . . . . . 8

2.3 Modelos de Tráfego . . . . . . . . . . . . . . . . . . 15

2.3.1 Conceitos Básicos para Análise de Séries Temporais . . . . 15

2.3.2 Dependência de Longa Duração . . . . . . . . . . . . . 17

2.3.3 Fractais .................... 20

2.3.4 Auto-similaridade . . . . . . . . . . . . 22

2.3.5 Ruído Gaussiano Fracionário (fGN) . . . . . . . . . 26

2.3.6 Análise e Síntese de Sinais com Wavelets . . . . . . . . . 30

2.3.7 Modelo Wavelet Multifractal (MWM) . . . . . . . . . 42

3 Geração e Análise de Séries Temporais 49

3.1 Síntese de Séries Temporais via Wavelets . . . . . . . . . . . 49

3.1 .1 Geração de Séries com DEP $1 / f \ldots . . . . . . .554$ 
3.1.2 Geração de Séries LRD Gaussianas . . . . . . . . . . 54

3.1.3 Geração de Séries LRD Não-Gaussianas pelo modelo MWM 56

3.1 .4 Inserção de SRD . . . . . . . . . . . . 57

3.2 Análise Estatística . . . . . . . . . . . . . . 59

3.2.1 Análise das Séries Gaussianas ........... 59

3.2.2 Análise das Séries não-Gaussianas do Modelo MWM . . . 68

4 Séries de Tráfego e Simulação $\quad 73$

4.1 Introdução . . . . . . . . . . . . . . . . . . 73

4.2 Conversão de Séries Temporais em Séries de Pacotes . . . . . . . . 74

4.2.1 Conversão para série de chunks em intervalos equiespaçados 74

4.2.2 Conversão para série de pacotes de tamanho constante . . 86

4.3 Uso de Tráfego LRD em Cenários de Simulação . . . . . . . . . . 95

4.3.1 Interface com o Simulador NS-2 . . . . . . . . . 95

4.3.2 MWM conversão $1 \ldots \ldots$. . . . . . . . . . . 98

4.3.3 MWM conversão $2 \ldots \ldots$. . . . . . . . . . 108

4.3.4 fGN conversão $1 \ldots \ldots$. . . . . . . . . . . 118

4.3 .5 fGN conversão $2 \ldots \ldots$. . . . . . . . . . 127

4.3.6 Consolidação dos resultados de simulação . . . . . . . . . 137

5 Conclusão

5.1 Sumário e Contribuições . . . . . . . . . . . . . . 138

5.2 Sugestões para Trabalhos Futuros . . . . . . . . . . . . 139 


\section{Lista de Figuras}

2.1 Diagrama de blocos de um gerador de tráfego . . . . . . . . . 12

2.2 Distribuição amostral de $\bar{x}$, extraída de (LIMA, 2002) . . . . . . . 18

2.3 Conjunto de Cantor (cinco iterações), extraída de (LIMA, 2002). 21

2.4 Comparação de realizações de tráfego . . . . . . . . . . . . . 23

2.5 DEPs de processos $\operatorname{AR}(4), \operatorname{FD}(0,4)$ e $\operatorname{fGN}(0,9)$ de mesma potência 29

2.6 Função de escala e wavelet de Haar com $j=0$ e $k=0 \ldots 39$

2.7 Função de escala e wavelet de Haar com $j=1$ e $k=0 \ldots 40$

2.8 Função de escala e wavelet de Daubechies ordem 2 com $j=0 \mathrm{e}$ $k=0 \ldots \ldots \ldots \ldots \ldots \ldots \ldots \ldots$

2.9 Função de escala e wavelet de Daubechies ordem 2 com $j=1 \mathrm{e}$

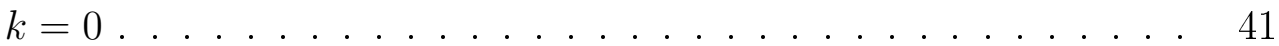

2.10 Construção iterativa da cascata binomial, extraída de (RIEDI et al., 1999). ........................ 44

2.11 Árvore binária dos coeficientes de escala. . . . . . . . . . . . . . 45

$2.12 \operatorname{PDF} g_{A}(a)$ de uma variável aleatória $A$ de distribuição $\beta(p, p)$ para alguns valores do parâmetro $p$, extraída de (RIEDI et al., 1999). . . 47

3.1 Coeficientes necessários para reconstrução da função original considerando utilização de filtro wavelet com $N=2$. . . . . . . . 52

3.2 Algoritmo de Reconstrucao baseado na IDWT . . . . . . . . . 53

3.3 Realização de um processo $1 / f$ obtida através do método wavelet. 56

3.4 Série fGN aproximada gerada pelo método FFT de Paxson, com

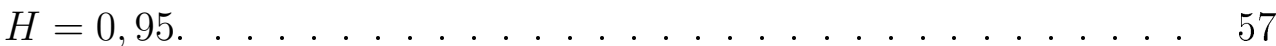

3.5 Realizações do modelo MWM. . . . . . . . . . . . . . 58

3.6 Filtro IIR utilizado para enfatizar médias freqüencias. . . . . . . 58

3.7 Autocorrelação de algumas séries geradas pelo método da FFT . . 62 
3.8 Periodograma suavizado de algumas séries geradas pelo método da

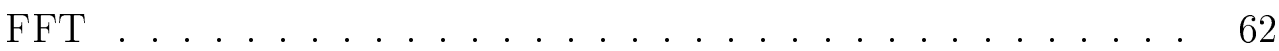

3.9 Autocorrelação de algumas séries geradas via wavelets . . . . . . 63

3.10 Periodograma suavizado de algumas séries geradas via wavelets . 63

3.11 Curva $H$ versus $\hat{H}$ para séries geradas via FFT . . . . . . . . 64

3.12 Curva $H$ versus $\hat{H}$ para séries geradas via wavelets . . . . . . 65

3.13 Autocorrelação de séries filtradas . . . . . . . . . . . 66

3.14 Periodograma suavizado de séries filtradas . . . . . . . . . 66

3.15 Curva $H$ versus $\hat{H}$ (método de Whittle) para séries filtradas . . . 67

3.16 Curva $H$ versus $\hat{H}$ (método do periodograma) para séries filtradas 68

3.17 Periodogramas das realizações MWM da Figura 3.5. . . . . . . . . 69

3.18 Gráficos de $H$ versus $\hat{H}$ utilizando: a) método de Whittle, b) método do Periodograma. . . . . . . . . . . 70

3.19 Periodogramas das realizações MWM da Figura 3.5, após filtragem passa-bandas. ....................... 71

3.20 Gráfico de $H$ versus $\hat{H}$ após filtragem passa-bandas, utilizando: a) método de Whittle, b) método do Periodograma. . . . . . . . . 72

4.1 Exemplo de trace após conversão para série de chunks em intervalos

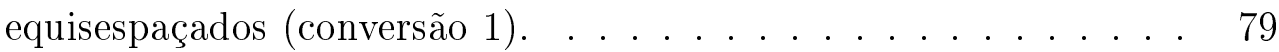

4.2 Comparação entre série temporal MWM e série de chunks, com $\mathrm{H}=0,8$ (conversão 1$) \ldots \ldots \ldots$. . . . . . . . . . . 82

4.3 Periodograma para série temporal MWM com $\mathrm{H}=0,8 \ldots$. . . . . 83

4.4 Periodograma para série de chunks MWM com $\mathrm{H}=0,8$ (conversão 1). 83

4.5 Comparação entre série temporal fGN e série de chunks, com $\mathrm{H}=0,8$ (conversão 1). . . . . . . . . . . . . . . . . . 84

4.6 Periodograma para série temporal fGN com $\mathrm{H}=0,8 \ldots \ldots$. . . . 85

4.7 Periodograma para série de chunks fGN com $\mathrm{H}=0,8$ (conversão 1). 85

4.8 Exemplo de trace após conversão para série de pacotes de tamanho constante, distribuídos uniformemente dentro do período de um bin (conversão 2) . . . . . . . . . . . . . . . . . 89 
4.9 Comparação entre série temporal MWM e série de número de pacotes, com $\mathrm{H}=0,8$ (conversão 2) . . . . . . . . . . . . 91

4.10 Periodograma para série temporal MWM com $\mathrm{H}=0,8 \ldots \ldots$. . . . 92

4.11 Periodograma para série de número de pacotes MWM com $\mathrm{H}=0,8$ (conversão 2) . . . . . . . . . . . . . . . . . . 92

4.12 Comparação entre série temporal fGN e série de número de pacotes, com $\mathrm{H}=0,8$ (conversão 2). . . . . . . . . . . . . . . . 93

4.13 Periodograma para série temporal fGN com $\mathrm{H}=0,8$. . . . . . . . 94

4.14 Periodograma para série de número de pacotes fGN com $\mathrm{H}=0,8$ (conversão 2) . . . . . . . . . . . . . . . . . 94

4.15 Cenário de simulação para série do modelo MWM, conversão 1, com $H=0,8$ e $T X_{a v g}=2$ Mbps. . . . . . . . . . . 98

4.16 Série de bytes/bin para o modelo MWM com $H=0,8$ e $T X_{a v g}=$

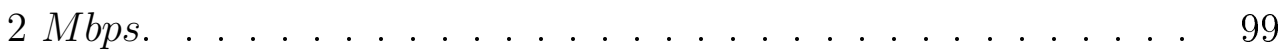

4.17 Atraso médio para o tráfego de interesse - cenário MWM - conversão 1. . . . . . . . . . . . . . . . . . 100

4.18 Perda de pacotes do tráfego de interesse - cenário MWM - conversão 1. . . . . . . . . . . . . . . . . . . . 101

4.19 Comprimento médio da fila - cenário MWM - conversão 1. . . . . 101

4.20 Perda de pacotes do tráfego agregado na fila - cenário MWM conversão 1. . . . . . . . . . . . . . . . . 102

4.21 Cenário de simulação de referência, Poisson com $T X_{a v g}=2 \mathrm{Mbps}$ e tamanho de pacotes 1518 bytes. . . . . . . . . . . . 103

4.22 Atraso médio para o tráfego de interesse - cenário Poisson - 2 Mbps com pacotes de 1518 bytes. . . . . . . . . . . . . . . . 105

4.23 Perda de pacotes do tráfego de interesse - cenário Poisson - 2 Mbps com pacotes de 1518 bytes. . . . . . . . . . . . . 106

4.24 Comprimento médio da fila - cenário Poisson - 2 Mbps com pacotes de 1518 bytes. . . . . . . . . . . . . . . 106

4.25 Perda de pacotes do tráfego agregado na fila - cenário Poisson 2 Mbps com pacotes de 1518 bytes. . . . . . . . . . . . 107 
4.26 Cenário de simulação para série do modelo MWM, conversão 2 com pacotes de 150 bytes, $H=0,8$ e $T X_{\text {avg }}=2$ Mbps. . . . . 108

4.27 Série de pacotes/bin para o modelo MWM com $H=0,8, T X_{a v g}=$ 2 Mbps e método de conversão 2 com pacotes de 150 bytes. . . . . 109

4.28 Atraso médio para o tráfego de interesse - cenário MWM - conversão 2. . . . . . . . . . . . . . . . . . 110

4.29 Perda de pacotes do tráfego de interesse - cenário MWM - conver-

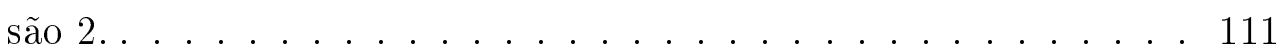

4.30 Comprimento médio da fila - cenário MWM - conversão 2. . . . . 111

4.31 Perda de pacotes do tráfego agregado na fila - cenário MWM conversão 2. . . . . . . . . . . . . . . . . . . 112

4.32 Cenário de simulação de referência, Poisson com $T X_{a v g}=2 \mathrm{Mbps}$ e tamanho de pacotes 150 bytes. . . . . . . . . . 113

4.33 Atraso médio para o tráfego de interesse - cenário Poisson - 2 Mbps com pacotes de 150 bytes. . . . . . . . . . . . . 115

4.34 Perda de pacotes do tráfego de interesse - cenário Poisson - 2 Mbps com pacotes de 150 bytes. . . . . . . . . . . . . . 116

4.35 Comprimento médio da fila - cenário Poisson - 2 Mbps com pacotes de 150 bytes. . . . . . . . . . . . . . . . 116

4.36 Perda de pacotes do tráfego agregado na fila - cenário Poisson 2 Mbps com pacotes de 150 bytes. . . . . . . . . . . 117

4.37 Cenário de simulação para série do modelo fGN, conversão 1, com $H=0,8$ e $T X_{a v g}=50$ Mbps. . . . . . . . . . 118

4.38 Série de bytes/bin para o modelo fGN com $H=0,8$ e $T X_{\text {avg }}=$ 50 Mbps............................ 119

4.39 Atraso médio para o tráfego de interesse - cenário fGN - conversão 1.120

4.40 Perda de pacotes do tráfego de interesse - cenário fGN - conversão 1.121

4.41 Comprimento médio da fila - cenário fGN - conversão 1. . . . . . 121

4.42 Perda de pacotes do tráfego agregado na fila - cenário fGN - conversão 1. . . . . . . . . . . . . . . . . . . . . 122

4.43 Cenário de simulação de referência, Poisson com $T X_{a v g}=50 \mathrm{Mbps}$ e tamanho de pacotes 1518 bytes. . . . . . . . . . . 123 
4.44 Atraso médio para o tráfego de interesse - cenário Poisson - 50 Mbps com pacotes de 1518 bytes. . . . . . . . . . . . . . . . . . 124

4.45 Perda de pacotes do tráfego de interesse - cenário Poisson - 50 Mbps com pacotes de 1518 bytes. . . . . . . . . . . . . . 125

4.46 Comprimento médio da fila - cenário Poisson - 50 Mbps com pacotes de 1518 bytes. . . . . . . . . . . . . . . . . . 125

4.47 Perda de pacotes do tráfego agregado na fila - cenário Poisson 50 Mbps com pacotes de 1518 bytes. . . . . . . . . . . . 126

4.48 Cenário de simulação para série do modelo fGN, conversão $2 \mathrm{com}$ pacotes de 150 bytes, $H=0,8$ e $T X_{\text {avg }}=50$ Mbps. . . . . . 127

4.49 Série de pacotes/bin para o modelo fGN com $H=0,8, T X_{a v g}=$ 50 Mbps e método de conversão 2 com pacotes de 150 bytes. . . . 128

4.50 Atraso médio para o tráfego de interesse - cenário fGN - conversão 2.129

4.51 Perda de pacotes do tráfego de interesse - cenário fGN - conversão 2.130

4.52 Comprimento médio da fila - cenário fGN - conversão 2 . . . . . 130

4.53 Perda de pacotes do tráfego agregado na fila - cenário fGN - con-

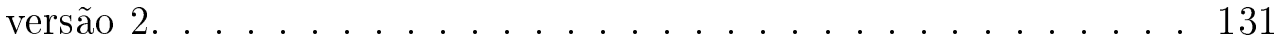

4.54 Cenário de simulação de referência, Poisson com $T X_{a v g}=50 \mathrm{Mbps}$ e tamanho de pacotes 150 bytes. . . . . . . . . . . . 132

4.55 Atraso médio para o tráfego de interesse - cenário Poisson - 50 Mbps com pacotes de 150 bytes. . . . . . . . . . . . . . 134

4.56 Perda de pacotes do tráfego de interesse - cenário Poisson - 50 Mbps com pacotes de 150 bytes. . . . . . . . . . . . . 135

4.57 Comprimento médio da fila - cenário Poisson - 50 Mbps com pacotes de 150 bytes. . . . . . . . . . . . . . 135

4.58 Perda de pacotes do tráfego agregado na fila - cenário Poisson 50 Mbps com pacotes de 150 bytes. . . . . . . . . . . 136 


\section{Lista de Tabelas}

2.1 Valores assintóticos para o parâmetro $p$ da distribuição beta como função de $\alpha($ ou $H) \ldots \ldots \ldots \ldots \ldots$. . . . . . . . . . . 48

3.1 Estimativas de assimetria e curtose das séries geradas via FFT e

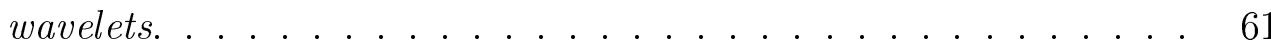

3.2 Estimativas de assimetria e curtose das séries geradas via wavelets após filtragem. . . . . . . . . . . . . 65

3.3 Estimativas de assimetria e curtose para as séries do modelo MWM. 69

3.4 Estimativas da assimetria e curtose para as séries do modelo MWM após filtragem passa-bandas. . . . . . . . . . . . . 71

4.1 Tabela de intervalos ideais para a média $T X_{a v g}$ e de valor sugerido para $T X_{\text {avg }}$ nas conversões das séries MWM, agrupadas pelas diferentes inicializações do parâmetro $\mathrm{p}$. . . . . . . . . . .

4.2 Tabela de intervalo ideal para a média $T X_{a v g}$ e de valor sugerido para $T X_{\text {avg }}$ nas conversões das séries fGN . . . . . . . .

4.3 Estimativas do parâmetro de Hurst para série temporal MWM gerada com $H=0,8$ e a respectiva série de chunks obtida pelo método de conversão $1 \ldots \ldots$. . . . . . . . . . . 84

4.4 Estimativas do parâmetro de Hurst para série temporal fGN gerada com $H=0,8$ e a respectiva série de chunks obtida pelo método de conversão 1. . . . . . . . . . . . . . . . . 86

4.5 Estimativas do parâmetro de Hurst para série temporal MWM gerada com $H=0,8$ e a respectiva série de número de pacotes obtida pelo método de conversão $2 \ldots \ldots 3$

4.6 Estimativas do parâmetro de Hurst para série temporal fGN gerada com $H=0,8$ e a respectiva série de número de pacotes obtida pelo método de conversão 2 . . . . . . . . . . . . . . 95

4.7 Tabela de modelos, métodos de conversão, taxa média de transmissão e tamanho do bin. . . . . . . . . . . . . . . . . . 97 
4.8 Tabela de modelos, métodos de conversão, tamanho de pacotes para dimensionamento da fila e tamanho da fila. . . . . . . . . 97

4.9 Tabela de parâmetros do cenário de simulação para série MWM utilizando conversão 1. . . . . . . . . . . . . . . . . 98

4.10 Tabela de parâmetros de QoS para cenário com tráfego interferente baseado no modelo MWM, conversão 1. . . . . . . . . . . . . . . . 99

4.11 Tabela de parâmetros do cenário de simulação de referência, Poisson com $T X_{a v g}=2$ Mbps, pacotes de 1518 bytes. . . . . . . . . 104

4.12 Tabela de parâmetros de QoS para cenário com tráfego interferente baseado no modelo Poisson, 2 Mbps, 1518 bytes. . . . . . . . . . . 104

4.13 Tabela de parâmetros do cenário de simulação para série MWM utilizando conversão 2. . . . . . . . . . . . . . . . 108

4.14 Tabela de parâmetros de QoS para cenário com tráfego interferente baseado no modelo MWM, conversão 2. . . . . . . . . . . . . . 109

4.15 Tabela de parâmetros do cenário de simulação de referência, Poisson com $T X_{\text {avg }}=2$ Mbps, pacotes de 150 bytes. . . . . . . . . 114

4.16 Tabela de parâmetros de QoS para cenário com tráfego interferente baseado no modelo Poisson, 2 Mbps, 150 bytes. . . . . . . . . 114

4.17 Tabela de parâmetros do cenário de simulação para série fGN utilizando conversão 1. . . . . . . . . . . . . . . 118

4.18 Tabela de parâmetros de QoS para cenário com tráfego interferente baseado no modelo fGN, conversão 1. . . . . . . . . . . . . . 119

4.19 Tabela de parâmetros do cenário de simulação de referência, Poisson com $T X_{\text {avg }}=50 \mathrm{Mbps}$, pacotes de 1518 bytes. . . . . . . . 123

4.20 Tabela de parâmetros de QoS para cenário com tráfego interferente baseado no modelo Poisson, 50 Mbps, 1518 bytes. . . . . . . . . 124

4.21 Tabela de parâmetros do cenário de simulação para série fGN utilizando conversão 2. . . . . . . . . . . . . . . . 127

4.22 Tabela de parâmetros de QoS para cenário com tráfego interferente baseado no modelo fGN, conversão $2 \ldots$. . . . . . . . 128

4.23 Tabela de parâmetros do cenário de simulação de referência, Poisson com $T X_{\text {avg }}=50$ Mbps, pacotes de 150 bytes. . . . . . . 133 
4.24 Tabela de parâmetros de QoS para cenário com tráfego interferente baseado no modelo Poisson, 50 Mbps, 150 bytes. . . . . . . . 133

4.25 Tabela de consolidação dos parâmetros de QoS para os diversos cenário de simulação. . . . . . . . . . . . . . . . . 137 


\title{
Lista de Abreviaturas
}

\author{
AR Auto Regressive \\ ATM Asynchronous Transfer Mode \\ CAC Controle de Admissão de Conexões \\ CBR Constant Bit Rate \\ CQS Classify, Queue and Schedule \\ CRM Customer Relationship Management \\ CSMA/CD Carrier Sense Multiple Access with Collision Detection \\ CWT Continuous Wavelet Transform \\ DEP Densidade Espectral de Potência \\ DFBM Discrete Fractional Brownian Motion \\ DiffServ Differentiated Services \\ D-ITG Distributed Internet Traffic Generator \\ DW Data Warehouse \\ DWPT Discrete Wavelet Packet Transform \\ DWT Discrete Wavelet Transform \\ ERP Enterprise Resource Planning \\ fBM Fractional Brownian Motion \\ FD Fractionally Differenced Process \\ FFT Fast Fourier Transform \\ fGN Fractional Gaussian Noise \\ GPS Generalized Processor Sharing
}


GSSM Gaussian Spectral Synthesis Method

IDWT Inverse Discrete Wavelet Transform

IETF Internet Engineering Task Force

IIR Infinite Impulse Response

IntServ Integrated Services

IP Internet Protocol

LSPs Label Switched Paths

LRD Long Range Dependence

MODWT Maximal Overlap Discrete Wavelet Transform

MPLS Multiprotocol Label Switching

MRA MultiResolution Analysis

MTU Maximum Transfer Unit

MWM Multifractal Wavelet Model

NS-2 NS-2 Network Simulator

PDF Probability Density Function

PHB Per-Hop Behavior

PPL Pure Power Law Process

PPP Point-to-Point Protocol

QoS Quality of Service

RED Random Early Detection

RSVP Resource Reservation Protocol

SNMP Simple Network Management Protocol

SRD Short Range Dependence

TI Tecnologia da Informação

WAN Wide Area Network

WFT Windowed Fourier Transform

WWW World Wide Web 


\section{Introdução}

\subsection{Objetivo}

O objetivo deste trabalho é modelar e implementar um gerador de tráfego agregado que exiba propriedades fractais. O tráfego agregado fractal é adequado para uso em ambientes de simulação e testes envolvendo redes multisserviço. O gerador de tráfego proposto emprega modelos para síntese de séries temporais que reproduzem as características estatísticas (auto-similaridade, Long Range Dependence (LRD) e Short Range Dependence (SRD)) encontradas em traces de tráfego das redes por comutação de pacotes reais, como a Internet (PARK; WILLINGER et al., 2000).

As principais contribuições desta pesquisa são:

1. implementação da síntese de séries temporais que aproximam realizações de um processo estocástico Fractional Gaussian Noise (fGN) via Discrete Wavelet Transform (DWT);

2. implementação da síntese de séries temporais segundo o modelo Multifractal Wavelet Model (MWM) via DWT;

3. flexibilidade para introdução de SRD via filtragem Infinite Impulse Response (IIR) das séries temporais sintetizadas;

4. implementação de duas alternativas de conversão de séries temporais em séries de pacotes;

5. validação das características estatísticas obtidas através de um método de análise apropriado;

6. criação de alguns cenários de simulação introduzindo tráfego interferente sintetizado;

7. comparações iniciais de resultados entre cenários de simulação com tráfego LRD versus tráfego Poisson; 
8. possibilidade de extensão do gerador para experimentação de diversos serviços e tecnologias de redes em ambiente de teste (testbed), emulando condições de tráfego reais.

\subsection{Organização do Trabalho}

Neste Capítulo, apresentam-se os objetivos desta pesquisa e uma seção introdutória expondo o contexto e motivações para uso de um gerador de tráfego auto-similar em redes multisserviço.

O Capítulo 2 constitui uma revisão teórica dos tópicos: geração de tráfego, auto-similaridade, processos LRD, transformada wavelet e modelos de tráfego.

Em seguida, apresentam-se os resultados experimentais que encontram-se divididos em dois Capítulos, 3 e 4.

O Capítulo 3 mostra os resultados obtidos com a geração de realizações aproximadas do modelo fGN e exatas do modelo MWM através da transformada wavelet discreta, introdução de SRD via filtragem IIR e análise estatística das séries temporais obtidas.

No Capítulo 4 apresentam-se duas alternativas de conversão de séries temporais em séries de pacotes. Ainda nesse capítulo, discute-se um método para utilização das séries de pacotes em cenários de simulação e exibem-se os resultados de simulação.

Conclusões e sugestões para trabalhos futuros são discutidos no Capítulo 5.

\subsection{Contexto e Motivação}

Os avanços tecnológicos dos últimos anos na área de telecomunicações, redes e aplicações comprovam um fato que era esperado: a Internet e as redes de dados corporativas serão a infra-estrutura para um cenário de convergência entre transmissão de dados e de fluxos de aplicações multimídia (voz sobre Internet Protocol (IP), transmissão de vídeo, mensagens instantâneas, internet banking etc) (ARMITAGE, 2001). Já é realidade nos desktops de muitos usuários da Internet, a presença de aplicativos para serviços avançados, como é o caso da telefonia IP (SKYPE, 2006). Apesar disso, muitas vezes a qualidade de serviço (Quality of Service (QoS)) obtida tanto em aplicações mais tradicionais (ex. navegar na web) quanto nas mais recentes fica abaixo das expectativas dos usuários, o que é 
possível de ser notado ao se acessar o conteúdo de um web site em momentos de alta utilização, ou ao se utilizar um serviço de telefonia via Internet para efetuar uma chamada de longa distância.

Grandes empresas estão em busca de visibilidade sobre os indicadores de desempenho e disponibilidade de cada uma de suas aplicações, uma vez que a maioria dos processos de negócio dessas corporações é informatizado e o baixo desempenho ou indisponibilidade dessas aplicações causa impacto na produtividade de seus funcionários e compromete suas receitas financeiras. Essas corporações dependem de sistemas complexos: Enterprise Resource Planning (ERP), Customer Relationship Management (CRM), Data Warehouse (DW), sistemas legados etc. Cada um desses sistemas precisa ser monitorado, tanto em termos de software (serviços, filas, hits/segundo etc.) como de hardware (CPU e memória de servidores, placas de rede, discos etc.). Adicionalmente, deve-se monitorar o caminho entre os servidores e os endpoints dos usuários. Para serem capazes de efetuar a gestão dos inúmeros fatores envolvidos em um cenário como esse, freqüentemente, as equipes da área de Tecnologia da Informação (TI) dessas corporações empregam ferramentas de gerenciamento (baseadas, por exemplo, no protocolo Simple Network Management Protocol (SNMP)) para coletar informações de cada nó da rede, de cada servidor e, mais recentemente, até mesmo do tempo de resposta das aplicações (BAC..., 2006).

Verifica-se, portanto, a preocupação atual em controlar um cenário complexo, heterogêneo e em constante mudança que é a rede de informação de uma grande corporação.

A Internet não é muito diferente: provedores de serviço estão interessados em medir, caracterizar e estimar cada parâmetro que possa influenciar a percepção dos usuários finais quando esses estiverem usando os mais diversos serviços possíveis de serem prestados através da rede de comutação de pacotes.

Alinhado com as constatações acima, (BAUER et al., 1998) apresenta um trabalho envolvendo os temas testbed e QoS. O artigo enfatiza o fato dos ambientes computacionais estarem se tornando cada vez mais distribuídos, as aplicações significativamente maiores, mais complexas, multimídia e sendo utilizadas em papéis críticos nas organizações empresariais. Ao mesmo tempo, cresce rapidamente a demanda dos usuários por desempenho, confiabilidade e disponibilidade das aplicações que deve ser atendida através de uma QoS adequada entregue a esses usuários. Por esses motivos, o tema QoS tem recebido considerável atenção da comunidade de pesquisa. 
Sabe-se que uma das razões para a ampla adoção e rápida evolução das redes IP deve-se a sua flexibilidade para incorporar novos serviços. Segundo (KWEON; CHO; SHIN, 2004), os avanços na tecnologia de redes de alta velocidade viabilizaram o transporte de tráfego de várias aplicações através das redes de dados, resultando na explosão de crescimento da Internet. Em particular, as redes Ethernet teriam atraído bastante interesse para serviços e aplicações distintas por apresentarem baixo custo, maturidade e estabilidade provadas através do uso massivo.

O tema principal discutido no artigo citado é a adaptação das redes Ethernet para suportar aplicações de automação industrial. Os autores evidenciam a importância da previsibilidade na entrega de pacotes para aplicações em tempo real. No contexto da automação industrial, o atraso de transmissão (delay) enfrentado por cada mensagem em tempo real é uma importante métrica de desempenho da rede, exercendo grande influência na QoS entregue às aplicações de tempo real, enquanto que o throughput médio é a métrica mais importante para pacotes de aplicações que não sejam de tempo real (non-real time).

O exemplo descrito acima mostra que, na área de redes de computadores, uma determinada métrica de desempenho da rede será mais ou menos relevante dependendo do tipo de aplicação (e conseqüentemente do tipo de tráfego) que deseja-se utilizar. Esse é um fator importante a ser considerado quando se busca inferir qual será o nível de QoS entregue a cada solicitação de acesso à rede. Portanto, uma rede inteligente, capaz de atender aos requisitos de QoS das aplicações que acessam seus serviços, precisa ser informada sobre quais métricas de desempenho da rede são relevantes para as diversas fontes de tráfego e quais são os limiares aceitáveis para essas métricas.

As redes IP são conhecidas por oferecerem um serviço do tipo melhor esforço (Best Effort). Entre as premissas fundamentais das redes IP, está a idéia de manter a rede o mais simples possível, provendo um conjunto mínimo de funcionalidades que permitam que os endpoints complexos em suas bordas possam se comunicar. Essa premissa não coincide com a arquitetura das redes de telecomunicações tradicionais, em que os terminais são extremamente simples e toda a inteligência está concentrada na rede. Para tornar as redes IP capazes de oferecer outros níveis de serviço além do Best Effort, é necessário agregar funcionalidades adicionais a essas redes, deixando-as mais "inteligentes". É com essa discussão que (ARMITAGE, 2001) dá início a uma série de explicações sobre técnicas, protocolos e novas tecnologias que estão sendo incorporadas às redes IP tradicionais visando oferecer QoS aos fluxos de aplicações que trafegam por essas redes. 
Em (BACKäR, 2000), pesquisa com foco semelhante ao deste trabalho, elaborase um breve resumo sobre a evolução das redes de pacotes. De acordo com o autor, existe uma diferença de demandas entre as redes de telefonia e as redes de pacotes. Apesar de as redes de telefonia oferecerem há muitas décadas o serviço de voz (baixa qualidade de áudio) e a transmissão de dados em baixas taxas de bit (utilizando tecnologia de modem), novas demandas e requisitos de serviços para aplicações em tempo real (como o processamento de voz) ou requisitos específicos de taxa de bit e atraso de transferência (aplicações de processamento de dados) estão surgindo. A atual abrangência e flexibilidade das redes de pacotes (consolidação em todo o mundo das redes IP) faz com que aumentem as expectativas de que essas redes sejam capazes de atender, de maneira eficiente, a todas essas novas solicitações. No entanto, o sucesso das tradicionais redes de telefonia pode ser atribuído à habilidade dos engenheiros de telecomunicações em projetarem, implantarem, monitorarem e controlarem de maneira apropriada esses sistemas com a finalidade de atenderem ao volume dimensionado de requisições de serviço. Da mesma forma, as redes de pacotes deverão atingir um grau de maturidade adequado em que projeto, implantação, monitoramento e controle de recursos permitam que se assegure a QoS oferecida às aplicações dos usuários e em que os serviços disponibilizados possam suprir as demandas atuais e futuras.

A análise de teletráfego é a aplicação da teoria das filas como uma ferramenta de análise de desempenho em redes de telecomunicações. Segundo o autor citado, essa ferramenta se mostrou essencial para o desenvolvimento de redes de telecomunicações eficientes que conseguiram atingir com custo aceitável, requisitos de desempenho satisfatórios para um determinado conjunto de serviços. O uso das técnicas de análise de teletráfego possibilitou a expansão com sucesso do serviço de telefonia tradicional e a identificação da maioria dos problemas de desempenho que surgiram nessas redes.

Nas últimas décadas, as demandas por serviços de dados cresceram mais rapidamente que as demandas pelos tradicionais serviços de voz. Diante disso, consideráveis investimentos foram feitos em novas tecnologias de banda larga, tanto em termos de conectividade (ex. redes Asynchronous Transfer Mode (ATM)) quanto em termos de serviços (computação distribuída, streaming de mídias, World Wide Web (WWW), vídeo sobre demanda, voz sobre IP etc). A investigação de modelos adequados e a caracterização do tráfego de pacotes têm recebido grande atenção e tornaram-se temas relevantes para o desenvolvimento de redes com serviços flexíveis, robustos e financeiramente acessíveis.

Em uma rede com suporte a QoS, as definições de ações preventivas para 
evitar congestionamento são conhecidas como funções de controle de tráfego e congestionamento. A necessidade para a inclusão dessas funções foi reconhecida desde o projeto e elaboração dos padrões das redes ATM (GINSBURG, 1999). Existem propostas de solução para controle de congestionamento baseadas em efetuar continuamente medições de caminhos da rede, buscando inferir o volume de tráfego agregado por esses caminhos (LIMA, 2002). Essas medições seriam o suporte para a ação de algoritmos de Controle de Admissão de Conexões (CAC) que controlam o acesso à rede visando a garantia da QoS requisitada.

A implementação de mecanismos preventivos de controle de tráfego, tais como o CAC (LIMA, 2002) e Controle Dinâmico de QoS (BARRA, 2005), é essencial para o bom funcionamento de uma rede multisserviço. Sem controle, a demanda irrestrita pelos recursos compartilhados (buffers, banda e processadores) pode degradar seriamente o desempenho da rede. O controle do tráfego é necessário para proteger a QoS percebida pelos usuários e para assegurar a utilização eficiente dos recursos da rede.

Portanto, face às recentes demandas por novos serviços e pela garantia de requisitos de QoS; face à relevância da análise de teletráfego para o desenvolvimento de redes de comunicação eficientes e de bom desempenho; face à necessidade de inclusão e validação de novos protocolos e funções nas redes de dados, como por exemplo as funções de controle de tráfego e congestionamento; torna-se indispensável reproduzir as condições das redes reais (volume e características do tráfego) em cenários de simulação e em ambientes flexíveis e controlados como o de redes de testes, a fim de habilitar o desenvolvimento bem sucedido dessas novas tecnologias. O gerador de tráfego agregado, proposto neste trabalho, é uma ferramenta imprescindível para a construção adequada desses ambientes.

A principal motivação para este trabalho está ligada ao fato dos testes de validação dos algoritmos de controle de tráfego deverem ser realizados com um tráfego agregado realista e bem definido. Deve-se ter a possibilidade de variar as propriedades do tráfego utilizado em redes de teste e nas simulações. Serão revisados e explorados neste trabalho dois modelos com aplicação para síntese de tráfego que tiveram boa aceitação em virtude de possuírem propriedades estatísticas semelhantes às encontradas em traces de tráfego real. O objetivo final é o emprego dos modelos fGN e MWM na geração de séries temporais LRD, conversão dessas séries temporais em séries de pacotes através de duas propostas distintas, análise dos resultados obtidos e implementação de um gerador de tráfego flexível que possa ser utilizado em simuladores de redes ou em uma rede experimental (testbed). 


\section{Revisão Teórica}

\subsection{Introdução}

Até o início da década de 1990, pensava-se que o tráfego das redes de pacotes poderia ser modelado pelo processo aleatório de Poisson (SATO, 1994) (SCHWARTZ, 1996). Entretanto, medidas em redes locais (LELAND et al., 1994) e de grande área (PAXSON; FLOYD, 1995) mostraram que o teletráfego possui propriedades fractais tais como auto-similaridade e LRD. A LRD implica a existência de um pólo na origem da Densidade Espectral de Potência (DEP). Um objeto matemático (conjunto, medida, etc.) é auto-similar quando apresenta similaridades estruturais em todas (ou pelo menos numa faixa dinâmica extensa) as escalas de observação. No caso do teletráfego, a alternância de períodos de surto e de suavidade (impulsividade ou burstiness) e a LRD são mantidas em várias escalas de tempo, na faixa de $m s$ a min ou $h$ (a auto-similaridade ocorre num sentido estatístico). A memória longa pode levar a maiores taxas de perda de pacotes do que as que são previstas pela teoria clássica das filas (LELAND et al., 1994) (ERRAMILLI; NARAYAN; WILLINGER, 1996).

Os artigos (LELAND et al., 1994) e (PAXSON; FLOYD, 1995) mostraram que não é razoável supor que séries de teletráfego possam ser geradas por modelos ARMA (AutoRegressive Moving Average - ARMA) ou Markovianos, cujas autocorrelações decaem exponencialmente para zero com o aumento do lag (BOX; JENKINS; REINSEL, 1994) (BROCKWELL; DAVIS, 1996). Na literatura, os processos LRD são também conhecidos como processos com espectro $1 / f$.

A transformada wavelet é indicada para as análises e sínteses de sinais $1 / f$ (PERCIVAL; WALDEN, 2000) (DAUBECHIES, 1992) (GENÇAY; SELÇUK; WHITCHER, 2001) porque:

1. Os coeficientes wavelet de um processo $1 / f$ são aproximadamente não correlacionados no plano tempo-escala. Portanto, a modelagem e o processamento desses sinais naquele domínio pode ser realizado de maneira eficiente. 
2. É o método mais eficiente do ponto de vista computacional. A complexidade (em termos de operações de adição e multiplicação) associada à geração de uma realização de $N$ amostras é $O(N)$. Métodos baseados na FFT (Fast Fourier Transform) (PERCIVAL, 1992) (PAXSON, 1997) possuem complexidade $O(N \log N)$. A técnica de geração no domínio do tempo de Hosking (HOSKING, 1984), baseada nas recursões de Levinson-Durbin, requer $O\left(N^{2}\right)$ operações.

3. Possibilidade de síntese de tráfego não-Gaussiano (importante para aplicações que trabalham em escalas refinadas de tempo (PAXSON; FLOYD, 1995) (RIEDI; VéHEL, 1997)).

4. A noção de escala temporal é intrínseca à definição da transformada (propriedade de resolução temporal variável).

\subsection{Geradores de Tráfego}

Ambientes complexos e heterogêneos podem ser formados por redes de comutação de pacotes com suporte a QoS. As pesquisas envolvendo simulações e experimentos realistas utilizando-se de redes de teste que emulem a operação das redes reais são de extrema importância para analisar inúmeras situações como: desempenho de aplicações multimídia em redes IP, predição e teste das operações de novos protocolos, avaliação da escalabilidade dos serviços operando na rede, validação de algoritmos de controle de tráfego e muitas outras.

Em cenários corporativos é muito comum a aplicação de simuladores e a execução de testes com geração de tráfego (carga) com o objetivo de efetuar o planejamento de capacidade de sistemas (Capacity Planning). Usualmente essas empresas configuram ao menos três ambientes de redes e aplicações distintos: ambiente de desenvolvimento, ambiente para execução de testes (Quality Assurance) e o ambiente de acesso dos usuários finais (ambiente de produção). Com a motivação principal de "estressar" elementos de rede, servidores Web, servidores de aplicação e bases de dados, ferramentas flexíveis e com muitos recursos foram desenvolvidas para atender às necessidades de teste de carga das empresas. O software LoadRunner (LOADRUNNER..., 2006) é uma ferramenta comercial cujo objetivo é reproduzir em ambiente de teste as condições experimentadas em ambientes reais. Através dessa ferramenta, a equipe de testes e gestão de capacidade tem a flexibilidade de escolher os locais onde estarão as fontes de tráfego, os protocolos que serão reproduzidos em cada uma das fontes e a quantidade de usuários 
emulados que acessam a rede de dados e a aplicação sob teste. Pode-se criar cenários de geração de carga distribuídos, emulando diversos acessos simultâneos de usuários que estivessem realizando processos de negócio distintos nas aplicações disponibilizadas pela empresa. Além disso, esse produto permite a coleta de métricas de QoS e de desempenho dos componentes do testbed e acompanha uma ferramenta estatística para a análise dos dados coletados. Dessa maneira é possível emular condições reais de uso da infra-estrutura ao mesmo tempo em que avalia-se o impacto em função da carga gerada, a interferência entre conexões refletida no aumento do tempo de resposta das aplicações e dimensiona-se a capacidade da rede e dos servidores, buscando atingir no ambiente de produção uma utilização ótima dos recursos disponíveis.

Outra possível solução normalmente considerada a fim de se introduzir tráfego agregado em um testbed ou ambiente de simulação consiste em capturar traces de tráfego em redes reais para posterior reprodução desses traces de tráfego nos cenários de teste e simulação. No entanto, essa solução possui desvantagens que podem passar despercebidas à primeira vista, conforme explicado por (FLOYD; PAXSON, 2001). Um efeito indesejado caso utilizem-se traces de tráfego em simulações, ocorre sob condições em que o tráfego agregado atinge níveis de carga que acionem mecanismos de controle de congestionamento e acionem os algoritmos de gestão de filas. Nessa situação, as fontes de tráfego que reconheçam a ação desses mecanismos (ex. fonte TCP mediante perda de pacotes) tendem a reduzir sua taxa de transmissão buscando aliviar a condição de congestionamento. Usuários reais poderiam desistir de suas conexões e aplicações adaptativas poderiam mudar o seu comportamento, tornando o trace de tráfego específico para a situação em que foi coletado. Em uma simulação com características diferentes das do ambiente real, a interação entre as fontes de tráfego e os mecanismos de controle de recursos de rede será distinta. Espera-se que fontes de tráfego adequadamente modeladas apresentem um comportamento de injeção de pacotes diferente do capturado pelo trace, dependendo das condições particulares de cada cenário de teste ou simulação.

O artigo citado menciona algumas técnicas para contornar as dificuldades em simular a Internet. Uma das técnicas é buscar por comportamentos empiricamente demonstráveis para uma grande variedade de ambientes, como é o caso do fenômeno da auto-similaridade, freqüentemente presente nos padrões de tráfego de redes de dados. Uma outra técnica enfatiza o cuidado que deve ser tomado ao explorar o espaço de parâmetros de uma simulação ou experimento. A recomendação é sempre analisar resultados para uma grande faixa de valores de entrada. 
Essa estratégia ajuda a abranger variações inerentes à grande heterogeneidade e às constantes mudanças da Internet.

A principal dificuldade em se encontrar um gerador de tráfego realista, que possa ser utilizado em testbeds e simulações, está no fato da modelagem e caracterização de tráfego em redes de dados ainda ser um tema sob estudo. A auto-similaridade é uma característica estatística que deseja-se reproduzir, uma vez que é encontrada em traces de tráfego reais e é bem aceita pelos pesquisadores na área de redes de dados. Em (PEREIRA, 2002), encontra-se um bom resumo da teoria sobre séries temporais auto-similares, são citados métodos para sua síntese e são indicadas algumas maneiras conhecidas para a estimação do parâmetro de Hurst de uma série auto-similar. Nesse trabalho, o estudo e as análises de uma disciplina de serviço Generalized Processor Sharing (GPS) foram realizados utilizando-se modelos de tráfego auto-similares, o que reforça a aceitação desse fenômeno.

Davies e Harte (DAVIES; HARTE, 1987) introduziram na literatura estatística o método DHM (Davies and Harte Method) de geração de realizações de processos estacionários Gaussianos de média nula. O método assume que a seqüência de autocovariância é conhecida, como é o caso para o fGN (MANDELBROT; NESS, 1968) e para os processos Fractionally Differenced Process (FD) (GRANGER; ; JOYEUX, 1980) (HOSKING, 1981). O método é baseado na Fast Fourier Transform (FFT). Percival (PERCIVAL, 1992) publicou outro método baseado na FFT denominado Gaussian Spectral Synthesis Method (GSSM). Paxson (PAXSON, 1997) também propôs um método de geração de realizações aproximadas do fGN baseado na FFT, porém sua estratégia foi baseada no artigo de Flandrin (FLANDRIN, 1992). Paxson demonstrou que o seu método gera séries estatisticamente indistingüíveis de realizações fGN e que essas séries podem ser utilizadas na geração de tráfego de redes auto-similar.

Em (FAN; MARS, 1997), utiliza-se a transformada wavelet para obter um método rápido e preciso de sintetizar séries que aproximam realizações de um processo Fractional Brownian Motion (fBM). O objetivo é utilizar as séries sintetizadas para geração de tráfego auto-similar em aplicações de simulação e análise de redes. Ainda no artigo, estima-se com precisão o parâmetro de Hurst de séries auto-similares através da análise do decaimento da variância dos coeficientes da transformada wavelet .

O modelo MWM proposto em (RIEDI et al., 1999) permite sintetizar séries não-Gaussianas com propriedades multifractais que possuem aplicação na geração 
de tráfego de redes. Esse modelo também é implementado através da transformada wavelet e será discutido em detalhes na Seção 2.3.7. Em (SHIMIZU, 2004), encontra-se uma outra proposta de um método para geração de tráfego de redes. O método consiste em dois estágios, em que o primeiro estágio, da mesma maneira que o MWM, parte de um sinal positivo denominado root signal e através da transformada wavelet gera uma série multifractal com distribuição de probabilidade marginal de cauda longa. No segundo estágio ajustam-se as características de dependência de curta duração utilizando-se uma técnica de decomposição em componentes de freqüência por filtros Volterra. O estudo apresentado nesta dissertação assemelha-se ao método citado pois também considera a geração de séries de tráfego em dois estágios, o primeiro modelando as características LRD do tráfego e o segundo em que inserem-se as características SRD.

A pesquisa desenvolvida por Bäckar (BACKäR, 2000) é uma das principais referências deste trabalho. O objetivo da pesquisa de Bäckar é sintetizar tráfego em "tempo-real" semelhante ao encontrado em redes reais. Ele menciona como motivação de seu trabalho a utilização, em ambientes de teste, do tráfego sintetizado com características reais (a auto-similaridade, a ocorrência de bursts e a LRD caracterizam o tráfego encontrado nas redes de dados) para comparação do desempenho de equipamentos de rede obtendo resultados mais realistas.

Efetuando-se pesquisas por ferramentas livres para geração de tráfego em testbeds, encontram-se várias opções de ferramentas com a função de geração de pacotes. Algumas delas são mais voltadas para a geração de tráfego HTTP, indicado para realizar testes de carga especificamente em servidores Web. Embora modelos auto-similares sejam aceitos para emulação de tráfego em redes de dados, são pouco comuns as ferramentas que incorporam esse tipo de modelo.

Essa constatação reforça a importância de modelar e implementar um gerador de tráfego baseado em modelos estatísticos adequados para redes de dados. Ao identificar as principais dificuldades para realizar a implementação de um gerador de tráfego, percebe-se que o primeiro desafio é a geração de séries temporais autosimilares que possam representar a contagem de bytes por unidade de tempo. Em seqüência, deve-se investigar alternativas para a conversão de uma série temporal (bytes/sec) em uma série com indicações de tamanho e tempo entre pacotes (série de pacotes), que permita o envio desses pacotes na rede. Neste trabalho a geração de séries temporais que se assemelham às realizações de um processo fGN e a geração de séries como especificado pelo modelo MWM são implementadas da mesma maneira descrita por (BACKäR, 2000). Posteriormente, as séries geradas são convertidas em séries de pacotes por dois métodos alternativos. Em um 
deles o tamanho dos pacotes enviados é mantido constante, variando-se o tempo entre pacotes característico de cada bin de transmissão. No segundo, os instantes de envio de blocos de pacotes são determinados e equi-espaçados, variando-se o tamanho dos blocos e dos pacotes enviados. Encontra-se em (WALL, 1999) e (VEITCH et al., 2000) uma descrição de conversão semelhante a essa última, aplicada no contexto de redes ATM.

A Figura 2.1 apresenta um diagrama de blocos proposto para uma futura implementação do gerador de tráfego que incluirá uma interface de rede para geração dos pacotes em um testbed. Na implementação atual, a interface do gerador é feita com o software simulador de redes NS-2 Network Simulator (NS2).

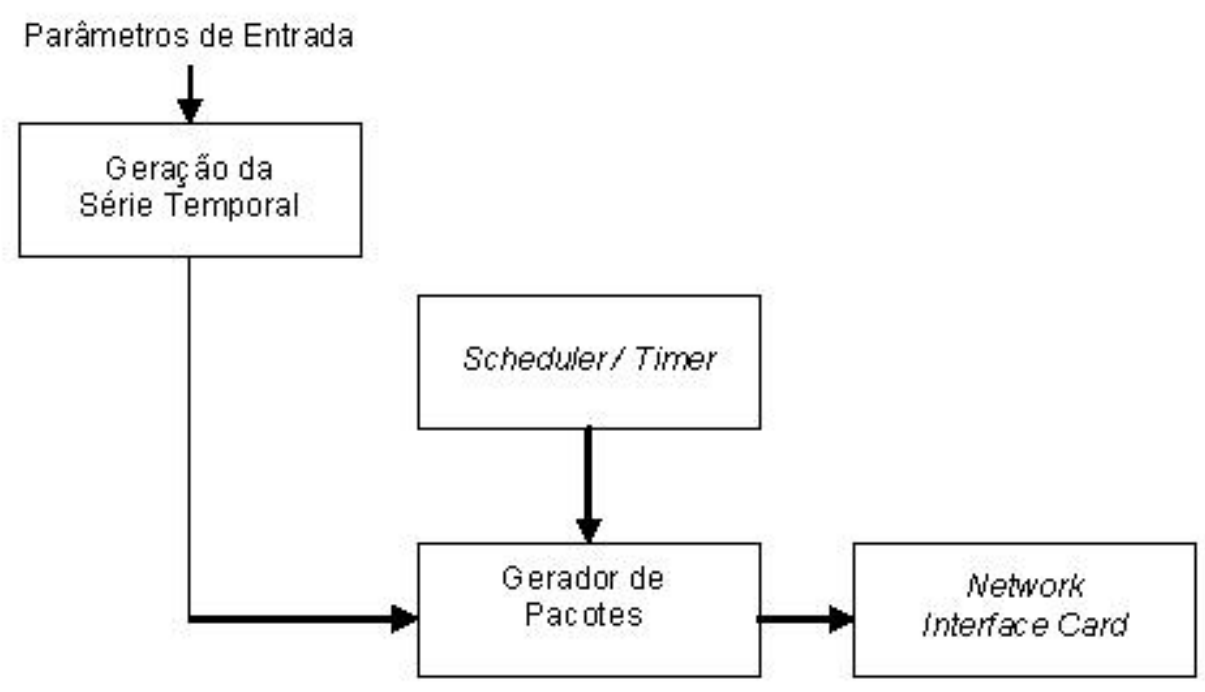

Figura 2.1: Diagrama de blocos de um gerador de tráfego

Na solução proposta, o usuário pode controlar o nível médio do tráfego gerado e a amplitude dos surtos através dos parâmetros de entrada da função de geração da série temporal. A série gerada é convertida em série de pacotes e encaminhada ao módulo gerador de pacotes que, além de montar os pacotes no tamanho especificado pela série sintetizada e com as informações de controle necessárias, determina com o auxílio da função de relógio (timer) o momento exato de solicitar à interface de rede o envio dos pacotes.

No momento em que o gerador de tráfego estiver implementado para ser conectado a redes de teste, deseja-se que o tráfego sintetizado por essa ferramenta reproduza com precisão as propriedades estatísticas encontradas em traces de tráfego reais. Isso implica que os requisitos temporais (tempo entre pacotes) 
das séries obtidas com os modelos de tráfego selecionados deverão ser rigorosamente respeitados. Existem investigações detalhadas sobre o nível de precisão que pode-se obter em função da abordagem adotada para a implementação do módulo gerador de pacotes (PáSZTOR, 2001), (HOLLABAUGH, 2002), (KHAN, 2002). Do ponto de vista de rede de acesso, é importante notar que a rede Ethernet é composta por um barramento compartilhado, em que o acesso ao meio de transmissão é governado pelo protocolo Carrier Sense Multiple Access with Collision Detection (CSMA/CD). Existindo outros nós compartilhando o meio de acesso (barramento) entre o nó do gerador de tráfego e o primeiro nó da rede (switch ou roteador), não há como garantir que os pacotes do gerador ingressem na rede no instante determinado pela série temporal gerada. Em (ARMITAGE, 2001), afirmase que "a natureza probabilística do protocolo CSMA/CD torna difícil prever o desempenho de um fluxo em um caminho IP através de um link Ethernet". Para contornar essa limitação utiliza-se uma rede de acesso baseada em switches (switch rich), em que não existem outros nós compartilhando o link entre a fonte de tráfego e o switch de acesso. Nesse cenário, o protocolo CSMA/CD não terá o efeito indesejado de tornar imprevisível o instante de emissão dos pacotes do gerador de tráfego.

Em (KWEON; CHO; SHIN, 2004), descreve-se um trabalho relacionado a interface com a rede de dados. O tema abordado é a limitação do delay na transmissão de pacotes em redes Ethernet. Nesse trabalho foram projetados e implementados dois suavizadores de tráfego adaptativos, o primeiro com programação no nível de kernel do sistema operacional e o segundo no nível de programas de usuário. A versão que trabalha ao nível de kernel é instalada entre a camada IP e a camada Ethernet apresentando melhor desempenho. O suavizador dá maior prioridade aos pacotes de aplicações em tempo real eliminando contenção desnecessária no nó local e suaviza o tráfego de pacotes non-real time reduzindo a probabilidade de colisões com pacotes de outros nós da rede. Em uma rede local Ethernet os pacotes transmitidos pelos diferentes nós podem colidir já que o protocolo de controle de acesso ao meio, CSMA/CD, permite que essas colisões ocorram. É a possibilidade das colisões que torna impossível obter delay previsível na entrega dos pacotes entre os nós locais. O suavizador de tráfego regula os bursts intrínsecos ao fluxo de pacotes vindos da camada de rede, tornando o fluxo tão suave quanto possível com o objetivo de reduzir a chance de colisão entre pacotes. É interessante notar o desenvolvimento de software que atua ao nível de kernel do sistema operacional, visando melhor desempenho no processamento a ser efetuado. Esse tipo de implementação trará ganhos de desempenho para uma futura 
interface do gerador de tráfego que permita o envio de pacotes na rede.

Em publicações recentes, Distributed Internet Traffic Generator (D-ITG) (EMMA; PESCAPE; VENTRE, 2004) (EMMA et al., 2004) é apresentado como uma solução distribuída para geração de tráfego. O D-ITG é uma plataforma para geração de tráfego que, segundo os autores, adere com precisão aos padrões estabelecidos por processos estocásticos que representem o tempo entre envios de pacotes e o tamanho de pacotes. Essa solução permite a escolha de uma dentre um conjunto de distribuições de probabilidade para a geração das séries de pacotes. Algumas das distribuições disponibilizadas ao usuário são: constante, uniforme, exponencial, normal, Pareto, Poisson etc. Adicionalmente, protocolos bastante utilizados nas redes IP estão mapeados em alguns modelos propostos, permitindo ao usuário da ferramenta escolher um protocolo ao invés das distribuições de probabilidades disponíveis. O D-ITG não possui modelos específicos para a geração de processos auto-similares.

Os trabalhos citados incluem uma explicação sobre cada um dos componentes da plataforma de geração de tráfego: ITGSend (módulo que envia os pacotes), ITGRecv (módulo que recebe os pacotes), ITGLog (recebe as informações de vários senders e receivers e armazena essas informações em arquivos de $l o g$ ) e ITGManager (possibilita controlar os módulos geradores de pacotes). Os autores também efetuam comparações entre o D-ITG e alguns geradores disponíveis na Internet, baseada no throughput obtido por cada gerador. Além do D-ITG, os geradores envolvidos são: Iperf, Mgen, Rudecrude, UDPgenerator e Mtools. 


\subsection{Modelos de Tráfego}

\subsubsection{Conceitos Básicos para Análise de Séries Temporais}

\subsubsection{Estacionariedade}

Considere um processo estocástico de tempo discreto $X(k)$ ou, abreviadamente, $X_{k}$. Considere ainda as variáveis aleatórias $X\left(k_{i}\right)$ ou $X_{i}$, correspondentes a observações do processo aleatório $X(k)$ nos instantes de tempo discreto $k_{i}=k_{1}, k_{2}, \ldots$..

Definição 1 (Processo Estritamente Estacionário) $X_{k}$ é estritamente estacionário quando $\left\{X\left(k_{1}\right), X\left(k_{2}\right), \ldots, X\left(k_{n}\right)\right\}$ e $\left\{X\left(k_{1}+m\right), X\left(k_{2}+m\right), \ldots, X\left(k_{n}+\right.\right.$ $m)\}$ possuem a mesma distribuição de probabilidade conjunta para todos os valores de $n \in \mathbb{Z}_{+}, k_{1}, \ldots, k_{n}, m \in \mathbb{Z}$.

A função distribuição de probabilidade $F$ da variável aleatória $X_{i}$ é definida por $F_{X_{i}}(\lambda)=\operatorname{Pr}\left\{X_{i} \leq \lambda\right\}$

Ao adotar-se $n=1$, é possível notar que a estacionariedade implica que a função distribuição de probabilidade $F_{X_{1}}(\lambda)$ será a mesma para todos os instantes $k$ e, portanto, o processo estocástico estacionário apresenta média e variância constantes.

Definição 2 (Processo Estacionário em Sentido Amplo) $X_{k}$ é estacionário em sentido amplo (ou fracamente estacionário) quando,

1. $E\left\{X_{k}\right\}=\mu, \forall k$

2. $\operatorname{Var}\left\{X_{k}\right\}=\sigma_{X}^{2}, \forall k$

3. $\operatorname{Cov}\left\{X_{i}, X_{j}\right\}=\gamma_{X}(|i-j|)$

em que $\mu$ é a média, $\sigma_{X}^{2}$ é a variância $e \gamma_{X}(|i-j|)$ é a seqüência de autocovariância (definida na Seção 2.3.1.2).

O restante deste trabalho refere-se aos processos estacionários em sentido amplo simplesmente como processos estacionários.

Para propósitos de modelagem de tráfego, é interessante que $X_{k}$ seja estacionário, de modo que o comportamento ou estrutura do processo de tráfego será invariante em relação a deslocamentos no tempo. 


\subsubsection{Autocovariância e Autocorrelação}

As propriedades de correlação entre observações de processos estocásticos em pontos diferentes do tempo podem ser estudadas através do uso das seqüências (ou funções) de autocovariância e autocorrelação.

Sejam duas variáveis aleatórias $X_{0}$ e $X_{1}$ com esperanças $E\left\{X_{0}\right\}=\mu_{0}$ e $E\left\{X_{1}\right\}=\mu_{1}$, respectivamente. Define-se a covariância entre $X_{0}$ e $X_{1}$ :

$$
\begin{aligned}
\operatorname{Cov}\left\{X_{0}, X_{1}\right\} & =E\left\{\left(X_{0}-\mu_{0}\right)\left(X_{1}-\mu_{1}\right)\right\} \\
& =\int_{-\infty}^{\infty} \int_{-\infty}^{\infty}\left(x_{0}-\mu_{0}\right)\left(x_{1}-\mu_{1}\right) f_{X_{0}, X_{1}}\left(x_{0}, x_{1}\right) d x_{0} d x_{1}
\end{aligned}
$$

em que $f_{X_{0}, X_{1}}\left(x_{0}, x_{1}\right)$ denota a função densidade de probabilidade (Probability Density Function (PDF)) conjunta de $X_{0}$ e $X_{1}$ no ponto $\left(x_{0}, x_{1}\right)$.

Nas condições em que $X_{0}$ e $X_{1}$ são variáveis aleatórias correspondentes a observações em instantes de tempo discreto de um processo aleatório $X_{k}, \operatorname{Cov}\left\{X_{0}, X_{1}\right\}$ é denominada autocovariância de $X_{k}$ entre os instantes 0 e 1 .

Assumindo que um processo estocástico seja estacionário, sua PDF conjunta $p\left(X_{k_{1}}, X_{k_{2}}\right)$ será a mesma para todos os valores $k_{1}, k_{2}$ desde que o intervalo $k_{2}-k_{1}$ seja mantido constante. A covariância entre $X_{i}$ e $X_{i+\tau}$ separadas por $\tau$ intervalos de tempo é denominada seqüência de autocovariância $\operatorname{com} \operatorname{lag} \tau$ :

$$
\gamma_{X}(\tau)=\operatorname{cov}\left[X_{i}, X_{i+\tau}\right]=E\left[\left(X_{i}-\mu\right)\left(X_{i+\tau}-\mu\right)\right]
$$

em que $\mu=E\left[X_{i}\right]=E\left[X_{i+\tau}\right]$.

A seqüência de autocorrelação com $\operatorname{lag} \tau$ é definida como:

$$
\rho_{X}(\tau)=\frac{E\left[\left(X_{i}-\mu\right)\left(X_{i+\tau}-\mu\right)\right]}{\sqrt{E\left[\left(X_{i}-\mu\right)^{2}\right] E\left[\left(X_{i+\tau}-\mu\right)^{2}\right]}}=\frac{E\left[\left(X_{i}-\mu\right)\left(X_{i+\tau}-\mu\right)\right]}{\sigma_{X}{ }^{2}},
$$

pois para processos estacionários a variância $\sigma_{X}^{2}=\gamma_{X}(0)$ é a mesma tanto no instante de tempo $i+\tau$ quanto no instante $i$. Portanto, pode-se escrever a autocorrelação com $\operatorname{lag} \tau$ :

$$
\rho_{X}(\tau)=\frac{\gamma_{X}(\tau)}{\gamma_{X}(0)}
$$

\subsubsection{Função Densidade Espectral de Potência}

Para muitos processos estacionários de valores reais e que são de interessse para servirem como modelos de fenômenos físicos (assume-se que estes processos apresentem espectro limitado em freqüência), a informação sobre $X(k)$ que está con- 
tida na seqüência de autocovariância pode ser reescrita em termos da função Densidade Espectral de Potência (DEP) (PERCIVAL; WALDEN, 2000). Se a seqüência de autocovariância é uma seqüência de quadrado integrável, então a DEP pode ser obtida através da $(2.5)^{1}$,

$$
S_{X}(f)=\sum_{\tau=-\infty}^{\infty} \gamma_{X}(\tau) e^{-i 2 \pi f \tau}
$$

A relação (2.5) significa que $S_{X}(f)$ é a calculada através da transformada de Fourier de $\gamma_{X}(\tau)$. A antitransformada da DEP leva à seqüência de autocovariância $^{2}$,

$$
\gamma_{X}(\tau)=\int_{-f_{N}}^{f_{N}} S_{X}(f) e^{i 2 \pi f \tau} d f \quad,
$$

em que $f_{N}$ corresponde à freqüência de Nyquist.

Antitransformando para $\tau=0$ obtém-se um resultado fundamental que mostra como $S_{X}(f)$ decompõe a variância do processo aleatório em respeito à freqüência:

$$
\int_{-f_{N}}^{f_{N}} S_{X}(f) d f=\gamma_{X}(0)=\operatorname{Var}\left\{X_{k}\right\}
$$

Essas relações também implicam que existindo forte correlação para grandes valores do $\operatorname{lag} \tau$, haverá picos no espectro de potência para baixos valores da freqüência $f$. Portanto, a característica LRD deve ser encontrada em séries temporais que possuam espectro de potência com pico ou pólo na origem (comportamento $1 / f)$.

\subsubsection{Dependência de Longa Duração}

Em (LIMA, 2002), encontra-se um bom resumo da teoria de séries temporais com dependência de longa duração. Esse resumo será a base das próximas seções.

Considere o processo estocástico estacionário $X(k)$, e as variáveis aleatórias $X_{i}$, obtidas do processo $X(k)$ nos instantes de tempo discreto $k_{i}, i=1,2, \ldots$ :

$$
X\left(k_{i}\right)=X_{i}
$$

Sejam $\mu=\bar{X}$ a média, $\sigma_{X}^{2}$ a variância, $\gamma_{X}(|i-j|)$ a autocovariância e $\rho_{X}(i, j)=\rho_{X}(|i-j|)$ a autocorrelação de $X(k)$ em qualquer intervalo $\tau=|i-j|$.

\footnotetext{
${ }^{1}$ A seqüência de autocovariância ser de quadrado integrável é uma condição suficiente, mas não necessária para que exista a DEP.

${ }^{2}$ Mesmo que a DEP exista mas não possa ser expressa por (2.5), a relação (2.6) é válida.
} 
Considere $x_{1}, x_{2}, \ldots, x_{n}$ observações de uma realização $x(k)$ de $X(k)$ nos instantes de tempo $k_{i}, i=1,2, \ldots, n$. Se as variáveis aleatórias $X_{1}, X_{2}, \ldots, X_{n}$ são independentes ou não-correlacionadas, isto é, se $\rho_{X}(i, j)=0$ para $i \neq j$, então, a variância amostral de $\bar{x}$ (estimador de $\mu$ ) é dada pela (2.9), em que $\bar{x}$ é a média da amostra de $\mathrm{n}$ elementos:

$$
\begin{gathered}
\sigma_{\bar{x}}^{2}=\frac{\sigma_{X}^{2}}{n}, \\
\bar{x}=\frac{1}{n} \sum_{i=1}^{n} x_{i} .
\end{gathered}
$$

Se a amostra é suficientemente grande, a distribuição amostral do estimador $\bar{x}$ é normal (veja Figura 2.2). A expressão do intervalo de confiança para $\mu$, ao nível de confiança $(1-\beta)$, é dada pela (2.11), conforme visto em Neto, 1997 apud (LIMA, 2002).

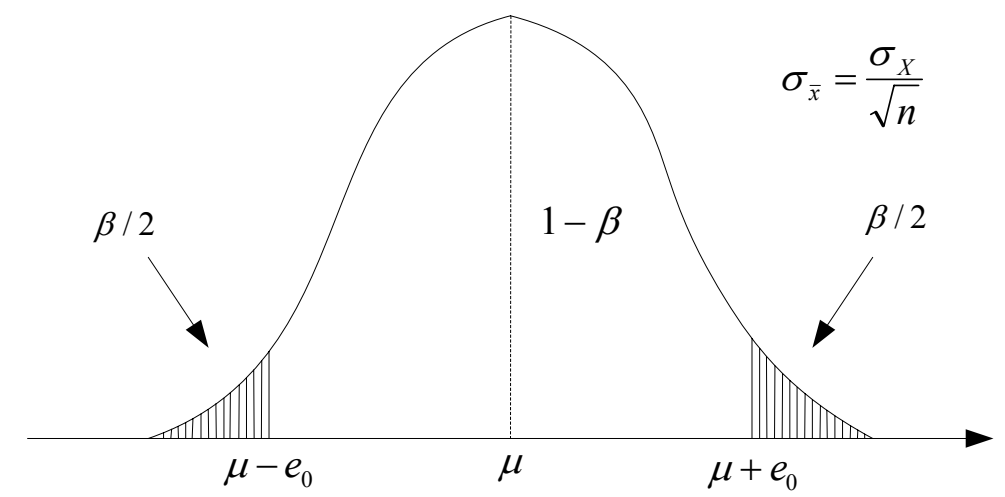

Figura 2.2: Distribuição amostral de $\bar{x}$, extraída de (LIMA, 2002).

$$
\bar{x} \pm z_{\beta / 2} \frac{\sigma_{X}}{\sqrt{n}}
$$

Em (2.11), $z_{\beta / 2}=\frac{\left(\mu+e_{0}\right)-\mu}{\sigma_{X} / \sqrt{n}}$ é a variável normal padronizada e $e_{0}$ denota a semi-amplitude do intervalo de confiança.

O comportamento da variância do estimador $\bar{x}$ não segue a (2.9) quando o processo $X(k)$ exibe autocorrelação $\rho_{X}(\tau)$ não desprezível para grandes valores de $\tau$. Nessa condição, diz-se que o processo $X(k)$ possui característica LRD conforme a definição: 
Definição 3 (Dependência de Longa Duração) Um processo estacionário $X(k)$ possui memória longa ou dependência de longa duração se a sua função de autocorrelação $\rho_{X}(\tau)$, para valores suficientemente grandes de $\tau$, decresce segundo uma função potência.

$$
\rho_{X}(\tau) \sim|\tau|^{-(1-\alpha)}, \quad \tau \rightarrow \infty
$$

em que $0<\alpha<1$.

O decaimento para zero da funçao de autocorrelação é muito mais lento para um processo LRD do que para processos que apresentem apenas memória curta, SRD. Isso implica em observações bastante separadas no tempo apresentarem correlação não desprezível (observações correntes mantém alguma "memória" de eventos distantes no passado).

As autocorrelações decaem para zero tão lentamente (o decaimento é hiperbólico) que não são somáveis, como exibido na (2.13):

$$
\sum_{\tau=-\infty}^{\infty} \rho_{X}(\tau)=\infty
$$

Em (BERAN, 1994 apud PERCIVAL; WALDEN, 2000), enuncia-se o equivalente à Definição 3 no domínio da freqüência. A (2.12) implica a existência de um pólo na origem (freqüência $f=0$ ) da DEP como indicado na (2.14):

$$
\lim _{f \rightarrow 0} \frac{S_{X}(f)}{C_{S}|f|^{-\alpha}}=1
$$

em que $0<\alpha<1$ e $C_{S}>0$.

Observa-se que com $\alpha \in(0,1)$ (intervalo aberto), $S_{X}(f)$ tende ao infinito na origem. Usualmente a literatura refere-se ao parâmetro $\alpha$ como expoente de escala (scaling exponent).

Segundo (BERAN, 1994 apud LIMA, 2002), se $X(k)$ é LRD (ou chamado "ruído $\left.1 / f^{\prime \prime}\right)$, a variância de $\bar{x}$ decresce com o tamanho $n$ da amostra mais lentamente do que no caso tradicional (variáveis independentes ou não-correlacionadas), como apresentado na (2.15):

$$
\sigma_{\bar{x}}^{2} \approx \sigma_{X}^{2} c(\rho) n^{-(1-\alpha)}
$$

$\operatorname{com} \alpha \in(0,1)$ e $c(\rho)$ definido por: 


$$
c(\rho)=\lim _{n \rightarrow \infty} n^{-(1+\alpha)} \sum_{i \neq j} \rho_{X}(i, j)
$$

Nesse caso, a distribuição de $\bar{x}$ é assintoticamente Gaussiana, com $E(\bar{x})=\mu$. O comportamento LRD de $X(t)$ torna a estimação de parâmetros como $\bar{x}$ mais difícil. Nesse caso, a equação do intervalo de confiança para $\bar{x}$ (2.11) não é aplicável.

Alguns exemplos de séries temporais LRD:

- nível mínimo anual do rio Nilo (medição registrada há centenas de anos);

- tráfego agregado em redes;

- tráfego gerado por uma fonte VBR (Variable Bit Rate - taxa de transmissão variável);

- temperatura global para o hemisfério norte (medida mensalmente) entre os anos 1854-1989.

\subsubsection{Fractais}

O estudo de fractais está relacionado ao interesse por conjuntos de objetos irregulares que normalmente não são abordados ou descritos pelos métodos da geometria e matemática clássica (BACKäR, 2000).

Fractal é um termo que vem do latim fractus, com o significado de fraturado, quebrado. Foi proposto por Mandelbrot, 1982 apud (LIMA, 2002), em seu ensaio fundamental sobre a matemática dos conjuntos irregulares ou não suaves. Uma forma geométrica é fractal ou auto-similar (num sentido determinístico) se as mesmas estruturas geométricas são observadas independentemente da distância com que se olha um objeto. Uma maneira de apresentar o conceito de fractais é destacando algumas de suas principais propriedades, através da análise de um exemplo como o conjunto de Cantor (Figura 2.3).

Pode-se notar que a Figura 2.3 exibe a mesma aparência ou formato quando observada em diferentes escalas de uma mesma dimensão. Ressalta-se que a dimensão pode ser o espaço ou o tempo e que para fins de modelagem, análise e síntese de tráfego, processos estocásticos que exibem auto-similaridade temporal podem ser utilizados. Para a construção recursiva do conjunto de Cantor, adotamse as seguintes regras: 


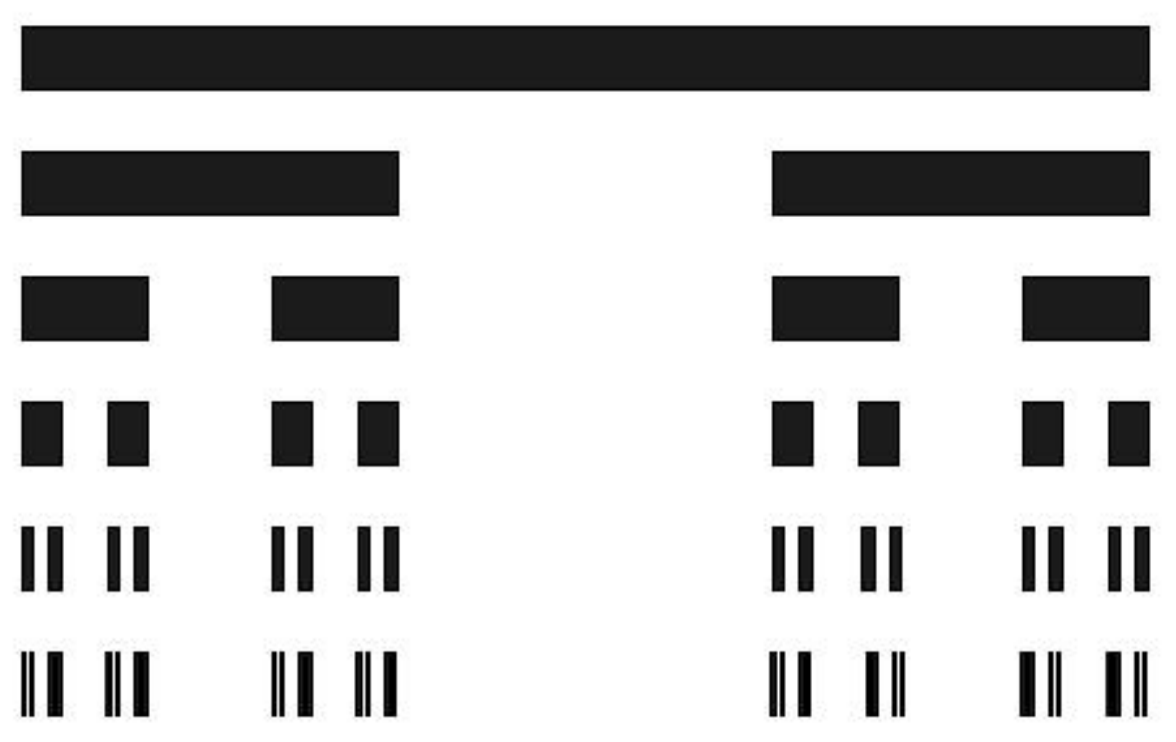

Figura 2.3: Conjunto de Cantor (cinco iterações), extraída de (LIMA, 2002).

1. Parte-se um segmento no intervalo $[0,1]$.

2. Remove-se o terço do meio desse segmento.

3. A cada iteração, remove-se o terço do meio dos segmentos resultantes do passo anterior.

Existe uma descrição matemática para a construção do conjunto de Cantor:

- $E_{0}$ é o conjunto dos números reais contidos no intervalo [0,1];

- Removendo-se o terço do meio do conjunto $E_{0}$, tem-se $E_{1}$, composto pelos intervalos $[0,1 / 3]$ e $[2 / 3,1]$;

- $E_{2}$ é obtido a partir de $E_{1}$, apagando-se o terço do meio dos intervalos $[0,1 / 3]$ e $[2 / 3,1]$, resultando os quatro intervalos: [0,1/9], [2/9,1/3], $[2 / 3,7 / 9],[8 / 9,1]$

- As iterações seguem de forma que cada $E_{k}$ é obtido apagando-se o terço do meio de cada segmento em $E_{k-1}$.

Chega-se então ao conjunto de Cantor $F$, que consiste dos números que estão em $E_{k}$ para todo $k$, ou seja, $F=\bigcup_{k=0}^{\infty} E_{k}$. A característica perceptível na Figura 2.3, em que o formato de uma determinada parte do objeto, quando magnificada, se assemelha ao formato do todo, é o fenômeno da auto-semelhança ou autosimilaridade. 
Em Stallings, 2001 apud (LIMA, 2002), ressalta-se que o conjunto de Cantor possui duas propriedades comuns a todos os objetos auto-similares:

- Possui uma estrutura rica em detalhes em escalas arbitrariamente pequenas e por isso a sua geometria não é facilmente descrita em termos clássicos. Esse fenômeno não ocorre em figuras "suaves" da geometria clássica.

- As estruturas se repetem. Uma estrutura auto-similar contém réplicas menores de si mesma em todas as escalas. A cada iteração, as porções da esquerda e da direita do conjunto de Cantor são réplicas exatas do segmento no passo anterior.

\subsubsection{Auto-similaridade}

De maneira intuitiva (definição formal adiante), diz-se que um processo aleatório é auto-similar se as suas propriedades estatísticas não são alteradas com uma mudança na escala de tempo.

No contexto de tráfego de dados, a Figura 2.4 exibe as diferenças qualitativas entre o tráfego Ethernet real e o tráfego sintetizado através do modelo clássico de Poisson (LIMA, 2002). Nessa figura, os traces de tráfego apresentados em quaisquer dos gráficos com unidade de tempo igual a 10 segundos correspondem a magnificações (zoom in) dos traces de tráfego representados nos gráficos com unidade de tempo igual a 100 segundos, aproximadamente entre os instantes de tempo discreto 150 e 250. Para o tráfego sintetizado através de um modelo autosimilar (à direita) com $H=0,9$, o gráfico com unidade de tempo igual a 1 segundo corresponde à magnificação do tráfego representado no gráfico com unidade de tempo igual a 10 segundos, aproximadamente entre os instantes de tempo discreto 720 e 820. O mesmo se aplica aos demais gráficos. Não há uma escala de tempo característica (ou um tamanho natural) para a ocorrência de períodos de surtos no caso do tráfego real (à esquerda). A alternância de períodos de surtos e de suavidade é preservada em várias escalas de tempo. Já para o tráfego Poisson (ao centro), nota-se que períodos de surtos de tráfego ocorrem em escalas de tempo menores (10 milissegundos e 0,1 segundo) e que a agregação do processo resulta em uma série semelhante à de um ruído branco Gaussiano (identificado na unidade de tempo igual a 10 segundos). Esse comportamento do tráfego Poisson é uma clara indicação de que as propriedades estatísticas do processo não são mantidas ao longo de várias escalas de agregação. Finalmente, observa-se para o tráfego sintetizado através de um modelo auto-similar que, da mesma maneira 
que para o tráfego real, também há alternância em várias escalas de tempo de períodos de surtos e de suavidade.

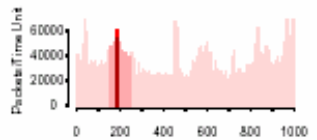

Thount - 100 Seccorts

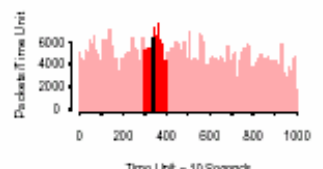

Thro Lit = 10 Sesinst

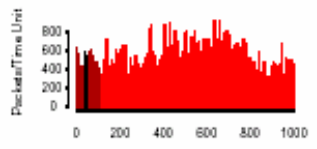

Tima unt -1 semant

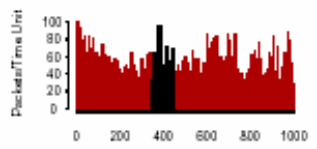

The Unt -0.1 5osorr

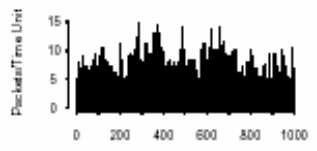

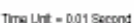

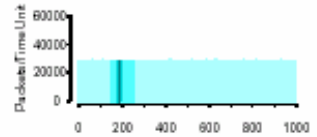

Time Unit- nosesmat
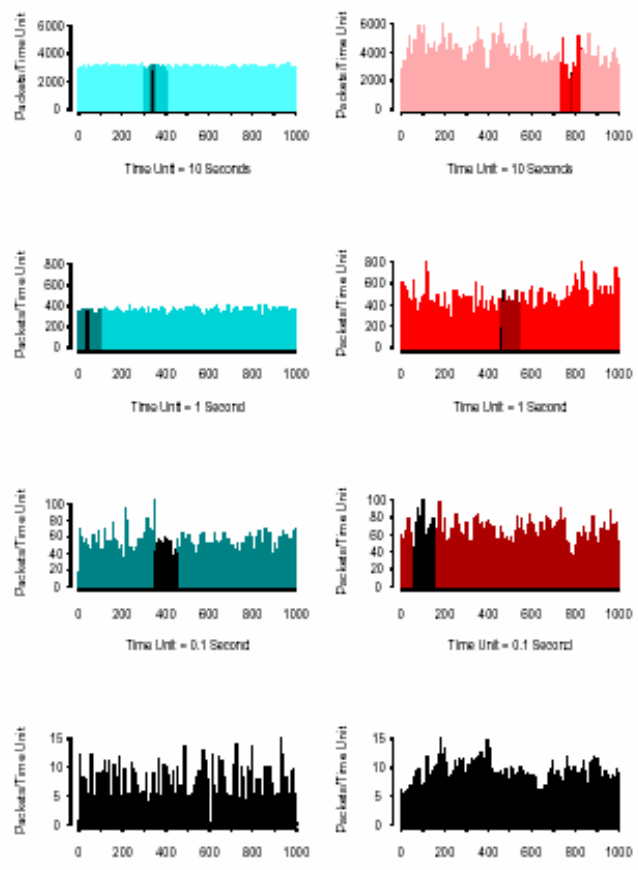

Thount 0.0 .01 50000rt
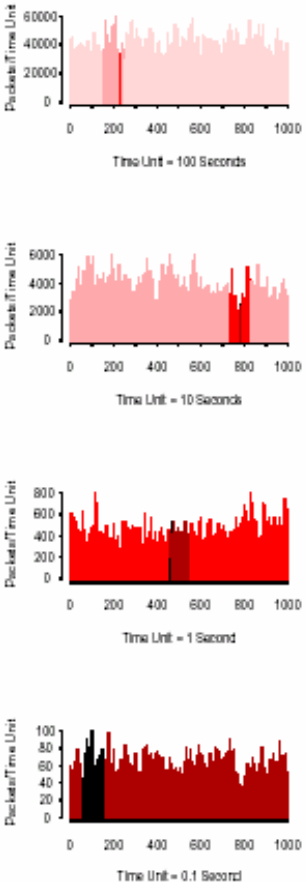

Thount - 100 seccorts

Time Urte 0.1 Sooserd

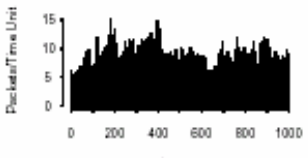

Tire Lit $=0.01$ Secons

Figura 2.4: Comparação de realizações de tráfego extraída de Willinger et al., 1995 apud (LIMA, 2002). À esquerda a realização de tráfego real, ao centro a realização do tráfego sintetizado com modelo Poisson e à direita a realização do tráfego sintetizado com modelo auto-similar

Diferentemente de fractais, os traces de tráfego da Figura 2.4 não apresentam semelhança exata entre suas porções em diferentes escalas. A auto-similaridade ocorre num senso estatístico e não determinístico. A auto-similaridade é relacionada à preservação de burstness (alternância entre surtos e períodos de maior suavidade) (PARK; WILLINGER et al., 2000).

\subsubsection{Processos auto-similares de tempo contínuo}

Matematicamente, pode-se definir um processo estocástico auto-similar da seguinte forma (PEREIRA, 2002):

Definição 4 (Processos estocásticos auto-similares) Seja um processo estocástico de tempo contínuo $Y(t), t \in \mathbb{R}$. $Y(t)$ é auto-similar com parâmetro de 
auto-similaridade $H(0<H<1)$ ( $H$-ss self-similar with parameter $H)$ se, para todo $c>0$, os processos $Y(t)$ e $c^{-H} Y(c t)$ são identicamente distribuídos, como exibido na (2.17):

$$
Y(t) \stackrel{d}{=} c^{-H} Y(c t)
$$

em que $\stackrel{d}{=}$ denota igualdade de distribuição.

O parâmetro de auto-similaridade $H$ é denominado parâmetro de Hurst, em homenagem a H. E. Hurst (PEREIRA, 2002). Em Stallings, 2001 apud (LIMA, 2002), afirma-se que o parâmetro de Hurst $H$ mede o grau de persistência de um fenômeno estatístico, sendo uma medida da intensidade da dependência de longa duração de um processo estocástico. Além disso, o parâmetro $H$ pode ser escrito em termos do parâmetro $\alpha$ da (2.12): $H=(\alpha+1) / 2$. A dependência de longa duração fica caracterizada se $1 / 2<H<1$. Quanto mais próximo $H$ estiver de 1, maior será o grau de persistência ou do comportamento LRD.

Segundo a Definição $4, Y(t)$ é não-estacionário devido ao fator $c^{-H}{ }^{3}$. O processo $Y(t)$ pode ser interpretado como o volume de tráfego acumulado até o instante de tempo $t$, sendo denominado processo de acumulação. A ele usualmente associa-se um processo de incrementos, que representa o volume de tráfego acumulado em um dado intervalo de tempo $\left[t_{0} ; t_{0}+t\right]$. Também define-se o conceito de auto-similaridade para processos de incrementos (PEREIRA, 2002):

Definição 5 (Processo auto-similar de incrementos) O processo de incrementos $X(t), t \in \mathbb{R}$, associado ao processo $Y(t)$, é denominado auto-similar com parâmetro de auto-similaridade $H(0<H<1)$ se, para todo $c>0$ e $t_{0} \geq 0$ :

$$
X(t)=Y\left(t_{0}+t\right)-Y\left(t_{0}\right) \stackrel{d}{=} c^{-H}\left[Y\left(t_{0}+c t\right)-Y\left(t_{0}\right)\right]
$$

Pode-se demonstrar que, se o processo $Y(t)$ é auto-similar, o correspondente processo de incrementos $X(t)$ também é auto-similar (PEREIRA, 2002). Se o processo de incrementos $X(t)$ de $Y(t)$ for um processo estacionário, então $Y(t)$ é denominado $H$-sssi ( $H$ self-similar with stationary increments), ou seja, autosimilar com incrementos estacionários.

\footnotetext{
${ }^{3}$ Excetuando-se o caso em que $Y(t)$ é degenerado, i. e., $Y(t)=0, \forall t \in \mathbb{R}$
} 


\subsubsection{Processos auto-similares de tempo discreto}

O processo estacionário de incrementos $X(t)$ pode ser discretizado para obter $X(k)$, capaz de representar o volume de tráfego em um instante $k \in \mathbb{Z}$. Assumese aqui que $E[X(k)]=\mu=0$ a fim de que a notação seja simplificada. Pode-se então, definir processos agregados $X^{(m)}(k), k \in \mathbb{Z}$ como a média amostral do processo original $X(k)$ em blocos não sobrepostos de tamanho $m$ :

$$
X^{(m)}(k)=\frac{1}{m} \sum_{i=m(k-1)+1}^{m k} X(i) .
$$

Utilizando-se da estacionariedade e auto-similaridade de $X(k)$, pode-se demonstrar que $X^{(m)}(k) \stackrel{d}{=} m^{H-1} X(k)$. Portanto, se $Y(t)$ é H-sssi, então o correspondente processo de incrementos em tempo discreto satisfaz uma relação semelhante àquela utilizada para definir auto-similaridade em tempo contínuo (Definição 4), de acordo com a seguinte definição (PEREIRA, 2002):

\section{Definição 6 (Processos estocásticos auto-similares de tempo discreto)}

Seja um processo $X(k), k \in \mathbb{Z}$. Esse processo é denominado auto-similar com parâmetro de auto-similaridade $H(0<H<1)$ se, para todo $m>0$ e $k \geq 0$, os processos $X(k)$ e $m^{1-H} X^{(m)}(k)$ são identicamente distribuídos:

$$
X(k) \stackrel{d}{=} m^{1-H} X^{(m)}(k) .
$$

Os processos estocásticos que satisfazem (2.20) são denominados exatamente auto-similares, visto que a sua distribuição se mantém invariável em todas as escalas de agregação. Nos casos em que a auto-similaridade se manifeste somente em escalas de agregação maiores, utiliza-se a definição de processo estocástico assintoticamente auto-similar:

Definição 7 (Processos discretos assintoticamente auto-similares) Seja um processo $X(k), k \in \mathbb{Z}$. Esse processo é denominado assintoticamente auto-similar com parâmetro de auto-similaridade $H(0<H<1)$ se, para todo $k \geq 0$,

$$
\lim _{m \rightarrow \infty} m^{1-H} X^{(m)}(k) \stackrel{d}{=} X(k) .
$$


Quando apenas as propriedade estatísticas até segunda ordem são relevantes, assumindo-se $X(k)$ estacionário (sentido amplo), pode-se definir a autosimilaridade de segunda ordem (PARK; WILLINGER et al., 2000):

Definição 8 (Processos discretos auto-similares de segunda ordem) O processo estocástico estacionário de tempo discreto $X(k)$ é exatamente auto-similar de segunda ordem com parâmetro Hurst $H(1 / 2<H<1)$ se,

$$
\gamma_{X}(\tau)=\frac{\sigma_{X}^{2}}{2}\left[(\tau+1)^{2 H}-2 \tau^{2 H}+(\tau-1)^{2 H}\right]
$$

para todo $\tau \in \mathbb{Z}$.

$X(k)$ é assintoticamente auto-similar de segunda ordem se,

$$
\lim _{m \rightarrow \infty} \gamma_{X}^{(m)}(\tau)=\frac{\sigma_{X}^{2}}{2}\left[(\tau+1)^{2 H}-2 \tau^{2 H}+(\tau-1)^{2 H}\right],
$$

em que $\gamma_{X}^{(m)}(k)$ é a autocovariância de $X^{(m)}(k)$, que é o processo agregado de $X(k)$ ao nivel de agregação $m$.

Pode-se verificar que a $(2.22)$ implica $\gamma_{X}(\tau)=\gamma_{X}^{(m)}(\tau)$ para todo $m \geq 1$. Portanto, a auto-similaridade de segunda ordem captura a propriedade de estrutura de autocovariância exatamente preservada (2.22) ou assintoticamente preservada (2.23) em diferentes escalas de agregação. A auto-similaridade de segunda ordem tem sido tema de diversos trabalhos na área de modelagem de tráfego de redes (PARK; WILLINGER et al., 2000).

Em (LIMA, 2002) e (PARK; WILLINGER et al., 2000), ressalta-se que autosimilaridade e dependência de longa duração são conceitos distintos. Existem processos auto-similares que não são LRD e vice-versa. Por exemplo, o movimento Browniano é "1/2-sssi" 4 e o processo de incrementos associado é o ruído Gaussiano branco que não é LRD. Entretanto, para o caso dos processos auto-similares de segunda ordem, a auto-similaridade implica o comportamento LRD, já que por definição $1 / 2<H<1$.

\subsubsection{Ruído Gaussiano Fracionário (fGN)}

O Ruído Gaussiano Fracionário, em inglês Fractional Gaussian Noise (fGN), é um processo estocástico estacionário, auto-similar e de memória longa, proposto por

\footnotetext{
${ }^{4} \mathrm{O}$ movimento Browniano é um processo auto-similar de incrementos estacionários com parâmetro $H=\frac{1}{2}$.
} 
(MANDELBROT; NESS, 1968 apud PERCIVAL; WALDEN, 2000) e bastante explorado na literatura de séries temporais. Por ser um processo estacionário, o fGN possui seqüência de autocovariância dada pela (2.22).

O processo fGN $X_{k}$ é normalmente definido como o processo de incrementos associado ao processo Fractional Brownian Motion (fBM) $Y(t), t \in \mathbb{R}$, sendo o fBM um processo Gaussiano e H-sssi. Desta maneira, o fGN corresponde à primeira diferença de um processo auto-similar $Y_{k}$ denominado movimento Browniano fracionário de tempo discreto (Discrete Fractional Brownian Motion (DFBM)) (BERAN, 1994 apud PERCIVAL; WALDEN, 2000), em que o DFBM é obtido através da amostragem do processo de tempo contínuo fBM. Essa relação é apresentada em (2.24):

$$
X_{k}=Y_{k}-B Y_{k}=Y_{k}-Y_{k-1}=\nabla Y_{k}
$$

em que $B$ denota o operador atraso unitário e $\nabla=(1-B)$ é o operador diferença.

A DEP do DFBM é dada pela fórmula (PERCIVAL; WALDEN, 2000, pág. 280):

$$
S_{Y}(f)=\sigma_{X}^{2} C_{H} \sum_{j=-\infty}^{\infty} \frac{1}{|f+j|^{2 H+1}},
$$

em que $\sigma_{X}^{2}$ é a potência do fGN, $C_{H}=\frac{\Gamma(2 H+1) \sin (\pi H)}{2 \pi^{2 H+1}}$ e $0<H<1$. De acordo com (2.25), a DEP do DFBM possui um pólo na origem, pois

$$
S_{Y}(f) \propto|f|^{-1-2 H}, f \rightarrow 0 .
$$

O DFBM é um processo integrado de ordem 1 não-estacionário. Como $X_{k}=$ $\nabla Y_{k}$, o fGN e o DFBM estão relacionados através da função de transferência (na variável complexa z), em que $X(z)$ é obtido a partir de $Y(z)$ :

$$
H(z)=\frac{X(z)}{Y(z)}=1-z^{-1} .
$$

A resposta em freqüência é dada por:

$$
H(f)=\left.H(z)\right|_{z=e^{j 2 \pi f}}=1-e^{-j 2 \pi f} .
$$

Como a relação entrada/saída em termos das DEPs é igual a (2.29)(STARK; WOODS, 2002, pág.351) (assumindo $Y(f)$ como DEP do processo de entrada na função de transferência):

$$
S_{X}(f)=|H(f)|^{2} S_{Y}(f),
$$


em que $|H(f)|^{2}$ é a função de transferência de magnitude,

$$
|H(f)|^{2}=G(f)=4 \sin ^{2}(\pi f),
$$

então,

$$
S_{X}(f)=4 \sin ^{2}(\pi f) S_{Y}(f)
$$

Como para pequenos valores de $f$ tem-se $\sin (\pi f) \approx f$, a DEP do fGN apresenta o seguinte comportamento próximo à origem:

$$
S_{X}(f) \propto f^{1-2 H}, f \rightarrow 0,
$$

então o fGN satisfaz a relação (2.14) de um processo estacionário de memória longa quando $0<2 H-1<1$, ou seja, $1 / 2<H<1$.

Assim, (2.25) e (2.31) mostram que a DEP do fGN é caracterizada por somente dois parâmetros: $\sigma_{X}^{2}$ e $H$ (responsável pela forma do espectro). Além disso, é importante salientar que o fGN é completamente especificado pelas suas estatísticas até segunda ordem, como a média e DEP, pois é Gaussiano.

Pelo fato do fGN apresentar seqüência de autocovariância conforme (2.22), trata-se de um processo exatamente auto-similar de segunda ordem quando $1 / 2<$ $H<1$. Para $H=1 / 2$, o fGN reduz-se a um ruído branco Gaussiano. Quando $0<H<1 / 2$, o processo é SRD.

Em (PAXSON, 1997) é mostrado que a (2.31) pode ser reescrita na forma:

$$
S_{X}(f)=A(f, H)\left[|2 \pi f|^{-2 H-1}+B(f, H)\right]
$$

em que $A(f, H)=2 \sin (\pi H) \Gamma(2 H+1)(1-\cos (2 \pi f))$ e $B(f, H)=\sum_{j=1}^{\infty}[(2 \pi j+$ $\left.2 \pi f)^{-2 H-1}+(2 \pi j-2 \pi f)^{-2 H-1}\right]$.

Em (PERCIVAL; WALDEN, 2000), definem-se e comparam-se resultados de síntese de outros dois processos LRD que assemelham-se ao fGN: Pure Power Law Process (PPL) e FD.

A Fig. 2.5 apresenta os gráficos das DEPs de um modelo Auto Regressive $(\mathrm{AR})(4) X_{n}=2,7607 X_{n-1}-3,8106 X_{n-2}+2,6535 X_{n-3}-0,9238 X_{n-4}+w_{n}(\mathrm{SRD})$, em que $w_{n}$ é uma seqüência de inovação (ruído branco de potência $\sigma_{W}^{2}$ ), e dos processos do tipo $1 / f$ fGN $(H=0,9)$ e $\operatorname{FD}(d=0,4)$. Uma vez que $(2.33)$ da DEP do fGN envolve uma somatória infinita, a sua DEP foi desenhada com base na aproximação fornecida por Paxson em (PAXSON, 1997). Os três processos têm a mesma potência $\sigma^{2}$. Note-se que a DEP de um processo LRD tem um pólo na 
origem e que as DEPs do fGN e do FD estão superpostas na região de freqüências muito baixas.

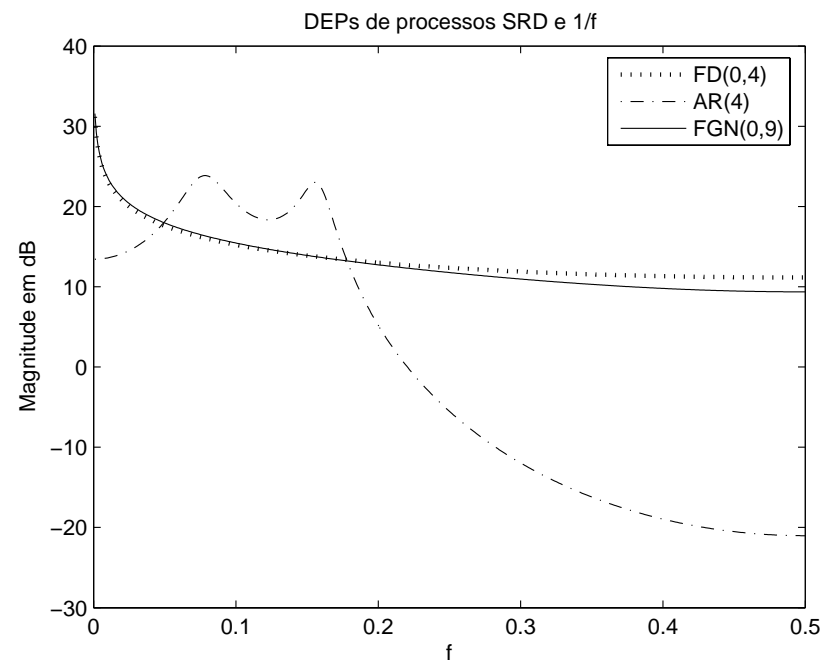

Figura 2.5: DEPs de processos $\operatorname{AR}(4), \operatorname{FD}(0,4)$ e $\operatorname{fGN}(0,9)$ de mesma potência

Processos de integração fracionária como o FD são caracterizados pelo parâmetro de memória longa $d$, que está relacionada a $H$ por (2.34),

$$
d=H-1 / 2 .
$$

O principal inconveniente para o uso de um processo $f G N$ como um processo gerador de séries de pacotes por unidade de tempo é o fato do $f G N$ poder apresentar valores negativos. Por outro lado, sua estrutura Gaussiana lhe atribui uma utilidade especial como modelo para tráfego agregado de rede, em que a agregação de fontes de tráfego independentes, pelo teorema do limite central, levam à propriedade Gaussiana (PARK; WILLINGER et al., 2000). 


\subsubsection{Análise e Síntese de Sinais com Wavelets}

Uma wavelet é uma função de suporte compacto (duração finita) com média temporal nula. Há decomposições wavelet em tempo contínuo e em tempo discreto. Este trabalho utiliza-se de uma das versões discretas, a Discrete Wavelet Transform (DWT), que é a ferramenta básica para o estudo de séries temporais via wavelets. O leitor interessado poderá encontrar em (DAUBECHIES, 1992), (KAISER, 1994) e (MALLAT, 1989) descrições aprofundadas da teoria wavelet.

Bases ortonormais construídas a partir de funções wavelet são utilizadas para descrever sinais no plano tempo-escala (ou tempo-freqüência), de maneira análoga à transformada janelada de Fourier. A transformada wavelet é uma solução natural para a análise de séries temporais auto-similares, porque a sua aplicação envolve "dilações"5 (expansões) de bandas espectrais. Portanto, a DWT possui resolução temporal variável (a transformada janelada de Fourier não possui esta funcionalidade). Além disso, os coeficientes da DWT de um sinal $1 / f$ são praticamente não-correlacionados (intra e inter-escalas) (PERCIVAL; WALDEN, 2000). Por essa razão, as wavelets têm sido amplamente empregadas nas análise e síntese (simulação) de sinais fractais (ABRY; VEITCH, 1998).

\subsubsection{Transformadas Wavelet Contínua e Discreta}

A transformada de Fourier de um sinal $x(t)$, caso exista, é definida pela integral:

$$
X(f)=\mathrm{TF}\{x(t)\}=\int_{-\infty}^{\infty} x(t) e^{-j 2 \pi f t} d t
$$

Gabor (GABOR, 1946) mostrou que é possível representar o conteúdo espectral local de um sinal $x(t)$ em torno de um instante de tempo $\tau$ através da transformada janelada de Fourier (Windowed Fourier Transform (WFT))

$$
X_{T}(f, \tau)=\int_{-\infty}^{\infty} x(t) g_{T}(t-\tau) e^{-j 2 \pi f t} d t
$$

em que $g_{T}(t)$ é uma janela de suporte finito de duração $T$ e $f$ denota freqüência.

A WFT é uma representação bidimensional definida no plano ou domínio tempo-freqüência, porque depende dos parâmetros $f$ e $\tau$. A WFT equivaleria a uma descrição do tipo "partitura" musical contínua de $x(t)$.

De acordo com o principio da incerteza (KAISER, 1994), um sinal cujo conteúdo de energia esteja bem localizado no tempo tem essa energia bastante espa-

\footnotetext{
${ }^{5}$ Dilations, em inglês.
} 
lhada no domínio da freqüência. Como a janela da (2.36) tem um certo tamanho $T$ fixo, conclui-se que a WFT não é uma boa alternativa para analisar (ou identificar) comportamentos de $x(t)$ que aconteçam em tempo muito menores ou maiores do que $T$, como, por exemplo, fenômenos transitórios de duração $\Delta t<<T$ ou ciclos que existam em períodos maiores do que $T$. A transformada wavelet resolve esse problema por meio da mudança de escala, conforme descrito a seguir. Daubechies (DAUBECHIES, 1992) relaciona os seguintes tipos de transformada wavelet.

- Transformada wavelet contínua;

- Transformada wavelet discreta: a) sistemas discretos redundantes (frames) e b) bases de wavelets ortonormais (análise de multiresolução - MultiResolution Analysis (MRA)).

Pode-se representar sinais no plano tempo-freqüência em termos bastante gerais utilizando-se funções da classe

$$
\mathbb{W}=\left\{\frac{1}{\sqrt{s}} \psi\left(\frac{t-\tau}{s}\right)\right\}
$$

em que $\psi(t) \in \mathbb{R}$ é denominada wavelet "mãe" ou geratriz da classe $\mathbb{W}$ e $s \in \mathbb{R}^{+}$ denota o parâmetro de escala. Os membros da família $\mathbb{W}$ são obtidos por dilações (ou compressões) e atrasos. O fator $\frac{1}{\sqrt{s}}$ é usado por conveniência para que todas as funções da classe $\mathbb{W}$ tenham mesma norma (energia).

A geratriz $\psi(t)$ é uma função de suporte compacto que deve obedecer às seguintes restrições (PERCIVAL; WALDEN, 2000)(KAISER, 1994):

1. a sua integral é zero

$$
\int_{-\infty}^{\infty} \psi(t) d t=0
$$

2. pertence ao espaço das funções ${ }^{6} L^{2}(\mathbb{R})$,

$$
\int_{-\infty}^{\infty}|\psi(t)|^{2} d t=1
$$

3. satisfaz à condição de admissibilidade, pela qual a sua transformada de Fourier $\Psi(f)$ é tal que existe uma constante finita,

$$
0<C_{\psi}=\int_{0}^{\infty} \frac{|\Psi(f)|^{2}}{f} d f<\infty
$$

\footnotetext{
${ }^{6} L^{2}(\mathbb{R})$ é um espaço de Hilbert (DAUBECHIES, 1992) infinito-dimensional.
} 
As condições (2.38) e (2.39) estão associadas ao fato de uma wavelet ser uma função de duração finita, que oscila em torno do eixo das abcissas de um modo tal que a sua média é nula. Essa característica de cruzamentos por zeros garante que $\psi(t)$ possa descrever funções genéricas. A condição (2.40) garante que é possível reconstruir $x(t)$ a partir de sua transformada wavelet de tempo contínuo (Continuous Wavelet Transform (CWT)), definida por

$$
W_{\psi}(s, \tau)=\left\langle\psi_{s, \tau}, x\right\rangle=s^{-1 / 2} \int_{-\infty}^{\infty} \psi\left(\frac{t-\tau}{s}\right) x(t) d t
$$

em que $\langle\psi, x\rangle$ representa o produto interno ${ }^{7}$ entre as funções $\psi$ e $x$. Diferentemente da WFT, onde a reconstrução é feita a partir da mesma família de funções que foi usada na análise, na CWT a síntese é feita com funções $\tilde{\psi}_{s, \tau}$ que devem satisfazer

$$
\tilde{\psi}_{s, \tau}(t)=\frac{1}{C_{\psi}} \frac{1}{s^{2}} \psi_{s, \tau}(t)
$$

Sendo assim, $x(t)$ é recuperado completamente via transformada wavelet contínua inversa (ICWT):

$$
x(t)=\frac{1}{C_{\psi}} \int_{0}^{\infty}\left[\int_{-\infty}^{\infty} W_{\psi}(s, \tau) \frac{1}{\sqrt{s}} \psi\left(\frac{t-\tau}{s}\right) d \tau\right] \frac{d s}{s^{2}} .
$$

A diferença fundamental entre a CWT e a WFT reside no fato das funções $\psi_{s, \tau}$ sofrerem dilações e compressões. A análise em escalas refinadas de tempo (pequenos valores de $s$ ) requer funções $\psi_{s, \tau}$ "rápidas", isto é, de pequeno suporte, enquanto que a análise em escalas agregadas de tempo (valores elevados de $s$ ) requer funções $\psi_{s, \tau}$ mais "lentas", isto é, de suporte mais largo. O produto interno definido por (2.41) é uma medida da semelhança entre a wavelet $\psi\left(\frac{t-\tau}{s}\right)$ e o sinal $x(t)$ num certo instante de tempo $\tau$ e numa determinada escala $s$. Para um $\tau$ fixo, grandes valores de $s$ correspondem a uma análise em baixas freqüências, ao passo que pequenos valores de $s$ estão associados a uma análise em altas freqüências. Portanto, a transformada wavelet possui uma resolução temporal variável (isto é, capacidade de analisar o sinal de perto - "zoom in" - ou de longe - "zoom out"), sendo adequada para o estudo de fenômenos que acontecem em várias escalas de tempo.

Segundo Kaiser (KAISER, 1994), a CWT e a WFT são casos especiais de um método mais geral de análise e reconstrução de sinais, denominado teoria dos frames ou arcabouços em maior generalidade. O uso de frames na descrição de sinais é uma alternativa ao uso de bases. Enquanto as bases utilizam um

\footnotetext{
${ }^{7} \mathrm{O}$ produto interno entre funções $f$ e $g$ definidas em um domínio $\mathcal{D}$ é calculado por $\langle f, g\rangle=$ $\int_{\mathcal{D}} w(t) f^{*}(t) g(t) d t$, em que $w(t)$ é uma função não negativa arbitrária.
} 
número mínimo de vetores necessários para representar um vetor (sinal) qualquer, os frames são conjuntos com mais vetores que o mínimo necessário (ou seja, são redundantes). A família de funções $\psi_{s, \tau}$ é linearmente dependente porque cada vetor do frame (que é infinito-dimensional) pode ser decomposto como uma superposiçao linear contínua dos outros vetores ${ }^{8}$.

O processo de transformação linear definido pela CWT, $\mathbf{T}: X \rightarrow Y$ é chamado de análise. O processo inverso realizado pela ICWT denomina-se síntese, S : $Y \rightarrow X$ (BACCALá, 2003). A (2.43) é válida porque o operador síntese $\mathbf{S}$ da ICWT foi definido da forma

$$
\mathbf{S}=\left(\mathbf{T}^{*} \mathbf{T}\right)^{-1} \mathbf{T}^{*}
$$

em que $\mathbf{T}: X \rightarrow Y$ corresponde ao operador de análise e $\mathbf{T}^{*}: Y \rightarrow X$ é o operador adjunto de $\mathbf{T}$, que deve satisfazer a relação

$$
\langle y, \mathbf{T} x\rangle=\left\langle\mathbf{T}^{*} y, x\right\rangle
$$

ou seja, $\mathbf{T}^{*}$ preserva o produto escalar no espaço original (BACCALá, 2003).

Se $\left(\mathbf{T}^{*} \mathbf{T}\right)^{-1}$ existe, como é o caso da CWT (e também da WFT), garante-se que vale a resolução da identidade(DAUBECHIES, 1992, pág.24)

$$
\mathrm{ST}=\mathbf{I}
$$

em que o operador identidade $\mathbf{I}$ é definido por $\mathbf{I} x \equiv x$, para todo $x$.

Kaiser (KAISER, 1994) afirma que pode-se passar da descrição em tempo contínuo para uma descrição em tempo discreto em que $\tau=k \Delta \tau, k \in \mathbb{Z}$, e $s=\sigma^{m}$, $m \in \mathbb{R}$, desde que o tempo de amostragem $\Delta \tau$ seja suficientemente pequeno $(\Delta \tau \approx 0)$ e que o fator de escala $\sigma$ seja escolhido suficientemente próximo da unidade, isto é, $\sigma \approx 1$ (representação de $x(t)$ num plano tempo-escala finamente discretizado). Esse resultado não surpreende, porque se frames contínuos são infinitamente redundantes, então espera-se que frames discretos, obtidos com $\Delta \tau \approx 0$ e $\sigma \approx 1$, sejam altamente redundantes. Entretanto, Mallat (MALLAT, 1989) propôs, por volta de 1986, um método radicalmente diferente (e surpreendente) de implementação da transformada wavelet discreta, em que sinais são representados com $\Delta \tau$ finito e $\sigma \neq 1+\epsilon$, com $\epsilon$ arbitrário, denominado análise de multiresolução (MRA). As propriedades de análise e reconstrução são mantidas mesmo sem variações de escala e de tempo do tipo infinitesimal. A MRA é com-

\footnotetext{
${ }^{8}$ Observe-se que um frame contínuo é definido num espaço linear de funções ou espaço funcional, que tem dimensão infinita.
} 
pletamente recursiva, sendo portanto ideal para implementações computacionais.

Na MRA, $\Delta \tau=1$ e $\sigma=2$, o que resulta numa forma de decomposição de $x(t)$ em que as escalas de tempo são diádicas (potências de 2). A reconstrução de $x(t)$ é perfeita. As wavelets usadas na MRA formam conjuntos de bases ortonormais ao invés de frames. Portanto, essas novas wavelets não podem ser obtidas via discretização de um frame contínuo genérico, pois $\sigma=2$, como dito acima. A teoria da MRA provê a "prescrição" para a construção dessas novas wavelets, as quais devem satisfazer outras restrições além da condição de admissibilidade (2.40).

\subsubsection{Análise de Multiresolução}

Uma das intenções do uso da transformada wavelet é obter uma descrição mais compacta de uma função existente no domínio do tempo. Por meio do uso da transformada wavelet e da técnica chamada "Análise de Multiresolução" (MRA), uma função é recursivamente dividida em duas partes: a aproximação menos refinada e o resíduo correspondente, denominado detalhe.

A MRA consiste de uma seqüência $\left\{V_{j}\right\}, j \in \mathbb{Z}$, de espaços sucessivos de aproximação do espaço das funções de quadrado integrável $L^{2}(\mathbb{R})$ que satisfaz às seguintes propriedades (DAUBECHIES, 1992):

1. ... $V_{2} \subset V_{1} \subset V_{0} \subset V_{-1} \subset V_{-2} \subset \ldots$;

2. $\bigcap_{j \in Z} V_{j}=\{0\}$;

3. $\bigcup_{j \in Z} V_{j}=L^{2}(\mathbb{R})$;

4. $x(t) \in V_{j} \Leftrightarrow x\left(2^{j} t\right) \in V_{0}, j>0$;

5. Existe uma função $\phi_{j}(t)=2^{-j / 2} \phi_{0}\left(2^{-j} t\right)$ em $V_{j}$, denominada função de escala, tal que o conjunto $\left\{\phi_{j, k}, k \in \mathbb{Z}\right\}$ é uma base ortonormal de $V_{j}$, em que as funções $\phi_{j, k}(t)=2^{-j / 2} \phi_{0}\left(2^{-j} t-k\right) \forall j, k \in \mathbb{Z}$.

A obtenção da função de escala $\phi_{0}(t)$ da Propriedade 5 depende da família wavelet escolhida (Haar, Daubechies etc.) O leitor interessado poderá encontrar maiores detalhes sobre o assunto em (DAUBECHIES, 1992).

Se a projeção sobre $V_{j}$ de $x(t)$ é representada pelos coeficientes de escala $u_{j, k}=$ $\left\langle x(t), \phi_{j, k}\right\rangle$, então as Propriedades 1 e 3 garantem que $\lim _{j \rightarrow-\infty} \sum_{k} u_{j, k} \phi_{j, k}(t)=$ $x(t), \forall x \in L^{2}(\mathbb{R})$. A Propriedade 4 implica que o subespaço $V_{j}$ é uma versão 
em escala do subespaço $V_{0}$ (multiresolução). A base ortonormal mencionada na Propriedade 5 é obtida por translações no tempo da função passa-baixas $\phi_{j}$.

Considere a seqüência de aproximações sucessivas de $x(t)$,

$$
\operatorname{aprox}_{j}(t)=x_{j}(t)=\sum_{k} u_{j, k} \phi_{j, k}(t) .
$$

De acordo com a Propriedade 1, tem-se que

$$
x_{j}(t)=x_{j+1}(t)+d_{j+1}(t)
$$

em que $d_{j+1}(t)$ (dito detalhe de $x_{j}(t)$ ) pertence ao subespaço $W_{j+1}$, correspondente ao complemento ortogonal do subespaço $V_{j+1}\left(W_{j+1} \perp V_{j+1}\right)^{9}$. Note-se que $V_{j}=V_{j+1} \oplus W_{j+1}$. O detalhe $d_{j+1}(t)$ corresponde à parte que falta à projeção de $x(t)$ sobre $V_{j+1}$ para chegar na projeção mais refinada de $x(t)$ sobre $V_{j}$, sendo obtido através da equação

$$
d_{j+1}(t)=\sum_{k} \psi_{j+1, k}(t)\left\langle\psi_{j+1, k}(t), x(t)\right\rangle
$$

em que $\left\langle\psi_{j+1, k}(t), x(t)\right\rangle=w_{j+1, k}$ denotam os coeficientes wavelet e $\left\{\psi_{j+1, k}(t)\right\}$ é uma família de funções wavelets que gera o subespaço $W_{j+1}$. A família de funções wavelets é ortogonal à família de funções de escala $\left\{\phi_{j+1, k}(t)\right\}$ que gera o subespaço $V_{j+1}$, isto é,

$$
\left\langle\psi_{j+1, n}, \phi_{j+1, p}\right\rangle=0, \forall n, p
$$

Na prática, um sinal de tráfego $x(t)$ pode ser capturado em várias escalas de tempo, resultando num conjunto de séries temporais $\left\{x_{j, k}\right\}$, em que o índice $j=0,1,2, \ldots, J-1$ está associado às escalas de interesse $(j=0$ corresponde à escala mais rápida) e $k$ é um índice de tempo. A análise de $x$ começa com a série $u_{0}(k)=\left\langle x_{0, k}, \phi_{0, k}(t)\right\rangle, k=0,1, \ldots, M-1$. A seqüência $\left\{u_{0}(k)\right\}$ é decomposta, via filtragem e subamostragem por um fator de 2 (downsampling) em duas seqüências: $\left\{u_{1}(k)\right\}$ e $\left\{w_{1}(k)\right\}$, cada uma contendo $M / 2$ pontos. Esse processo de filtragem e subamostragem é repetido várias vezes, obtendo-se as seqüências

$$
\left\{\left\{u_{0}(k)\right\}_{M},\left\{u_{1}(k)\right\}_{\frac{M}{2}},\left\{u_{2}(k)\right\}_{\frac{M}{4}}, \ldots,\left\{u_{J-1}(k)\right\}_{\frac{M}{2^{J-1}}}\right\}
$$

$\mathrm{e}$

$$
\left\{\left\{w_{1}(k)\right\}_{\frac{M}{2}},\left\{w_{2}(k)\right\}_{\frac{M}{4}}, \ldots,\left\{w_{J-1}(k)\right\}_{\frac{M}{2^{J-1}}}\right\}
$$

A reconstrução ou síntese de $x(t)$ é implementada via filtragem e sobreamos-

\footnotetext{
${ }^{9}$ Além disso, $W_{j+1}$ está contido no subespaço $V_{j}$.
} 
tragem por um fator de 2 (upsampling) das seqüências (2.51) e (2.52). Após $J$ iterações, o sinal original $x_{0, k}$ pode ser reconstruído através de (2.53)

$$
x_{0, k}=\operatorname{aprox}_{J-1}+d_{1}+d_{2}+\cdots+d_{J-1} .
$$

Diz-se que a função $\phi(t)$ determina uma análise de multiresolução (MultiResolution Analysis (MRA)) de $x(t)$ de acordo com (2.53), se a mesma obedece às seguintes condições:

1. ortonormalidade intra-escala (Propriedade 5)

$$
\langle\phi(t-m), \phi(t-n)\rangle=\delta_{m, n},
$$

em que $\delta_{m, n}$ é o delta de Kronecker $\left(\delta_{m, n}=1\right.$ se $m=n, \delta_{m, n}=0$ para $m \neq n)$. (2.54) impõe uma condição de ortonormalidade na escala $j=0$.

2. média unitária

$$
\int_{-\infty}^{\infty} \phi(t) d t=1
$$

3. equação de dilação

$$
\frac{1}{\sqrt{2}} \phi\left(\frac{t}{2}\right)=\sum_{k} g_{k} \phi(t-k)
$$

em que $g_{k}$ são os coeficientes de um filtro passa-baixas de resposta impulsiva finita (FIR).

Mallat (MALLAT, 1989) propôs uma maneira eficiente de implementar a decomposição recursiva de (2.51) e (2.52) utilizando-se bancos de filtros. A MRA é então implementada via bancos de filtros passa-baixas $G(f)$ e passa-altas $H(f)$ (em que $G(f)=\sum_{k=-\infty}^{\infty} g_{k} e^{-j 2 \pi f k}$ e $H(f)=\sum_{k=-\infty}^{\infty} h_{k} e^{-j 2 \pi f k}$ ) adequadamente posicionados para separação dos sinais de aproximação e de detalhe. Posteriormente é possível reconstruir o sinal original pelo mesmo processo de filtragens, de modo que os filtros de decomposição e de reconstrução formam um sistema conhecido como Quadrature Mirror Filters (QMF). O algoritmo de Mallat é conhecido como algoritmo da pirâmide. Ressalta-se que a complexidade desse algoritmo é $O(M)$, ao passo que o cálculo "direto" da IDWT (que envolve multiplicação de matrizes) é $O\left(M^{2}\right)$ (PERCIVAL; WALDEN, 2000).

A Propriedade 1 da MRA permite que se escreva a Equação de Dilação (2.56), $\frac{1}{\sqrt{2}} \phi\left(\frac{t}{2}\right)=\sum_{k} g_{k} \phi(t-k)$, pois "cabem" várias $\phi(t-k)$ em $\phi\left(\frac{t}{2}\right)$. A (2.56) pode ser reescrita na forma

$$
\phi(t)=\sum_{k} \sqrt{2} g_{k} \phi(2 t-k) .
$$


As (2.56) e (2.57) podem ser escritas, respectivamente, no domínio das freqüências como

$$
\sqrt{2} \Phi(2 f)=G(f) \Phi(f)
$$

e

$$
\Phi(f)=\frac{1}{\sqrt{2}} G(f) \Phi\left(\frac{f}{2}\right),
$$

em que $\Phi(f)=\mathrm{TF}\{\phi(t)\}$ e $G(f)=\sum_{k} g_{k} e^{-j 2 \pi f k}$, conhecido como filtro de escala (passa-baixas), representa um filtro periódico em $f$.

Como o subespaço $W_{j+1}$ é ortogonal a $V_{j+1}$ e está contido em $V_{j}$, tem-se que

$$
\frac{1}{\sqrt{2}} \psi\left(\frac{t}{2}\right)=\sum_{k} h_{k} \phi(t-k),
$$

$\mathrm{Ou}$

$$
\psi(t)=\sum_{k} \sqrt{2} h_{k} \phi(2 t-k),
$$

que é a Equação da Wavelet. Aplicando-se a transformada de Fourier às (2.60) e (2.61) obtém-se, respectivamente,

$$
\sqrt{(2)} \Psi(2 f)=H(f) \Phi(f)
$$

e

$$
\Psi(f)=\frac{1}{\sqrt{2}} H(f) \Phi\left(\frac{f}{2}\right),
$$

em que $H(f)$ é o filtro wavelet (passa-altas).

Reescrevendo a $(2.50)\left(\left\langle\psi_{j, n}, \phi_{j, p}\right\rangle=0\right)$ em termos do domínio das freqüências e usando (2.58) e (2.62) resulta a condição de ortogonalidade,

$$
\int_{-\infty}^{\infty} H(f) G^{*}(f)|\Phi(f)|^{2} d f=0
$$

que o filtro $H$ deve atender para que a família $\left\{\psi_{1, k}(t)\right\}$ seja ortogonal à família $\left\{\phi_{1, k}(t)\right\}$. Filtros $H$ e $G$ que obedecem à (2.64) são denominados Quadrature Mirror Filters (QMF).

De acordo com a equação de dilação (2.57), a MRA começa a partir de uma definição (dentre várias possíveis) dos coeficientes do filtro digital $\left\{g_{n}\right\}$. A escolha de um filtro $\left\{g_{n}\right\}$ FIR implica um $\left\{h_{n}\right\}$ que também seja FIR. As funções de escala $\phi(t)$ e wavelet $\psi(t)$ associadas aos filtros FIR $\left\{g_{n}\right\}$ e $\left\{h_{n}\right\}$, respectivamente, possuem suporte compacto; oferecendo, portanto, a funcionalidade de resolução temporal.

Até o final da década de 1980, a MRA baseada no sistema de funções $\phi(t)$ 
de Haar era o único exemplo conhecido de MRA com filtros FIR (MRA-FIR) (KAISER, 1994). Até então conhecia-se outros sistemas MRA-IIR (boa resolução em freqüência), como os de Shannon e o de Meyer, que não são atrativos do ponto de vista prático, porque não têm uma boa resolução no domínio do tempo. Ingrid Daubechies (DAUBECHIES, 1988) foi a primeira a propor um método para construção de seqüências de funções de transferência $\left\{G^{(N)}(z)\right\}_{N=1,2,3, \ldots}$ e $\left\{H^{(N)}(z)\right\}_{N=1,2,3, \ldots}$, em que $G^{(1)}(z)$ está associada ao filtro FIR passa-baixas $\left\{g_{n}\right\}^{10}$ e $H^{(1)}(z)$ ao filtro passa-altas $\left\{h_{n}\right\}$. As funções de escala e wavelet correspondentes, obtidas através das (2.57) (dilação) e (2.60) (wavelet) são válidas para $[0,2 N-1]$. O primeiro membro da seqüência é o sistema de Haar $\left\{\phi^{(1)}, \psi^{(1)}\right\}:\left\{g_{i}\right\}_{i \in \mathbb{Z}}=\left\{\ldots, 0, g_{0}=\frac{\sqrt{2}}{2}, g_{1}=\frac{\sqrt{2}}{2}, 0, \ldots\right\}$, que implica o filtro wavelet $\left\{h_{i}\right\}_{i \in \mathbb{Z}}=\left\{\ldots, 0, h_{0}=\frac{\sqrt{2}}{2}, h_{1}=-\frac{\sqrt{2}}{2}, 0, \ldots\right\}$.

Pode-se generalizar as restrições 2.54 (ortogonalidade) e 2.55 (média unitária) (KAISER, 1994):

1. Condição de ortogonalidade

$$
\sum_{n=0}^{M-2 k} g_{n}^{*} g_{n+2 k}=\delta_{k, 0} k=0,1, \ldots,\lfloor M / 2\rfloor
$$

em que $\lfloor M / 2\rfloor$ denota o ínfimo de $M / 2$ (maior inteiro $\leq M / 2$ ).

2. Média unitária

$$
\sum_{n=0}^{M} g_{i}=\sqrt{2}=G(z=1),
$$

Em $z$, a condição de ortogonalidade (2.65) torna-se

$$
|G(z)|^{2}+|G(-z)|^{2}=2
$$

Observe-se que se M for par, então a aplicação da (2.65), com coeficientes $g_{n}$ reais e $k=M / 2$, resulta em $g_{0} g_{M}=0$, o que contradiz a premissa do filtro de comprimento finito $M+1\left(g_{0}, g_{M} \neq 0\right)$. Portanto, $\mathrm{M}$ deve ser impar e toma-se $M=2 N-1$, com $N \geq 1$, de modo que $\lfloor M / 2\rfloor=N-1$. Sendo assim, as condições (2.65) e (2.66) implicam um sistema de $N+1$ equações a $2 N$ variáveis $g_{0}, g_{1}, \ldots, g_{2 N-1}$ (sistema indeterminado para $\left.N>1\right)$. Quando $N=1(N+1=$ $2 N)$, a solução é única e igual a $g_{0}=g_{1}=\frac{\sqrt{2}}{2}$ (sistema de Haar). Quando $N \geq 2$, deve-se impor $N-1$ restrições adicionais à condição (2.65).

A contribuição de Daubechies foi impor que o polinômio $G(z)$ tenha um zero

\footnotetext{
${ }^{10} G(z)$ é a transformada $z$ de $\left\{g_{n}\right\}$, definida por $G(z)=\sum_{n=-\infty}^{\infty} g_{n} z^{-n}$.
} 
de multiplicidade $\mathrm{N}$ em $z=-1$. Portanto, $G(Z)$ pode ser fatorado na forma

$$
G(z)=\left(\frac{1+z}{2}\right)^{N} W(z)=\left(\frac{1+z}{2}\right)^{N} \sum_{n=0}^{N-1} w_{n} z^{-n}
$$

Na literatura, os filtros de Daubechies são denotados pelo número total de coeficientes (taps) que possuem (vide tabela de coeficientes em (PERCIVAL; WALDEN, 2000, pág.109)). Por exemplo, D(2) corresponde ao filtro de Haar e assim por diante. Os filtros de Daubechies são filtros maximamente planos (Butterworth). As wavelets de Daubechies são funções mais "suaves" (regulares) no domínio do tempo do que as de Haar. Portanto, oferecem maior resolução em freqüência, de acordo com o princípio da incerteza.

A (2.68) tem várias conseqüências. A mais importante está relacionada ao fato da wavelet $\psi$, associada a $\phi$, possuir $\mathrm{N}$ momentos ou cumulantes nulos, ou seja,

$$
\int_{-\infty}^{\infty} t^{m} \psi(t) d t=0, \quad m=0,1, \ldots, N-1
$$

Para $m=0$ a (2.69) corresponde à condição (2.38).

As Figuras 2.6, 2.7, 2.8 e 2.9 exibem as funções de escala e as funções wavelets de Haar e Daubechies ordem 2 nas escalas $j=0$ e $j=1$.
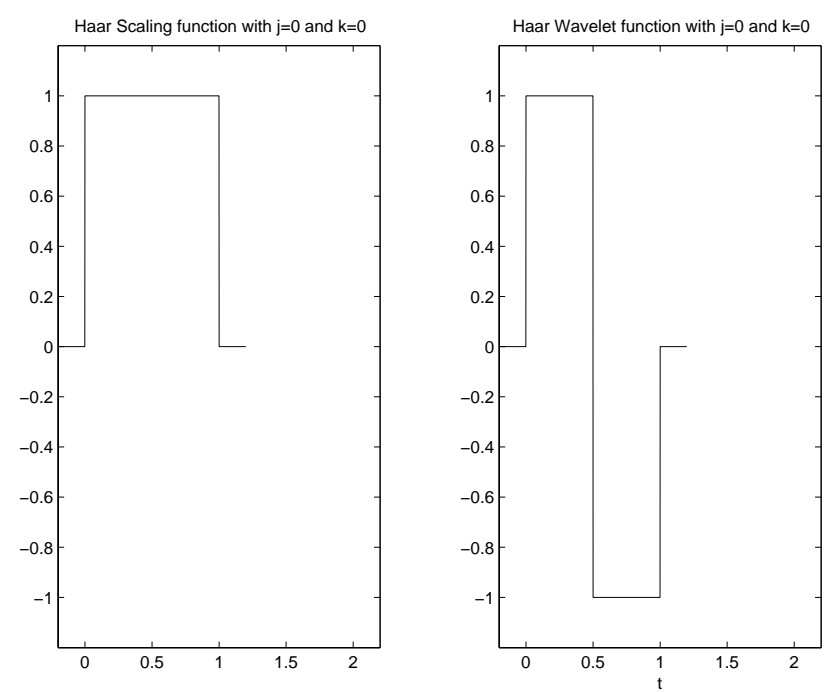

Figura 2.6: Função de escala e wavelet de Haar com $j=0$ e $k=0$ 

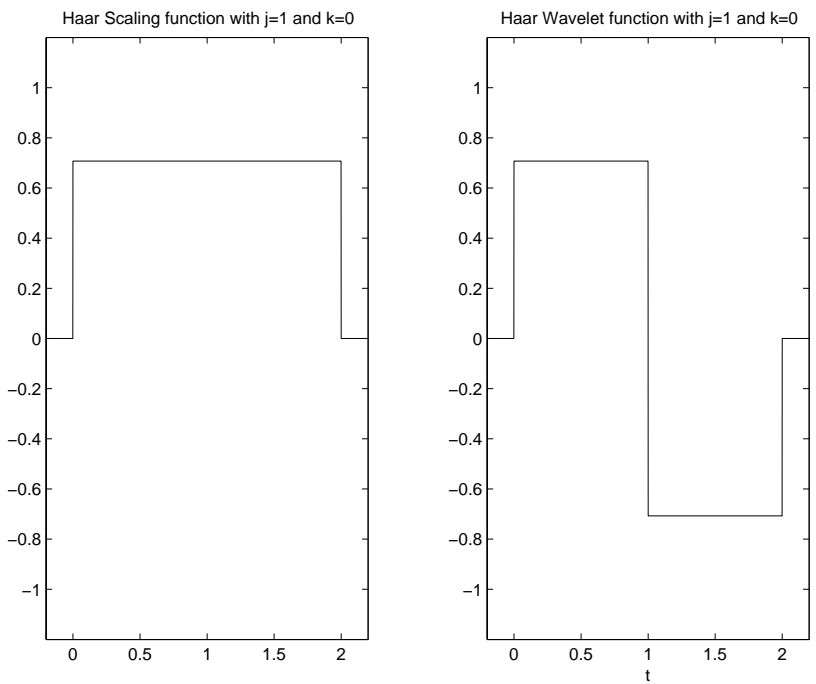

Figura 2.7: Função de escala e wavelet de Haar com $j=1$ e $k=0$
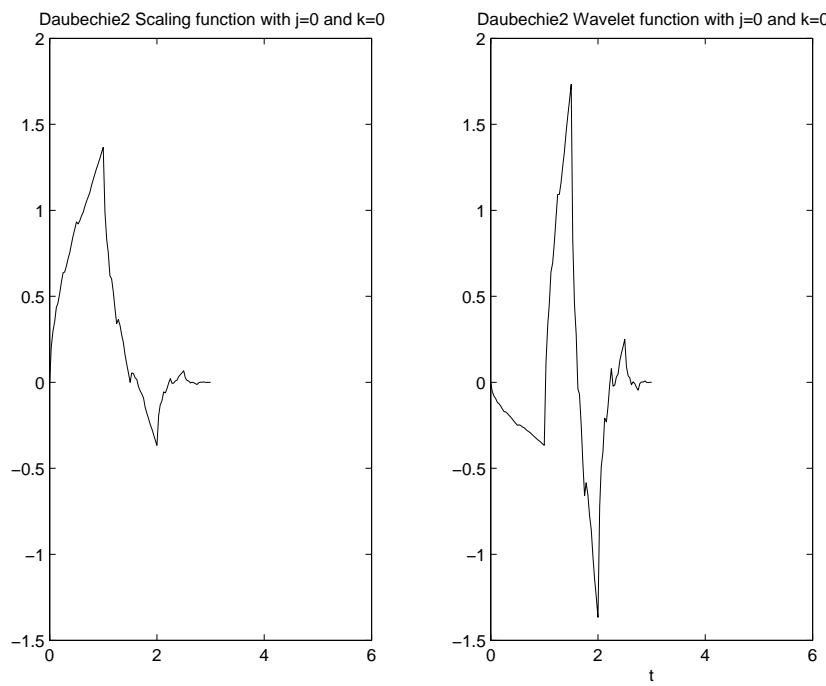

Figura 2.8: Função de escala e wavelet de Daubechies ordem 2 com $j=0$ e $k=0$ 

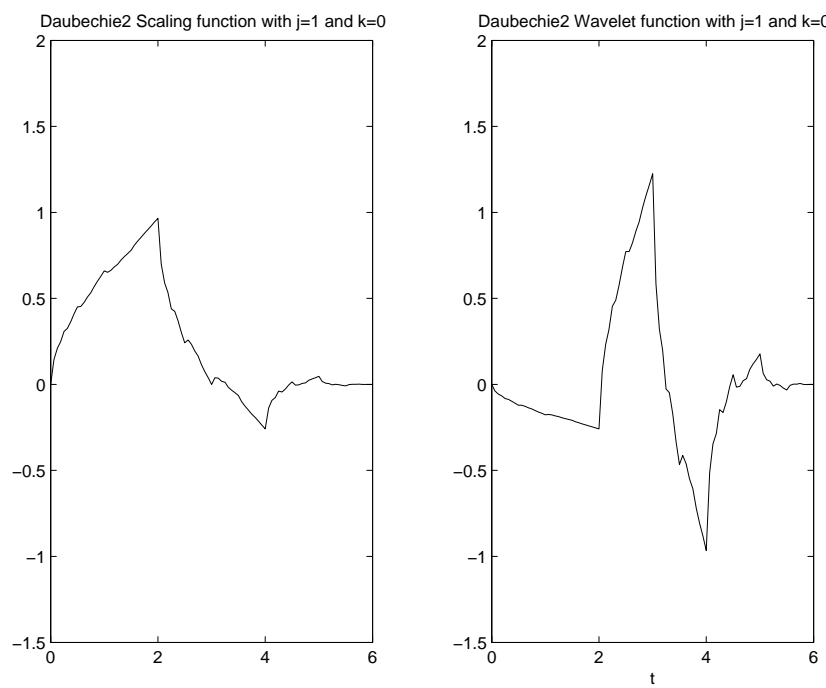

Figura 2.9: Função de escala e wavelet de Daubechies ordem 2 com $j=1$ e $k=0$ 


\subsubsection{Modelo Wavelet Multifractal (MWM)}

Apesar de capturarem características que os modelos clássicos de Poisson e Markov não reproduzem adequadamente, os modelos fractais como o fBM e fGN possuem certas limitações. Enquanto o fBM e fGN são modelos Gaussianos, muitos processos LRD, incluindo tráfego de rede e dados financeiros apresentam valores estritamente positivos e caraterizados por surtos e significativas variações locais (spiky) (RIEDI et al., 1999).

Riedi e Véhel (RIEDI; VéHEL, 1997 apud LIMA, 2002) foram os primeiros a constatar empiricamente que o tráfego presente nas modernas redes de comunicações possui natureza multifractal. Outros estudos (Feldmann; Gilbert; Willinger, 1998); (Gilbert; Willinger; Feldmann, 1999) (apud (LIMA, 2002)) confirmaram a descoberta de Riedi e Véhel.

Riedi et. al. (RIEDI et al., 1999) apresentam o conceito de que os processos aleatórios multifractais possuem um expoente de escala generalizado, $h(t)$, variável no tempo e que esse expoente de escala está intimamente relacionado ao "grau de suavidade local" de um processo. Além disso, os multifractais possuem momentos estatísticos que não variam linearmente com mudanças de escalas de agregação.

Com o objetivo de quantificar as variações locais do tráfego num determinado instante de tempo $t_{0}$, (LIMA, 2002) propõe tomar-se $Y=(Y(t): 0 \leq t \leq 1)$, um processo de acumulação que representa o número de pacotes ou bytes transmitidos através de um enlace durante o tempo $t$. Considere-se ainda o processo de incrementos $X(k)=\left\{Y\left((k+1) 2^{-n}\right)-Y\left(k 2^{-n}\right)\right\}, k=0,1, \ldots, 2^{n}-1$, para algum $n>0$. O tráfego possui um expoente de escala local $h\left(t_{0}\right)$ no instante de tempo $t_{0}$, denominado expoente de Hölder, se $\left\{Y\left((k+1) 2^{-n}\right)-Y\left(k 2^{-n}\right)\right\} \approx$ $\left(2^{-n}\right)^{h\left(t_{0}\right)}$ para $k 2^{-n} \rightarrow t_{0}$ e $n \rightarrow \infty$. Ressalta-se que $h\left(t_{0}\right)<1$ corresponde a instantes de tempo em que o tráfego apresenta surtos de alta carga (irregularidades locais), ao passo que $h\left(t_{0}\right)>1$ ocorre nas regiões em que o tráfego é "suave" (apresenta pouca variação local). Segundo (LIMA, 2002), de maneira informal pode-se dizer que o tráfego é monofractal se o expoente de escala não varia com o tempo, tornando-se $h\left(t_{0}\right)=H$ (expoente de Hurst). Se o expoente de escala varia no tempo, o tráfego é denominado multifractal.

O Multifractal Wavelet Model (MWM) proposto por Riedi et. al. é um modelo multiplicativo, baseado na teoria de cascatas binomiais e implementado através da transformada wavelet (domínio tempo-escala). Ele reproduz as propriedades 
multifractais do tráfego nas escalas "rápidas" de tempo (até centenas de milissegundos) e o comportamento assintoticamente auto-similar de segunda ordem do tráfego em escalas de tempo de maior agregação (segundos, minutos e etc). A razão para esse comportamento está no fato do modelo tornar-se aproximadamente aditivo nas escalas mais lentas e de modo oposto, em escalas rápidas, apresentar um comportamento de particionamento multiplicativo (não-aditivo). Além disso, uma das vantagens do MWM é sua propriedade de assegurar que o processo $X(k)$ seja positivo, o que não ocorre quando se utiliza modelos Gaussianos, tais como o fGN, na síntese de tráfego.

Existem diversas classes de processos multifractais, sendo que o MWM baseiase nos multifractais construídos a partir de cascatas multiplicativas. O MWM estende um modelo multifractal clássico denominado medida binomial $\mu$. A medida $\mu$ é convenientemente construída de maneira iterativa através da chamada estrutura de cascatas (cascatas binomiais). O processo iterativo de construção da cascata parte de uma massa total $M_{0}^{0}$ distribuída uniformemente ao longo de um intervalo unitário. A massa $M_{0}^{0}$ é então redistribuída entre os dois subintervalos de comprimento 0,5 , na razão $M_{0}^{1}$ e $M_{1}^{1}$, em que $M_{0}^{1}+M_{1}^{1}=1$. Sendo $M_{0}^{1} \neq M_{1}^{1}$, um dos intervalos recebe uma densidade de massa maior que o outro. O processo continua de maneira iterativa, de modo que após $n$ passos existem $2^{n}$ intervalos com densidade de massa aleatóriamente distinta entre eles. Nota-se que a criação de spikiness é intrísica ao processo pois intervalos com baixa densidade de massa sempre darão origem a um intervalo filho com densidade ainda menor; da mesma forma, intervalos com alta densidade de massa sempre darão origem a um intervalo filho com densidade de massa ainda maior. A Figura 2.10 ilustra a construção iterativa de uma cascata binomial.

Em relação ao tráfego de redes, técnicas baseadas em auto-similaridade modelam o processo de chegada de bytes como uma taxa média superposta por variações de um processo fGN. Essa modelagem condiz com o conceito do tráfego agregado ser a superposição de diversos componentes de tráfego individuais (fontes) e é precisa para escalas de tempo bastante agregadas. Por outro lado, modelos multiplicativos representam o processo de chegadas de tráfego como o produto de multiplicadores aleatórios, o que reproduz o particionamento do throughput total do tráfego em porções distintas. Essa é uma técnica mais apropriada para escalas de tempo mais refinadas.

As wavelets podem ser utilizadas para síntese de uma aproximação eficiente da expansão de Karhunen-Loève (Ash e Gardner, 1975 apud (LIMA, 2002)) dos ruídos $1 / f$, devido aos coeficientes da transformada wavelet serem variáveis alea- 

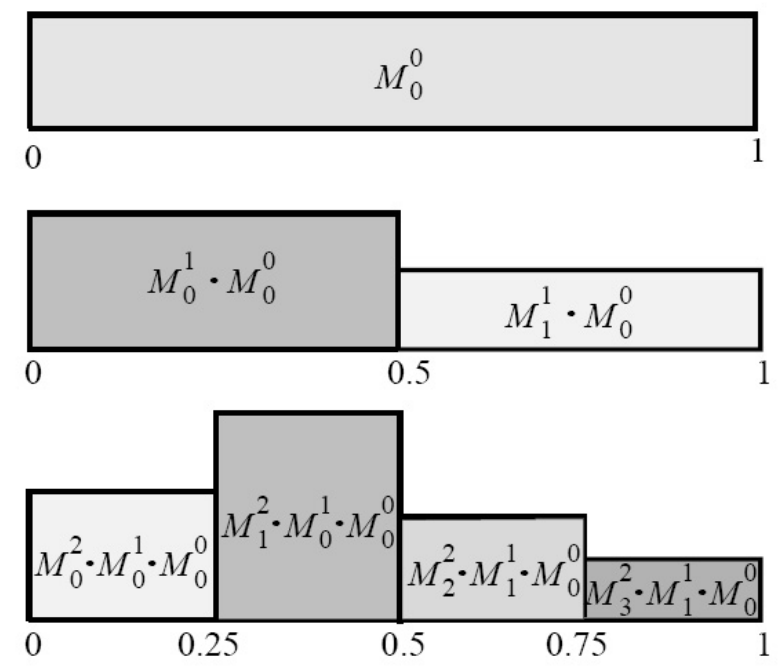

Figura 2.10: Construção iterativa da cascata binomial, extraída de (RIEDI et al., 1999). Parte-se de uma escala inicial (escala 0) com o coeficiente $M_{0}^{0}$ que representa a massa total que será redistribuída. Na escala seguinte, 2 coeficientes $\left(M_{0}^{1}\right.$ e $M_{1}^{1}$, em que o sobrescrito representa a escala e o subscrito a posição no intervalo) são utilizados como fatores para redistribuir a massa $M_{0}^{0}$. Na $2^{\mathrm{a}}$ escala, dos 4 coeficientes (ou fatores) $\left(M_{0}^{2}, M_{1}^{2}, M_{2}^{2}\right.$ e $\left.M_{3}^{2}\right), 2$ são utilizados para redistribuir a massa do $1^{\circ}$ intervalo da escala $1\left(M_{0}^{2}\right.$ e $\left.M_{1}^{2}\right)$ e os outros 2 são utilizados para redistribuir a massa do $2^{\circ}$ intervalo da escala $1\left(M_{2}^{2}\right.$ e $\left.M_{3}^{2}\right)$.

tórias "praticamente" não-correlacionadas. Essa propriedade também serve como motivação para o uso das wavelets na síntese de sinais pelo modelo MWM. O MWM está embasado na teoria matemática da MRA, em que as escalas de tempo são diádicas (potências de dois).

Baseando-se nas (2.47),(2.48) e (2.49) que definem os sinais de aproximação e detalhe da MRA, pode-se decompor uma dada aproximação de $x(t)$ na escala $j$, $\operatorname{aprox}_{j}(t)$, em termos do sinal de detalhe $d_{j+1}(t)$ e de uma aproximação menos refinada $\operatorname{aprox}_{j+1}(t)$.

Sendo assim, pode-se efetuar uma decomposição recursiva da aproximação inicial $\operatorname{aprox}_{0}(t)$ (projeção de $x(t)$ no subespaço $V_{0}$ de maior resolução que corresponde a escalas "rápidas" de tempo), em termos de uma aproximação no subespaço $V_{J}, J>0$ (subespaço de menor resolução, correspondente a escalas "lentas" de tempo) e de um conjunto de sinais de detalhe de resolução decrescente:

$$
\begin{array}{r}
x(t) \approx \operatorname{aprox}_{0}(t)=\operatorname{aprox}_{J}(t)+\sum_{j=1}^{J} d_{j}(t) \\
=u_{J, 0} \phi_{J, 0}(t)+\sum_{j=1}^{J} \sum_{k} w_{j, k} \psi_{j, k}(t) .
\end{array}
$$


Partindo-se da wavelet mãe $\psi_{0}(t)$ posicionada no tempo zero e centrada na freqüência $f_{0}$, pode-se dizer que o coeficiente wavelet $w_{j, k}$ mede o conteúdo do sinal aleatório em torno do instante de tempo $2^{j} k$ e freqüência $2^{-j} f_{0}$. Por sua vez, o coeficiente de escala $u_{j, k}$ da (2.47) está associado à média local em torno do instante de tempo $2^{j} k$. Nota-se em (2.70) que o índice $j$ representa a escala de análise e a resolução decresce com o aumento de $j$.

A Figura 2.11 exibe uma representação da árvore binária dos coeficientes de escala. Cada linha (ou escala) $j$ dessa árvore permite obter uma aproximação de $x(t)$ com resolução proporcional a $2^{j}$. Em uma árvore complementar a essa, em que estivessem representados os coeficientes wavelet, cada linha $j$ da árvore de coeficientes wavelet estaria associada ao sinal de detalhe que quando combinado com o sinal de aproximação na escala $j$ gera a aproximação mais refinada, em uma escala $j-1$.

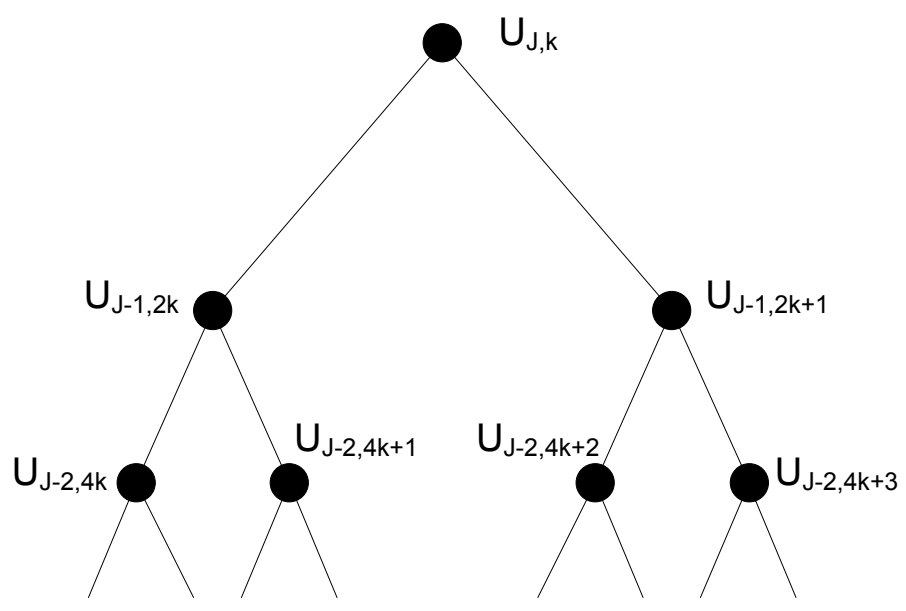

Figura 2.11: Árvore binária dos coeficientes de escala.

O MWM utiliza-se das wavelets de Haar, de modo que os coeficientes de escala podem ser recursivamente calculados através das relações de síntese:

$$
\begin{gathered}
u_{j-1,2 k}=2^{-1 / 2}\left(u_{j, k}+w_{j, k}\right), \\
u_{j-1,2 k+1}=2^{-1 / 2}\left(u_{j, k}-w_{j, k}\right) .
\end{gathered}
$$

Utilizando-se as equações de síntese, pode-se garantir que uma realização $x_{0, k}$ seja positiva através da imposição da seguinte condição: 


$$
\left|w_{j, k}\right| \leq u_{j, k}
$$

O modelo multiplicativo MWM incorpora a condição (2.73) para os coeficientes $w_{j, k}$. Considere a variável aleatória $A_{j, k}$, de domínio no intervalo $[-1,1] \mathrm{e}$ definam-se os coeficientes $w_{j, k}$ segundo (2.74),

$$
w_{j, k}=A_{j, k} u_{j, k}
$$

Cria-se, dessa forma, uma relação que satisfaz a condição enunciada em (2.73).

O multiplicador $A_{j, k}$ da (2.74) pode ser modelado através de uma distribuição beta simétrica com parâmetro $p, \beta(p, p)$. Mais detalhes sobre essa distribuição podem ser encontrados em Johnson; Kotz; Balakrishnan, 1994 (apud (LIMA, 2002)). (RIEDI et al., 1999) também investiga o uso de uma distribuição ponto-massa simétrica para os multiplicadores $A_{j, k}$, porém neste trabalho utilizase apenas a distribuição $\beta(p, p)$. A $\beta(p, p)$ possui a seguinte $\mathrm{PDF}$ :

$$
g_{A}(a)=\frac{(1+a)^{p-1}(1-a)^{p-1}}{\mathcal{B}(p, p) 2^{2 p-1}} \quad p>0,
$$

em que $\mathcal{B}(p, p)$ é a função beta definida por:

$$
\mathcal{B}(x, y)=\int_{0}^{1} u^{x-1}(1-u)^{y-1} d u \quad x>0, y>0 .
$$

A Figura 2.12 ilustra o formato da PDF de uma variável aleatória $A$ de distribuição $\beta(p, p)$. Para valores baixos do parâmetro $p$ a PDF aproxima-se da PDF de uma variável aleatória binomial. Para $p=1$ obtém-se a PDF uniforme. Para $p>1$ a PDF se assemelha à de uma variável aleatória Gaussiana. Note-se que a distribuição $\beta(p, p)$ é simétrica em torno de zero.

O MWM assume que os multiplicadores $A_{j, k}$ são identicamente distribuídos dentro de uma mesma escala de tempo (variáveis aleatórias do tipo $A_{j}$ de distribuição $\beta(p, p))$. A variância do multiplicador $A_{j}$ é dada em função do valor do parâmetro $p$ em uma escala $j$ :

$$
\operatorname{Var}\left[A_{j}\right]=E\left[A_{j}^{2}\right]=\frac{1}{2 p_{j}+1} .
$$

As equações (2.71) e (2.72) podem ser expressas em função dos multiplicadores $A_{j, k}$ e dos coeficientes $u_{j, k}$, como mostrado nas relações: 


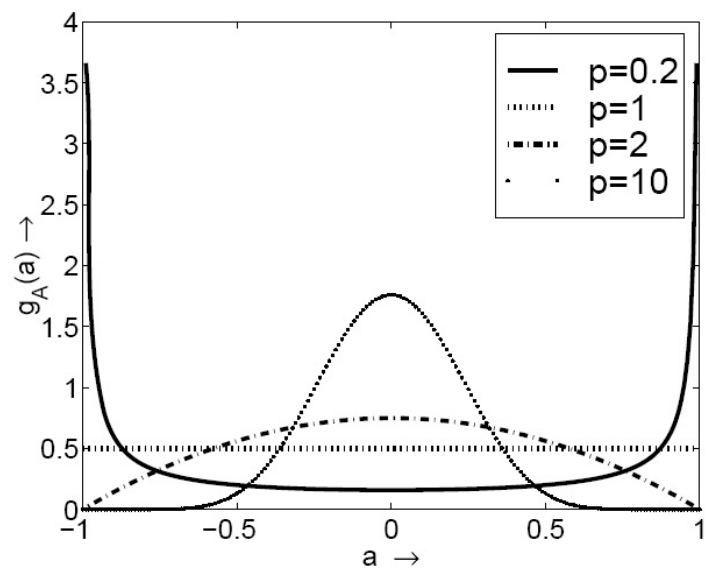

Figura 2.12: $\operatorname{PDF} g_{A}(a)$ de uma variável aleatória $A$ de distribuição $\beta(p, p)$ para alguns valores do parâmetro $p$, extraída de (RIEDI et al., 1999).

$$
\begin{gathered}
u_{j-1,2 k}=\left(\frac{1+A_{j, k}}{\sqrt{2}}\right) u_{j, k}, \\
u_{j-1,2 k+1}=\left(\frac{1-A_{j, k}}{\sqrt{2}}\right) u_{j, k} .
\end{gathered}
$$

Essas relações mostram que o MWM é realmente um modelo de cascata binomial.

É possível controlar de maneira aproximada a correlação do sinal sintetizado, através da configuração apropriada dos momentos de segunda ordem (energia) dos coeficientes wavelet em cada escala. A forma mais simples de controlar a energia dos coeficientes ao longo das escalas é fixando a energia na escala mais agregada $(j=J)$ e então estabelecer as relações de energia entre as escalas através do parâmetro $\eta_{j}=\frac{\operatorname{Var}\left[w_{j}\right]}{\operatorname{Var}\left[w_{j-1}\right]}, j<J$. Para processos estacionários do tipo $1 / f$, o decaimento de energia é dado pela relação $\eta_{j}=2^{2 H-1}$ constante.

Para o MWM pode-se obter a expressão (2.80) que permite calcular o parâmetro $p_{j-1}$ da distribuição beta para uma escala $j-1$ mais refinada, em função do $p_{j}$ e de um decaimento de energia desejado (scaling behavior) para os coeficientes wavelet, controlado por $\eta_{j}$.

$$
p_{j-1}=\frac{\eta_{j}}{2}\left(p_{j}+1\right)-\frac{1}{2}
$$

O MWM assume que o coeficiente de escala inicial (escala mais agregada) $U_{J, 0}$ pode ser modelado através de uma variável aleatória Gaussiana de relação média/variância suficientemente elevada de modo a evitar eventos com $U_{J, 0}<0$.

Ao utilizar o MWM para modelar um processo estacionário do tipo $1 / f$ (uti- 
lizando $\eta_{j}=2^{2 H-1}=$ cte) é possível mostrar que o $p_{j}$ converge para

$$
p_{-\infty}=\lim _{j \rightarrow-\infty} p_{j}=\frac{2^{\alpha}-1}{2-2^{\alpha}}
$$

em que $\alpha=2 H-1$.

A Tabela 2.1 mostra alguns valores de convergência do parâmetro $p$ em função do parâmetro de Hurst desejado.

Tabela 2.1: Valores assintóticos para o parâmetro $p$ da distribuição beta como

\begin{tabular}{c|c|c|c|c}
\multicolumn{5}{c}{ função de $\alpha($ ou $H)$} \\
\hline \hline$\alpha$ & 0,1 & 0,2 & 0,5 & 0,8 \\
\hline$p$ & 0,077 & 0,175 & 0,707 & 2,86 \\
\hline$H$ & 0,55 & 0,6 & 0,75 & 0,9 \\
\hline \hline
\end{tabular}

Riedi et. al. (RIEDI et al., 1999) afirmam que se a variável aleatória $A_{j, k}$ converge em distribuição à medida que $j \rightarrow-\infty$, então a série gerada pelo MWM possui propriedades multifractais. O aumento do número de escalas na transformada wavelet faz com que a densidade de probabilidade marginal do modelo convirja para a de uma variável aleatória lognormal.

As propriedades estatísticas do tráfego gerado através do modelo MWM são mais adequadas que as do modelo fGN, pois o MWM consegue reproduzir as estatísticas de maior ordem do tráfego real devido à sua estrutura multiplicativa. Da mesma forma que o fGN, o MWM consegue modelar com bastante precisão a DEP e, conseqüentemente, o comportamento LRD do tráfego real. Para isso, no caso do MWM, as variâncias dos multiplicadores $A_{j, k}$ devem ser escolhidas de modo apropriado (afetando o comportamento do decaimento da energia dos coeficientes wavelet entre as escalas de tempo). 


\section{Geração e Análise de Séries Temporais}

\subsection{Síntese de Séries Temporais via Wavelets}

Na Seção 2.3.6 explica-se como as funções wavelet e funções de escala são obtidas a partir de deslocamentos no tempo (que dá a característica de localização temporal da DWT) e dilações em relação às funções originais. De maneira intuitiva, a identificação de variações "lentas" (baixa freqüência e baixa resolução) de sinais analisados via wavelets é feita através de funções dilatadas capazes de capturar trechos mais extensos do sinal. Já a detecção de surtos "rápidos" ou spikes, que envolvem componentes em altas freqüências, é efetuada por funções mais comprimidas (escalas mais refinadas).

Também é dito que a MRA decompõe de modo recursivo um sinal $x(t)$ em $J$ seqüências de coeficientes wavelet ( $J$ escalas) e uma seqüência de coeficientes de aproximação (ou de escala) na escala menos refinada. Através do algoritmo da pirâmide a MRA é implementada por bancos de filtros passa-baixas e passa-altas adequadamente posicionados para recursivamente separar os sinais de aproximação e de detalhe. Como os coeficientes dos filtros são reais (é o caso para as wavelets de Haar e de Daubechies) a relação entre os coeficientes de um filtro de reconstrução e os coeficientes do respectivo filtro de decomposição é bastante simples, bastando inverter a ordem dos coeficientes para passar de um filtro a outro (operação fliplr do software Matlab).

Tomando-se as seqüências $\left\{g_{n}\right\}$ para os coeficientes do filtro de escala de reconstrução (passa-baixas) e $\left\{h_{n}\right\}$ para os coeficientes do filtro wavelet de reconstrução (passa-altas), pode-se obter as relações de análise que indicam como os coeficientes de escala e os coeficientes wavelet de um sinal em uma escala $j$ (mais agregada) são calculados a partir dos coeficientes da escala $j-1$ (BACKäR, 2000): 


$$
u_{j, k}=\sum_{n=0}^{2 N-1} g_{n} u_{j-1, n+2 k} \text { e } w_{j, k}=\sum_{n=0}^{2 N-1} h_{n} u_{j-1, n+2 k},
$$

em que N é o número de vanishing moments do filtro wavelet adotado.

Os coeficientes $\left\{g_{n}\right\}$ e $\left\{h_{n}\right\}$ dos filtros são chamados de seqüências geradoras por (VEITCH et al., 2000) e apresentam $2 N$ elementos não nulos $(\mathrm{N}=1$ para wavelet de Haar). $\left\{g_{n}\right\}$ e $\left\{h_{n}\right\}$ estão tabelados (PERCIVAL; WALDEN, 2000, pág.109), sendo que a seqüência $\left\{g_{n}\right\}$ pode ser obtida através da função dbaux do Matlab para as wavelets de Daubechies.

Percival (PERCIVAL; WALDEN, 2000) apresenta a (3.2) que permite calcular os coeficientes do filtro wavelet $\left\{h_{n}\right\}$, quando são conhecidos os coeficientes do filtro de escala:

$$
h_{n}=(-1)^{n} g_{2 N-1-n}
$$

Bäckar (BACKäR, 2000) também apresenta a equação de reconstrução (3.3), necessária para obter os coeficientes de aproximação em uma escala mais refinada a partir de uma escala de menor resolução:

$$
u_{j, k}=\sum_{l=\lfloor k / 2\rfloor}^{\lfloor k / 2\rfloor-N+1}\left(g_{k-2 l} u_{j+1, l}+h_{k-2 l} w_{j+1, l}\right) .
$$

A primeira somatória de (3.3) pode ser calculada utilizando-se a operação de convolução entre a série $\left\{g_{n}\right\}$ e uma série obtida pela intercalação de zeros nos coeficientes de aproximação apropriados (upsampling). Similarmente, na segunda somatória efetua-se a convolução entre a série $\left\{h_{n}\right\}$ e os coeficientes wavelet apropriados após upsampling. No software Matlab utiliza-se a função conv para efetuar a operação de convolução e dyadup para a operação upsampling. A referência citada mostra que ao se utilizar a operação de convolução são gerados alguns coeficientes adicionais que devem ser descartados. Para contornar esse problema, é preciso rastrear a que ponto no tempo cada coeficiente se refere e quais eram os coeficientes necessários em cada uma das escalas. Com esse controle é possível descartar os coeficientes indesejados.

As equações (3.4) e (3.5) indicam os índices extremos necessários em uma escala menos refinada em função dos índices desejados para a escala imediatamente inferior. Com essas equações pode-se partir da escala mais refinada $j=0$, em que é conhecido o número de pontos que se deseja sintetizar, e calcular os índices 
$k_{\min }$ e $k_{\max }$ necessários em cada uma das escalas superiores até o nível de menor resolução, $j=J$. As equações (3.6) e (3.7) indicam os índices mínimo e máximo obtidos ao se efetuar a operação upsampling em uma escala $j+1$. Finalmente, através das equações (3.8) e (3.9) sabe-se quais os índices obtidos em uma escala $j$ após as operações de upsampling e convolução sobre os coeficientes da escala $j+1$. Comparando-se os índices após a convolução com os desejados, calculados pelas equações (3.4) e (3.5) na inicialização do algoritmo, sabe-se como descartar os coeficientes desnecessários.

$$
\begin{gathered}
k_{\min }(j+1)=\left\lfloor\frac{k_{\min }(j)}{2}\right\rfloor-(N-1) \\
k_{\max }(j+1)=\left\lfloor\frac{k_{\max }(j)}{2}\right\rfloor \\
k_{u}^{\min }(j+1)=2 k_{\min }(j+1) \\
k_{u}^{\max }(j+1)=2 k_{\max }(j+1) \\
k_{c}^{\min }(j)=k_{u}^{\min }(j+1) \\
k_{c}^{\max }(j)=k_{u}^{\max }(j+1)+2 N-1
\end{gathered}
$$

A Figura 3.1 exibe a relação entre os coeficentes em diferentes escalas para reconstrução do sinal original. Os círculos da figura estão posicionados na grade diádica, que é o conjunto de pontos $\left\{(t\right.$, escala $\left.)=\left(k 2^{j}, 2^{j}\right), j, k \in Z\right\}$ no plano tempoescala, correspondendo às localizações em torno das quais as funções $\psi_{j, k}$ e $\phi_{j, k}$ estão centradas e às quais os coeficientes de aproximação e wavelet correspondem. Nessa Figura, a wavelet escolhida possui ordem $N=2$, de modo que o comprimento das seqüências $\left\{g_{n}\right\}$ e $\left\{h_{n}\right\}$ é $2 N=4$. Ressalta-se que em uma escala menos refinada os coeficientes de aproximação e wavelet são utilizados para gerar somente os coeficientes de aproximação da escala imediatamente inferior. Na próxima iteração os coeficientes wavelet, que estariam armazenados caso a etapa de análise tivesse ocorrido, são adicionados ao algoritmo para gerar os coeficientes de aproximação da próxima escala (mais refinada).

O autor citado ainda faz algumas observações em relação ao cálculo dos co- 


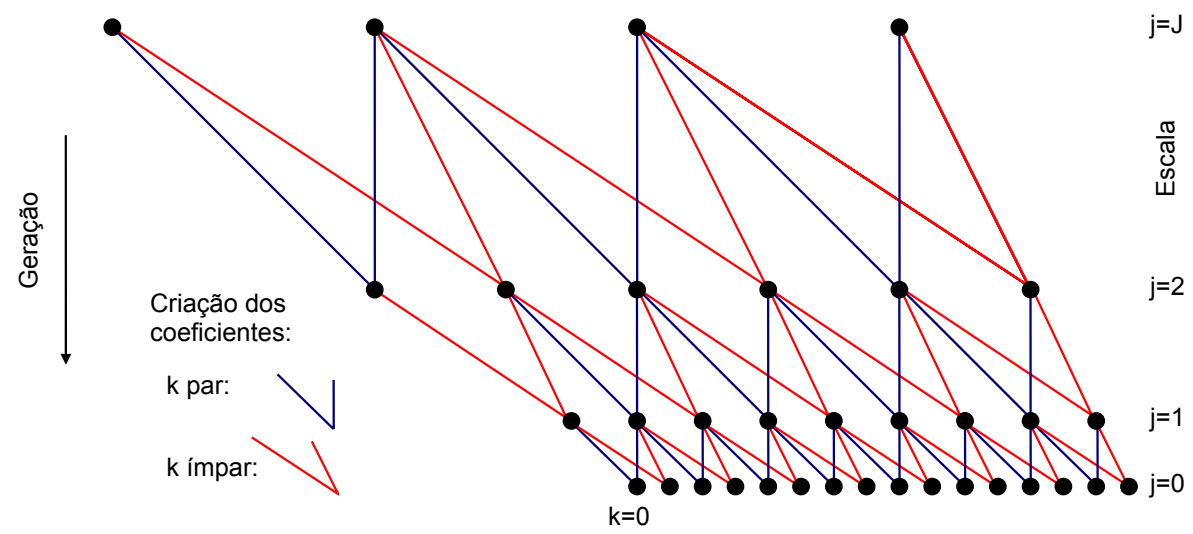

Figura 3.1: Coeficientes necessários para reconstrução da função original considerando utilização de filtro wavelet $\operatorname{com} N=2$.

eficientes de aproximação de um sinal em escalas mais refinadas a partir de coeficientes de aproximação e wavelet em escalas de menor resolução (reconstrução ou síntese). A primeira delas é que tanto um coeficiente de aproximação com índice $k$ par quanto o coeficiente seguinte de índice $k+1$, ambos são calculados a partir dos mesmos coeficientes de aproximação e wavelet da escala imediatamente superior, porém os coeficientes dos filtros $\left\{g_{n}\right\}$ e $\left\{h_{n}\right\}$ utilizados são diferentes. Coeficientes pares dos filtros dão origem ao coeficiente de aproximação com índice $k$ par e coeficientes ímpares dos filtros dão origem ao coeficiente de aproximação com índice $k+1$ ímpar. A segunda observação é que para a geração da aproximação mais refinada de um sinal (escala $j=0$ ) em que o coeficiente inicial corresponda ao instante $k=0$, são necessários coeficientes em escalas menos refinadas correspondentes a instantes de tempo em que $k<0$.

O diagrama da Figura 3.2 mostra como as operações de upsampling e de convolução dos coeficientes de escala e wavelet com os coeficientes dos filtros passa-baixas e passa-altas são recursivamente combinados para se obter coeficientes de aproximação em escalas mais refinadas. Esse diagrama de reconstrução equivale à Inverse Discrete Wavelet Transform (IDWT) aliada à teoria MRA, implementado através do algoritmo da pirâmide de Mallat (MALLAT, 1989).

Tanto o sinal de detalhe quanto o sinal de aproximação de uma determinada escala podem ser reconstruídos a partir dos respectivos coeficientes wavelet ou de aproximação passando-se esses coeficientes através do banco de filtros do algoritmo da pirâmide, porém mantendo-se os valores dos demais coeficientes em zero. A adição de todos os sinais de detalhe mais o sinal de aproximação menos refinado forma o sinal original ou sinal sintetizado. 


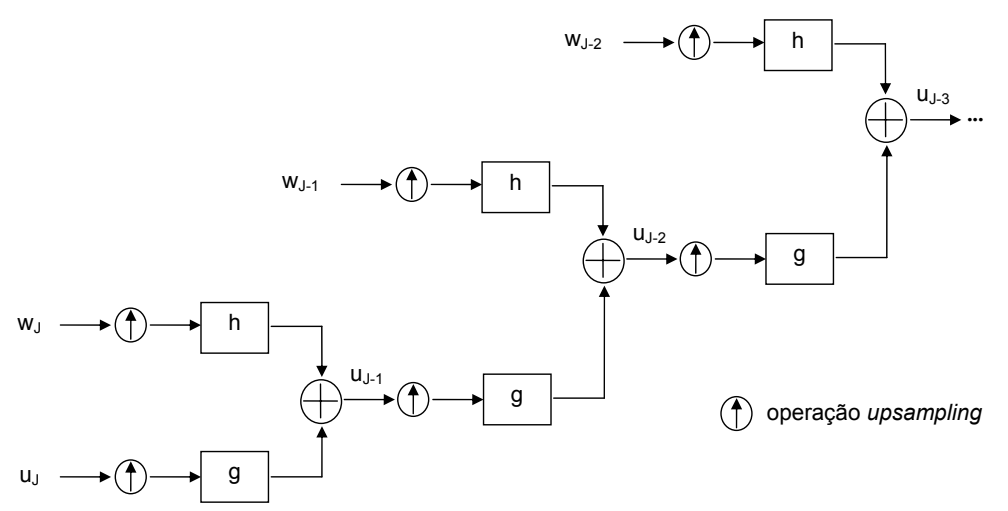

Figura 3.2: Algoritmo de Reconstrucao baseado na IDWT

Pode-se resumir o procedimento de síntese de séries via wavelets através dos seguintes passos:

1. Determina-se o número total de escalas $J+1$, em que $j=J$ será a escala menos refinada e $j=0$ será a escala mais refinada;

2. Determina-se o número total de pontos $M$ desejados ao final da síntese ${ }^{1}$;

3. Calculam-se os coeficientes dos filtros $\left\{g_{n}\right\}$ (dbaux) e $\left\{h_{n}\right\}$ (3.2) dependendo da wavelet escolhida ${ }^{2}$;

4. Utilizando-se (3.4) e (3.5) calculam-se os índices de coeficientes $k_{\min }(j)$ e $k_{\max }(j)$ para cada escala $j$;

5. Através de modelo apropriado determinam-se os coeficientes de aproximação na escala menos refinada $j=J$;

6. Através de modelo apropriado calculam-se os coeficientes wavelet na escala menos refinada $j=J$;

7. Efetuam-se as operações de upsampling (dyadup) e convolução (conv);

8. Comparando-se o resultado de (3.8) e (3.9) com os valores de $k_{\min }(j)$ e $k_{\max }(j)$, descartam-se os coeficientes cujos índices não sejam necessários;

9. Somam-se as séries dos coeficientes wavelet e de aproximação da escala $j=$ $J$ após upsampling e convolução para obter os coeficientes de aproximação na escala $j=J-1$;

\footnotetext{
${ }^{1}$ Em particular para o modelo MWM, $M=2^{J}$.

${ }^{2}$ Para o MWM utiliza-se sempre a wavelet de Haar.
} 
10. Repetem-se os 4 últimos passos, substituindo-se $j$ por $j-1$ até que os coeficientes de aproximação na escala $j=0$ sejam obtidos.

\subsubsection{Geração de Séries com DEP $1 / f$}

Kaplan e Kuo (KAPLAN; KUO, 1993) mostraram que a aplicação da DWT com a base de Haar ao FGN produz coeficientes wavelet pouco correlacionados, com uma variância que é exponencialmente relacionada à escala:

$$
\operatorname{Var}\left\{w_{j, k}\right\} \propto 2^{j \alpha}
$$

Resultados similares também foram obtidos por Flandrin (FLANDRIN, 1989) (FLANDRIN, 1992) para um FBM de tempo contínuo analisado através da transformada wavelet de tempo contínuo. Mais recentemente, Percival(PERCIVAL; WALDEN, 2000) aprofunda a questão ao mostrar que a DWT também descorrelaciona outros processos de memória longa, tais como o PPL e o FD. A (3.10) afirma que processos $1 / f$ são caracterizados pela linearidade do diagrama logscale $\log _{2}\left(\operatorname{Var}\left\{w_{j, k}\right\}\right)$ versus $\log _{2}\left(2^{j}\right)$.

O gerador de tráfego de Bäckar (BACKäR, 2000) segue a prescrição de Kaplan e Kuo e foi implementado via algoritmo da pirâmide. As séries geradas dependem:

- do filtro wavelet;

- do número de escalas da MRA;

- do processo estocástico que gera a realização $\left\{u_{J}(k)\right\}$;

- do processo estocástico que gera as realizações $\left\{w_{j}(k)\right\}_{j=J, J-1, \ldots, 1}$.

Portanto, para garantir que as séries geradas correspondam a realizações de processos com DEP $1 / f$, o processo estocástico que controla a criação dos coeficientes wavelet $\left\{w_{j}(k)\right\}_{j=J, J-1, \ldots, 1}$ deve ser escolhido de modo que $\eta_{j}=\frac{\operatorname{Var}\left[w_{j}\right]}{\operatorname{Var}\left[w_{j-1}\right]}=$ $2^{\alpha}, j \leq J$. Ou seja, o decaimento da energia dos coeficientes wavelet entre escalas consecutivas é constante.

\subsubsection{Geração de Séries LRD Gaussianas}

A fim de gerar séries Gaussianas com LRD (e DEP 1/f), Bäckar adotou os seguintes modelos para os coeficientes wavelet $\left\{w_{j, k}\right\}$ : 
1. ruído branco Gaussiano;

2. processo AR(1) (auto-regressivo de ordem 1) com choque Gaussiano.

Esses modelos também foram implementados e explorados neste trabalho. As características que controlam a síntese de séries LRD para o modelo baseado no ruído branco Gaussiano são:

- wavelet de Daubechies de ordem $N$;

- número de escalas $J+1$ ( $J$ é a escala menos refinada e 0 a mais refinada);

- número de pontos que serão sintetizados $M$;

- parâmetro $\alpha$ que controla o decaimento de energia dos coeficientes wavelet;

- coeficientes de aproximação na escala menos refinada configurados para o valor 0 ;

- coeficientes wavelet com distribuição Gaussiana independente e identicamente distribuída de média 0 e variância 1,0 na escala $J$. A variância dos coeficientes wavelet decai de uma escala para outra pelo fator $2^{\alpha}$.

Para o modelo baseado no processo $\mathrm{AR}(1)$, as características que controlam a síntese das séries são semelhantes:

- wavelet de Daubechies de ordem $N$;

- número de escalas $J+1$;

- número de pontos que serão sintetizados $M$;

- parâmetro $\alpha$ que controla o decaimento de energia dos coeficientes wavelet;

- parâmetro $\phi$ que controla em cada escala a influência do valor do coeficiente wavelet imediatamente anterior no valor do coeficiente atual (AR);

- coeficientes de aproximação na escala menos refinada configurados para o valor 0 ;

- coeficientes wavelet com distribuição AR(1) e choque Gaussiano independente e identicamente distribuído de média 0 e variância 1,0 na escala $J$. A variância dos coeficientes wavelet decai de uma escala para outra pelo fator $2^{\alpha}$. 
O método de geração via DWT não especifica a forma da DEP em freqüências médias e altas, muito menos que a DEP da série gerada corresponda à do fGN, dada por (2.33). O que o método garante é que a série tenha espectro $1 / f$. As densidades marginais de probabilidade são controladas pelas estatísticas dos coeficientes wavelet (Gaussianas para os modelos citados acima). No entanto, as DEPs estimadas das séries geradas via DWT aproximam a DEP teórica do fGN (conforme será visto no item 3.2) podendo-se afirmar, do ponto de vista prático, que as séries efetivamente simulam o fGN (mas elas também simulam o PPL e o FD). A Figura 2.5 reforça este ponto de vista, pois mostra que as DEPs de processos fGN e FD equivalentes (isto é, potência e $H$ iguais) estão superpostas nas baixas freqüências. A Figura 3.3 mostra uma realização $1 / f$ com $\alpha=0,9(H=0,95)$, que foi gerada pelo algoritmo da pirâmide. Note-se que essa realização é visualmente bastante parecida com a série fGN aproximada da Figura 3.4, que foi gerada pelo método da FFT de Paxson.

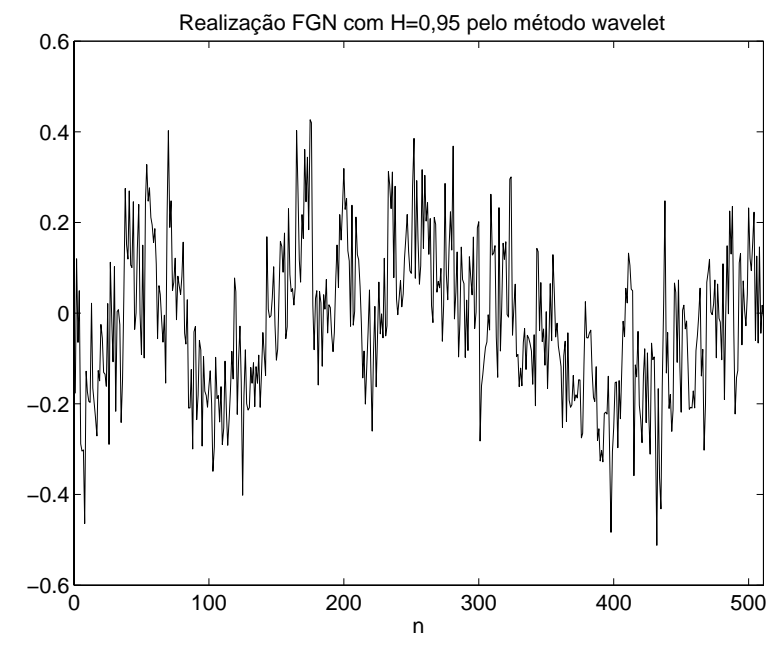

Figura 3.3: Realização de um processo $1 / f$ obtida através do método wavelet utilizando função de Haar, sorteio IID Gaussiano dos coeficientes wavelet e escolha de $\alpha=0,9(H=0,95)$ para controle da variância das variáveis aleatórias Gaussianas.

Sendo assim, pode-se afirmar que o método de geração via wavelets implementado por Bäckar sintetiza séries $1 / f$ Gaussianas, se os coeficientes wavelet forem modelados conforme descrito anteriormente.

\subsubsection{Geração de Séries LRD Não-Gaussianas pelo modelo MWM}

As seguintes características controlam a síntese de séries LRD pelo modelo MWM:

- wavelet de Daubechies de ordem $N=1$ (wavelet de Haar); 


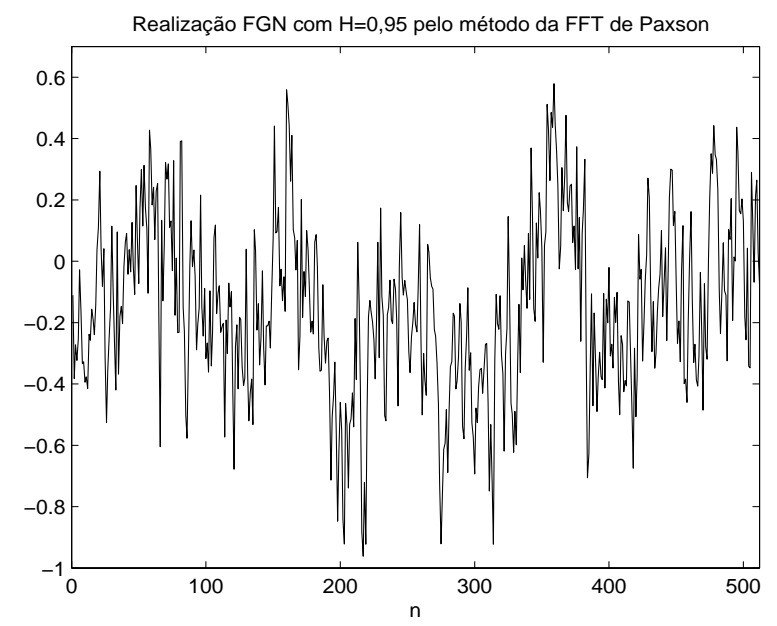

Figura 3.4: Série fGN aproximada gerada pelo método FFT de Paxson, com $H=0,95$.

- número de escalas $J+1$;

- número de pontos que serão sintetizados será determinado por $J, M=2^{J}$;

- parâmetro $\alpha$ que controla o decaimento de energia dos coeficientes wavelet;

- parâmetro $p$ inicial que controla a variância do multiplicador $A_{J}$ na escala menos refinada. $p$ é recalculado em cada escala segundo a (2.80);

- coeficiente de aproximação na escala menos refinada (root) segue uma distribuição Gaussiana de média 2.0 e variância 1.0;

- coeficientes wavelet são derivados dos respectivos coeficientes de escala pelos multiplicadores de distribuição $\beta(p, p)$ (2.74). A variância dos coeficientes wavelet decai de uma escala para outra pelo fator $2^{\alpha}$.

Ao fixar $\eta_{j}=2^{\alpha}$, define-se que o MWM irá gerar realizações sempre positivas e não-Gaussianas de um processo do tipo $1 / f$. A Figura 3.5 exibe realizações de um processo $1 / f$ sintetizadas através do modelo MWM.

\subsubsection{Inserção de SRD}

Motivado pelo fato de que traces reais de tráfego podem apresentar SRD em algumas escalas de tempo, o gerador deste trabalho é implementado em dois estágios. O primeiro sintetiza séries de memória longa via algoritmo da pirâmide. O segundo estágio introduz dependência de curta duração através de uma filtragem IIR (Infinite Impulse Response) passa-bandas da saída do primeiro estágio. Portanto, o gerador implementado é mais flexível que o de Bäckar, uma vez que 

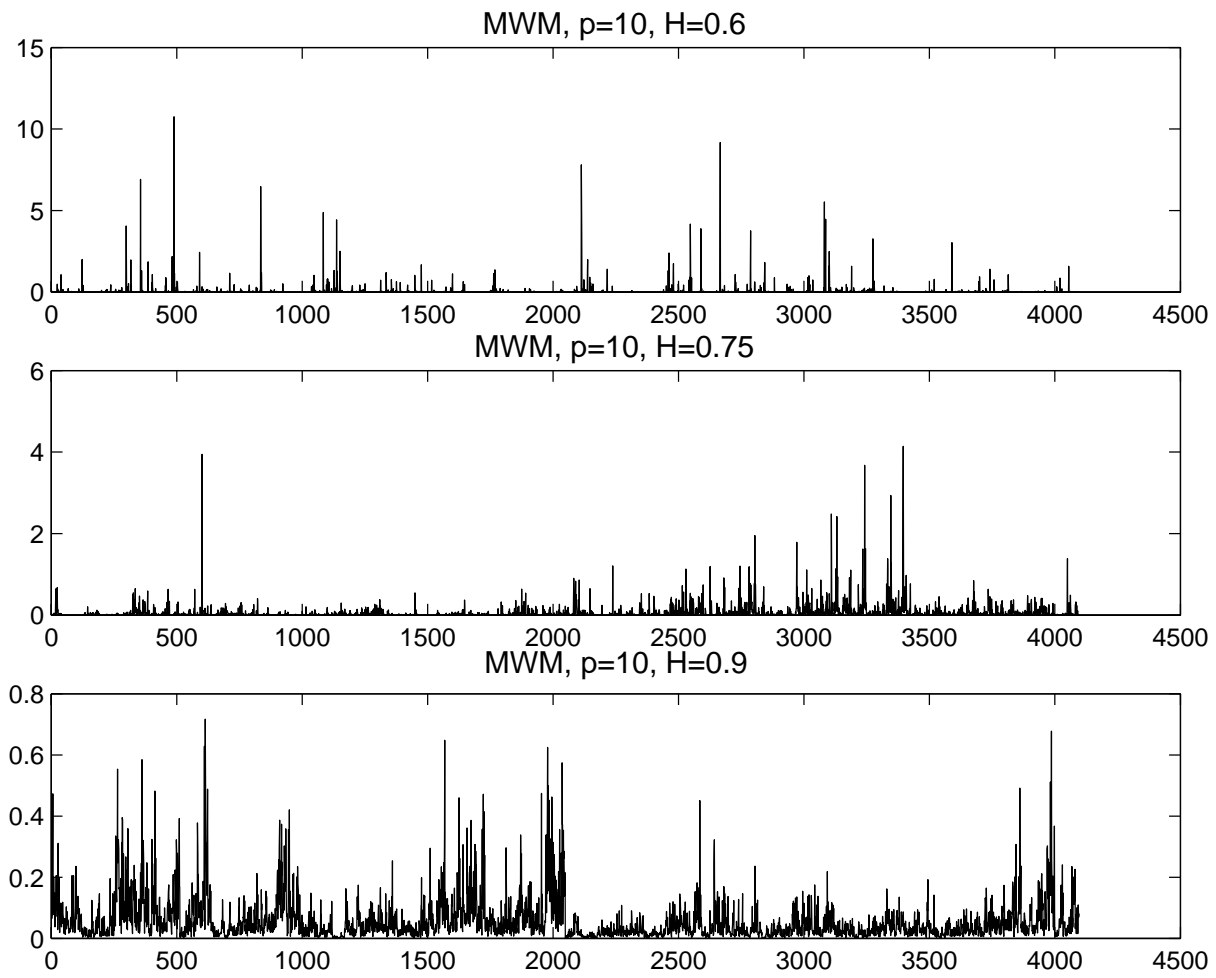

Figura 3.5: Três realizações do modelo MWM geradas com escala menos refinada $J=12$ e parâmetro $p=10$. As realizações na parte superior, ao centro e na parte inferior desta figura possuem $H=0,6,0,75$ e 0,9 , respectivamente.

a sua saída pode ser somente $1 / f, 1 / f$ e SRD ou somente SRD. A função de transferência IIR usada é dada por

$$
H(f)=\frac{1}{1-0,3 e^{-j 2 \pi f}+0,4 e^{-j 4 \pi f}} .
$$

A Figura 3.6 mostra a magnitude da resposta em freqüência.

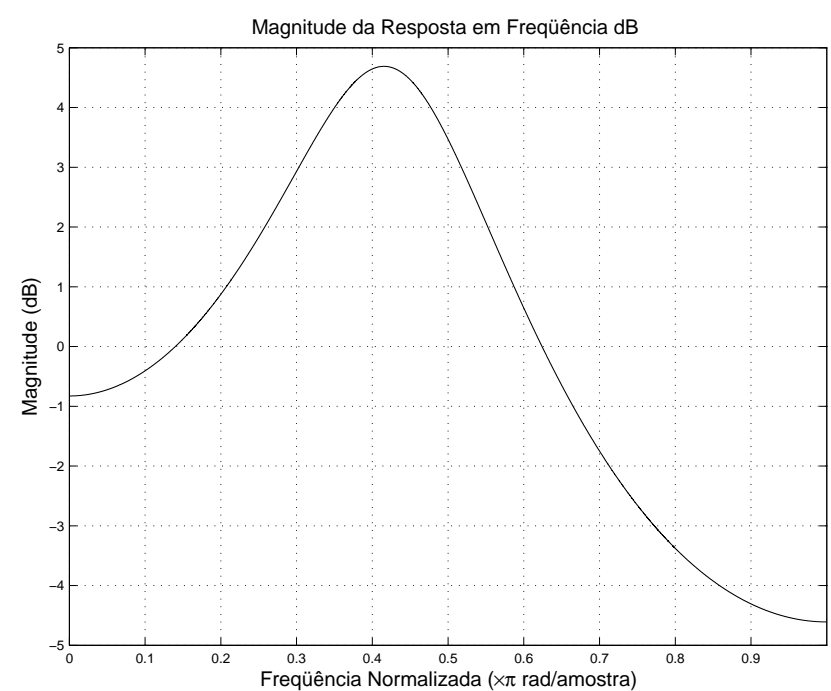

Figura 3.6: Filtro IIR utilizado para enfatizar médias freqüencias. 
Ressalta-se que o filtro IIR adotado (3.11) é, de certa maneira, arbitrário. É válido indagar sobre o grau de SRD que deve estar presente nas simulações de tráfego. Entretanto, a resposta a essa pergunta não faz parte do escopo deste trabalho. Porém, note-se que a resposta em freqüência adotada procura reforçar a DEP do ruído $1 / f$ nas médias freqüências, conforme sugerido, sob um ponto de vista qualitativo, pela DEP do AR(4) (Figura 2.5).

\subsection{Análise Estatística}

\subsubsection{Análise das Séries Gaussianas}

A análise estatística das séries Gaussianas foi feita em duas partes: I) efetuou-se uma análise comparativa entre as séries geradas pelo método da FFT de Paxson (usado como referência) e as do método wavelet; II) compararam-se as séries geradas pelo método wavelet antes e depois da filtragem. As realizações foram geradas variando-se o parâmetro $H$ na faixa de 0,5 a 1,0 em passos de 0,05, sendo que para cada valor do parâmetro $H$ foram sintetizadas três realizações (ou seja, 33 realizações por método ou 96 no total).

As seguintes estatísticas foram utilizadas:

1. função de autocorrelação $\rho_{X}(\tau)$;

2. DEP $P_{X}(f)$;

3. assimetria $A\left(X_{n}\right)$, que representa a concentração dos valores em um dos extremos da distribuição;

4. curtose $K\left(X_{n}\right)$, que indica o grau de achatamento de uma densidade de probabilidade em relação à normal;

5. H, pelos métodos de Whittle e do periodograma;

6. JB, de Jarque e Bera (JARQUE; BERA, 1987), que testa a normalidade dos dados.

O estimador da função de autocorrelação é dado por:

$$
\hat{\rho}_{X}(\tau)=\frac{1}{M s_{X}^{2}} \sum_{k=m+1}^{M}\left(X_{k}-\hat{\mu}\right)\left(X_{k-m}-\hat{\mu}\right),
$$

em que $M$ é o número de amostras, $s_{X}^{2}$ é a variância amostral e $\hat{\mu}$ é o estimador da média $\mu$ de $X$. Note-se que $-1 \leq \rho \leq 1$. 
O estimador $\hat{P}_{X}(f)$ da DEP é obtido pelo método não-paramétrico ${ }^{3}$ do periodograma (PERCIVAL; WALDEN, 1993), com janelamento de dados (data tapering, para redução de vazamento de potência) e suavização (smoothing, para redução da variabilidade de $\left.\hat{P}_{X}(f)\right)$. O periodograma é calculado via ${ }^{4}$ :

$$
\hat{P}_{X}(f)=\frac{1}{M}|X(f)|^{2}
$$

A assimetria é um momento de $3^{3}$ ordem e é dada por

$$
A\left(X_{n}\right)=E\left[\frac{\left(X_{n}-\mu\right)^{3}}{\sigma^{3}}\right]
$$

em que $\mu$ é a média e $\sigma$ é o desvio-padrão da série $X_{n}$.

O estimador de assimetria é definido como

$$
\hat{A}\left(X_{n}\right)=\frac{1}{M \hat{\sigma}^{3}} \sum_{n=1}^{M}\left(X_{n}-\mu\right)^{3},
$$

em que $\hat{\sigma}$ denota o desvio-padrão amostral.

A curtose é um momento de $4^{\underline{a}}$ ordem e é definida como

$$
K(X)=E\left[\frac{(X-\mu)^{4}}{\sigma^{4}}\right] .
$$

O estimador da curtose é dado pela fórmula

$$
\hat{K}\left(X_{n}\right)=\frac{1}{M \hat{\sigma}^{4}} \sum_{n=1}^{M}\left(X_{n}-\mu\right)^{4} .
$$

Observe-se que a normal possui $A=0$ e $K=3$.

O teste de Jarque-Bera é baseado nas medidas de assimetria e curtose. A estatística desse teste é definida como

$$
J B=\frac{M}{6}\left(\hat{A}^{2}+\frac{(\hat{K}-3)^{2}}{4}\right) .
$$

Sob a hipótese nula $\left(H_{0}\right)$ de que os dados sejam normalmente distribuídos esperase que $J B \sim \chi^{2}(2)$ (chi-quadrada com dois graus de liberdade).

\footnotetext{
${ }^{3}$ Os métodos paramétricos de análise espectral são baseados em modelos AR, MA e ARMA. Portanto não devem ser aplicados para estimação da DEP de um ruído $1 / f$.

${ }^{4} \mathrm{~A}$ definição foi dada sem incluir o janelamento e a suavização, para melhor compreensão da natureza essencial do estimador.
} 
Os testes de hipótese foram avaliados com base na estatística p-value (CASELLA; BERGER, 2002). Para um dado nível de significância $\alpha$, rejeita-se $H_{0}$ se $p \leq \alpha$, ao passo que aceita-se $H_{0}$ se $p \geq \alpha$. Desse modo, quanto menor for o valor do $p$-value maior será a evidência empírica de que $H_{0}$ deve ser rejeitada em favor da hipótese alternativa $H_{1}$.

O método de estimação do parâmetro H de Whittle (ZIVOT; WANG, 2003) é baseado numa estimação de máxima verossimilhança no domínio da freqüência do modelo $\mathrm{FD}(\mathrm{d})$. Esse método usa o periodograma. O método de estimação de $\mathrm{H}$ pelo periodograma baseia-se no fato de que $P_{X}(f) \propto f^{2 H-1}$ para freqüências próximas de zero.

\subsubsection{Comparação entre as Séries Geradas via Wavelets e FFT}

O teste de Jarque-Bera rejeitou a normalidade de apenas 2 de 33 realizações geradas pelo método da FFT a um nível de significância $\alpha=1 \%$. Para as séries geradas pelo método wavelet, o teste rejeitou apenas uma das realizações com o mesmo $\alpha$. A Tabela 3.1 mostra as estimativas de assimetria e de curtose para as séries geradas via FFT e wavelets.

Portanto, os testes realizados indicam que as séries geradas pelos dois métodos têm distribuição aproximadamente Gaussiana.

Tabela 3.1: Estimativas de assimetria e curtose das séries geradas via FFT e wavelets.

\begin{tabular}{l|c|c|c}
\hline & $\mathbf{H}$ & $\hat{\mathbf{A}}$ & $\hat{\mathbf{K}}$ \\
\hline \hline \multirow{2}{*}{ FFT } & $H \rightarrow 0,5$ & $|\hat{A}| \leq 0,05$ & $|\hat{K}-3| \leq 0,1$ \\
\cline { 2 - 4 } & $H \rightarrow 1,0$ & $|\hat{A}| \leq 0,2$ & $|\hat{K}-3| \leq 0,1$ \\
\hline \hline \multirow{2}{*}{ Wavelets } & $H \rightarrow 0,5$ & $|\hat{A}| \leq 0,05$ & $|\hat{K}-3| \leq 0,15$ \\
\cline { 2 - 4 } & $H \rightarrow 1,0$ & $|\hat{A}| \leq 0,1$ & $|\hat{K}-3| \leq 0,15$ \\
\hline \hline
\end{tabular}

As Figuras 3.7, 3.8, 3.9 e 3.10 mostram os gráficos da função de autocorrelação e do periodograma suavizado para séries simuladas via FFT e wavelets com $H=$ $0,6,0,75$ e 0,9 . 
Series : fGn.FFT.H.60

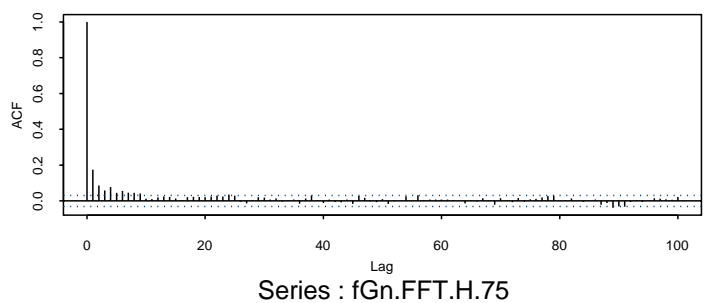

Series : fGn.FFT.H.75
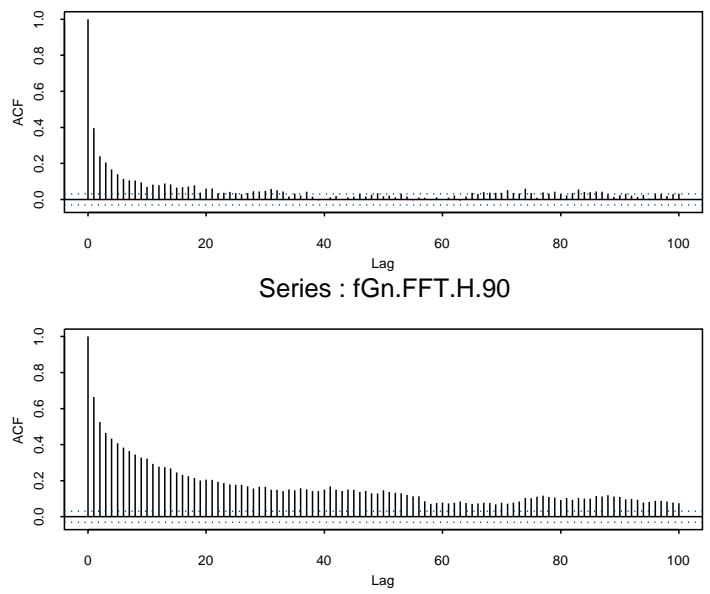

Figura 3.7: Autocorrelação de algumas séries geradas pelo método da FFT
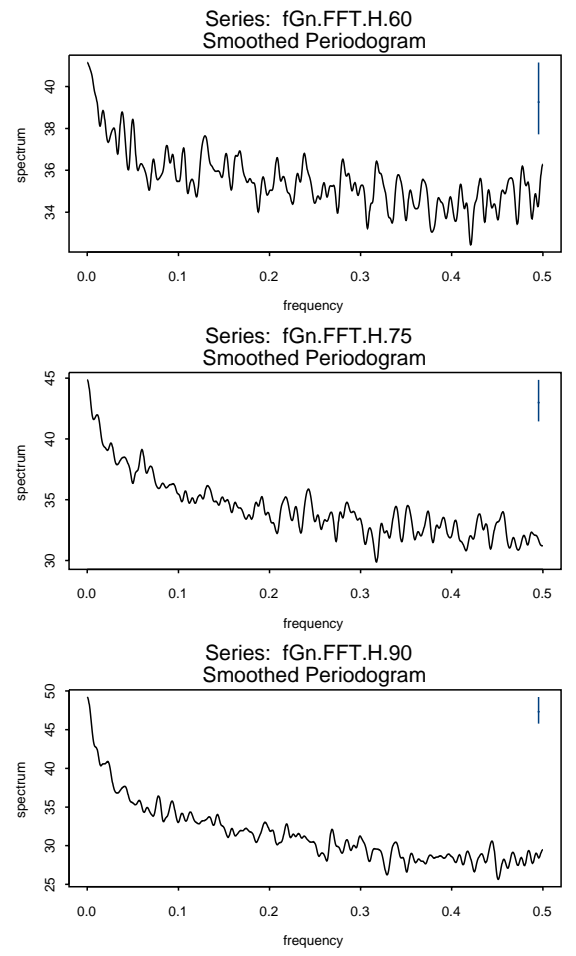

Figura 3.8: Periodograma suavizado de algumas séries geradas pelo método da FFT 

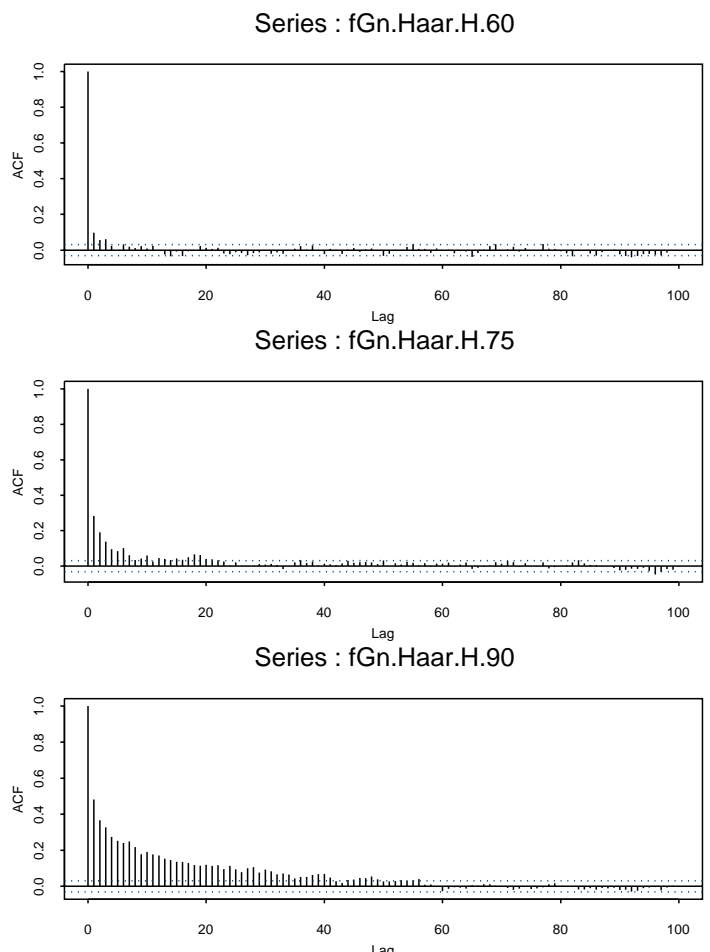

Figura 3.9: Autocorrelação de algumas séries geradas via wavelets
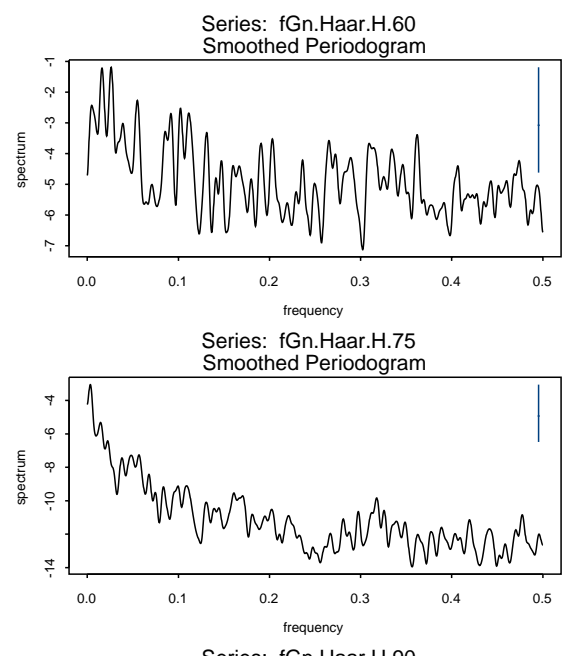

Smothed Periodogram

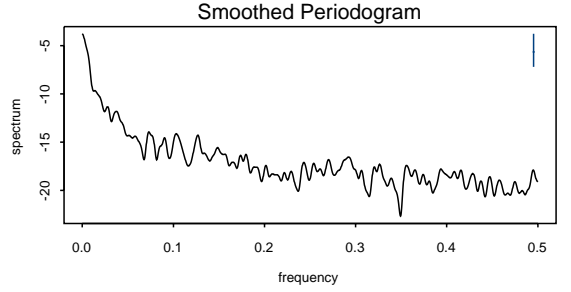

Figura 3.10: Periodograma suavizado de algumas séries geradas via wavelets 
Os periodogramas mostram que as DEPs das séries com $H=0,75$ e 0,9 de ambos os métodos têm pólos na origem, ou seja, que as séries são $1 / f$. Já para o caso das simulações com $H=0,6$, observa-se que: a) a variabilidade do periodograma da série gerada via wavelets é maior do que a variabilidade do periodograma da série FFT; b) o periodograma da série wavelet não indica, de modo claro, se há ou não um pólo na origem. A comparação entre os gráficos de autocorrelação para $H=0,75$ e 0,9 mostra que a taxa de decaimento da autocorrelação é mais lenta com o aumento do parâmetro H.

As Figuras 3.11 e 3.12 mostram as curvas de $H$ (usado como parâmetro de modelagem) versus $\hat{H}$ estimado através do método de Whittle (BERAN, 1994) para os dois tipos de geração. De acordo com Paxson (PAXSON, 1997), esse é um bom método de estimação de $H$ para séries que apresentam LRD.

A Figura 3.11 sugere que o método de geração via FFT tende a gerar séries com $H$ superior ao que é usado como entrada do modelo (viés positivo), enquanto que a Figura 3.12 sugere que o método wavelet tende a produzir séries com $H$ inferior ao da entrada do modelo (viés negativo). A Figura 3.11 sugere que pode haver saturação para valores de $H>=0,95$ quando se usa o método da FFT.

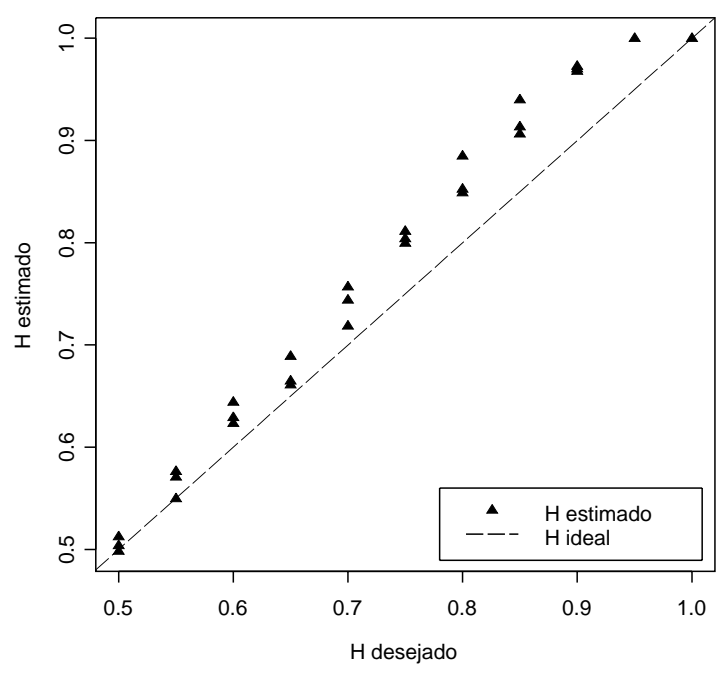

Figura 3.11: Curva $H$ versus $\hat{H}$ para séries geradas via FFT

\subsubsection{Comparação entre as Séries Geradas pelo Método Wavelet com e sem Filtro IIR}

O teste de Jarque-Bera rejeitou a normalidade de apenas 3 séries com SRD a um nível de significância $\alpha=1 \%$. A Tabela 3.2 mostra as medidas de assimetria e 


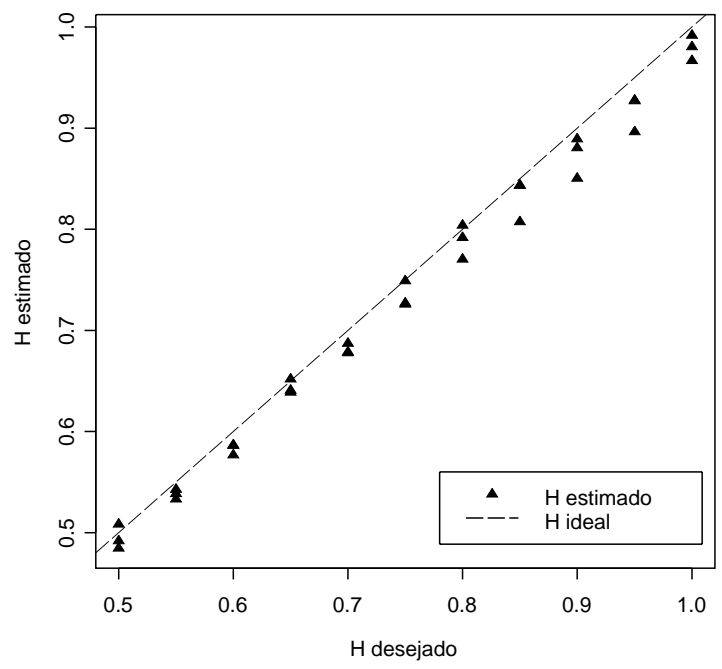

Figura 3.12: Curva $H$ versus $\hat{H}$ para séries geradas via wavelets

curtose.

Portanto, os testes realizados indicam que as séries geradas continuam a apresentar distribuição aproximadamente Gaussiana (como esperado).

Tabela 3.2: Estimativas de assimetria e curtose das séries geradas via wavelets após filtragem.

\begin{tabular}{l|c|c|c}
\hline & $\mathbf{H}$ & $\hat{\mathbf{A}}$ & $\hat{\mathbf{K}}$ \\
\hline \hline \multirow{2}{*}{$\begin{array}{l}\text { Wavelets } \\
\text { com filtro IIR }\end{array}$} & $H \rightarrow 0,5$ & $|\hat{A}| \leq 0,06$ & $|\hat{K}-3| \leq 0,3$ \\
\cline { 2 - 4 } & $H \rightarrow 1,0$ & $|\hat{A}| \leq 0,06$ & $|\hat{K}-3| \leq 0,3$ \\
\hline \hline
\end{tabular}

As Figuras 3.13 e 3.14 mostram os gráficos da autocorrelação e periodograma suavizado para séries simuladas com $H=0,6,0,75$ e 0,9, após filtragem. 

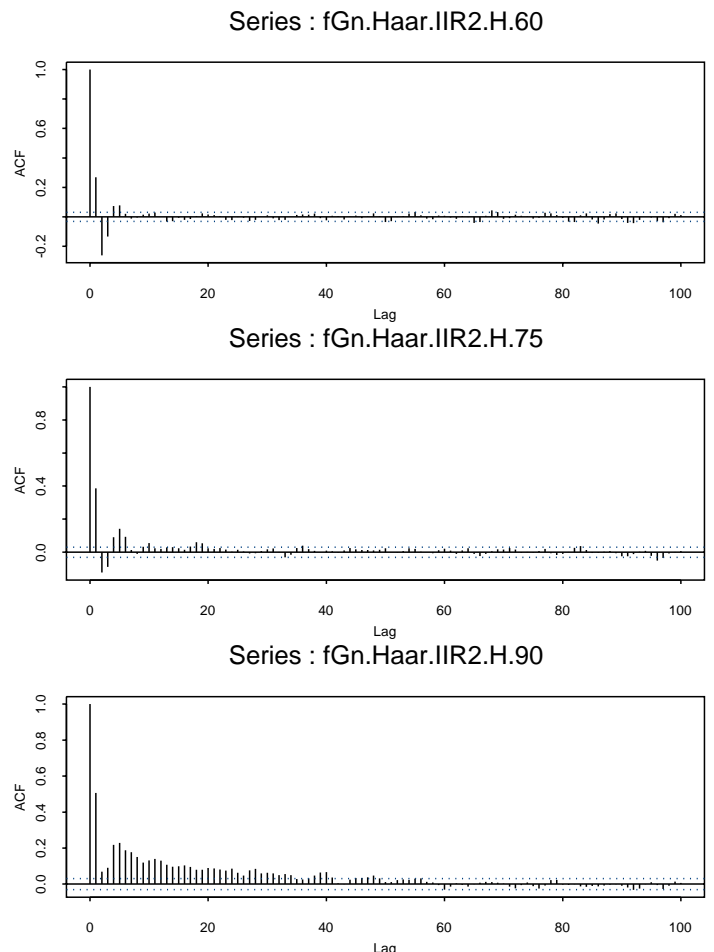

Figura 3.13: Autocorrelação de séries filtradas
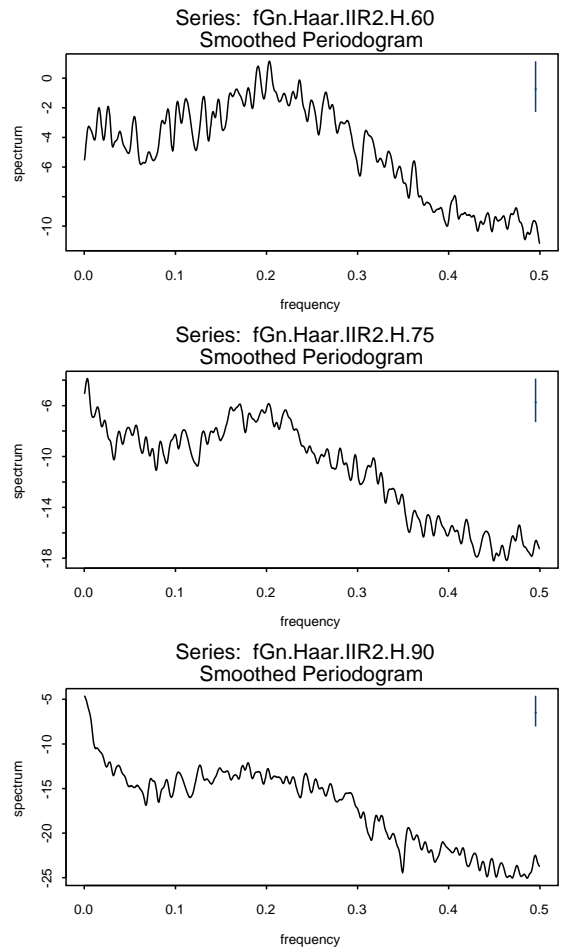

Figura 3.14: Periodograma suavizado de séries filtradas 
O periodograma da série gerada com $H=0,6$ não apresenta pólo na origem. Por outro lado, o periodograma da série sintetizada com $H=0,9$ mostra de forma clara que a série é mista, isto é, há presença simultânea de LRD e SRD (para tal, deve-se comparar esse gráfico com o periodograma para $H=0,9$ da Figura 3.10). O periodograma da série modelada com $H=0,75$ sugere uma situação de transição do comportamento SRD observado no gráfico com $H=0,6$ para a característica mista da série com $H=0,9$.

Diferentemente do procedimento usado nos dois conjuntos anteriores de realizações, em que as curvas $H$ versus $\hat{H}$ foram levantadas com base somente no método de Whittle, as curvas $H$ versus $\hat{H}$ relativas às séries filtradas foram obtidas por dois métodos distintos, o de Whittle (Figura 3.15) e o do periodograma (Figura 3.16) com a finalidade de se avaliar o desempenho desses dois estimadores nessa nova situação, qual seja, presença simultânea de LRD e SRD.

A curva obtida pelo método de Whittle é similar a do caso em que as séries foram geradas via wavelets, porém sem filtragem. Por outro lado, a Figura 3.16 mostra que o método do periodograma tende a subestimar o valor de $H$, apresentando maior variabilidade do que o estimador de Whittle. Sato (SATO, 2004) também observou a maior variância do estimador via periodograma em sua pesquisa. De acordo com (PERCIVAL; WALDEN, 1993), o periodograma é um estimador que tem os seguintes problemas: inconsistência, grande variância e viés para $M$ finito. Portanto, justifica-se o comportamento observado na Figura 3.16.

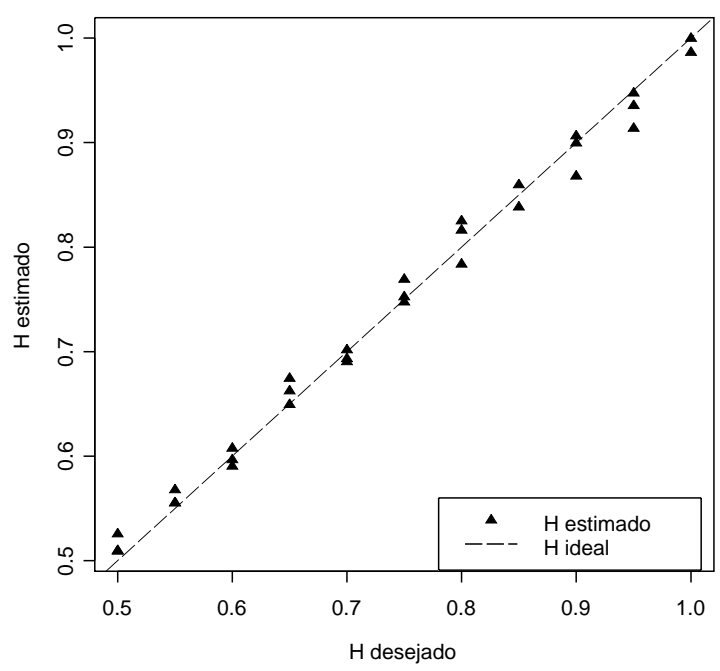

Figura 3.15: Curva $H$ versus $\hat{H}$ (método de Whittle) para séries filtradas 


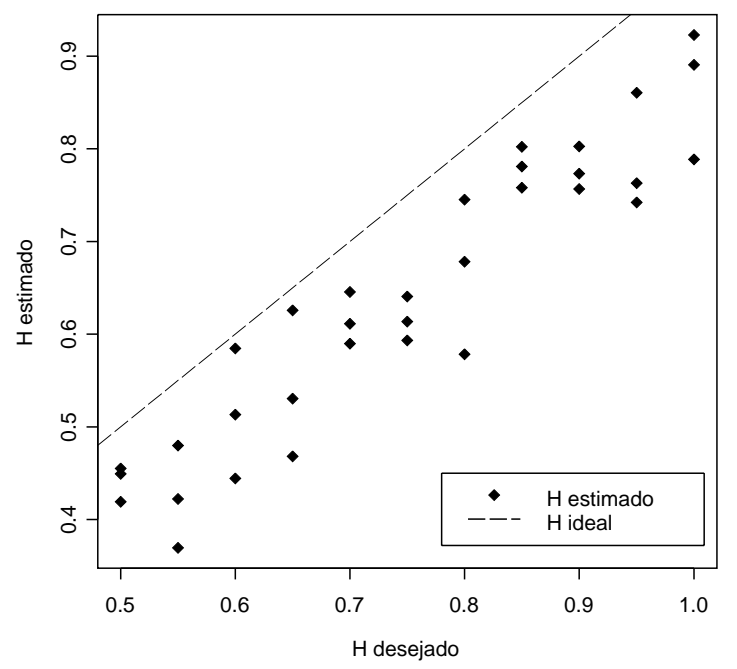

Figura 3.16: Curva $H$ versus $\hat{H}$ (método do periodograma) para séries filtradas

\subsubsection{Análise das Séries não-Gaussianas do Modelo MWM}

Neste estudo são analisadas 27 realizações do modelo MWM (geradas com $J=12$ )

e as mesmas séries após filtragem pelo filtro IIR da (3.11). Foram executadas simulações com diferentes valores para o parâmetro $H, 0,55 \leq H \leq 0,95, \Delta H=$ 0,05 , com valor inicial do parâmetro $p, p_{(12)}=10$. Sintetizaram-se três realizações para cada valor de $H$.

Algumas das estatísticas utilizadas na análise das séries Gaussianas LRD e SRD foram utilizadas na análise das séries não-Gaussianas geradas através do modelo MWM:

1. DEP $P_{X}(f)$;

2. assimetria $A\left(X_{n}\right)$;

3. curtose $K\left(X_{n}\right)$;

4. H, pelos métodos de Whittle e do periodograma;

5. JB, de Jarque e Bera.

\subsubsection{Análise das séries MWM sem filtragem}

O teste de Jarque-Bera rejeitou a hipótese nula de séries Gaussianas para todas as realizações, a um nível de significância de 1\%. A Tabela 3.3 mostra as estima- 
tivas de assimetria e curtose. Esses resultados demonstram que as realizações do modelo MWM são não-Gaussianas.

Tabela 3.3: Estimativas de assimetria e curtose para as séries do modelo MWM.

\begin{tabular}{c|c|c}
\hline $\mathbf{H}$ & $\hat{\mathbf{A}}$ & $\hat{\mathbf{K}}$ \\
\hline \hline$H \rightarrow 0,55$ & $\hat{A}=19$ & $\hat{K}-3=500$ \\
\hline$H \rightarrow 0,95$ & $\hat{A}=2,8$ & $\hat{K}-3=12$ \\
\hline \hline
\end{tabular}

A Figura 3.17 mostra as estimativas das DEPs para as três séries da Figura 3.5. Os periodogramas ao centro e na parte inferior da Figura 3.17 sugerem que as realizações com $H=0,75$ e $H=0,9$ possuem LRD, porque eles apresentam DEP elevada para freqüências próximas de zero. Nota-se que a magnitude da singularidade na freqüência zero aumenta com incrementos em $H$, conforme ilustrado pelos periodogramas citados. Por outro lado, não há evidências de comportamento SRD nessas séries. A DEP da realização para $H=0,6$ (periodograma na parte superior) não se assemelha à DEP de processos do tipo $1 / f$.
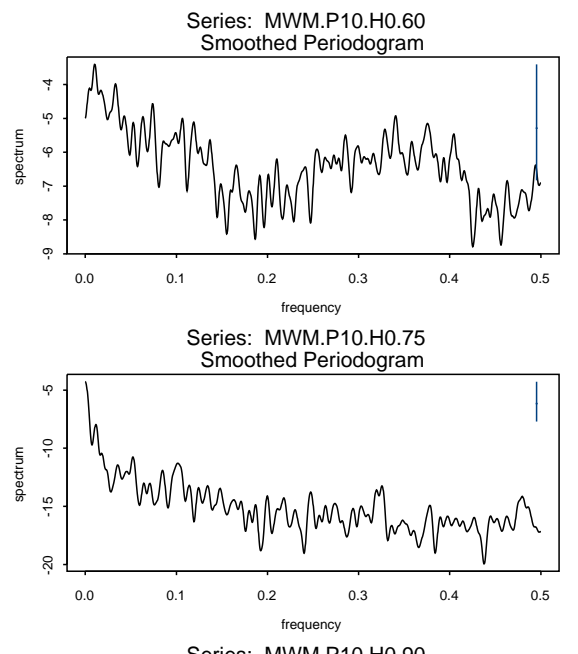

Series: MWM.P10.H0.90

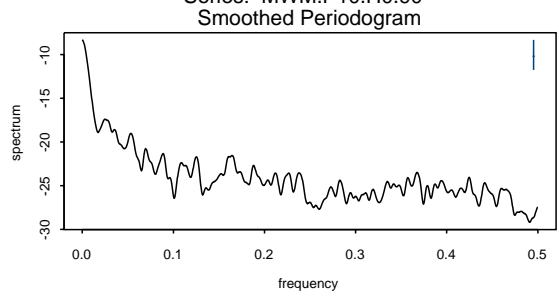

Figura 3.17: Periodogramas das realizações MWM da Figura 3.5. 
É importante testar se o valor do estimador para o parâmetro $H, \hat{H}$, é consistente com o valor de $H$ usado na geração das séries temporais. A Figura 3.18 exibe dois gráficos de $H$ versus sua estimativa $\hat{H}$ na região de interesse $1 / 2<H<1$. Portanto, as realizações são consistentes com o valor de $H$ utilizado no modelo MWM. No entanto, o gráfico à direita demonstra que o estimador do método do periodograma possui uma variância maior que o de Whittle, como já havia sido constatado no caso das séries Gaussianas.

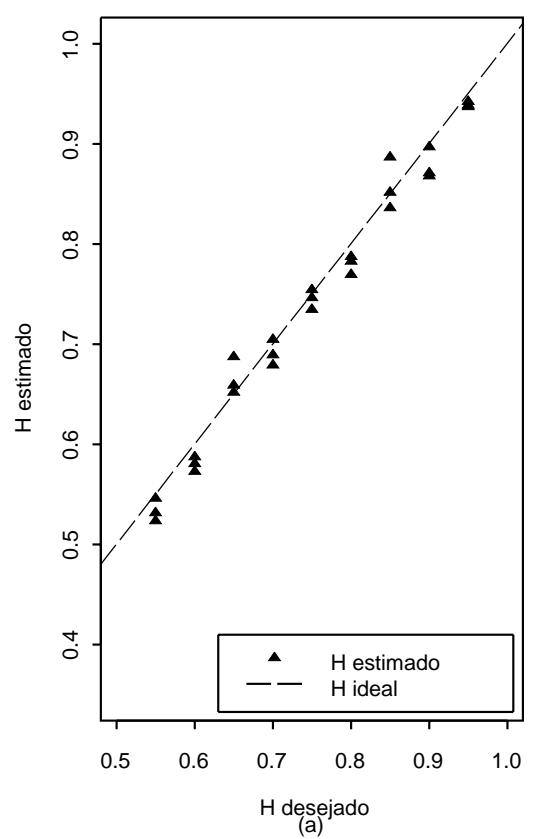

(a)

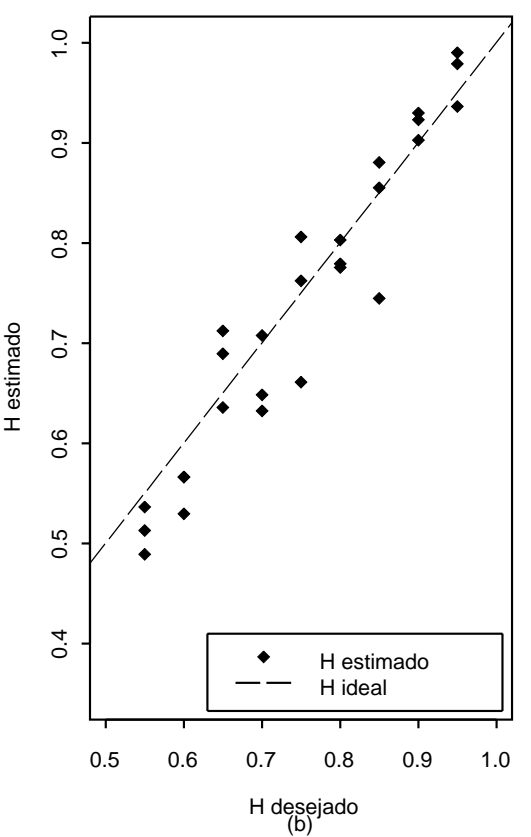

(b)

Figura 3.18: Gráficos de $H$ versus $\hat{H}$ utilizando: a) método de Whittle, b) método do Periodograma.

\subsubsection{Análise das séries MWM após filtragem}

Ao ativar-se o segundo estágio da geração de séries temporais (inserção de SRD), o filtro passa-bandas da (3.11) é utilizado. Novamente, o teste de Jarque-Bera rejeitou a hipótese de normalidade para todas as séries, ao nível de significância de 1\%. A Tabela 3.4 mostra as estimativas da assimetria e curtose. Portanto, as séries geradas são não-Gaussianas, conforme o esperado.

A Figura 3.19 mostra as estimativas das DEPs para as três séries da Figura 3.5 após filtragem passa-bandas ( $H=0,6,0,75$ e 0,9 , respectivamente). Os periodogramas ao centro e na parte inferior da Figura 3.19 evidenciam que as realizações com $H=0,75$ e $H=0,9$, após filtragem, apresentam simultaneamente as características de séries LRD e SRD, o que pode ser notado ao compará-los 
Tabela 3.4: Estimativas da assimetria e curtose para as séries do modelo MWM após filtragem passa-bandas.

\begin{tabular}{c|c|c}
\hline $\mathbf{H}$ & $\hat{\mathbf{A}}$ & $\hat{\mathbf{K}}$ \\
\hline \hline$H \rightarrow 0,55$ & $\hat{A}=15$ & $\hat{K}-3=3$ \\
\hline$H \rightarrow 0,95$ & $\hat{A}=325$ & $\hat{K}-3=12$ \\
\hline \hline
\end{tabular}

aos respectivos periodogramas da Figura 3.17. Ambas as DEPs tiveram suas magnitudes enfatizadas pelo filtro passa-bandas no intervalo $0,1<f<0,3$ (aproximadamente).

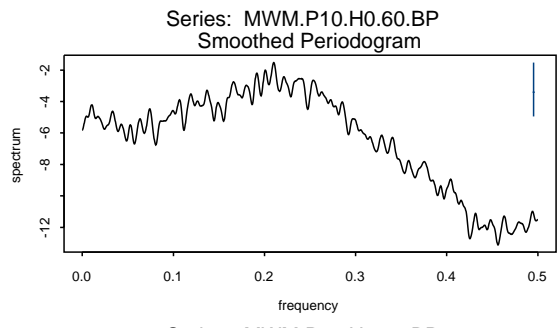

Series: MWM.P10.H0.75.BP

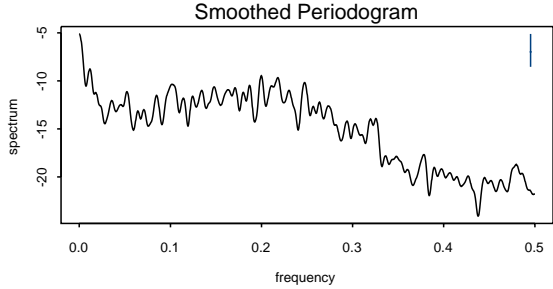

Series: MWM.P10.H0.90.BP

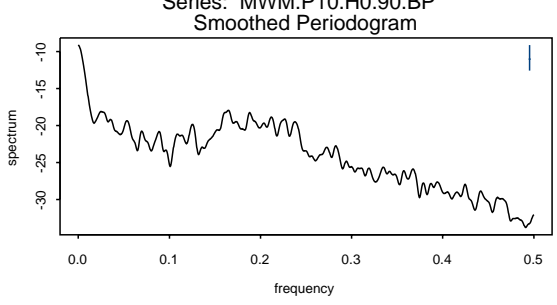

Figura 3.19: Periodogramas das realizações MWM da Figura 3.5, após filtragem passa-bandas.

A Figura 3.20 mostra os gráficos de $H$ versus $\hat{H}$ considerando as séries filtradas pelo filtro passa-bandas. Pode-se notar que estes gráficos são bastante semelhantes aos da Figura 3.18. Portanto, a filtragem passa-bandas não alterou de maneira significativa o comportamento LRD das séries MWM. 

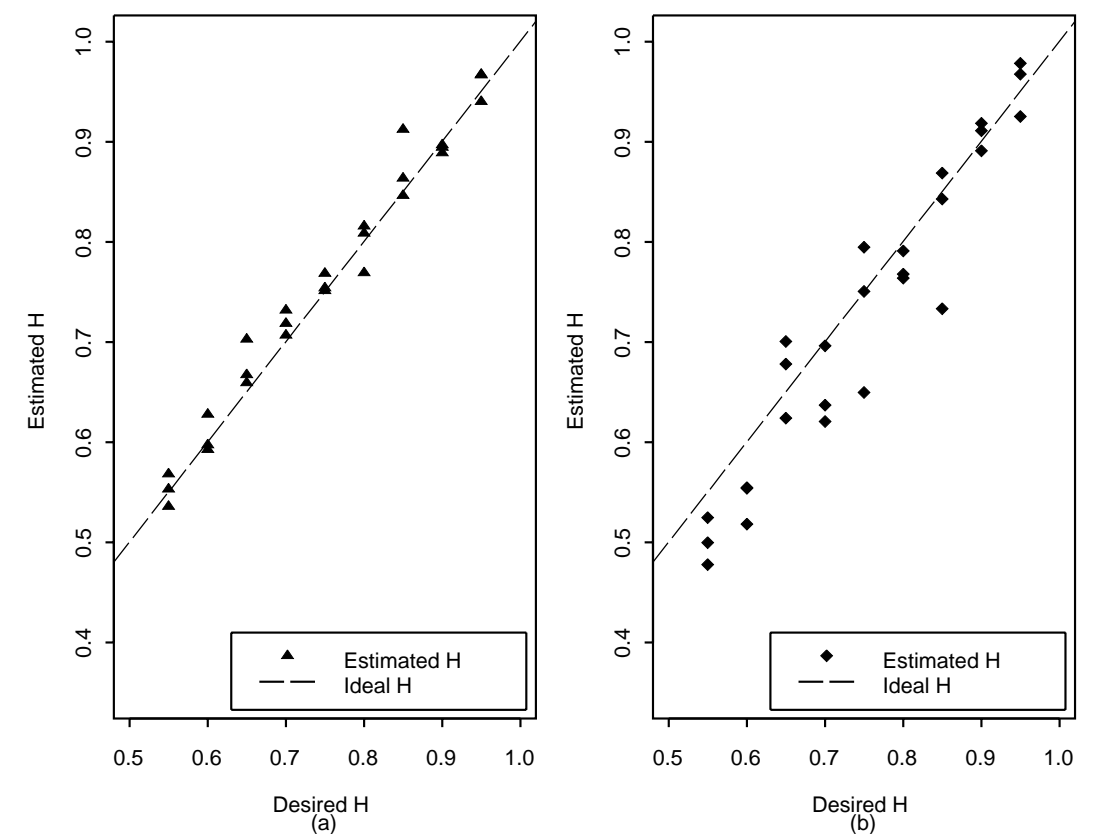

Figura 3.20: Gráfico de $H$ versus $\hat{H}$ após filtragem passa-bandas, utilizando: a) método de Whittle, b) método do Periodograma. 


\section{Séries de Tráfego e Simulação}

\subsection{Introdução}

Uma vez que as séries temporais LRD estejam geradas, é necessário elaborar um algoritmo para converter as séries temporais em séries de pacotes (séries de tráfego). As séries de pacotes podem ser enviadas a um módulo gerador de pacotes que irá montar e inserir os pacotes na rede de dados, nos instantes de tempo indicados pela série de entrada. Essa possibilidade de aplicação das séries de pacotes não será explorada neste trabalho. Uma outra aplicação relevante é a utilização das séries de pacotes como fonte de tráfego agregado em cenários de simulação, que é o uso demonstrado neste trabalho.

As séries temporais sintetizadas possuem tantos pontos quantos solicitados na escolha dos parâmetros de entrada do programa de geração das séries (as eventuais limitações serão por capacidade computacional e de memória para armazenamento). Não há restrição sobre o valor assumido para o intervalo de tempo compreendido entre pontos consecutivos (equivalente ao período de amostragem), denominado bin da série temporal. Portanto, o bin é um parâmetro de livre interpretação dos usuários da série. No entanto, a fim de manter as características estatísticas da série temporal após a conversão para série de pacotes, é importante que a resolução da série temporal seja tão próxima quanto possível do mínimo intervalo de tempo entre pacotes consecutivos. Conforme discutido na Seção 2.3, o modelo MWM é mais apropriado para escalas refinadas de tempo, enquanto que o fGN é um bom modelo para escalas agregadas, em que o tráfego torna-se Gaussiano. Seguindo essa constatação, nas simulações apresentadas neste trabalho arbitrou-se bin $=1 \mathrm{~ms}$ para traces baseados no modelo MWM e bin $=10 \mathrm{~ms}$ para traces baseados no modelo fGN.

É importante notar que as séries temporais não representam diretamente uma grandeza física do tipo contagem de bytes. No caso do modelo fGN não há sequer uma compatibilidade simples entre o modelo matemático e o fenômeno físico, por exemplo com a ocorrência de valores negativos na série temporal. Torna-se 
essencial criar essa compatilibidade através de operações de transformação e normalização, porém sem que haja perda das propriedades estatísticas de interesse. Um requisito imposto para as operações de normalização é que deve haver um mecanismo para controlar a grandeza carga média do tráfego gerado, de acordo com um parâmetro de entrada informado pelo usuário do trace de tráfego sintético. Para confirmar que as séries de pacotes continuam apresentando as propriedades LRD e SRD que foram modeladas na etapa anterior, será efetuada a análise estatística das séries convertidas, comparando-se os resultados com os obtidos durante a síntese da série temporal.

Dentro do período de cada bin haverá uma quantidade de bytes que deverão ser transmitidos, porém não existe a priori uma indicação de como esses bytes devem ser particionados em pacotes. Sendo assim, propõem-se duas alternativas distintas de conversão, utilizadas para determinar qual a quantidade de pacotes e em que instantes de tempo (dentro de um bin) deve-se enviá-los de modo a atender o valor de bytes indicado para o bin:

1. envio de chunks (blocos formados por pacotes consecutivos) em intervalos de tempo equiespaçados (início de cada bin);

2. envio de pacotes de tamanho constante posicionados uniformemente dentro do período do bin.

Em uma última etapa, as séries de pacotes obtidas ao final de cada alternativa de conversão são utilizadas em cenários de simulação elaborados no simulador $N S$ 2 Network Simulator (NS-2). A interface que permite o uso das séries de pacotes criadas pelo gerador de tráfego dentro do software NS-2 é aqui descrita. Um breve estudo (não conclusivo) com comparações de indicadores de QoS como perda de pacotes, atraso de transmissão e tamanho da fila também é apresentado.

\subsection{Conversão de Séries Temporais em Séries de Pacotes}

\subsubsection{Conversão para série de chunks em intervalos equies- paçados}

Essa alternativa de conversão baseia-se em um método em que toda a quantidade de bytes que deve ser transmitida em um bin é enviada em um único bloco formado por pacotes consecutivos, denominado chunk. O início de transmissão 
do chunk corresponde ao instante de tempo de início do bin, portanto caracterizase por instantes de início de transmissão equiespaçados. No restante deste texto, denomina-se essa alternativa de conversão como conversão 1.

No início de cada bin, a conversão 1 permite o envio de um único (ou nenhum) chunk de tamanho variável. O tamanho do chunk está associado ao número de pacotes consecutivos que serão efetivamente enviados naquele bin. Dessa maneira, um chunk será constituído de $M, M \geq 0$, pacotes de tamanho Maximum Transfer Unit (MTU) (a variável $M T U$ dependerá da tecnologia da rede em que o tráfego será injetado) e zero (0) ou um (1) pacote adicional de tamanho $V, V<M T U$, caso necessário.

Um mecanismo de virtual buffer é usado para acomodar excesso de bytes a serem transmitidos dentro de um intervalo de transmissão (dependendo das características da tecnologia de rede escolhida determina-se o número máximo de bytes que podem ser transmitidos no período de um bin). Através desse mecanismo transfere-se eventuais bytes excedentes para um próximo bin.

Os seguintes parâmetros, relacionados à tecnologia de rede adotada, são solicitados pelo programa implementado para dar flexibilidade ao método de conversão da série temporal em série de pacotes:

1. MTU. É o limite máximo para o tamanho de um pacote que pode ser transmitido. Exemplo para IP sobre Ethernet: 1500 bytes.

2. minTU. É o limite mínimo para o tamanho de um pacote que pode ser transmitido. Exemplo para IP sobre Ethernet: 46 bytes.

3. $T X_{\max }$. Indica a taxa máxima de transmissão (em Mbps) do meio escolhido.

Sobre o uso do parâmetro min $T U$, faz-se a seguinte observação: o programa de conversão efetua a transformação da série temporal truncando em 0 os valores da série que estejam abaixo de um valor limiar apropriado. Valores iguais a esse limiar são mapeados para minTU. Quando um chunk é composto por $M>0$ pacotes de tamanho $M T U$ e há um restante de bytes a serem transmitidos que ficam abaixo de $\operatorname{minTU}$, ou seja, $V<\operatorname{minTU}$, então faz-se uso da técnica de stuffing tornando $V=\operatorname{minT} U$.

Adicionalmente aos parâmetros associados à tecnologia de rede, o programa de conversão também solicita os seguintes parâmetros:

1. bin. É o intervalo de tempo constante (em $m s$ ) entre pontos da série temporal. Ressalta-se que o intervalo definido em bin é utilizado para determinar 
o instante de transmissão de chunks, característico desse método de conversão.

2. $T X_{a v g}$. É a taxa média de transmissão que deseja-se obter (em Mbps).

3. fator $_{n e g}$. Representa um fator usado antes da normalização das séries com valores negativos, cujo efeito é a adição de uma componente DC que elimina uma quantidade dos valores negativos proporcional a esse fator ${ }^{1}$. Para fator $_{n e g}=0$, a série temporal não é alterada e para fator $_{n e g}=1$, é adicionada uma componente DC na série temporal que elimina por completo os valores negativos (menor valor da série é mapeado para 0).

Observa-se que valores de bin muito pequenos $(<1 \mathrm{~ms})$ podem implicar em impossibilidade para um módulo gerador de pacotes (ex. packet sender (PáSZTOR, 2001)) gerar pacotes na rede (características de implementação cujo limite será a resolução que o módulo gerador de pacotes irá operar). Não está no escopo deste trabalho determinar a resolução atingida pelo módulo gerador de pacotes, pois toda a parte experimental será conduzida por meio de um simulador de rede.

A implementação do programa de conversão permite, através do parâmetro $T X_{a v g}$, controlar o nível médio da carga injetada pelo trace em um cenário de simulação. Esse parâmetro é usado para efetuar a normalização da série temporal. Trata-se de uma funcionalidade relevante pois possibilita efetuar medidas comparativas de desempenho entre um gerador de tráfego baseado em modelo autosimilar, LRD e SRD, versus um gerador baseado em modelos clássicos (Poisson, Constant Bit Rate (CBR)).

As variáveis listadas abaixo são calculadas em função dos valores informados para o conjunto de parâmetros solicitados pelo programa.

1. $M A X_{-} B Y T E S_{b i n}$. É o número máximo de bytes que podem ser enviados dentro de um bin, conforme (4.1):

$$
M A X_{-} B Y T E S_{b i n}=\operatorname{bin} \cdot \frac{T X_{\max }}{8} \cdot 10^{3} \text { bytes. }
$$

2. AVG_CHUNK $K_{\text {size }}$. Representa o tamanho médio dos chunks transmitidos. Pode ser calculado através da (4.2):

$$
A V G_{-} C H U N K_{\text {size }}=\text { bin } \cdot \frac{T X_{\text {avg }}}{8} \cdot 10^{3} \text { bytes. }
$$

\footnotetext{
${ }^{1}$ fator $_{n e g}$ poderá assumir qualquer valor no intervalo $[0,1]$.
} 
3. limiar. Variável calculada por uma equação arbitrária que resulte em valores suficientemente pequenos em relação ao ponto de máximo da série temporal. Adotou-se a (4.3) para definir o limiar, que é um limite abaixo do qual os valores da série temporal serão truncados em 0 . Valores iguais a limiar são mapeados para minTU.

$$
\text { limiar }=\frac{\max (\text { série temporal })}{M A X_{-} B Y T E S_{b i n}},
$$

em que max(série temporal) é o ponto de máximo da série temporal.

Nota-se que há um limite máximo $M_{\max }$ para o número de pacotes de tamanho $M T U$. Esse limite pode ser calculado por (4.4):

$$
M_{\max }=\left\lfloor\frac{M A X_{-} B Y T E S_{b i n}}{M T U}\right\rfloor,
$$

em que o operador $\lfloor x\rfloor$ representa o arredondamento para o maior inteiro menor que $x$.

Uma última consideração que precisa ser feita é como normalizar a série temporal de maneira adequada. Existem diversas possibilidades de como efetuar as operações de normalização, sendo que neste trabalho elaborou-se o procedimento descrito na Seção 4.2.1.1.

\subsubsection{Procedimento de normalização da série temporal pela conver- são 1}

1. Caso a série possua valores negativos, adicionar uma componente DC controlada pelo fator $_{n e g}$;

2. Calcular o valor limiar que será mapeado para minTU;

3. Truncar a série temporal de modo que valores abaixo de limiar sejam mapeados para 0 ;

4. Calcula-se o valor da diferença $M A X_{-} B Y T E S_{b i n}-M_{\max } \cdot M T U$. Caso essa diferença seja menor que $\operatorname{minTU}$, faz-se $M A X_{-} B Y T E S_{b i n}=M_{\max } \cdot M T U$. Dessa forma, $M A X_{-} B Y T E S_{b i n}$ será igual a um múltiplo de $M T U$ somado a 0 ou 1 pacote de tamanho $V \geq \operatorname{minTU}$;

5. Utilizando-se o parâmetro de entrada $T X_{\text {avg }}$, calcula-se através da (4.2) o valor de $A V G_{-} C H U N K_{\text {size }}$ desejado;

6. Calcular a fração de pontos $P$ que foram mapeados para 0 ; 
7. $Q=1-P$ será a fração de pontos iguais ou acima de limiar e que serão transformados em $0 \leq M \leq M_{\max }$ pacotes de tamanho $M T U$ e 0 ou 1 pacotes de tamanho $V \geq \operatorname{minTU}$;

8. Calcular a média da série temporal modificada, desconsiderando os pontos

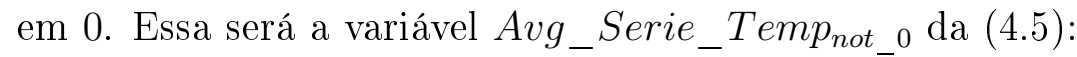

$$
\text { Avg_Serie_Temp } p_{\text {not } 0}=\frac{\sum_{i=0}^{N-1} \operatorname{serie} \_\operatorname{temp}(i)}{N \cdot Q}
$$

em que serie_temp $(i)$ é o valor do ponto de índice $i$ da série temporal e $N$ é o número total de pontos da série temporal;

9. A variável $A V G \_C H U N K_{\text {size }}$, calculada através da (4.2), está relacionada com uma variável auxiliar $Q_{-} A V G_{-} C H U N K_{\text {size }}$ pela (4.6):

$$
\begin{array}{r}
A V G_{-} C H U N K_{\text {size }}=0 \cdot P+Q_{-} A V G_{-} C H U N K_{\text {size }} \cdot Q \\
Q_{-} A V G_{-} C H U N K_{\text {size }}=\frac{A V G_{-} C H U N K_{\text {size }}}{1-P}
\end{array}
$$

10. A variável $A v g_{-}$Serie_Temp $p_{\text {not_o }}$ será mapeada para a variável auxiliar $Q_{-} A V G \_C H U N K_{\text {size }}$ através do fator de normalização

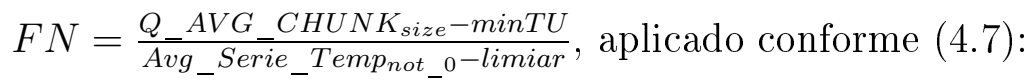

$$
\begin{array}{r}
\text { se serie_temp }(i) \geq \text { limiar então } \\
C H U N K(i)=F N \cdot(\text { serie_temp }(i)-\text { limiar })+m i n T U \\
\text { caso contrário } \\
C H U N K(i)=0
\end{array}
$$

11. Nota-se que o ponto máximo da série normalizada poderá ser menor ou maior que $M A X_{-} B Y T E S_{b i n}$. No caso de valores acima de $M A X_{-} B Y T E S_{b i n}$ adota-se o mecanismo de virtual buffer (acumulador para próximo(s) bin(s));

12. Efetua-se a conversão ponto a ponto da série $C H U N K$ em $M \cdot M T U+V$. Quando $V<\operatorname{minTU}$ utiliza-se do conceito de stuffing e faz-se $V=\operatorname{minTU}$;

13. Montam-se os vetores de tamanho de pacotes (serie_pacotes) e de tempo entre pacotes (tempo_entre_pacotes) que podem ser enviados a um módulo gerador de pacotes ou ao simulador através de interface adequada.

A Figura 4.1 ilustra o envio de chunks de pacotes de acordo com a conversão 1. 


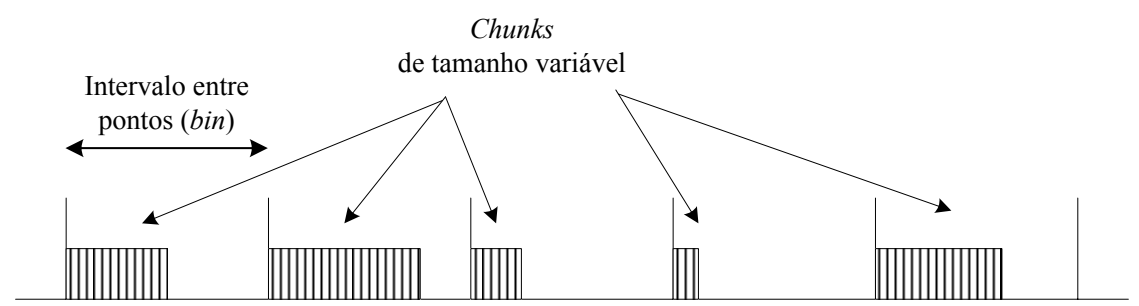

Figura 4.1: Exemplo de trace após conversão para série de chunks em intervalos equisespaçados (conversão 1).

\subsubsection{Dados de exemplo para conversão 1}

Elaborou-se um programa denominado "media_ideal" que, de acordo com a série temporal e com uma parte dos parâmetros de entrada da conversão, possibilita identificar valores apropriados para a média obtida após a normalização da conversão, sem que haja efeito de virtual buffer. Essa condição é desejada pois a utilização do mecanismo de virtual buffer insere distorções na série de tráfego que alteram as características estatísticas modeladas na etapa anterior.

Na geração das séries temporais MWM, valores distintos para a inicialização do parâmetro $p$ foram utilizados: 0,$1 ; 10$ e $p_{J}$, em que $p_{J}$ é obtido recalculando-se $p$ da escala mais refinada para a escala menos refinada, partindo-se da escala mais refinada com um valor $10 \%$ acima de $p_{-\infty}(2.81)$.

Cada realização obtida com os diversos valores para o parâmetro $\alpha$ possui um valor máximo apropriado para a taxa média $T X_{a v g}$, sem que haja efeito de virtual buffer. A Tabela 4.1 relaciona o intervalo obtido entre o menor e o maior valor de médias apropriadas para cada uma das séries temporais e, em função desse intervalo, um valor sugerido para a taxa média resultante da conversão.

Tabela 4.1: Tabela de intervalos ideais para a média $T X_{a v g}$ e de valor sugerido para $T X_{\text {avg }}$ nas conversões das séries MWM, agrupadas pelas diferentes inicializações do parâmetro $\mathrm{p}$

\begin{tabular}{||c||c||c||}
\hline \hline $\mathbf{p}$ & Intervalo de Médias & $\boldsymbol{T} \boldsymbol{X}_{\text {avg }}$ (Mbps) \\
\hline \hline$p_{J}$ & $0,5-17,5$ & 2,0 \\
\hline 0,1 & $0,04-4,4$ & 1,0 \\
\hline 10 & $0,4-18,4$ & 2,0 \\
\hline \hline
\end{tabular}

Do mesmo modo que há uma preocupação em não se enfatizar os efeitos do virtual buffer, também é indesejado truncar uma quantidade excessiva de pontos que fiquem abaixo de limiar. Para o MWM que é um modelo com maior burstness 
que o fGN, ocorre que os valores de média apropriados para evitar o virtual buffer são consideravelmente mais baixos que para o fGN. A escolha de valores excessivamente baixos para a média após conversão poderá acentuar as distorções por truncamento de pontos abaixo de limiar. Neste trabalho, arbitrou-se utilizar nas simulações do MWM a $3^{a}$ realização gerada com $J=12, \alpha=0,6$ ou $H=0,8$ e $p$ de inicialização $p_{J}=4,03$. Para a conversão dessa realização foi adotado o parâmetro taxa média $T X_{a v g}=2,0$ Mbps.

Portanto, partindo-se da série temporal do modelo MWM, efetuou-se a conversão para série de tráfego utilizando o método de conversão 1 e adotando-se os seguintes valores para os dados de entrada:

- $M T U=1518$ bytes;

- $\operatorname{minTU}=64$ bytes;

- $T X_{\max }=150$ Mbps;

- $b i n=1 m s ;$

- $T X_{\text {avg }}=2$ Mbps.

A escolha dos valores acima resulta em $M A X_{-} B Y T E S_{b i n}=18750$ bytes e $A V G_{-} C H U N K_{\text {size }}=250$ bytes. Nota-se que $A V G_{-} C H U N K_{\text {size }}$ corresponde em média a um valor de $M$ igual a 0 e a um pacote de tamanho $V=250$ bytes. Essas informações podem ser usadas para projetar o tamanho da fila do link gargalo do cenário de simulação.

No caso das séries fGN, também utilizou-se o programa "media_ideal" a fim de identificar valores apropriados para a média obtida após conversão (Tabela $4.2)$.

Tabela 4.2: Tabela de intervalo ideal para a média $T X_{a v g}$ e de valor sugerido para $T X_{\text {avg }}$ nas conversões das séries fGN

\begin{tabular}{||c||c||}
\hline \hline Intervalo de Médias & $\boldsymbol{T} \boldsymbol{X}_{\text {avg }}(\mathrm{Mbps})$ \\
\hline \hline $43,5-62,8$ & 50,0 \\
\hline \hline
\end{tabular}

Arbitrou-se utilizar para as simulações com o fGN a $3^{\text {a }}$ realização das séries geradas com 4096 pontos, $J=9$, wavelet de Haar e $\alpha=0,6$ ou $H=0,8$. Partindo da série temporal do modelo fGN, foram utilizados os seguintes valores para os dados de entrada da conversão 1: 
- $M T U=1518$ bytes;

- $\operatorname{minTU}=64$ bytes;

- $T X_{\max }=150$ Mbps;

- bin $=10 \mathrm{~ms}$;

- $T X_{a v g}=50$ Mbps;

- fator $_{n e g}=0,5$.

A escolha dos valores acima resulta em $M A X_{-} B Y T E S_{b i n}=187500$ bytes e $A V G_{-} C H U N K_{\text {size }}=62500$ bytes. Nota-se que $A V G_{-} C H U N K_{\text {size }}$ corresponde em média a um valor de $M$ igual a 41 pacotes de tamanho $M T U$ e a um pacote adicional de tamanho $V=262$ bytes. Essas informações podem ser usadas para projetar o tamanho da fila do link gargalo do cenário de simulação.

Ressalta-se que as séries obtidas através dos modelos MWM e fGN foram normalizadas para valores de taxa média correspondentes a níveis distintos de agregação de tráfego. O modelo de tráfego mais apropriado para redes de acesso (MWM) foi mapeado para uma taxa média de 2 Mbps. Já o modelo mais apropriado para backbones (fGN - Gaussiano e, portanto, coerente com o Teorema do Limite Central) foi mapeado para taxa média de 50 Mbps. Da mesma maneira adotou-se $\operatorname{bin}=1 \mathrm{~ms}$ para a série MWM (mais refinada) e bin $=10 \mathrm{~ms}$ para a série fGN (mais agregada).

\subsubsection{Análise estatística das séries de pacotes após conversão 1}

A Figura 4.2 mostra a realização do modelo MWM, indicada na Seção 4.2.1.2, acima da série de chunks (série de pacotes reagregada), obtida através do método de conversão 1 . 
Serie Temporal MWM; $\mathrm{H}=0,8 ; \mathrm{p}=4,03$
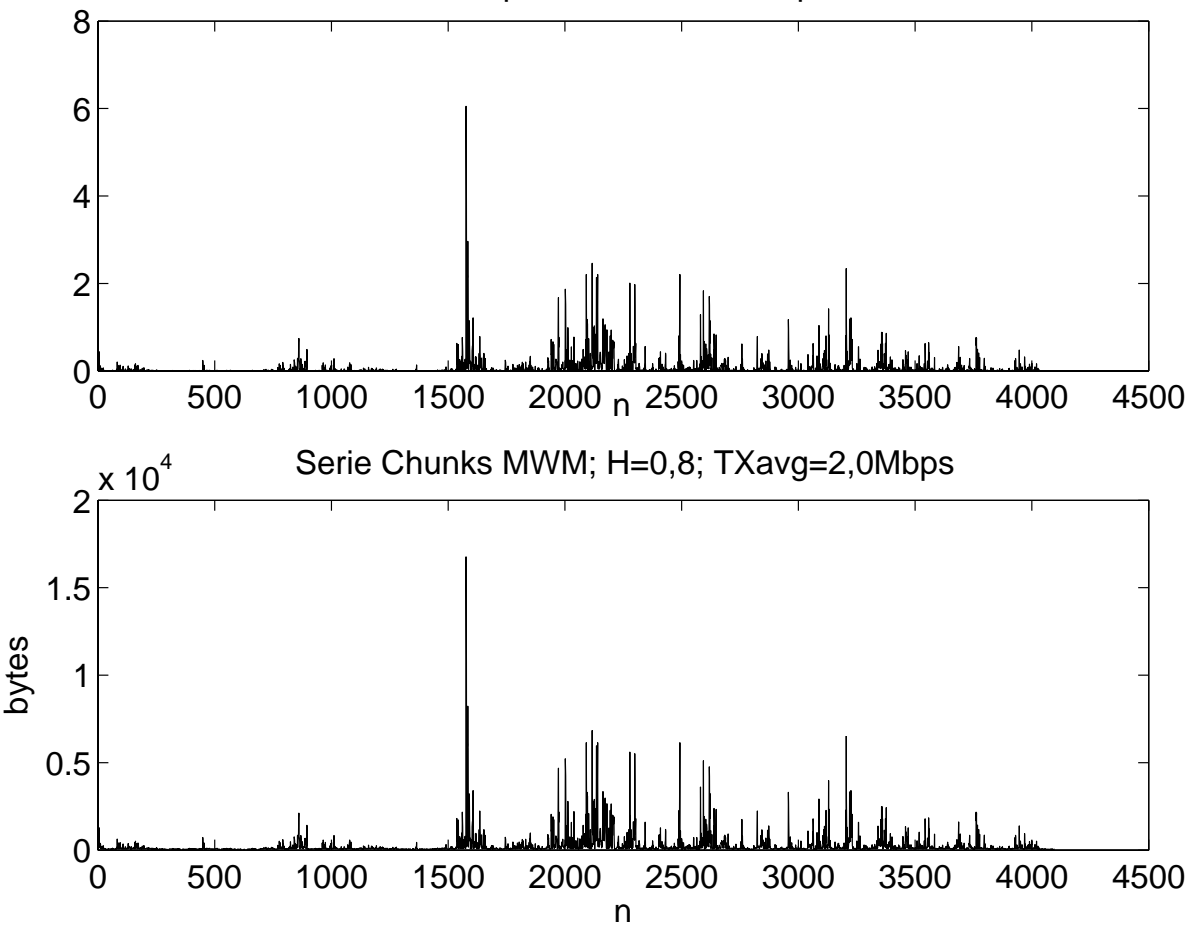

Figura 4.2: Comparação entre série temporal MWM e série de chunks, com $\mathrm{H}=0,8$ (conversão 1$)$. 
Efetuando-se uma comparação visual entre a DEP da série temporal MWM antes da conversão (Figura 4.3) e a DEP da respectiva série de chunks (Figura 4.4), nota-se que as características LRD modeladas na série temporal continuam existindo após a conversão 1 .

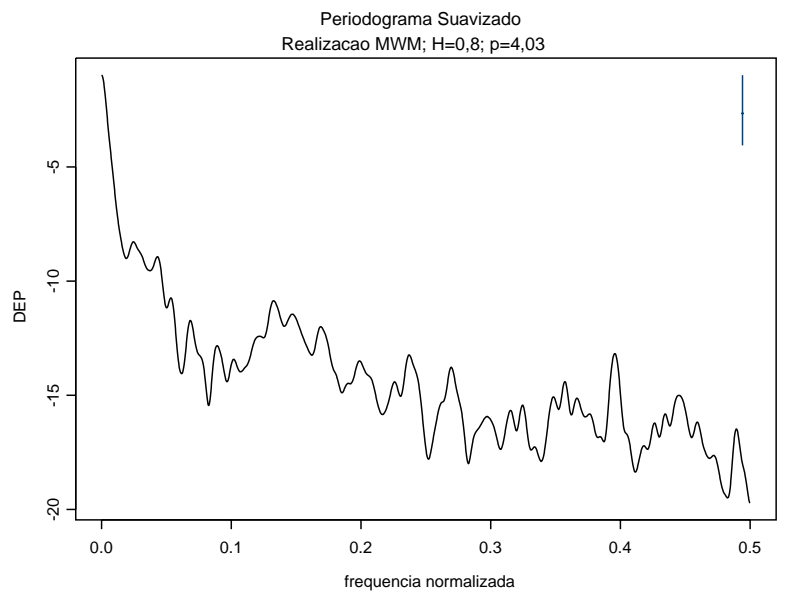

Figura 4.3: Periodograma para série temporal MWM com $\mathrm{H}=0,8$.

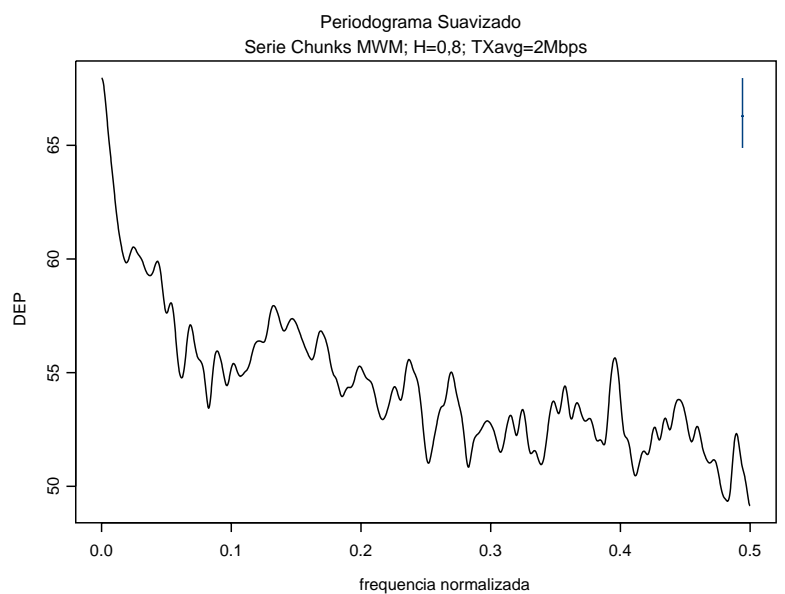

Figura 4.4: Periodograma para série de chunks MWM com $\mathrm{H}=0,8$ (conversão 1). 
A Tabela 4.3 apresenta os resultados de estimativas do parâmetro de Hurst, pelo método de Whittle e do periodograma, para a série temporal MWM gerada com $H=0,8$ e a respectiva série de chunks obtida pela técnica de conversão 1 . Em ambos os métodos não ocorrem variações relevantes entre as estimativas de $H$ para a série temporal original e para a série de chunks.

Tabela 4.3: Estimativas do parâmetro de Hurst para série temporal MWM gerada com $H=0,8$ e a respectiva série de chunks obtida pelo método de conversão 1.

\begin{tabular}{l|l|c}
\hline & H Whittle & H periodograma \\
\hline \hline série temporal & $H=0,84$ & $H=0,81$ \\
\hline série chunks & $H=0,84$ & $H=0,82$ \\
\hline \hline
\end{tabular}

A Figura 4.5 mostra a realização do modelo fGN, indicada na Seção 4.2.1.2, acima da série de chunks, obtida através do método de conversão 1.
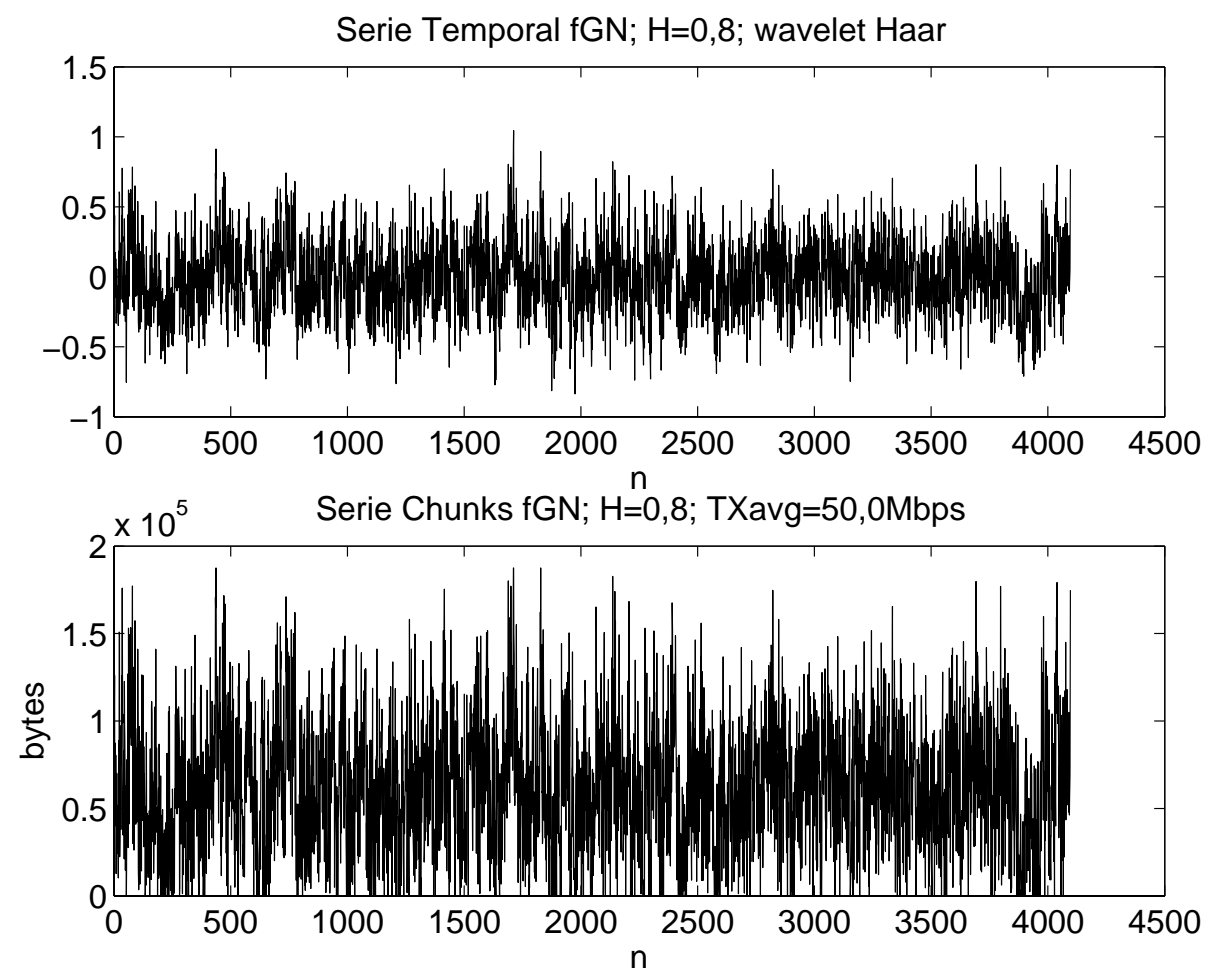

Figura 4.5: Comparação entre série temporal fGN e série de chunks, com $\mathrm{H}=0,8$ (conversão 1$)$. 
Efetuando-se uma comparação visual entre a DEP da série temporal fGN antes da conversão (Figura 4.6) e a DEP da respectiva série de chunks (Figura 4.7), nota-se que as características LRD modeladas na série temporal continuam existindo após a conversão 1 .

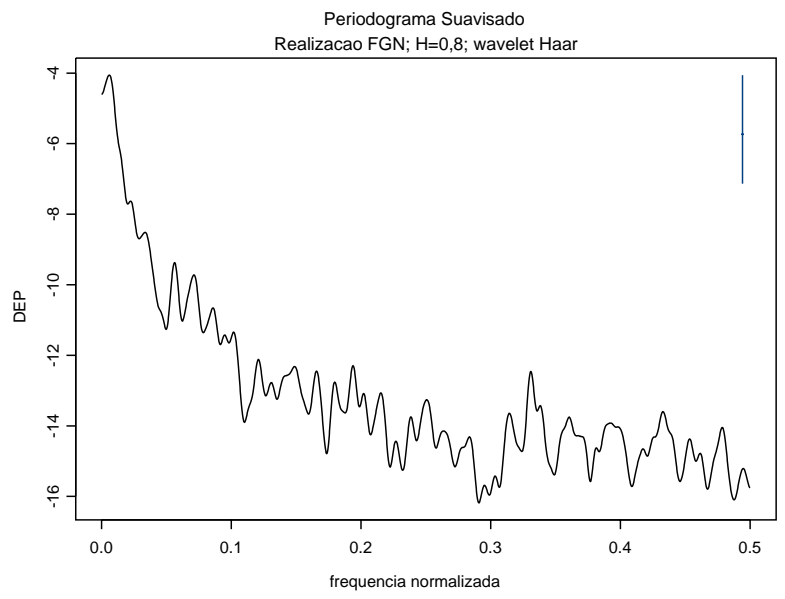

Figura 4.6: Periodograma para série temporal fGN com $\mathrm{H}=0,8$.

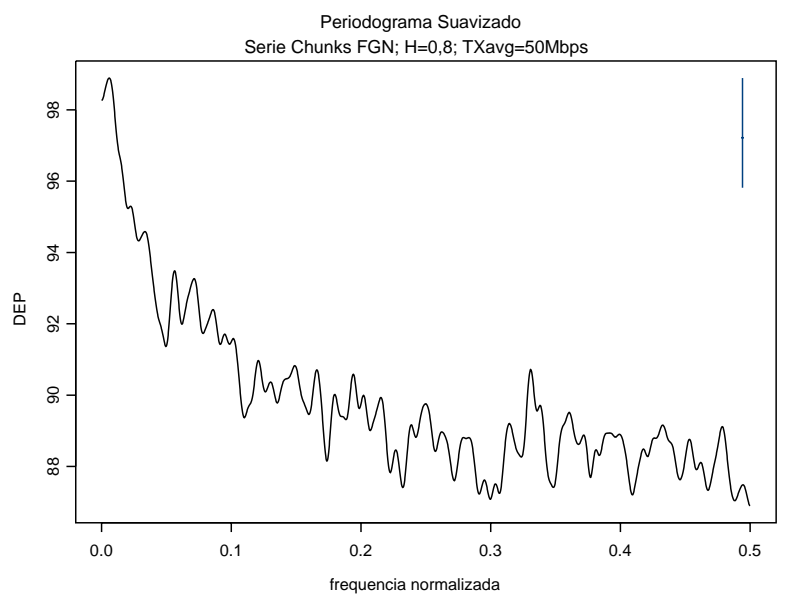

Figura 4.7: Periodograma para série de chunks fGN com $\mathrm{H}=0,8$ (conversão 1). 
A Tabela 4.4 apresenta os resultados de estimativas do parâmetro de Hurst, pelo método de Whittle e do periodograma, para a série temporal fGN gerada com $H=0,8$ e a respectiva série de chunks obtida pela técnica de conversão 1 . Em ambos os métodos não ocorrem variações relevantes entre as estimativas de $H$ para a série temporal original e para a série de chunks.

Tabela 4.4: Estimativas do parâmetro de Hurst para série temporal fGN gerada com $H=0,8$ e a respectiva série de chunks obtida pelo método de conversão 1.

\begin{tabular}{l|l|c}
\hline & H Whittle & H periodograma \\
\hline \hline série temporal & $H=0,80$ & $H=0,76$ \\
\hline série chunks & $H=0,80$ & $H=0,77$ \\
\hline \hline
\end{tabular}

\subsubsection{Conversão para série de pacotes de tamanho cons- tante}

Essa alternativa de conversão caracteriza-se pela transmissão de pacotes de tamanho fixo e uniformemente distribuídos dentro do período de um bin da série temporal original. A cada bin existe um número de bytes específico que deve ser enviado, o que corresponde a um determinado número de pacotes de tamanho constante que aproximam esse número de bytes. Ao comparar-se a quantidade de pacotes enviados dentro de cada bin, obtêm-se valores usualmente distintos. Por essa razão o espaçamento entre os pacotes observado dentro de um bin será uniforme, porém potencialmente diferente do espaçamento encontrado em outros intervalos de transmissão. No restante deste texto, denomina-se essa alternativa de conversão como conversão 2.

Diferentemente do método de conversão 1, em que o bin define o instante de envio de uma seqüência consecutiva de pacotes (sem espaçamento entre eles), no método de conversão 2 o instante de envio de cada pacote é determinado através da divisão do tamanho do bin pelo número de pacotes que devem ser enviados naquele bin.

A técnica de transmissão de pacotes de tamanho fixo exige cautela para considerar o efeito do erro de quantização. O erro de quantização ocorre porque efetua-se uma aproximação de cada ponto da série temporal normalizada por um número inteiro de pacotes de tamanho fixo. Em um experimento prático relacionado à síntese de tráfego, (VEITCH et al., 2000) e (WALL, 1999) constataram que com 350 níveis de quantização as distorções inseridas pelo erro de quantização eram suficientemente pequenas e, portanto, aceitáveis. Não está no escopo deste 
trabalho conduzir estudos aprofundados sobre os efeitos do erro de quantização, porém salienta-se que esse erro é uma das causas a serem investigadas em eventuais degradações, após a conversão 2, das características fractais sintetizadas na série temporal. Experimentos futuros de geração e análise utilizando diferentes níveis de quantização permitirão obter recomendações sobre a quantidade de níveis adequados para evitar alterações significativas nas estatísticas das séries após conversão.

Os seguintes parâmetros são solicitados pelo programa implementado para dar flexibilidade a esse método de conversão da série temporal em série de pacotes:

1. $T X_{\max }$. Representa a taxa máxima de transmissão (em Mbps) para o meio escolhido;

2. $T A M_{\text {pckt }}$. É o tamanho constante (em bytes) dos pacotes ou células que serão transmitidos;

3. bin. É o intervalo de tempo constante (em $\mathrm{ms}$ ) entre pontos da série temporal;

4. TX $X_{a v g}$. É a taxa média de transmissão que deseja-se obter (em Mbps);

5. fator $_{n e g}$. Representa um fator usado antes da normalização das séries com valores negativos, cujo efeito é a adição de uma componente DC que elimina uma quantidade dos valores negativos proporcional a esse fator ${ }^{2}$. Para fator $_{n e g}=0$, a série temporal não é alterada e para fator $_{n e g}=1$, é adicionada uma componente DC na série temporal que elimina por completo os valores negativos (menor valor da série é mapeado para 0 ).

Dentro de um bin pode-se enviar até $M A X_{-} P C K T S_{b i n}$ de tamanho $T A M_{p c k t}$. Recomenda-se $M A X_{-} P C K T S_{b i n} \geq 350$ para minimizar efeitos do erro de quantização. Caso haja interesse em se obter um valor específico para $M A X_{-} P C K T S_{b i n}$, pode-se calcular o tamanho do intervalo bin pela (4.8) e informá-lo como dado de entrada para o programa de conversão.

$$
\text { bin }=\frac{M A X_{-} P C K T S_{b i n} \cdot T A M_{p c k t}}{T X_{\max }} \cdot 8 \cdot 10^{-3} \mathrm{~ms} .
$$

Manipulando-se (4.8) é possível calcular $M A X_{-} P C K T S_{b i n}$ a partir de um valor informado para o parâmetro bin.

\footnotetext{
${ }^{2}$ fator $_{\text {neg }}$ poderá assumir qualquer valor no intervalo $[0,1]$.
} 
O parâmetro $T X_{a v g}$ é usado para controlar a carga média do trace após conversão. Esse parâmetro está relacionado com a quantidade média de pacotes por bin $A V G_{-} P C K T S_{b i n}$, conforme indicado na (4.9).

$$
T X_{\text {avg }}=\frac{A V G_{-} P C K T S_{b i n} \cdot T A M_{p c k t}}{\operatorname{bin}} \cdot 8 \cdot 10^{-3} \text { Mbps. }
$$

As operações de transformação e normalização ocorrem de maneira semelhante ao apresentado na Seção 4.2.1.1. O procedimento descrito na Seção 4.2.2.1 detalha essas operações para o método de conversão 2.

\subsubsection{Procedimento de normalização da série temporal pela conver- são 2}

1. Caso a série possua valores negativos, adicionar uma componente DC controlada pelo fator $_{n e g}$;

2. Calcular o valor limiar que será mapeado para 1 pacote de tamanho $T A M_{p c k t}$;

3. Truncar a série temporal de modo que valores abaixo de limiar sejam mapeados para 0 ;

4. Utilizando-se o parâmetro de entrada $T X_{\text {avg }}$, é possível calcular através da (4.9) o valor de $A V G \_P C K T S_{\text {bin }}$ desejado;

5. Calcular a fração de pontos $P$ que foram mapeados para 0 ;

6. $Q=1-P$ será a fração de pontos iguais ou acima de limiar e que serão transformados em 1 ou mais pacotes de tamanho $T A M_{p c k t}$;

7. Calcular a média da série temporal modificada, desconsiderando os pontos em 0. Essa será a variável Avg_Serie_Temp not_o $_{\text {da }}(4.10)$ :

$$
\text { Avg_Serie_Temp } p_{\text {not } 0}=\frac{\sum_{i=0}^{N-1} \operatorname{serie} \_t \operatorname{temp}(i)}{N \cdot Q}
$$

em que serie_temp $(i)$ é o valor do ponto de índice $i$ da série temporal e $N$ é o número total de pontos da série temporal;

8. A variável $A V G_{-} P C K T S_{b i n}$ está relacionada com uma variável auxiliar, $Q_{-} A V G_{-} P C K T S_{b i n}$ pela (4.11):

$$
\begin{array}{r}
A V G_{-} P C K T S_{b i n}=0 \cdot P+Q_{-} A V G_{-} P C K T S_{b i n} \cdot Q \\
Q_{-} A V G_{-} P C K T S_{b i n}=\frac{A V G_{-} P C K T S_{b i n}}{1-P} ;
\end{array}
$$


9. A variável $A v g_{-} S e r i e_{-} T e m p_{n o t} 0$ será mapeada para a variável auxiliar $Q_{-} A V G_{-} P C K T S_{b i n}$ através do fator de normalização $F N=\frac{Q_{-} A V G_{-} P C K T S_{\text {bin }}-1}{\text { Avg_Serie_Temp }_{\text {not }} 0_{-}-\text {limiar }}$, aplicado conforme (4.12):

$$
\begin{array}{r}
\text { se serie_temp }(i) \geq \text { limiar então } \\
n u m_{-} \text {pacotes }(i)=F N \cdot(\text { serie_temp }(i)-l i m i a r)+1 \\
\text { caso contrário } \\
n u m \_p a c o t e s(i)=0
\end{array}
$$

10. Em cada ponto a série num_pacotes poderá ser menor ou maior que $M A X_{-} P C K T S_{b i n}$. No caso de valores acima de $M A X_{-} P C K T S_{b i n}$ adota-se o mecanismo de virtual buffer (acumulador para próximo(s) bin(s));

11. Arredondar os pontos da série num_pacotes para que cada ponto corresponda a um número inteiro de pacotes a ser transmitido, entre $1 \mathrm{e}$ $M A X_{-} P C K T S_{b i n}$;

12. Calcular o tempo de separação entre pacotes de um mesmo bin através da (4.13). Montar os vetores de tamanho de pacotes (serie_pacotes; constante) e de tempo entre pacotes (tempo_entre_pacotes) que podem ser enviados a um módulo gerador de pacotes ou ao simulador através de interface adequada.

$$
\text { TIME_INTRA_BIN }(i)=\frac{\operatorname{bin}}{\text { num_pacotes }(i)} .
$$

A Figura 4.8 ilustra o envio de pacotes de tamanho constante, conforme o método de conversão 2 .

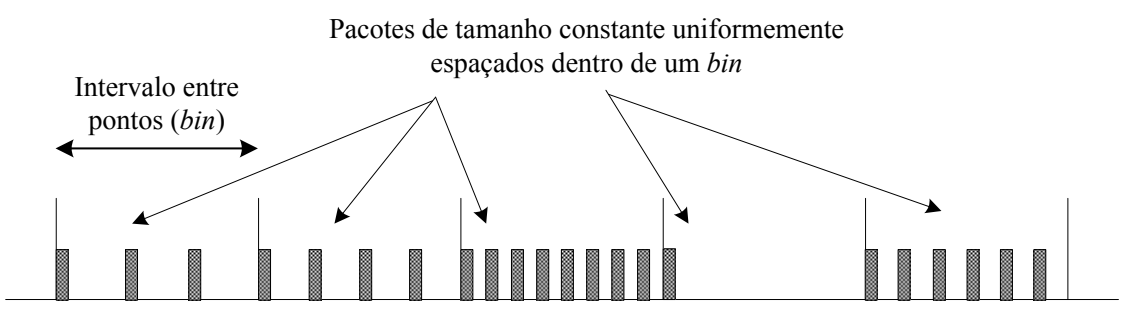

Figura 4.8: Exemplo de trace após conversão para série de pacotes de tamanho constante, distribuídos uniformemente dentro do período de um bin (conversão 2). 


\subsubsection{Dados de exemplo para conversão 2}

As mesmas realizações das séries temporais MWM e fGN e as mesmas premissas utilizadas no exemplo da Seção 4.2.1.2 foram novamente utilizadas para validação do método de conversão 2.

No caso do modelo MWM, foram adotados os seguintes valores para os dados de entrada do programa de conversão 2:

- $T X_{\max }=150$ Mbps;

- $T A M_{p c k t}=150$ bytes;

- $\operatorname{bin}=1 \mathrm{~ms}$;

- $T X_{\text {avg }}=2$ Mbps.

A escolha dos valores acima resulta em $M A X_{-} P C K T S_{b i n}=125 \mathrm{e}$ $A V G_{\text {_P }} P C K T S_{\text {bin }}=1,667$. Essas informações podem ser usadas para projetar o tamanho da fila do link gargalo do cenário de simulação.

Verifica-se que os baixos valores obtidos para $M A X_{-} P C K T S_{b i n}$ e principalmente $A V G_{-} P C K T S_{b i n}$ acentuam os efeitos do erro de quantização. Por outro lado, a vantagem do uso de um valor baixo para o parâmetro $T X_{\text {avg }}$, quando comparado a $T X_{\max }$, é minimizar as distorções causadas por excessos de uso do mecanismo de virtual buffer.

Para o modelo fGN, os seguintes valores foram utilizados para efetuar a conversão:

- $T X_{\max }=150 \mathrm{Mbps}$;

- $T A M_{p c k t}=150$ bytes;

- $b i n=10 \mathrm{~ms}$;

- $T X_{a v g}=50$ Mbps;

- fator $_{n e g}=0,5$.

A escolha dos valores acima resulta em $M A X_{-} P C K T S_{b i n}=1250 \mathrm{e}$ $A V G_{-} P C K T S_{\text {bin }}=416,67$. Essas informações podem ser usadas para projetar o tamanho da fila do link gargalo do cenário de simulação. 


\subsubsection{Análise estatística das séries de pacotes após conversão 2}

A Figura 4.9 mostra a realização do modelo MWM acima da série de número de pacotes (série de pacotes reagregada), obtida através do método de conversão 2 .
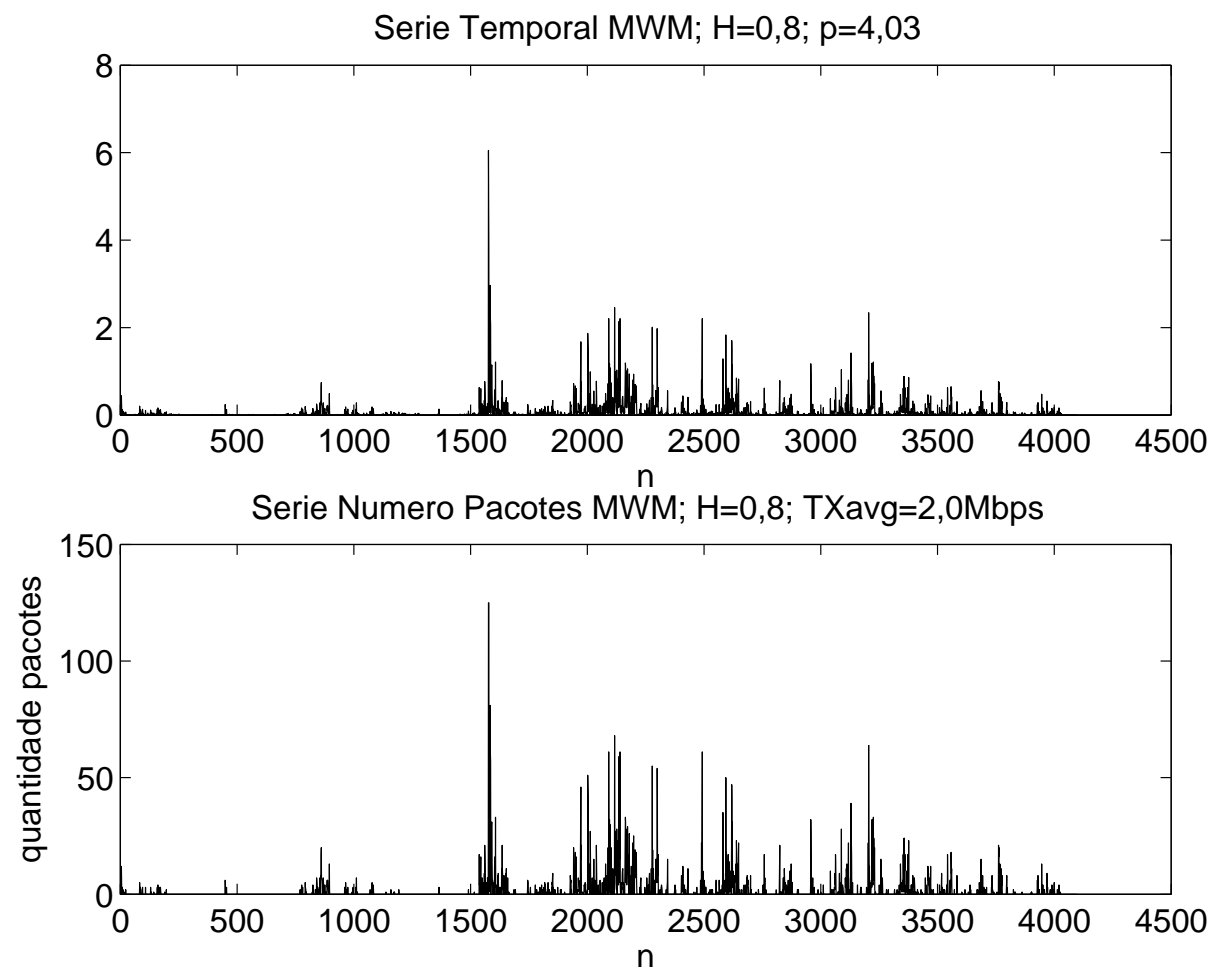

Figura 4.9: Comparação entre série temporal MWM e série de número de pacotes, com $\mathrm{H}=0,8$ (conversão 2). 
Efetuando-se uma comparação visual entre a DEP da série temporal MWM antes da conversão (Figura 4.10) e a DEP da respectiva série de número de pacotes (Figura 4.11), nota-se que as características LRD modeladas na série temporal continuam existindo após a conversão 2.

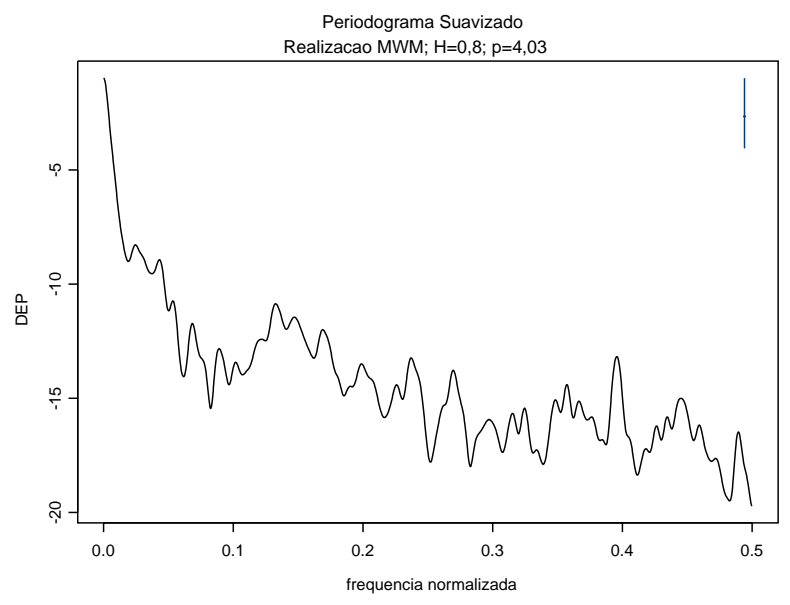

Figura 4.10: Periodograma para série temporal MWM com $\mathrm{H}=0,8$.

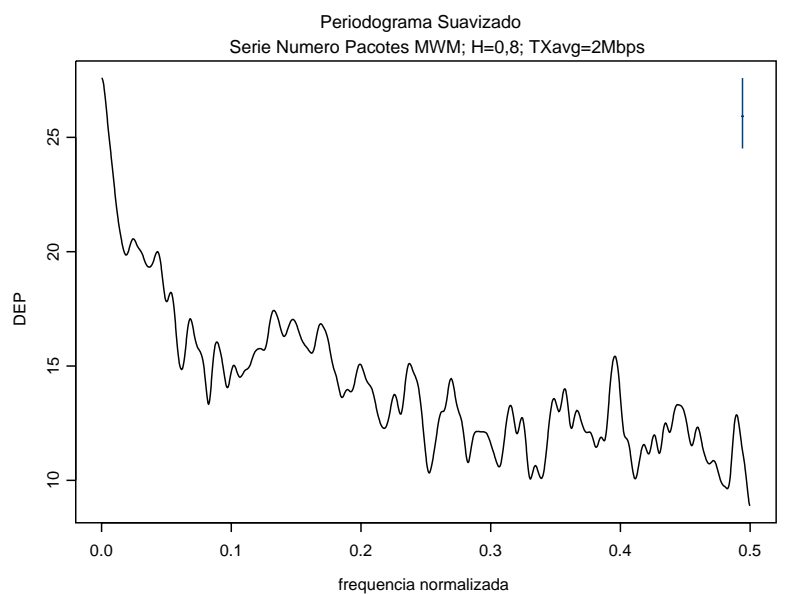

Figura 4.11: Periodograma para série de número de pacotes MWM com $\mathrm{H}=0,8$ (conversão 2). 
A Tabela 4.5 apresenta os resultados de estimativas do parâmetro de Hurst, pelo método de Whittle e do periodograma, para a série temporal MWM gerada com $H=0,8$ e a respectiva série de número de pacotes obtida pela técnica de conversão 2. Em ambos os métodos não ocorrem variações relevantes entre as estimativas de $H$ para a série temporal original e para a série de número de pacotes.

Tabela 4.5: Estimativas do parâmetro de Hurst para série temporal MWM gerada com $H=0,8$ e a respectiva série de número de pacotes obtida pelo método de conversão 2 .

\begin{tabular}{l|l|c}
\hline & H Whittle & H periodograma \\
\hline \hline série temporal & $H=0,84$ & $H=0,81$ \\
\hline série núm. pacotes & $H=0,86$ & $H=0,80$ \\
\hline \hline
\end{tabular}

A Figura 4.12 mostra a realização do modelo fGN acima da série de número de pacotes, obtida através do método de conversão 2 .
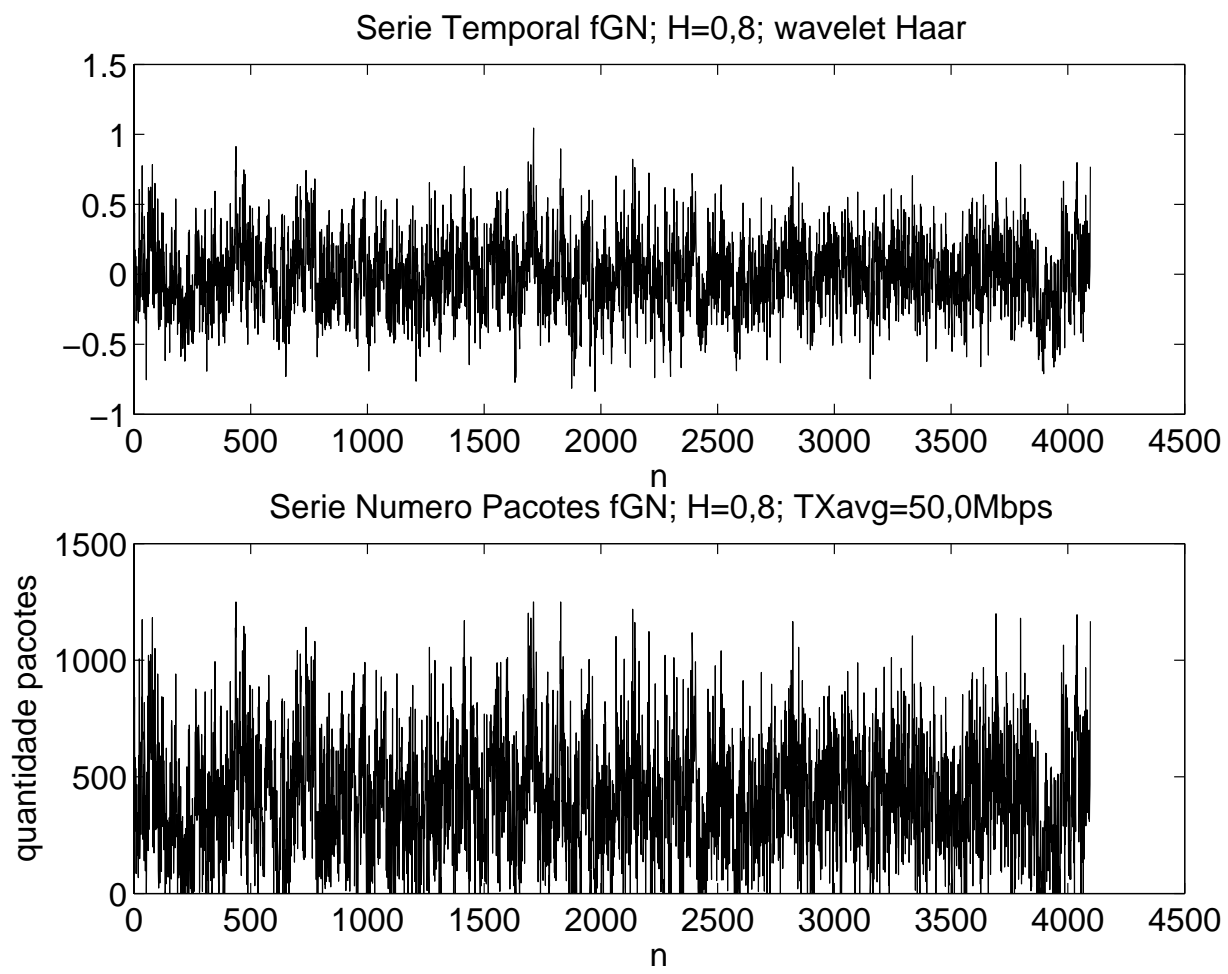

Figura 4.12: Comparação entre série temporal fGN e série de número de pacotes, com $\mathrm{H}=0,8$ (conversão 2). 
Efetuando-se uma comparação visual entre a DEP da série temporal fGN antes da conversão (Figura 4.13) e a DEP da respectiva série de número de pacotes (Figura 4.14), nota-se que as características LRD modeladas na série temporal continuam existindo após a conversão 2.

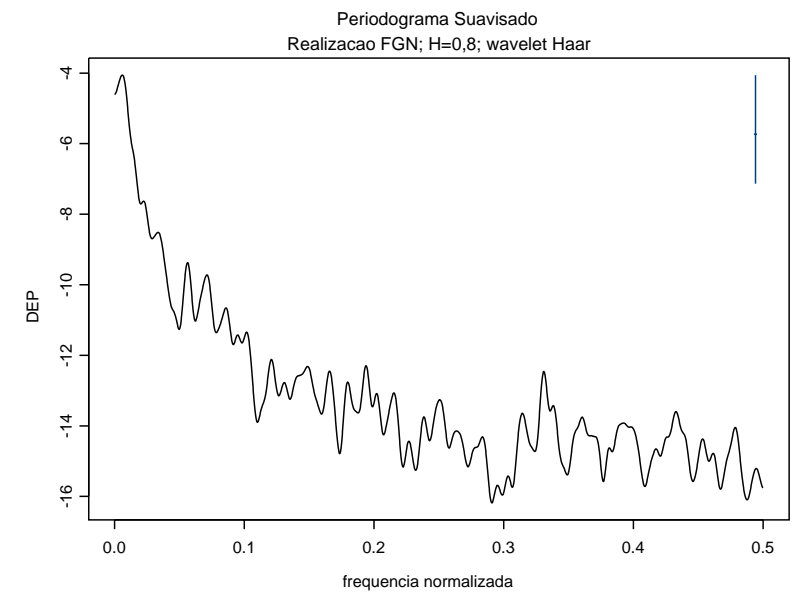

Figura 4.13: Periodograma para série temporal fGN com $\mathrm{H}=0,8$.

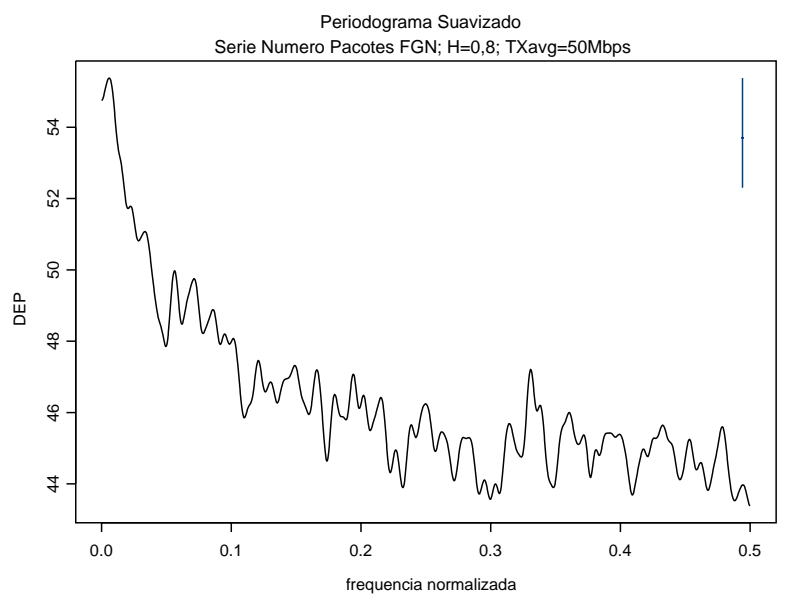

Figura 4.14: Periodograma para série de número de pacotes fGN com $\mathrm{H}=0,8$ (conversão 2). 
A Tabela 4.6 apresenta os resultados de estimativas do parâmetro de Hurst, pelo método de Whittle e do periodograma, para a série temporal fGN gerada com $H=0,8$ e a respectiva série de número de pacotes obtida pela técnica de conversão 2. Em ambos os métodos não ocorrem variações relevantes entre as estimativas de $H$ para a série temporal original e para a série de número de pacotes.

Tabela 4.6: Estimativas do parâmetro de Hurst para série temporal fGN gerada com $H=0,8$ e a respectiva série de número de pacotes obtida pelo método de conversão 2 .

\begin{tabular}{l|l|c}
\hline & H Whittle & H periodograma \\
\hline \hline série temporal & $H=0,80$ & $H=0,76$ \\
\hline série núm. pacotes & $H=0,80$ & $H=0,77$ \\
\hline \hline
\end{tabular}

\subsection{Uso de Tráfego LRD em Cenários de Simula- ção}

\subsubsection{Interface com o Simulador NS-2}

Pode-se utilizar os vetores de tamanho de pacotes (serie_pacotes) e de tempo entre pacotes (tempo_entre_pacotes), que são obtidos após a etapa de conversão das séries temporais, para gerar tráfego agregado em um cenário de simulação do software simulador de redes NS-2 Network Simulator (NS-2) (FALL; VARADHAN, 2006).

Conforme resumido por (LIPAS, 2005), o simulador NS-2 foi criado pelo projeto Virtual InterNetwork Testbed (VINT). O VINT é um projeto colaborativo que inclui a University of California at Berkeley (UCB), University of Southern California (USC)/Information Sciences Institute (ISI), Xerox Palo Alto Research Center (PARC) e o Lawrence Berkeley National Laboratory (LBNL). O propósito desse projeto é a construção de um simulador de redes que permita o estudo das interações dos protocolos de rede atuais e futuros. O simulador é orientado a objeto, escrito na linguagem de programação $C++$ e utiliza a linguagem Object Tool Command Language (OTcl) como interface de configuração e comando (interpretador). O NS-2 oferece uma plataforma aberta onde os usuários podem manipular as classes $C++$ e arquivos $O T c l$ existentes e também adicionar novas funcionalidades de acordo com as suas necessidades de simulação. A Tool Command Language ( $T c l$ ), que é uma linguagem de transcrição de alto nível, é utilizada no NS-2 para encapsular a instância real do interpretador OTcl. Os 
scripts Tcl, escritos pelo usuário, são então executados pelo simulador e provêem os meios para o acesso e comunicação com os métodos definidos pelo interpretador OTcl.

A interface do NS-2 que suporta a funcionalidade de integração de fonte de tráfego externa é baseada em uma classe $C++$ derivada da classe TrafficGenerator, denominada TrafficTrace. A classe TrafficTrace é usada em scripts de configuração do NS-2 para permitir a geração de tráfego de acordo com um arquivo de trace. Cada registro dentro do arquivo de trace consiste em 2 campos de 32 bits no formato utilizado em redes para a ordem dos bytes (big-endian) ${ }^{3}$. O primeiro campo deve conter o instante de tempo (em microssegundos $\mu s$ ) até que o próximo pacote deva ser gerado (tempo entre pacotes). O segundo campo deve conter o comprimento (em bytes) do próximo pacote que será gerado.

Utilizando o software Matlab para a síntese da série de tráfego é possível gerar o arquivo de trace no formato exigido pela classe TrafficTrace através das funções fopen e fwrite. Para a função fopen é necessário configurar o parâmetro MACHINEFORMAT com o valor ' $b$ ' que fará com que as operações de escrita da função fwrite sejam feitas em formato big endian. Para a função fwrite é necessário configurar o parâmetro PRECISION com o valor 'uint32' para garantir que os 2 campos, tempo entre pacotes e tamanho de pacotes, serão armazenados como inteiros de 32 bits.

O autor Marcelo Lipas desenvolveu scripts Tcl, OTcl e extensões de classes $C++$ do simulador NS-2 que foram utilizadas em (BARRA, 2005) para execução de simulações e captura de parâmetros de QoS. Neste trabalho também se utiliza os mesmos scripts e extensões para facilitar a configuração de topologias de simulação e a análise dos dados de interesse. A configuração dos cenários de simulação é especificada em um dos scripts Tcl citados.

Foram elaborados 4 cenários de simulação independentes a fim de validar as séries de pacotes dos modelos MWM e fGN obtidas por ambos os métodos de conversão. A razão para 4 cenários está associada ao dimensionamento do link gargalo e do tamanho da fila do cenário de simulação que torna-se específico para cada modelo e cada método de conversão. Associados a cada um dos 4 cenários com tráfego LRD foram criados outros 4 cenários com tráfego Poisson para permitir que sejam feitas comparações iniciais. No caso da conversão 1, assumiu-se para ambos os modelos que o tamanho dos pacotes seria de 1518 bytes (somente verdade para os $M$ pacotes de um bin, já que os dados de exemplo utilizados

\footnotetext{
${ }^{3}$ Computadores pessoais baseados em sistema operacional Windows armazenam bytes em formato little-endian.
} 
nessa conversão também permitiram o envio de pacotes de tamanho $V$ entre 64 e 1518 bytes). Analogamente, para o caso da conversão 2 assumiu-se para ambos os modelos que o tamanho dos pacotes seria de 150 bytes (é precisamente o resultado da conversão). O tamanho dos pacotes, juntamente com as variáveis bin e $T X_{\max }$, determinaram o dimensionamento da fila de cada cenário de simulação. Conhecendo-se bin e $T X_{\max }$ e assumindo que os pacotes que serão enviados tenham tamanho constante, projetaram-se as filas para suportarem aproximadamente o número máximo de pacotes que possam ser enviados dentro de 1 bin.

As definições dos cenários de simulação deste trabalho, sempre referem-se ao tamanho da fila ( $T A M_{\text {fila }}$, parâmetro configurado no script de simulação) como a quantidade de pacotes que a fila pode armazenar ${ }^{4}$.

As Tabelas 4.7 e 4.8 apresentam as premissas assumidas para o uso das séries obtidas por cada modelo com cada um dos tipos de conversão, assim como os valores do parâmetro $T A M_{\text {fila }}$ que serão adotados nos respectivos cenários de simulação.

Tabela 4.7: Tabela de modelos, métodos de conversão, taxa média de transmissão e tamanho do bin.

\begin{tabular}{||c||c||c||c||c||}
\hline \hline Rede & Modelo & Conversão & Taxa Média & bin (ms) \\
\hline \hline backbone & fGN & 1 (chunk) & $50 \mathrm{Mbps}$ & 10 \\
\hline backbone & fGN & 2 (pct.tam.cte.) & $50 \mathrm{Mbps}$ & 10 \\
\hline acesso & MWM & 1 (chunk) & $2 \mathrm{Mbps}$ & 1 \\
\hline acesso & MWM & 2 (pct.tam.cte.) & $2 \mathrm{Mbps}$ & 1 \\
\hline \hline
\end{tabular}

Tabela 4.8: Tabela de modelos, métodos de conversão, tamanho de pacotes para dimensionamento da fila e tamanho da fila.

\begin{tabular}{||c||c||c||c||}
\hline \hline Modelo & Conversão & Tam.Pct.Fila & $\boldsymbol{T A} \boldsymbol{M}_{\text {fila }}$ \\
\hline \hline fGN & 1 (chunk) & 1518 & 128 \\
\hline fGN & 2 (pct.tam.cte.) & 150 & 1024 \\
\hline MWM & 1 (chunk) & 1518 & 16 \\
\hline MWM & 2 (pct.tam.cte.) & 150 & 128 \\
\hline \hline
\end{tabular}

Apresentam-se nas próximas seções os dados referentes à elaboração de cada cenário de simulação (topologia e características), juntamente com os gráficos e resultados gerados pelo simulador.

\footnotetext{
${ }^{4} \mathrm{O}$ manual do NS-2 menciona que a fila configurada em um script de simulação irá armazenar $T A M_{\text {fila }}-1$ pacotes, em que $T A M_{\text {fila }}$ é o parâmetro informado para o tamanho da fila.
} 


\subsubsection{MWM conversão 1}

A Figura 4.15 apresenta os parâmetros do cenário de simulação em que se utilizou a série do modelo MWM com $H=0,8$ e taxa média $\left(T X_{\text {avg }}\right)$ de 2 Mbps.

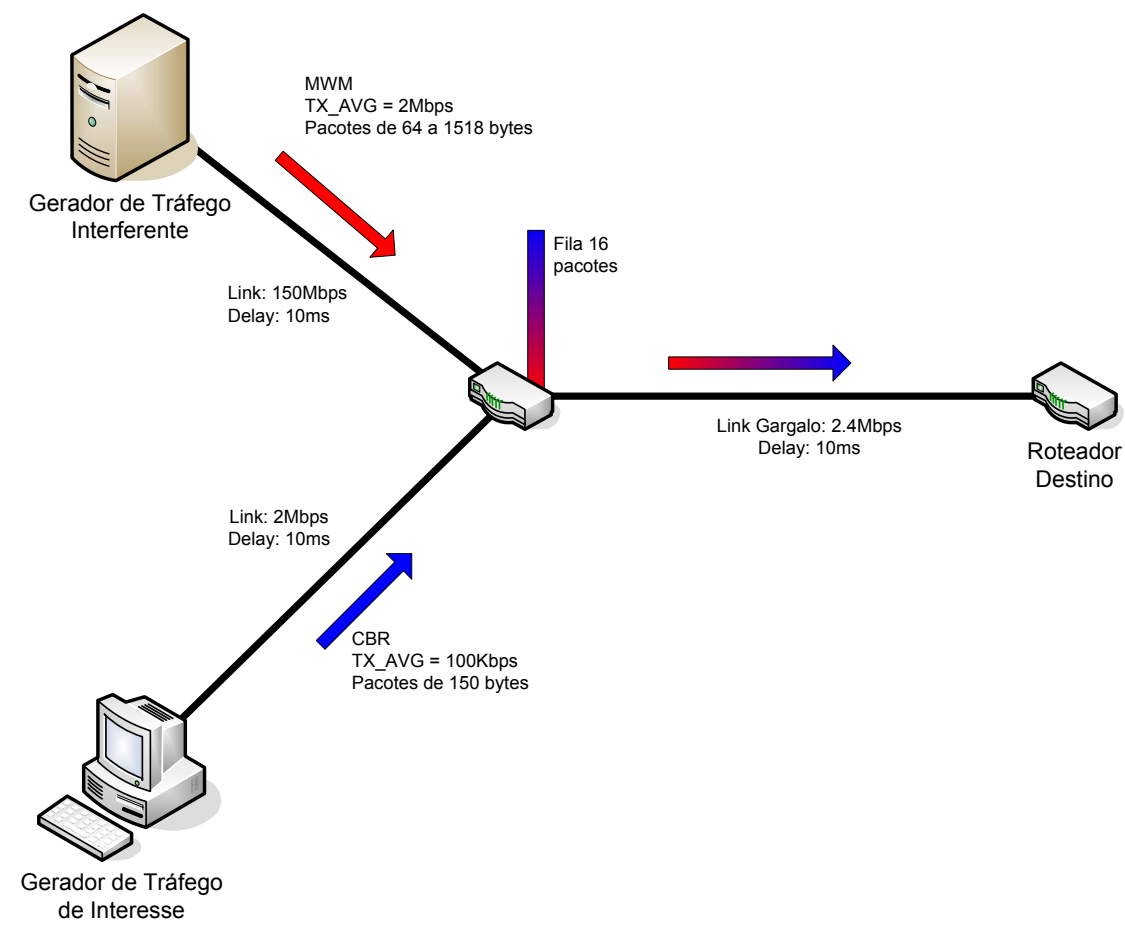

Figura 4.15: Cenário de simulação para série do modelo MWM, conversão 1, com $H=0,8$ e $T X_{\text {avg }}=2$ Mbps.

A Tabela 4.9 apresenta os parâmetros de maior interesse utilizados nesse cenário de simulação.

Tabela 4.9: Tabela de parâmetros do cenário de simulação para série MWM utilizando conversão 1.

\begin{tabular}{||c||c||}
\hline \hline \multicolumn{1}{|c||}{ Parâmetro } & Valor \\
\hline \hline bin série de pacotes & $1 \mathrm{~ms}$ \\
\hline \hline Taxa Média do Tráfego Interferente $\left(T X_{\text {avg }}\right)$ & $2 \mathrm{Mbps}$ \\
\hline \hline Hurst $(\mathrm{H})$ Tráfego Interferente & 0,8 \\
\hline \hline Tamanho de pacotes do Tráfego Interferente & 64 a 1518 bytes \\
\hline \hline Tamanho da Fila & 16 pacotes \\
\hline \hline Taxa máxima do Link Gargalo & $2,4 \mathrm{Mbps}$ \\
\hline \hline Taxa Média do Tráfego de Interesse & $100 \mathrm{kbps}$ \\
\hline \hline Tamanho dos pacotes do Tráfego de Interesse & 150 bytes \\
\hline \hline Tempo de simulação & 50 segundos \\
\hline \hline
\end{tabular}

A Tabela 4.10 apresenta os resultados obtidos para alguns parâmetros de 
QoS.

Tabela 4.10: Tabela de parâmetros de QoS para cenário com tráfego interferente baseado no modelo MWM, conversão 1 .

\begin{tabular}{||c||c||}
\hline \hline \multicolumn{1}{||c||}{ Parâmetro } & Valor \\
\hline \hline Atraso médio (Tráfego de interesse) & $26,21 \mathrm{~ms}(20 \mathrm{~ms}$ prop.) \\
\hline \hline Desvio padrão amostral do atraso & $7,5 \mathrm{~ms}$ \\
\hline \hline Perc. Perda de pacotes (Tráf. interesse) & $13,3 \%$ \\
\hline \hline Comprimento médio da fila & 4,16 pacotes \\
\hline \hline Perda total na fila & 7424 pacotes \\
\hline \hline
\end{tabular}

A Figura 4.16 apresenta a série do total de bytes por bin $(1 \mathrm{~ms})$ para o modelo MWM com $H=0,8$ e $T X_{\text {avg }}$ de 2 Mbps.

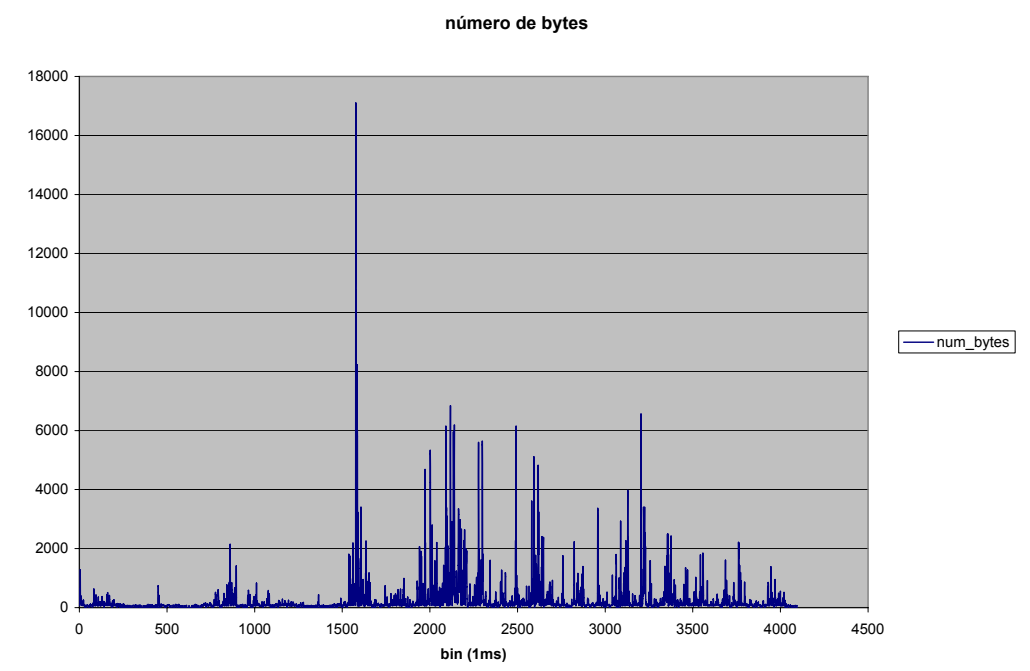

Figura 4.16: Série de bytes/bin para o modelo MWM com $H=0,8$ e

$$
T X_{\text {avg }}=2 \text { Mbps. }
$$


Configurando o simulador para um período de amostragem de estatísticas de QoS de 100 ms, foram gerados os gráficos em função do tempo para atraso médio do tráfego de interesse (4.17), perda de pacotes do tráfego de interesse (4.18), comprimento médio da fila (4.19), perda de pacotes do tráfego agregado na fila (4.20).

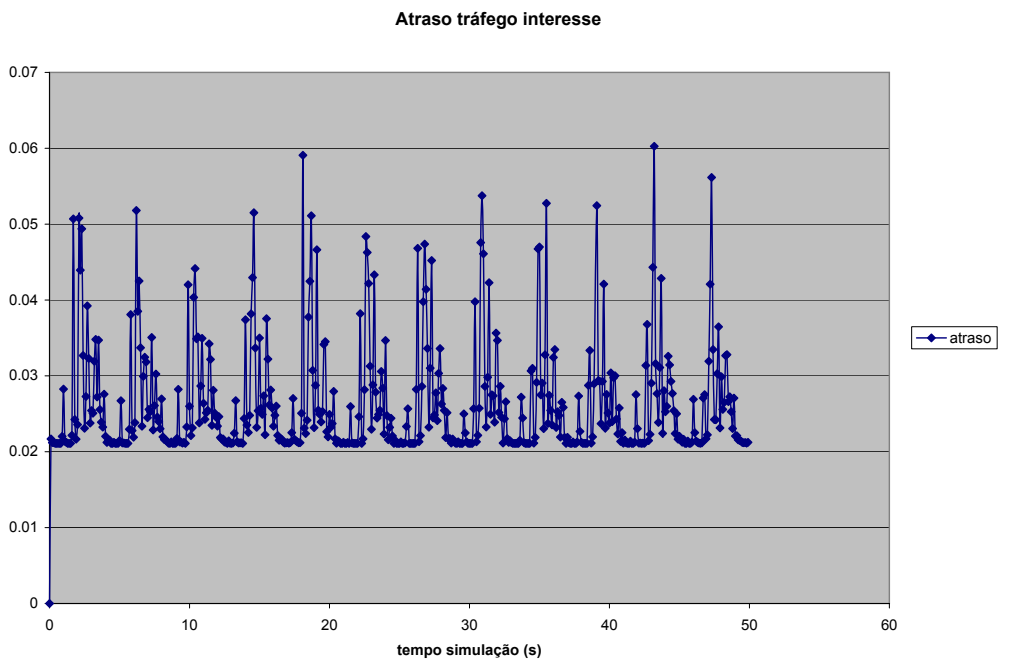

Figura 4.17: Atraso médio para o tráfego de interesse - cenário MWM conversão 1 . 


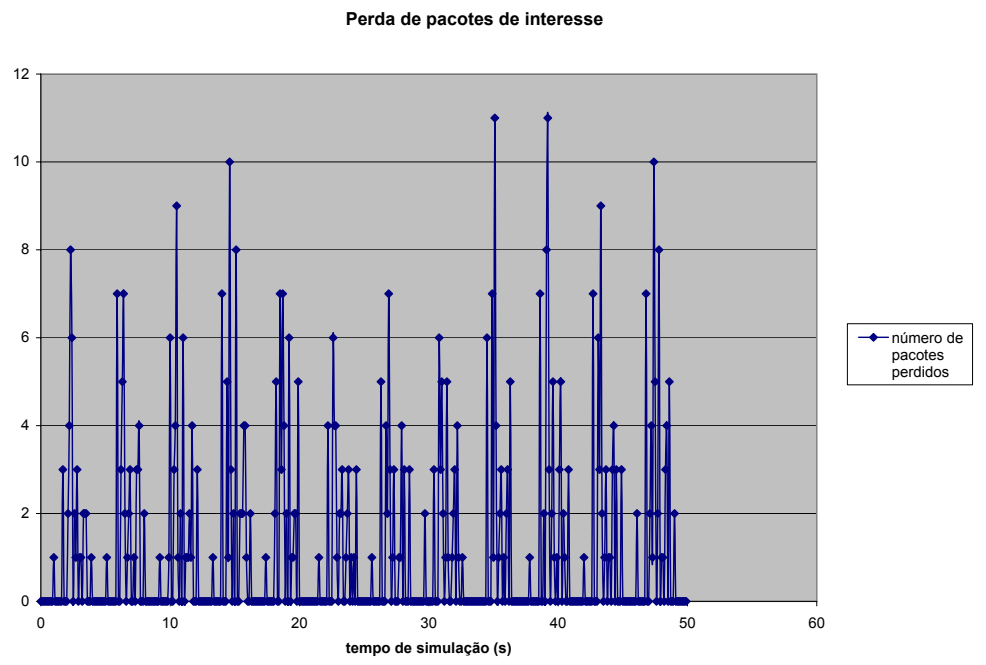

Figura 4.18: Perda de pacotes do tráfego de interesse - cenário MWM conversão 1 .

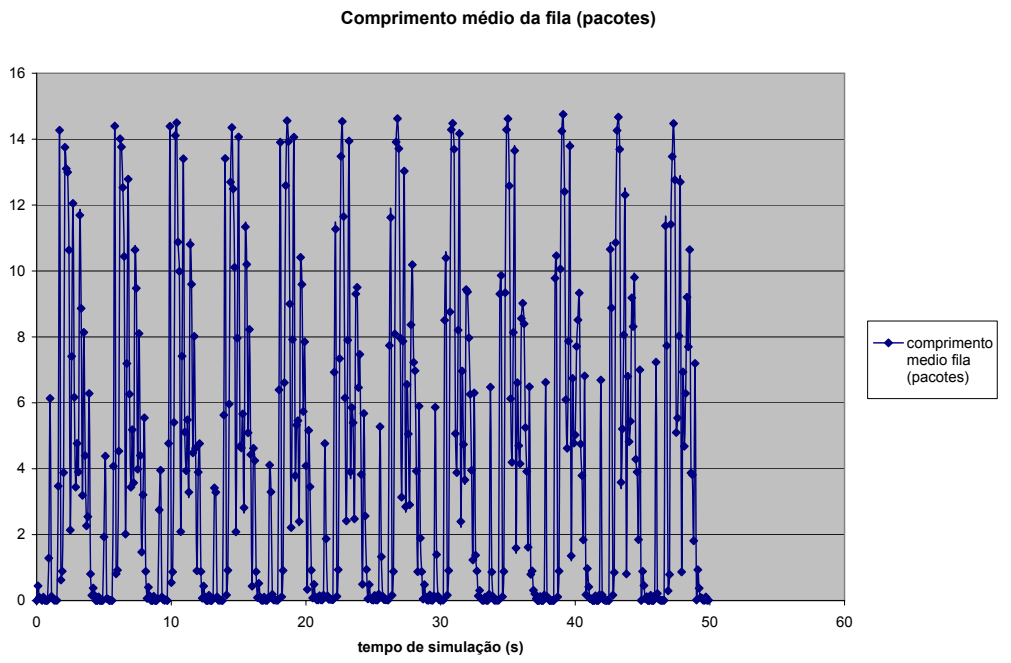

Figura 4.19: Comprimento médio da fila - cenário MWM - conversão 1. 
Perda de pacotes na fila (agregado)

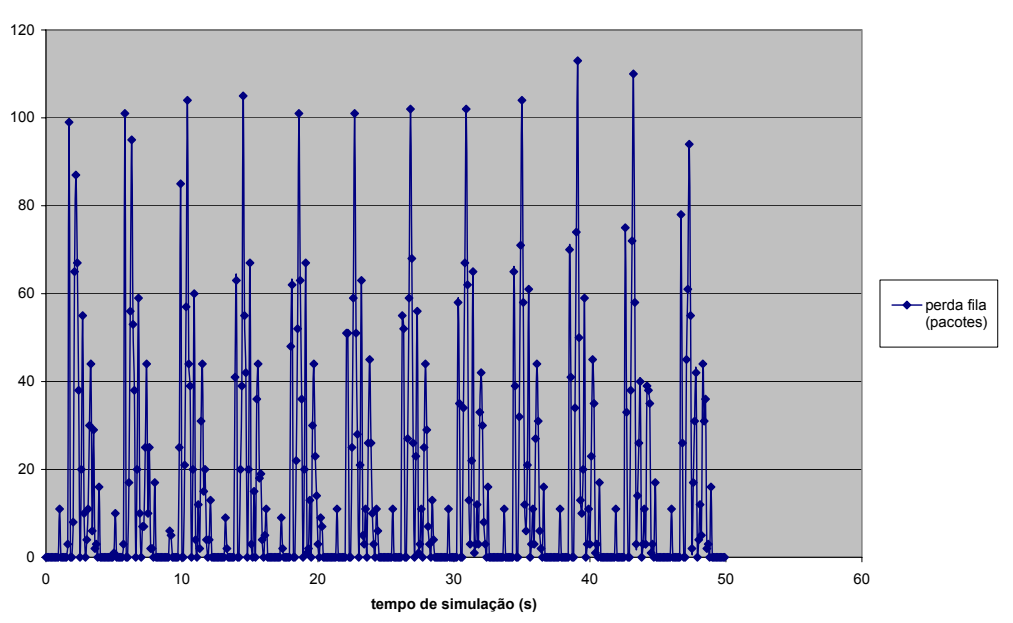

Figura 4.20: Perda de pacotes do tráfego agregado na fila - cenário MWM conversão 1 . 
Como cenário de referência elaborou-se um cenário similar, substituindo-se o tráfego interferente MWM por tráfego interferente Poisson parametrizado de modo a obter $T X_{\text {avg }}$ equivalente à utilizada com o modelo MWM. Esse modelo foi escolhido por tratar-se de um modelo clássico, Markoviano e freqüentemente citado em estudos de teoria das filas.

A Figura 4.21 apresenta os parâmetros utilizados no cenário de simulação de referência, tráfego interferente Poisson com $T X_{a v g}=2$ Mbps e tamanho de pacotes de 1518 bytes.

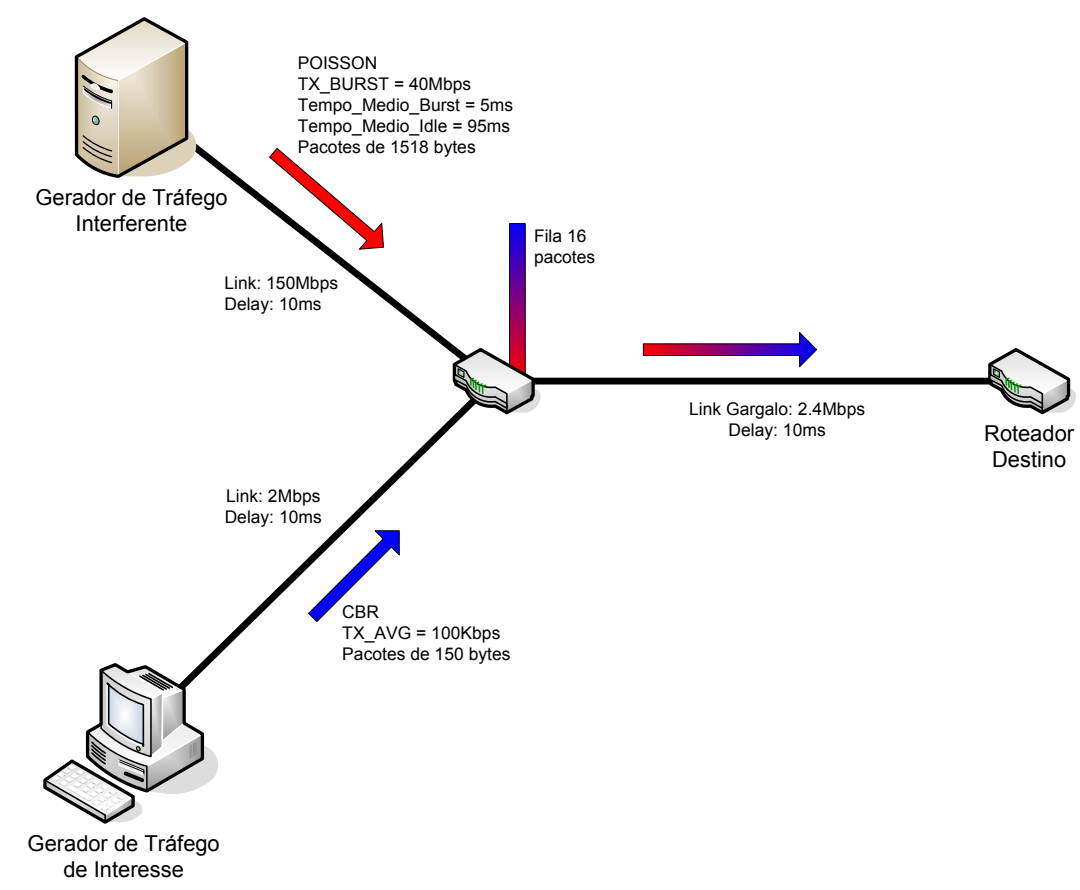

Figura 4.21: Cenário de simulação de referência, Poisson com $T X_{\text {avg }}=2$ Mbps e tamanho de pacotes 1518 bytes.

A Tabela 4.11 apresenta os parâmetros de maior interesse para a criação desse cenário de referência.

A Tabela 4.12 apresenta os resultados obtidos para alguns parâmetros de QoS. Comparando-se os resultados do cenário de referência com os resultados do cenário MWM nota-se que este último apresentou perda de pacotes na fila consideravelmente superior. Não há como concluir, no entanto, que esta seja uma característica relacionada somente ao modelo, já que um dos parâmetros de preparação do cenário, o tamanho dos pacotes para transmissão, é variável para o MWM e fixo para o Poisson. Isso significa que há probabilidade de transmissão de mais pacotes porém de tamanho menor no caso do MWM, o que pode resultar em maior perda na fila que é alocada por posição e não por quantidade de bytes. 
Tabela 4.11: Tabela de parâmetros do cenário de simulação de referência, Poisson com $T X_{\text {avg }}=2$ Mbps, pacotes de 1518 bytes.

\begin{tabular}{||c||c||}
\hline \hline \multicolumn{1}{||c||}{ Parâmetro } & Valor \\
\hline \hline$T X_{\text {avg }}$ do Tráf. Interferente & 2 Mbps \\
\hline \hline Taxa Transmissão em Burst & $40 \mathrm{Mbps}$ \\
\hline \hline Tempo Médio em Burst & $5 \mathrm{~ms}$ \\
\hline \hline Tempo Médio em Idle & $95 \mathrm{~ms}$ \\
\hline \hline Tam. pacotes do Tráf. Interferente & 1518 bytes \\
\hline \hline Tamanho da Fila & 16 pacotes \\
\hline \hline Taxa máxima do Link Gargalo & 2,4 Mbps \\
\hline \hline Taxa Média do Tráf. de Interesse & $100 \mathrm{kbps}$ \\
\hline \hline Tam. pacotes do Tráf. de Interesse & 150 bytes \\
\hline \hline
\end{tabular}

Tabela 4.12: Tabela de parâmetros de QoS para cenário com tráfego interferente baseado no modelo Poisson, 2 Mbps, 1518 bytes.

\begin{tabular}{||c||c||}
\hline \hline \multicolumn{1}{||c||}{ Parâmetro } & Valor \\
\hline \hline Atraso médio (Tráf. interesse) & $35,50 \mathrm{~ms}(20 \mathrm{~ms}$ prop.) \\
\hline \hline Desvio padrão amostral do atraso & $16,1 \mathrm{~ms}$ \\
\hline \hline Perc. Perda de pacotes (Tráf. interesse) & $3,4 \%$ \\
\hline \hline Comprimento médio da fila & 4,09 pacotes \\
\hline \hline Perda total na fila & 3863 pacotes \\
\hline \hline
\end{tabular}


Configurando o simulador para um período de amostragem de estatísticas de QoS de 100 ms, foram gerados os gráficos em função do tempo para atraso médio do tráfego de interesse (4.22), perda de pacotes do tráfego de interesse (4.23), comprimento médio da fila (4.24), perda de pacotes do tráfego agregado na fila (4.25).

Atraso tráfego interesse

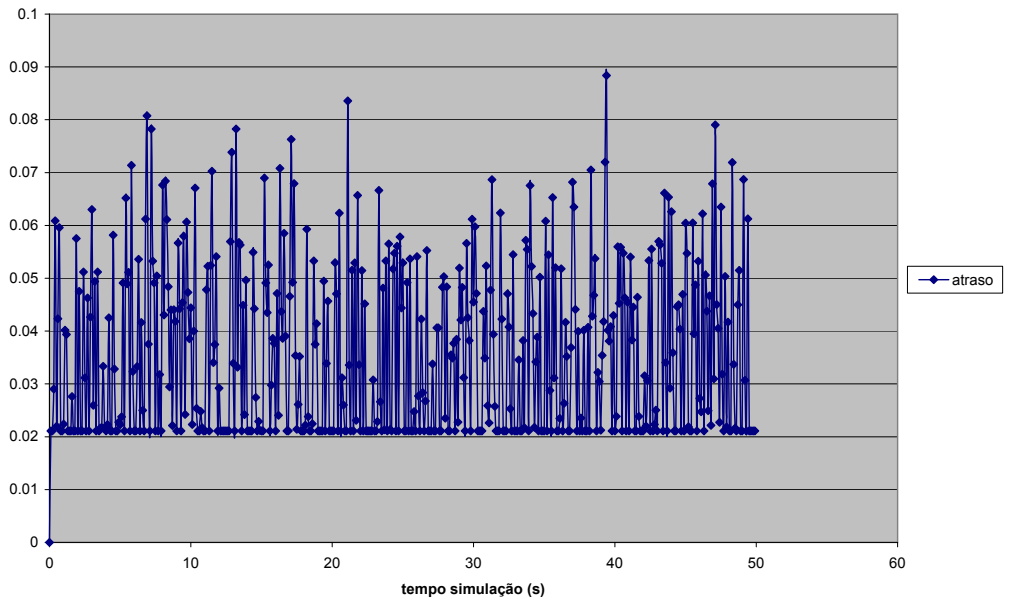

Figura 4.22: Atraso médio para o tráfego de interesse - cenário Poisson 2 Mbps com pacotes de 1518 bytes. 


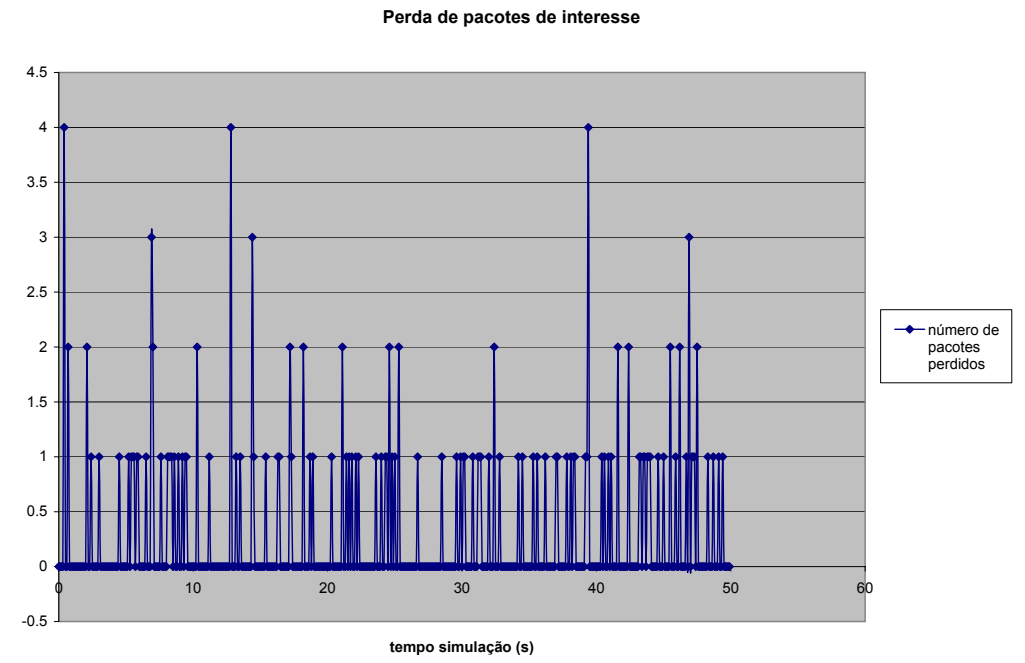

Figura 4.23: Perda de pacotes do tráfego de interesse - cenário Poisson 2 Mbps com pacotes de 1518 bytes.

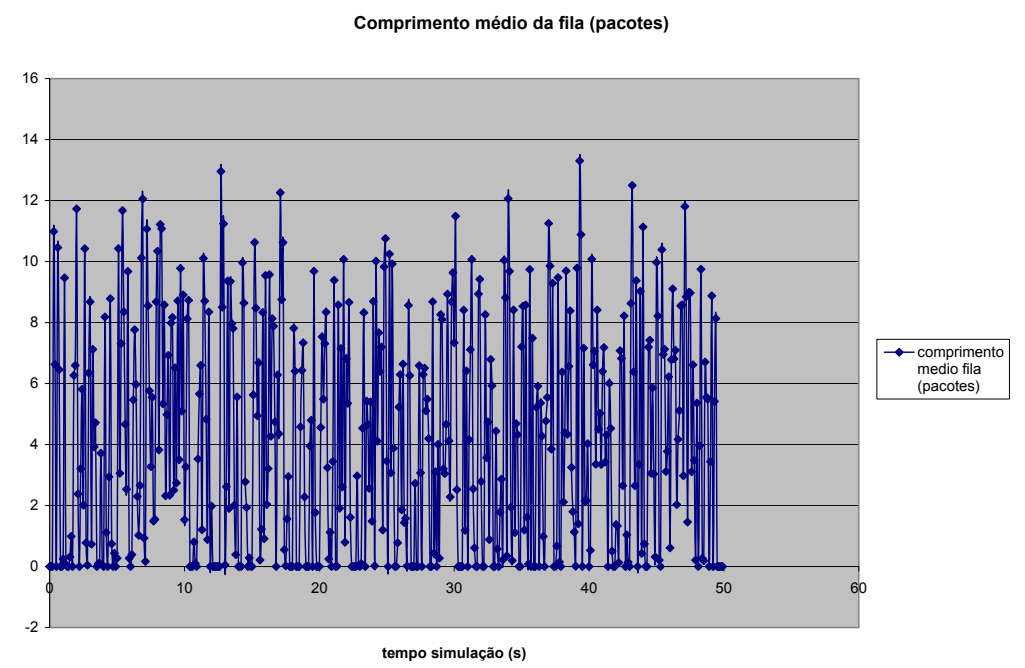

Figura 4.24: Comprimento médio da fila - cenário Poisson - 2 Mbps com pacotes de 1518 bytes. 
Perda de pacotes na fila (agregado)

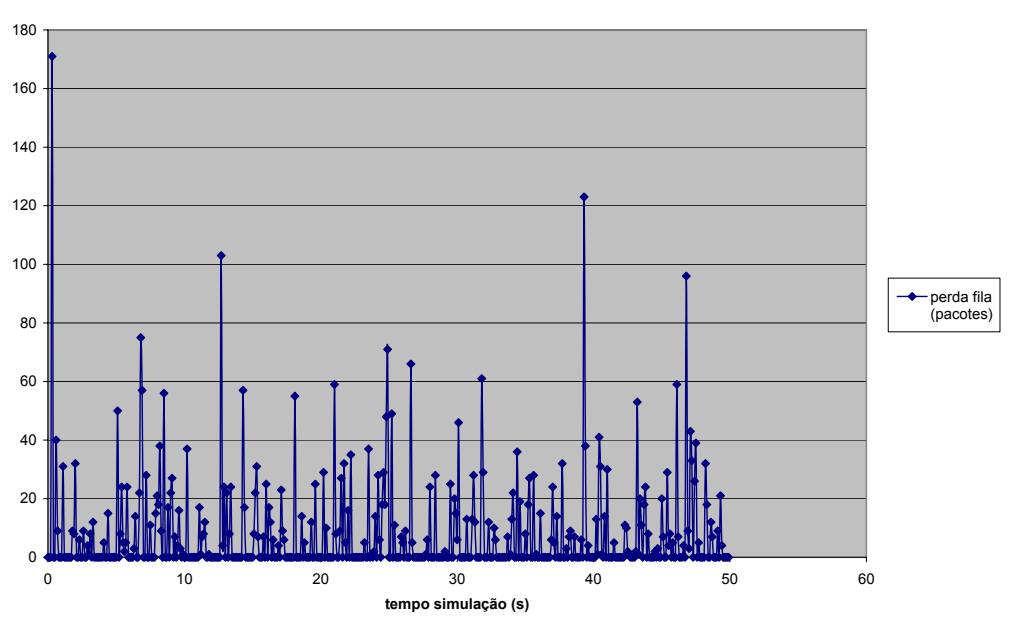

Figura 4.25: Perda de pacotes do tráfego agregado na fila - cenário Poisson 2 Mbps com pacotes de 1518 bytes. 


\subsubsection{MWM conversão 2}

A Figura 4.26 apresenta os parâmetros do cenário de simulação em que se utilizou a série do modelo MWM com $H=0,8, T X_{a v g}=2 M b p s$ e método de conversão 2 com pacotes de 150 bytes.

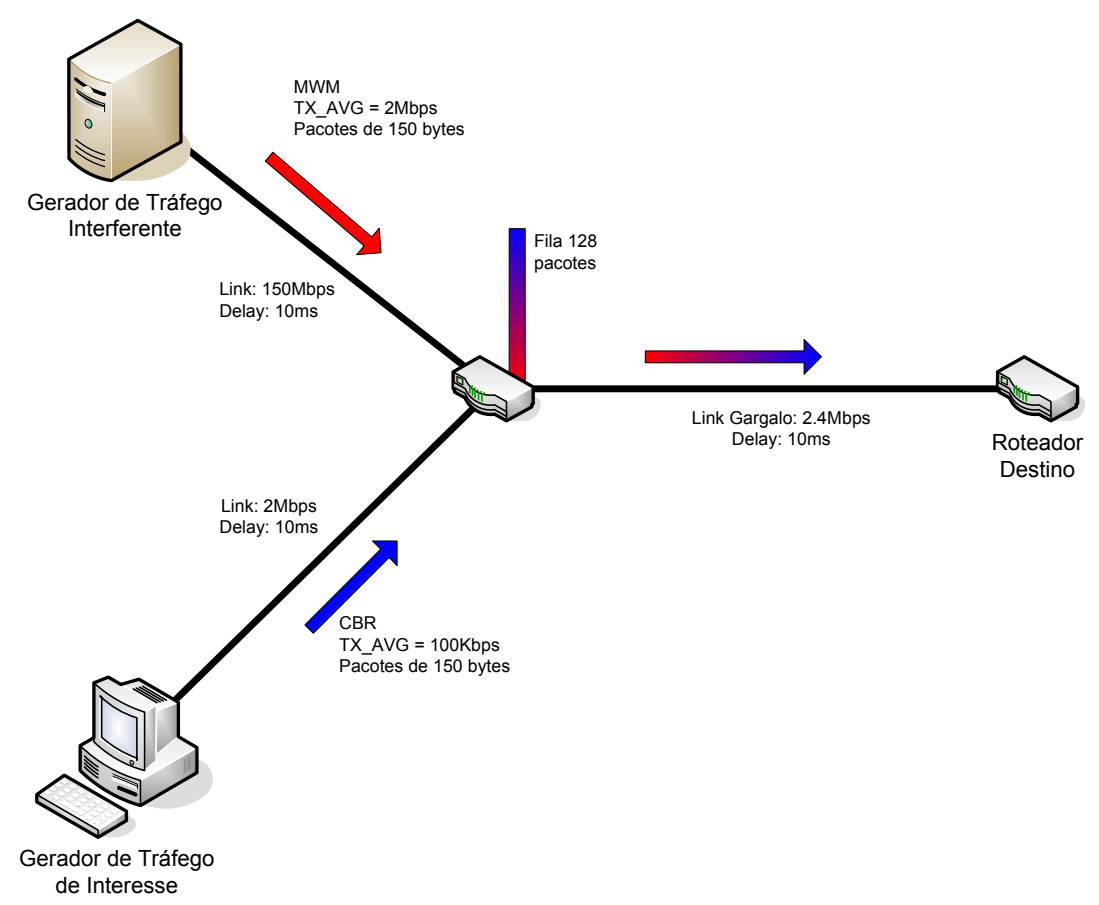

Figura 4.26: Cenário de simulação para série do modelo MWM, conversão 2 com pacotes de 150 bytes, $H=0,8$ e $T X_{a v g}=2$ Mbps.

A Tabela 4.13 apresenta os parâmetros de maior interesse utilizados nesse cenário de simulação.

Tabela 4.13: Tabela de parâmetros do cenário de simulação para série MWM utilizando conversão 2 .

\begin{tabular}{||c||c||}
\hline \hline \multicolumn{1}{||c||}{ Parâmetro } & Valor \\
\hline \hline bin série de pacotes & $1 \mathrm{~ms}$ \\
\hline \hline TX $X_{\text {avg }}$ do Tráf. Interferente & $2 \mathrm{Mbps}$ \\
\hline \hline Hurst (H) Tráf. Interferente & 0,8 \\
\hline \hline Tam. de pacotes do Tráf. Interferente & 150 bytes \\
\hline \hline Tam. da Fila & 128 pacotes \\
\hline \hline Taxa máxima do Link Gargalo & $2,4 \mathrm{Mbps}$ \\
\hline \hline Taxa Média do Tráf. de Interesse & $100 \mathrm{kbps}$ \\
\hline \hline Tam. dos pacotes do Tráf. de Interesse & 150 bytes \\
\hline \hline Tempo de simulação & 50 segundos \\
\hline \hline \multicolumn{2}{|c||}{}
\end{tabular}


A Tabela 4.14 apresenta os resultados obtidos para alguns parâmetros de QoS.

Tabela 4.14: Tabela de parâmetros de QoS para cenário com tráfego interferente baseado no modelo MWM, conversão 2.

\begin{tabular}{||c||c||}
\hline \hline \multicolumn{1}{||c||}{ Parâmetro } & Valor \\
\hline \hline Atraso médio (Tráf. de interesse) & $36,25 \mathrm{~ms}(20 \mathrm{~ms}$ prop.) \\
\hline \hline Desvio padrão amostral do atraso & $19,2 \mathrm{~ms}$ \\
\hline \hline Perc. Perda de pacotes (Tráf. interesse) & $4,1 \%$ \\
\hline \hline Comprimento médio da fila & 31,33 pacotes \\
\hline \hline Perda total na fila & 33064 pacotes \\
\hline \hline
\end{tabular}

A Figura 4.27 apresenta a série do total de pacotes (150 bytes) por bin (1 ms) para o modelo MWM com $H=0,8, T X_{\text {avg }}=2 M b p s$ e método de conversão 2.

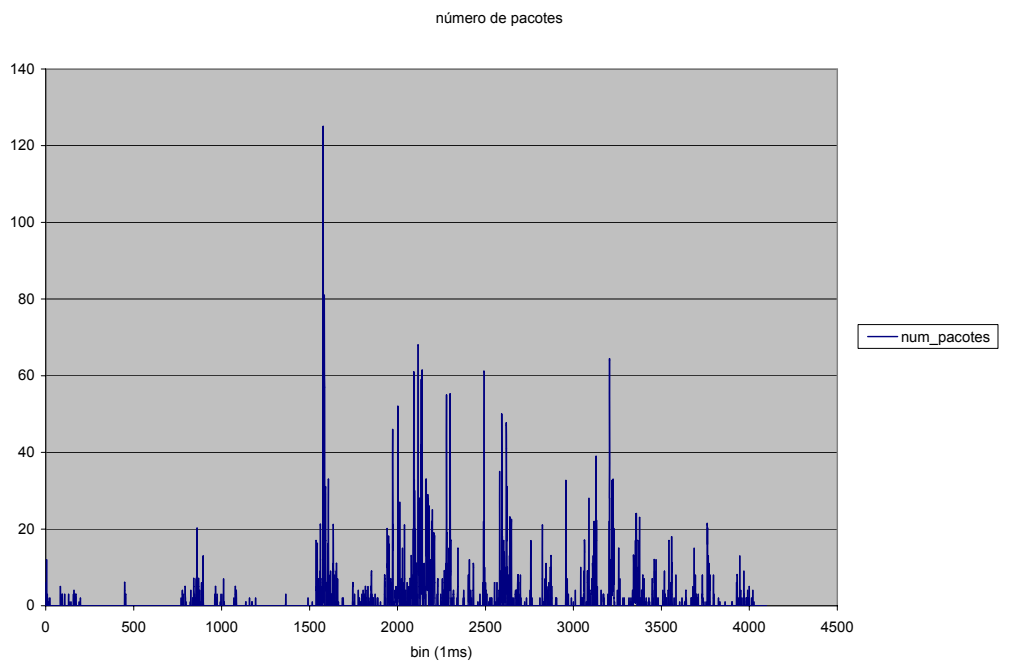

Figura 4.27: Série de pacotes/bin para o modelo MWM com $H=0,8$, $T X_{\text {avg }}=2$ Mbps e método de conversão 2 com pacotes de 150 bytes. 
Configurando o simulador para um período de amostragem de estatísticas de QoS de $100 \mathrm{~ms}$, foram gerados os gráficos em função do tempo para atraso médio do tráfego de interesse (4.28), perda de pacotes do tráfego de interesse (4.29), comprimento médio da fila (4.30), perda de pacotes do tráfego agregado na fila (4.31).

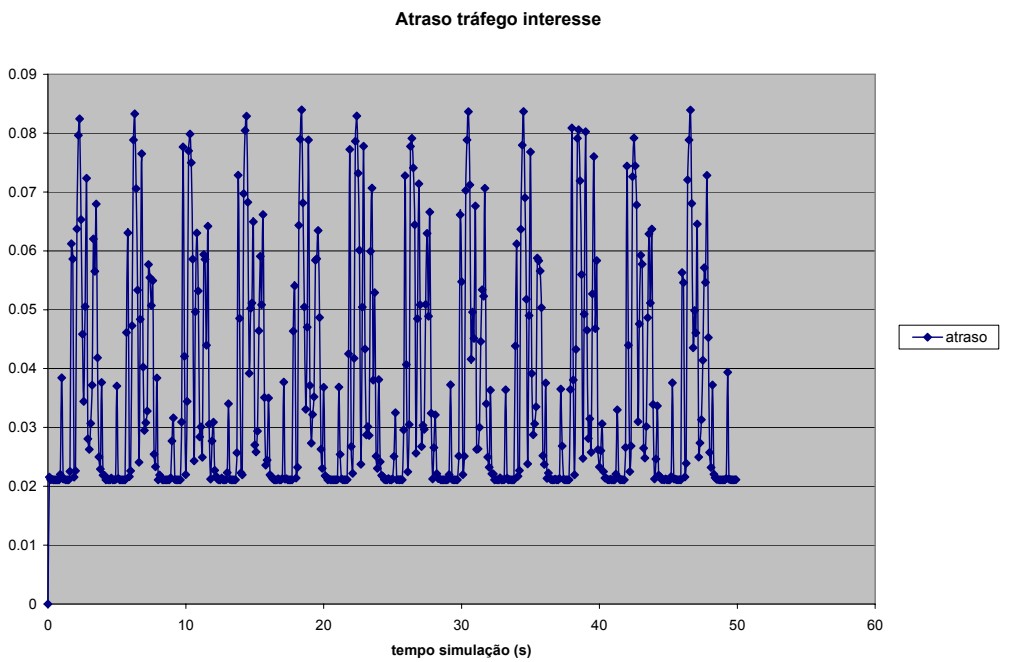

Figura 4.28: Atraso médio para o tráfego de interesse - cenário MWM conversão 2 . 


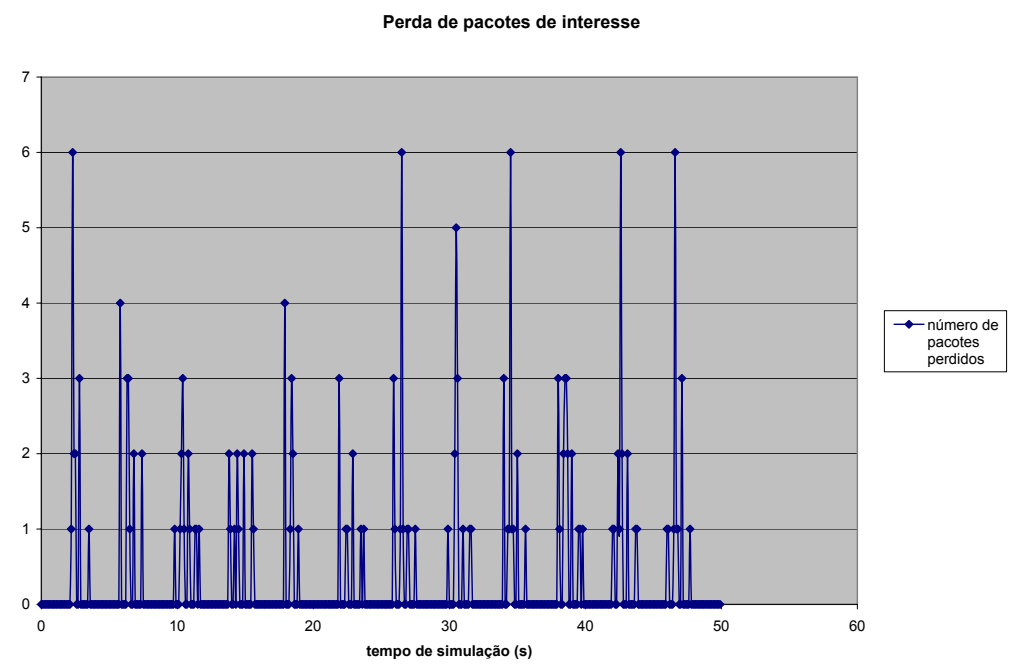

Figura 4.29: Perda de pacotes do tráfego de interesse - cenário MWM conversão 2 .

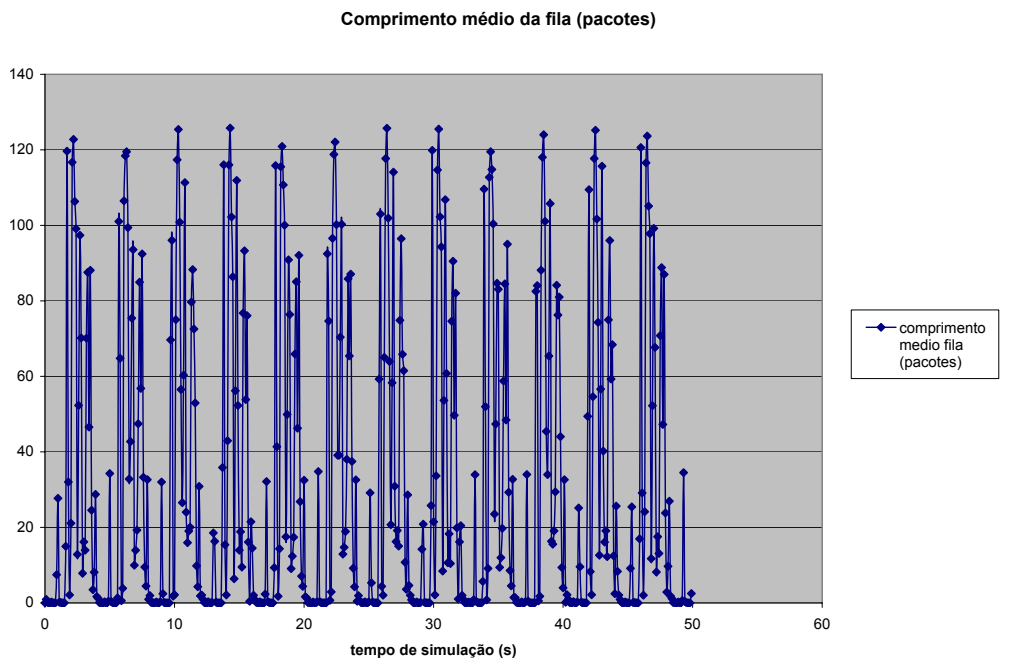

Figura 4.30: Comprimento médio da fila - cenário MWM - conversão 2. 
Perda de pacotes na fila (agregado)

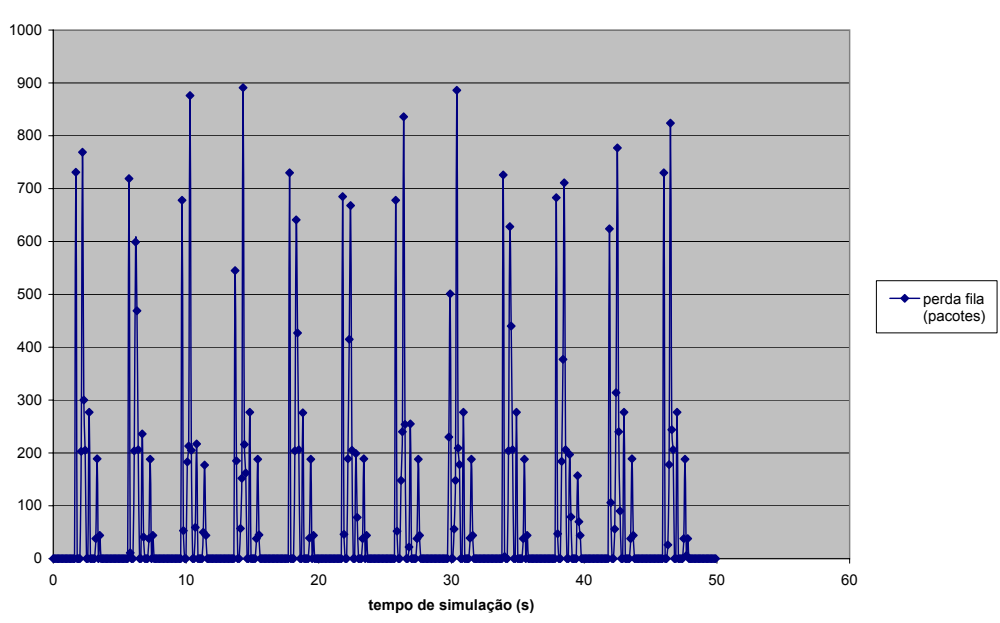

Figura 4.31: Perda de pacotes do tráfego agregado na fila - cenário MWM conversão 2 . 
Como cenário de referência elaborou-se um cenário similar, substituindo-se o tráfego interferente MWM por tráfego interferente Poisson parametrizado de modo a obter $T X_{\text {avg }}$ equivalente à utilizada com o modelo MWM. A fim de compatibilizar os parâmetros desse cenário Poisson com o cenário MWM, conversão 2, fixou-se o tamanho dos pacote do tráfego Poisson em 150 bytes.

A Figura 4.32 apresenta os parâmetros utilizados no cenário de simulação de referência, Poisson com $T X_{\text {avg }}=2$ Mbps e tamanho de pacotes de 150 bytes.

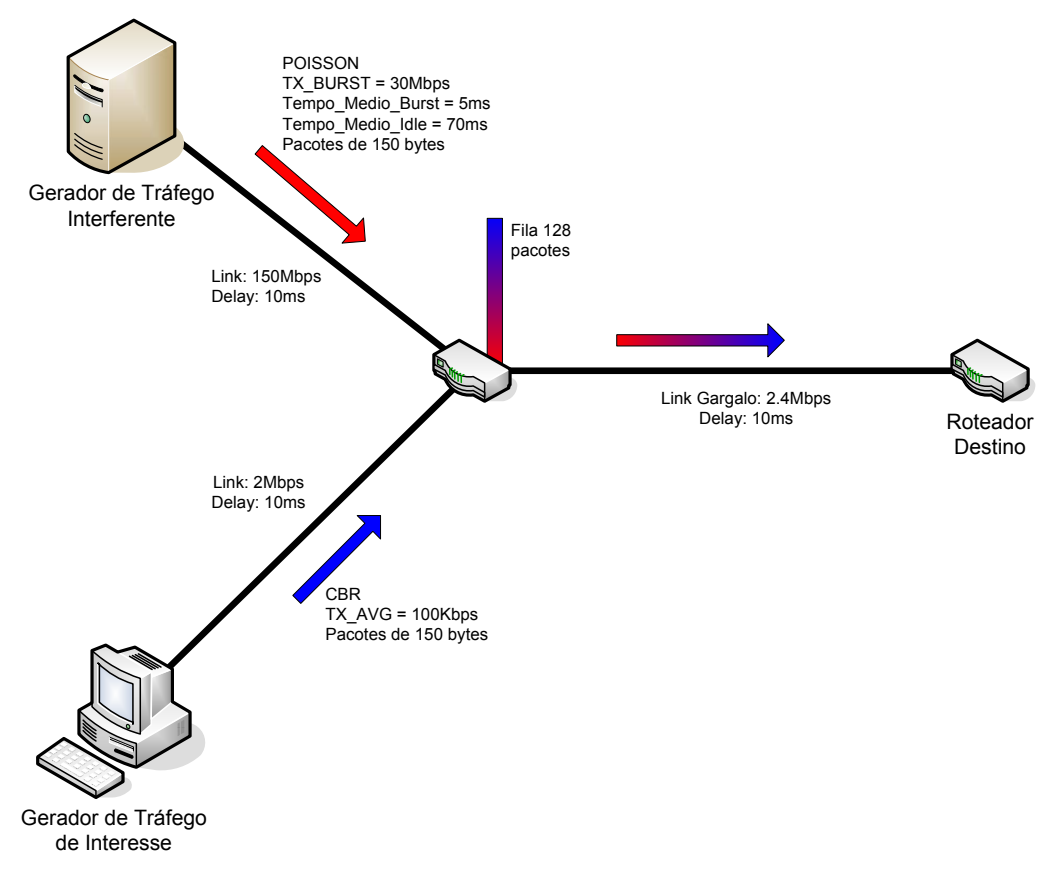

Figura 4.32: Cenário de simulação de referência, Poisson com $T X_{\text {avg }}=2$ Mbps e tamanho de pacotes 150 bytes.

A Tabela 4.15 apresenta os parâmetros de maior interesse para a criação desse cenário de referência.

A Tabela 4.16 apresenta os resultados obtidos para alguns parâmetros de QoS. 
Tabela 4.15: Tabela de parâmetros do cenário de simulação de referência, Poisson com $T X_{\text {avg }}=2 \mathrm{Mbps}$, pacotes de 150 bytes.

\begin{tabular}{||c||c||}
\hline \hline \multicolumn{1}{||c||}{ Parâmetro } & Valor \\
\hline \hline$T X_{\text {avg }}$ do Tráf. Interferente & $2 \mathrm{Mbps}$ \\
\hline \hline Taxa Transmissão em Burst & $30 \mathrm{Mbps}$ \\
\hline \hline Tempo Médio em Burst & $5 \mathrm{~ms}$ \\
\hline \hline Tempo Médio em Idle & $70 \mathrm{~ms}$ \\
\hline \hline Tam. pacotes do Tráf. Interferente & 150 bytes \\
\hline \hline Tam. da Fila & 128 pacotes \\
\hline \hline Taxa máxima do Link Gargalo & $2,4 \mathrm{Mbps}$ \\
\hline \hline Taxa Média do Tráf. de Interesse & $100 \mathrm{kbps}$ \\
\hline \hline Tam. pacotes do Tráf. de Interesse & 150 bytes \\
\hline \hline
\end{tabular}

Tabela 4.16: Tabela de parâmetros de QoS para cenário com tráfego interferente baseado no modelo Poisson, 2 Mbps, 150 bytes.

\begin{tabular}{||c||c||}
\hline \hline Parâmetro & Valor \\
\hline \hline Atraso médio (Tráf. interesse) & $36,28 \mathrm{~ms}(20 \mathrm{~ms}$ prop.) \\
\hline \hline Desvio padrão amostral do atraso & $14,4 \mathrm{~ms}$ \\
\hline \hline Perc. Perda de pacotes (Tráf. interesse) & $2,9 \%$ \\
\hline \hline Comprimento médio da fila & 32,93 pacotes \\
\hline \hline Perda total na fila & 33665 pacotes \\
\hline \hline
\end{tabular}


Configurando o simulador para um período de amostragem de estatísticas de QoS de $100 \mathrm{~ms}$, foram gerados os gráficos em função do tempo para atraso médio do tráfego de interesse (4.33), perda de pacotes do tráfego de interesse (4.34), comprimento médio da fila (4.35), perda de pacotes do tráfego agregado na fila (4.36).

Atraso tráfego interesse

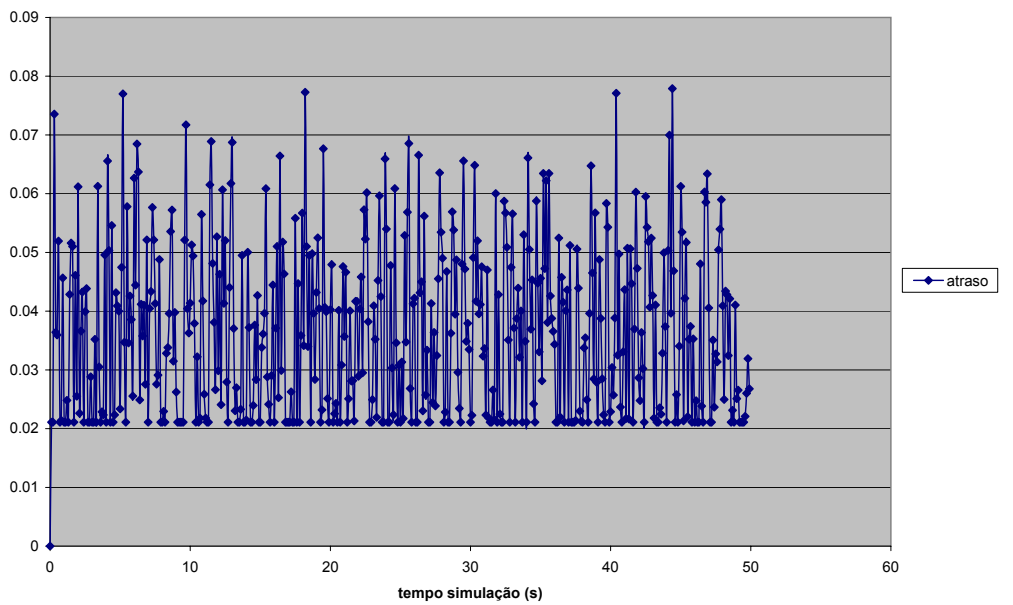

Figura 4.33: Atraso médio para o tráfego de interesse - cenário Poisson 2 Mbps com pacotes de 150 bytes. 


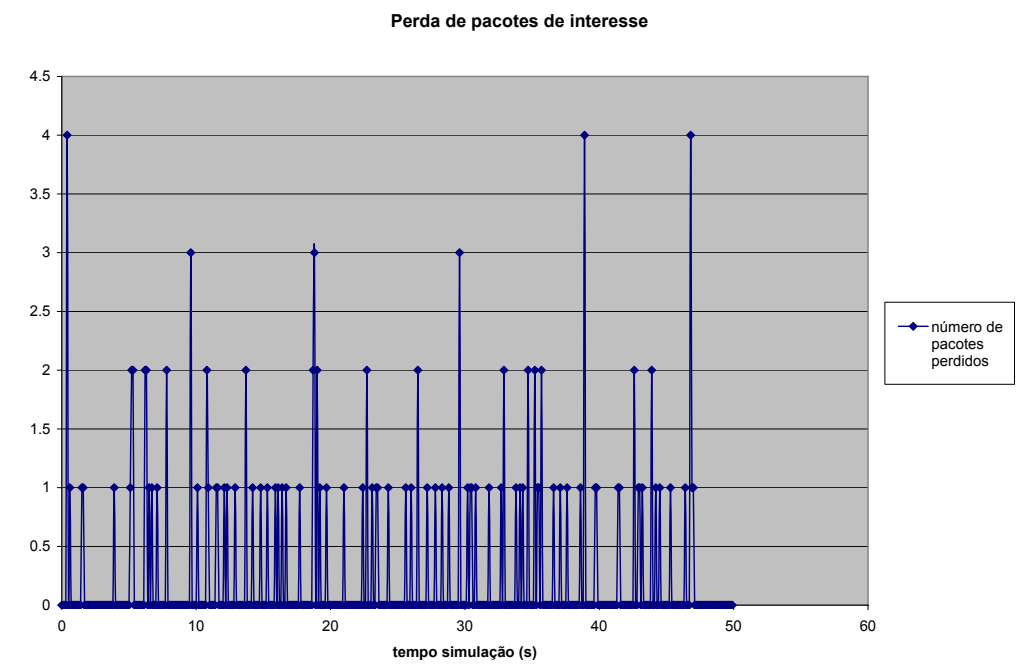

Figura 4.34: Perda de pacotes do tráfego de interesse - cenário Poisson 2 Mbps com pacotes de 150 bytes.

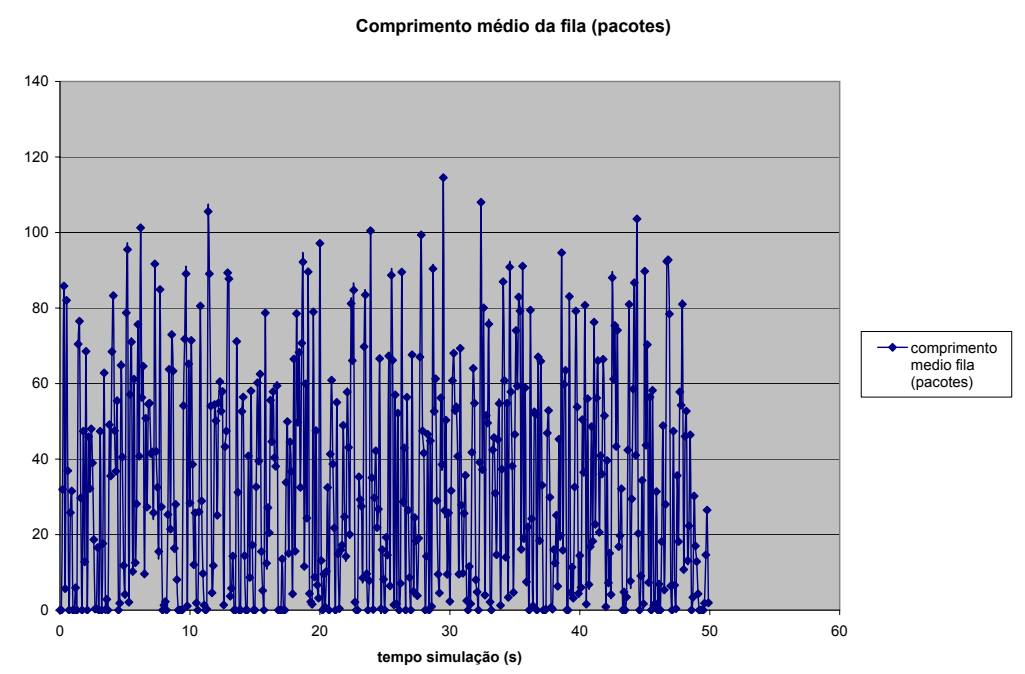

Figura 4.35: Comprimento médio da fila - cenário Poisson - 2 Mbps com pacotes de 150 bytes. 
Perda de pacotes na fila (agregado)

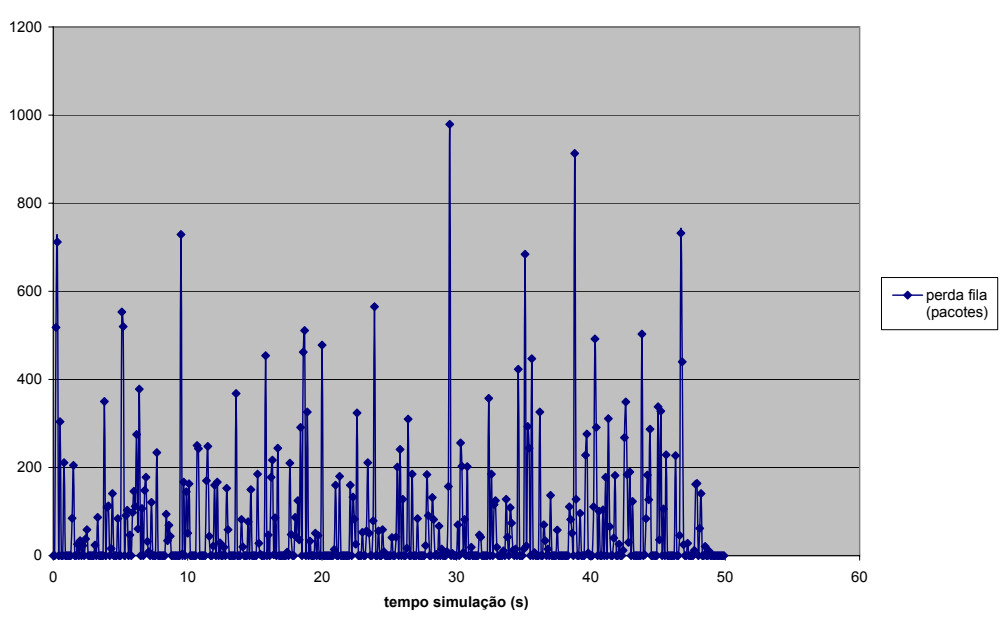

Figura 4.36: Perda de pacotes do tráfego agregado na fila - cenário Poisson 2 Mbps com pacotes de 150 bytes. 


\subsection{4 fGN conversão 1}

A Figura 4.37 apresenta os parâmetros do cenário de simulação em que se utilizou a série do modelo fGN com $H=0,8$ e $T X_{\text {avg }}=50 \mathrm{Mbps}$.

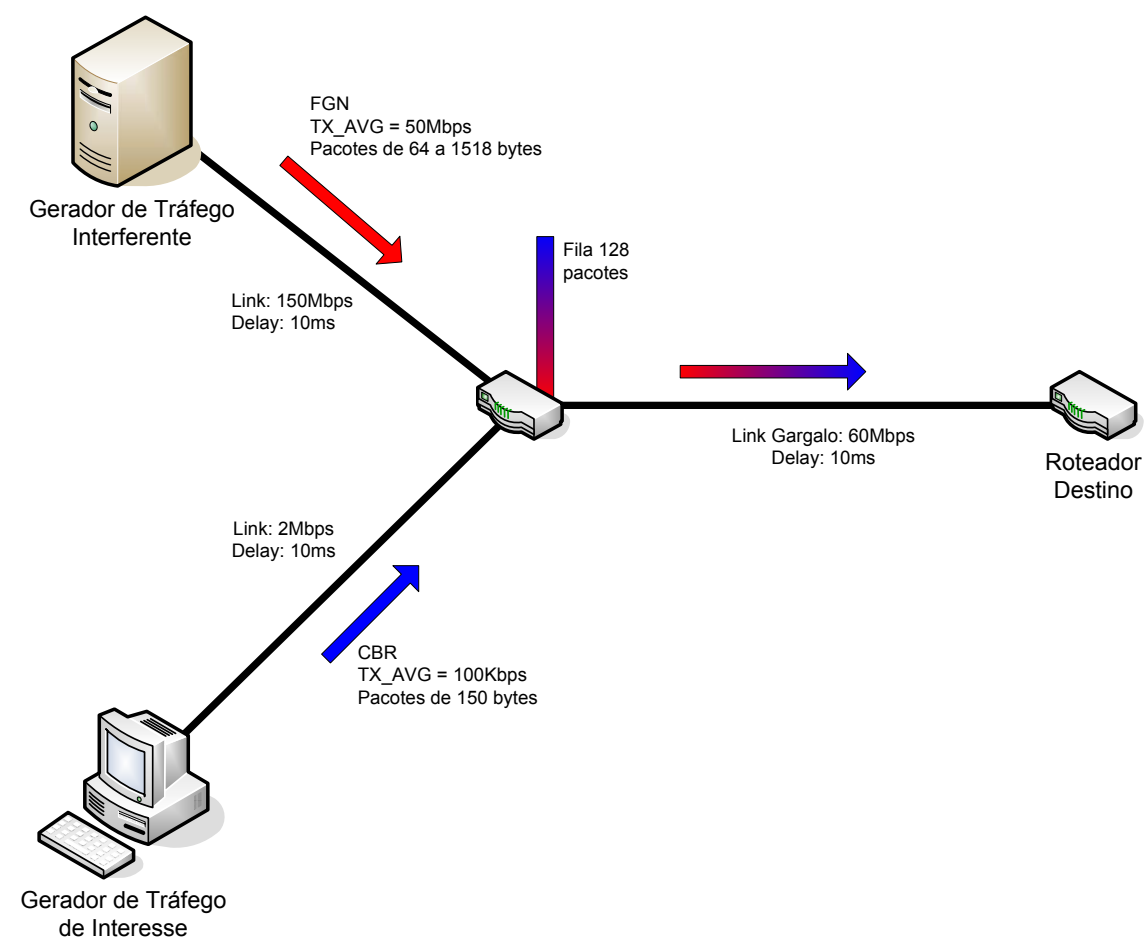

Figura 4.37: Cenário de simulação para série do modelo fGN, conversão 1 , com $H=0,8$ e $T X_{a v g}=50$ Mbps.

A Tabela 4.17 apresenta os parâmetros de maior interesse utilizados nesse cenário de simulação.

Tabela 4.17: Tabela de parâmetros do cenário de simulação para série fGN utilizando conversão 1 .

\begin{tabular}{||c||c||}
\hline \hline \multicolumn{1}{||c||}{ Parâmetro } & Valor \\
\hline \hline bin série de pacotes & $10 \mathrm{~ms}$ \\
\hline \hline TX $X_{\text {avg }}$ do Tráf. Interferente & $50 \mathrm{Mbps}$ \\
\hline \hline Hurst $(\mathrm{H})$ Tráf. Interferente & 0,8 \\
\hline \hline Tam. de pacotes do Tráf. Interferente & 64 a 1518 bytes \\
\hline \hline Tam. da Fila & 128 pacotes \\
\hline \hline Taxa máxima do Link Gargalo & $60 \mathrm{Mbps}$ \\
\hline \hline Taxa Média do Tráf. de Interesse & $100 \mathrm{kbps}$ \\
\hline \hline Tam. dos pacotes do Tráf. de Interesse & 150 bytes \\
\hline \hline Tempo de simulação & 50 segundos \\
\hline \hline
\end{tabular}

A Tabela 4.18 apresenta os resultados obtidos para alguns parâmetros de 
QoS.

Tabela 4.18: Tabela de parâmetros de QoS para cenário com tráfego interferente baseado no modelo fGN, conversão 1 .

\begin{tabular}{||c||c||}
\hline \hline \multicolumn{1}{||c||}{ Parâmetro } & Valor \\
\hline \hline Atraso médio (Tráf. interesse) & $28,65 \mathrm{~ms}(20 \mathrm{~ms}$ prop.) \\
\hline \hline Desvio padrão amostral do atraso & $6,9 \mathrm{~ms}$ \\
\hline \hline Perc. Perda de pacotes (Tráf. interesse) & $2,5 \%$ \\
\hline \hline Comprimento médio da fila & 41,10 pacotes \\
\hline \hline Perda total na fila & 10804 pacotes \\
\hline \hline
\end{tabular}

A Figura 4.38 apresenta a série do total de bytes por bin $(10 \mathrm{~ms})$ para o modelo fGN com $H=0,8$ e $T X_{\text {avg }}=50 \mathrm{Mbps}$.

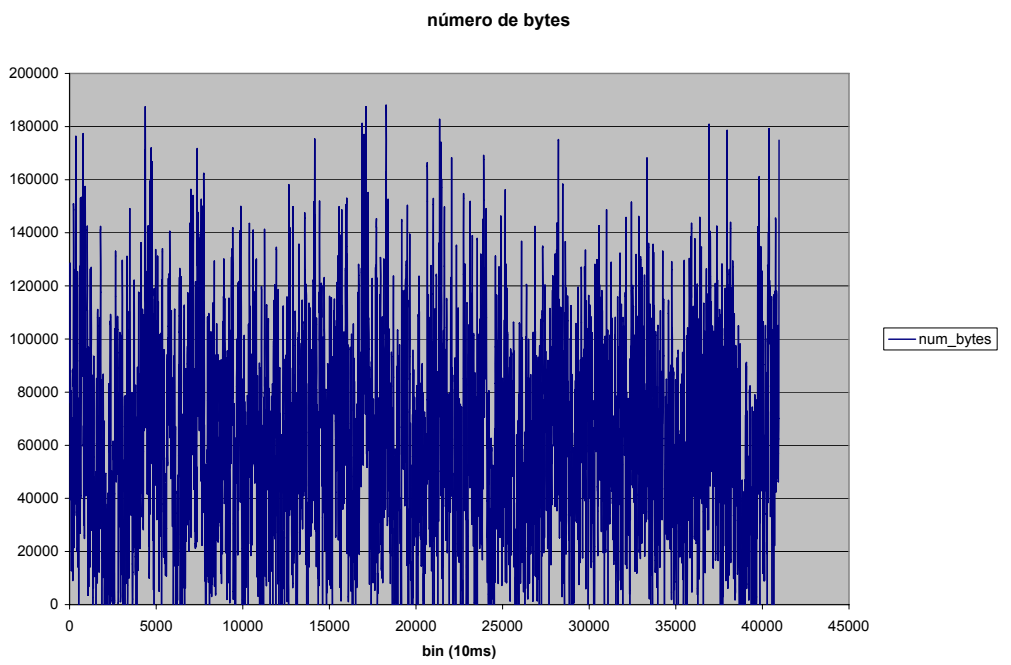

Figura 4.38: Série de bytes/bin para o modelo fGN com $H=0,8$ e

$$
T X_{\text {avg }}=50 \text { Mbps. }
$$


Configurando o simulador para um período de amostragem de estatísticas de QoS de $100 \mathrm{~ms}$, foram gerados os gráficos em função do tempo para atraso médio do tráfego de interesse (4.39), perda de pacotes do tráfego de interesse (4.40), comprimento médio da fila (4.41), perda de pacotes do tráfego agregado na fila (4.42).

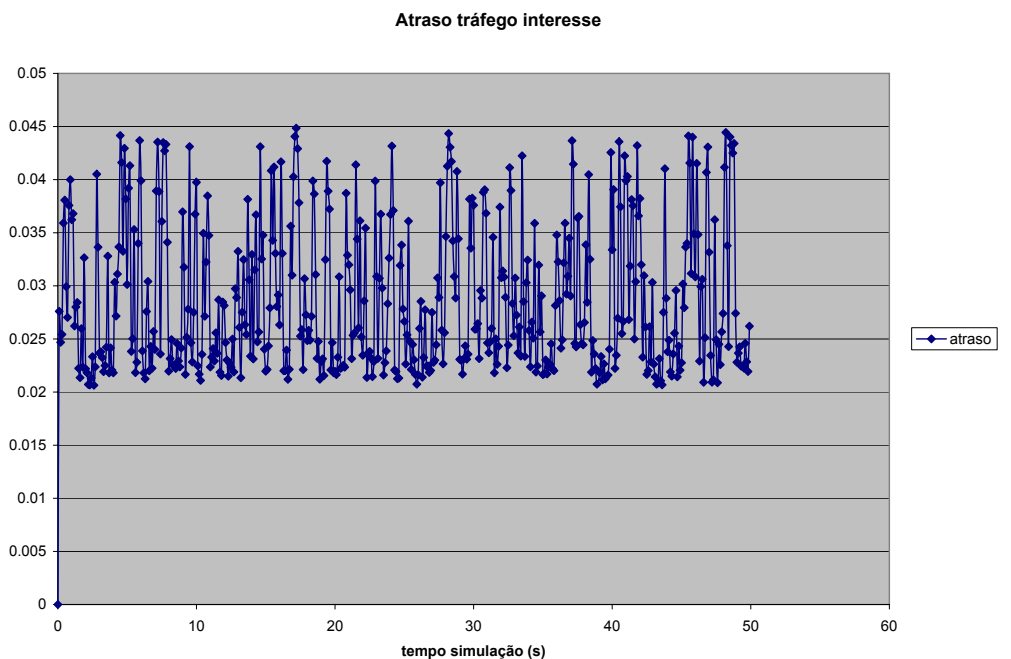

Figura 4.39: Atraso médio para o tráfego de interesse - cenário fGN conversão 1. 


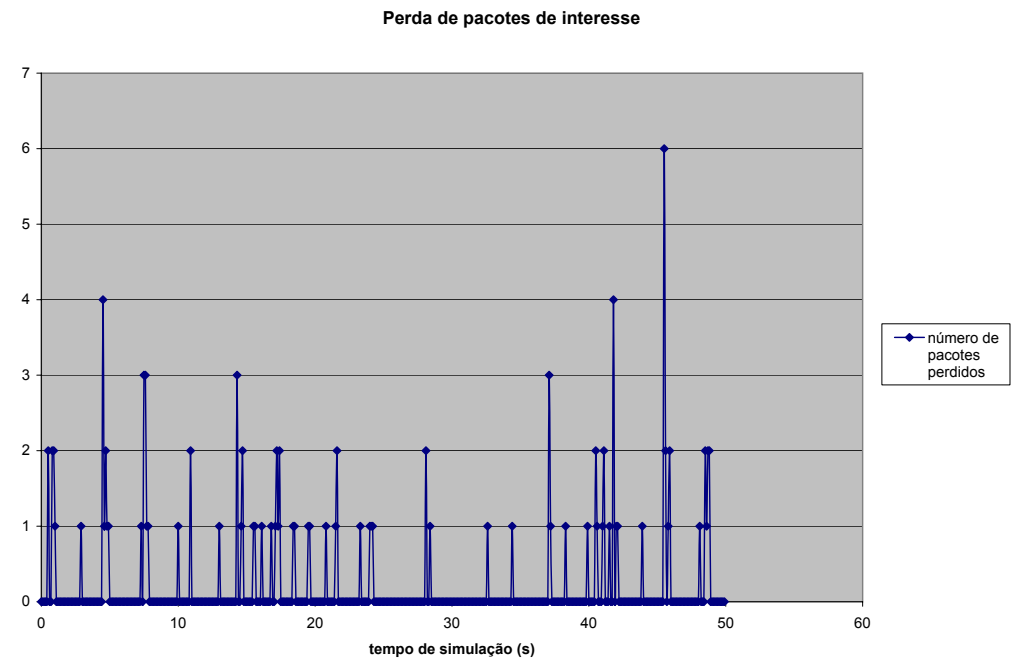

Figura 4.40: Perda de pacotes do tráfego de interesse - cenário fGN conversão 1.

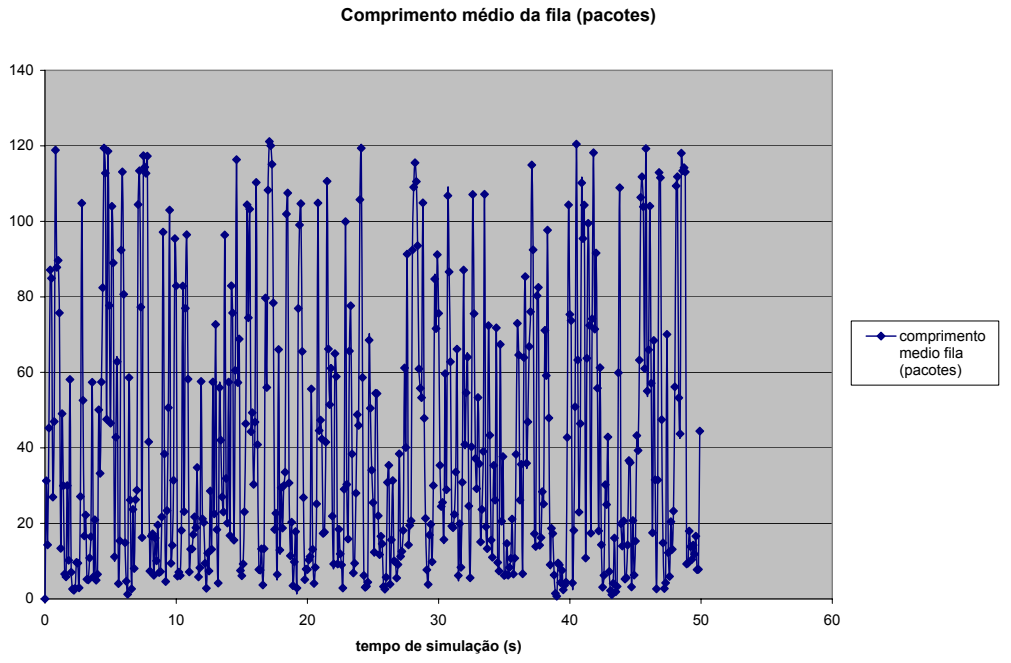

Figura 4.41: Comprimento médio da fila - cenário fGN - conversão 1. 
Perda de pacotes na fila (agregado)

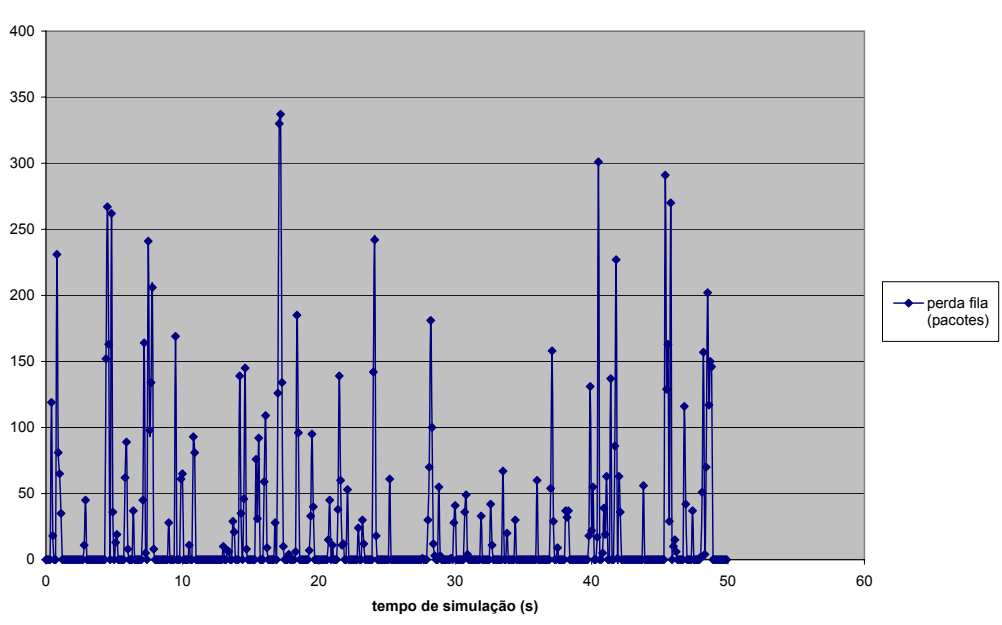

Figura 4.42: Perda de pacotes do tráfego agregado na fila - cenário fGN conversão 1 . 
Como cenário de referência elaborou-se um cenário similar, substituindo-se o tráfego interferente fGN por tráfego interferente Poisson, parametrizado de modo a obter $T X_{\text {avg }}$ equivalente à utilizada com o modelo fGN.

A Figura 4.43 apresenta os parâmetros utilizados no cenário de simulação de referência, Poisson com $T X_{a v g}=50$ Mbps e tamanho de pacotes de 1518 bytes.

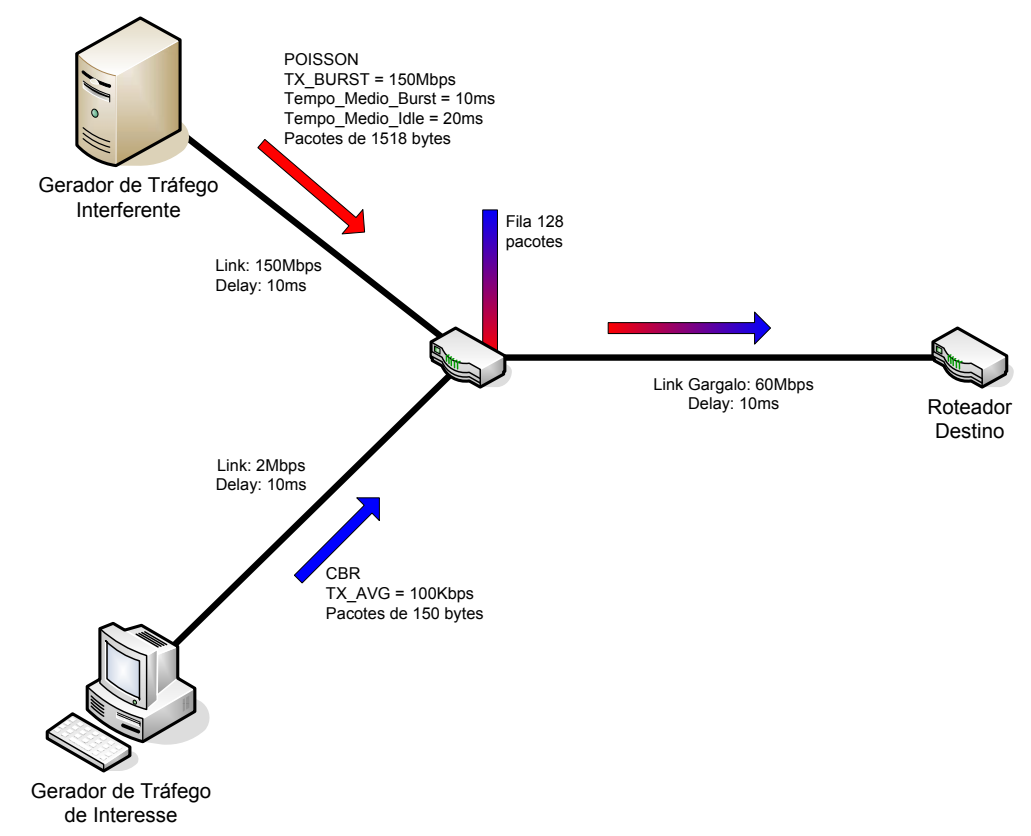

Figura 4.43: Cenário de simulação de referência, Poisson com $T X_{\text {avg }}=50 \mathrm{Mbps}$ e tamanho de pacotes 1518 bytes.

A Tabela 4.19 apresenta os parâmetros de maior interesse para a criação desse cenário de referência.

Tabela 4.19: Tabela de parâmetros do cenário de simulação de referência, Poisson com $T X_{\text {avg }}=50 \mathrm{Mbps}$, pacotes de 1518 bytes.

\begin{tabular}{||c||c||}
\hline \hline \multicolumn{1}{||c||}{ Parâmetro } & Valor \\
\hline \hline$T X_{\text {avg }}$ do Tráf. Interferente & $50 \mathrm{Mbps}$ \\
\hline \hline Taxa Transmissão em Burst & $150 \mathrm{Mbps}$ \\
\hline \hline Tempo Médio em Burst & $10 \mathrm{~ms}$ \\
\hline \hline Tempo Médio em Idle & $20 \mathrm{~ms}$ \\
\hline \hline Tam. pacotes do Tráf. Interferente & 1518 bytes \\
\hline \hline Tam. da Fila & 128 pacotes \\
\hline \hline Taxa máxima do Link Gargalo & $60 \mathrm{Mbps}$ \\
\hline \hline Taxa Média do Tráf. de Interesse & $100 \mathrm{kbps}$ \\
\hline \hline
\end{tabular}

A Tabela 4.20 apresenta os resultados obtidos para alguns parâmetros de 
QoS.

Tabela 4.20: Tabela de parâmetros de QoS para cenário com tráfego interferente baseado no modelo Poisson, $50 \mathrm{Mbps}, 1518$ bytes.

\begin{tabular}{||c||c||}
\hline \hline \multicolumn{1}{||c||}{ Parâmetro } & Valor \\
\hline \hline Atraso médio (Tráf. interesse) & $28,59 \mathrm{~ms}(20 \mathrm{~ms}$ prop.) \\
\hline \hline Desvio padrão amostral do atraso & $5,0 \mathrm{~ms}$ \\
\hline \hline Perc. Perda de pacotes (Tráf. interesse) & $8,7 \%$ \\
\hline \hline Comprimento médio da fila & 45,44 pacotes \\
\hline \hline Perda total na fila & 39104 pacotes \\
\hline \hline
\end{tabular}

Configurando o simulador para um período de amostragem de estatísticas de QoS de $100 \mathrm{~ms}$, foram gerados os gráficos em função do tempo para atraso médio do tráfego de interesse (4.44), perda de pacotes do tráfego de interesse (4.45), comprimento médio da fila (4.46), perda de pacotes do tráfego agregado na fila (4.47).

Atraso tráfego interesse

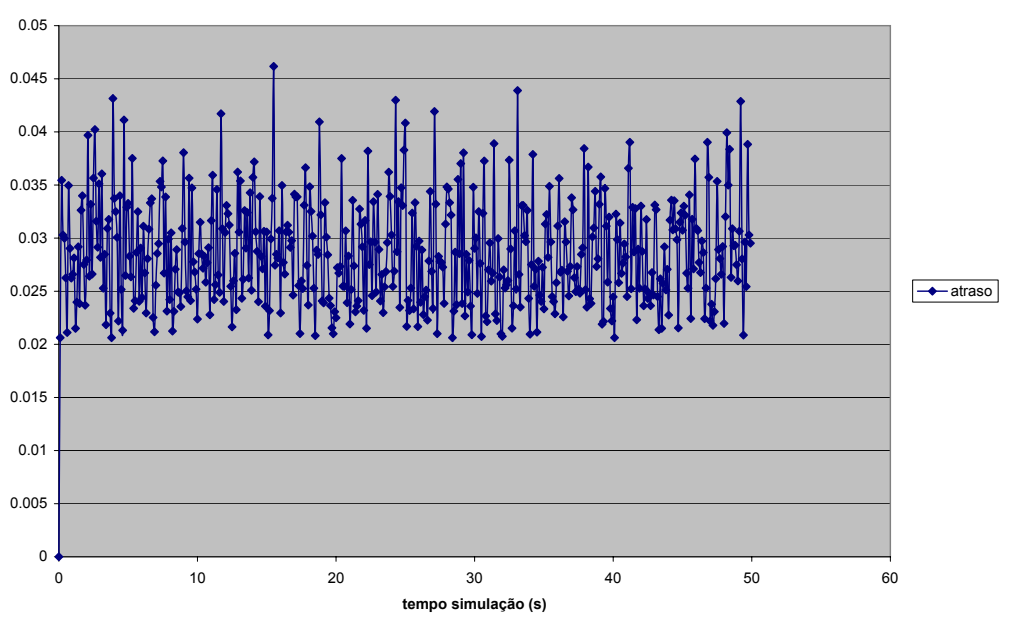

Figura 4.44: Atraso médio para o tráfego de interesse - cenário Poisson 50 Mbps com pacotes de 1518 bytes. 


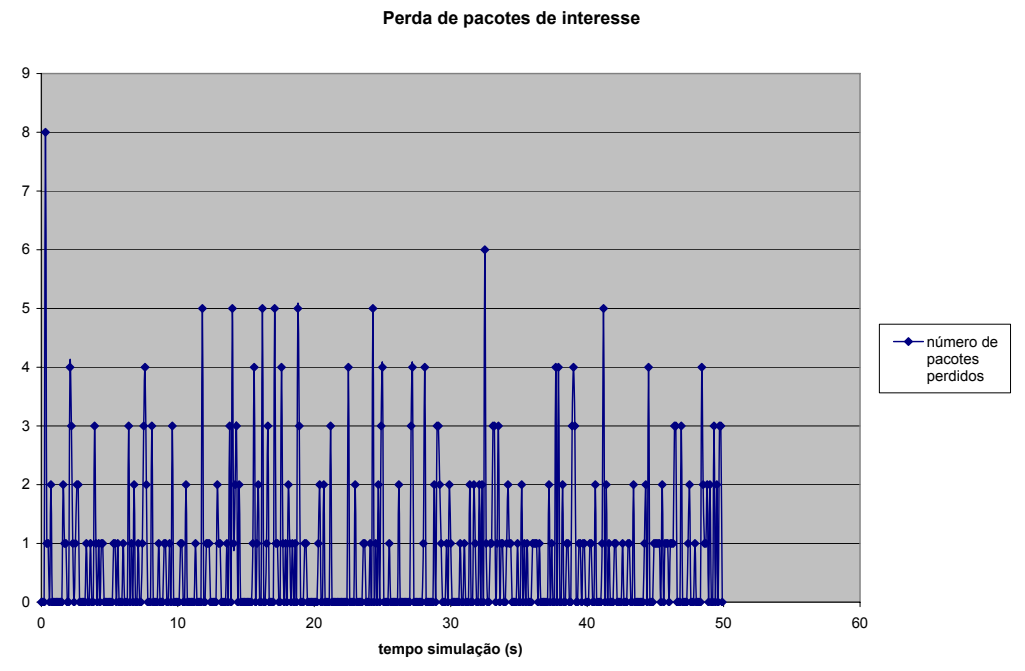

Figura 4.45: Perda de pacotes do tráfego de interesse - cenário Poisson 50 Mbps com pacotes de 1518 bytes.

Comprimento médio da fila (pacotes)

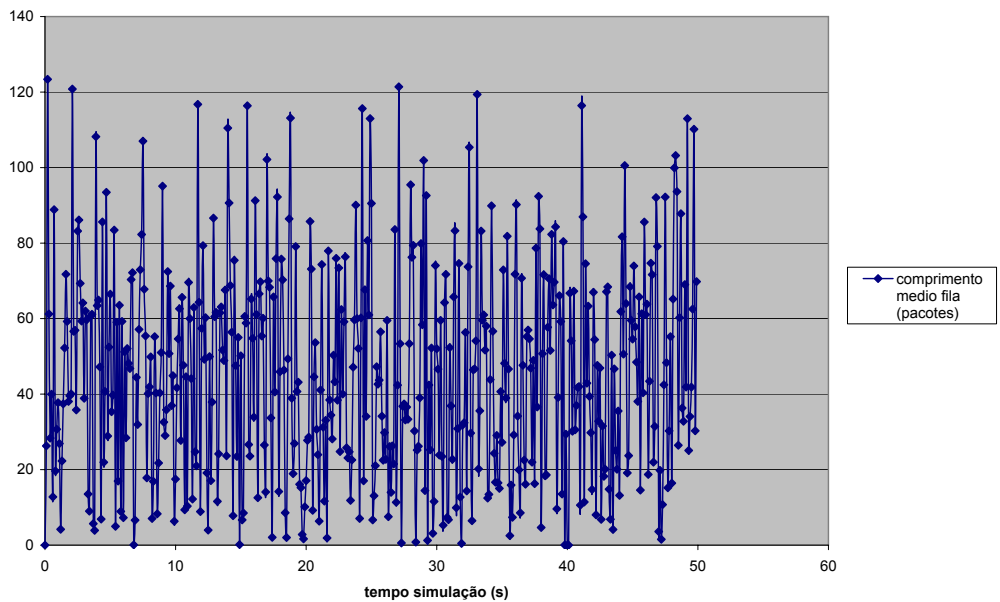

Figura 4.46: Comprimento médio da fila - cenário Poisson - 50 Mbps com pacotes de 1518 bytes. 
Perda de pacotes na fila (agregado)

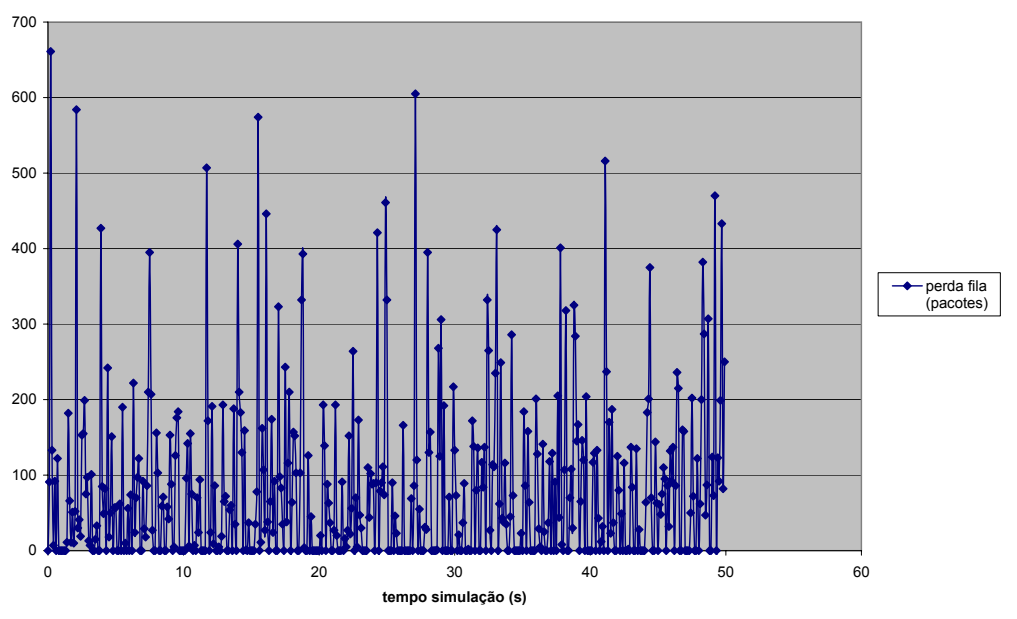

Figura 4.47: Perda de pacotes do tráfego agregado na fila - cenário Poisson 50 Mbps com pacotes de 1518 bytes. 


\subsection{5 fGN conversão 2}

A Figura 4.48 apresenta os parâmetros do cenário de simulação em que se utilizou a série do modelo fGN com $H=0,8, T X_{\text {avg }}=50$ Mbps e método de conversão 2 com pacotes de 150 bytes.

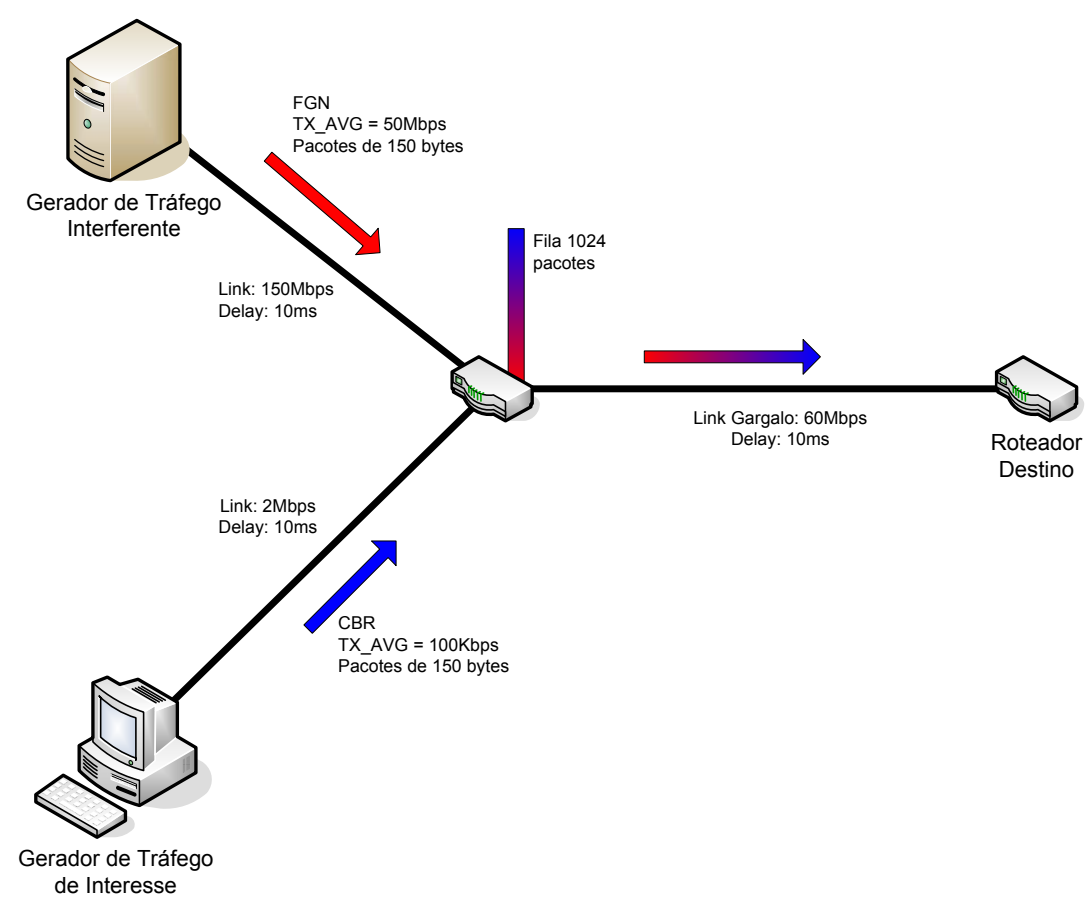

Figura 4.48: Cenário de simulação para série do modelo fGN, conversão $2 \mathrm{com}$ pacotes de 150 bytes, $H=0,8$ e $T X_{a v g}=50 \mathrm{Mbps}$.

A Tabela 4.21 apresenta os parâmetros de maior interesse utilizados nesse cenário de simulação.

Tabela 4.21: Tabela de parâmetros do cenário de simulação para série fGN utilizando conversão 2 .

\begin{tabular}{||c||c||}
\hline \hline \multicolumn{1}{|c||}{ Parâmetro } & Valor \\
\hline \hline bin série de pacotes & $10 \mathrm{~ms}$ \\
\hline \hline$T X_{\text {avg }}$ do Tráf. Interferente & $50 \mathrm{Mbps}$ \\
\hline \hline Hurst $(\mathrm{H})$ Tráf. Interferente & 0,8 \\
\hline \hline Tam. de pacotes do Tráf. Interferente & 150 bytes \\
\hline \hline Tam. da Fila & 1024 pacotes \\
\hline \hline Taxa máxima do Link Gargalo & $60 \mathrm{Mbps}$ \\
\hline \hline Taxa Média do Tráf. de Interesse & $100 \mathrm{kbps}$ \\
\hline \hline Tam. dos pacotes do Tráf. de Interesse & 150 bytes \\
\hline \hline Tempo de simulação & 50 segundos \\
\hline \hline
\end{tabular}


A Tabela 4.22 apresenta os resultados obtidos para alguns parâmetros de QoS.

Tabela 4.22: Tabela de parâmetros de QoS para cenário com tráfego interferente baseado no modelo fGN, conversão 2 .

\begin{tabular}{||c||c||}
\hline \hline \multicolumn{1}{||c||}{ Parâmetro } & Valor \\
\hline \hline Atraso médio (Tráf. interesse) & $26,12 \mathrm{~ms}(20 \mathrm{~ms}$ prop.) \\
\hline \hline Desvio padrão amostral do atraso & $6,0 \mathrm{~ms}$ \\
\hline \hline Perc. Perda de pacotes (Tráf. interesse) & $4,6 \%$ \\
\hline \hline Comprimento médio da fila & 285,13 pacotes \\
\hline \hline Perda total na fila & 87976 pacotes \\
\hline \hline
\end{tabular}

A Figura 4.49 apresenta a série do total de pacotes (150 bytes) por bin (10 ms) para o modelo fGN com $H=0,8, T X_{a v g}=50$ Mbps e método de conversão 2.

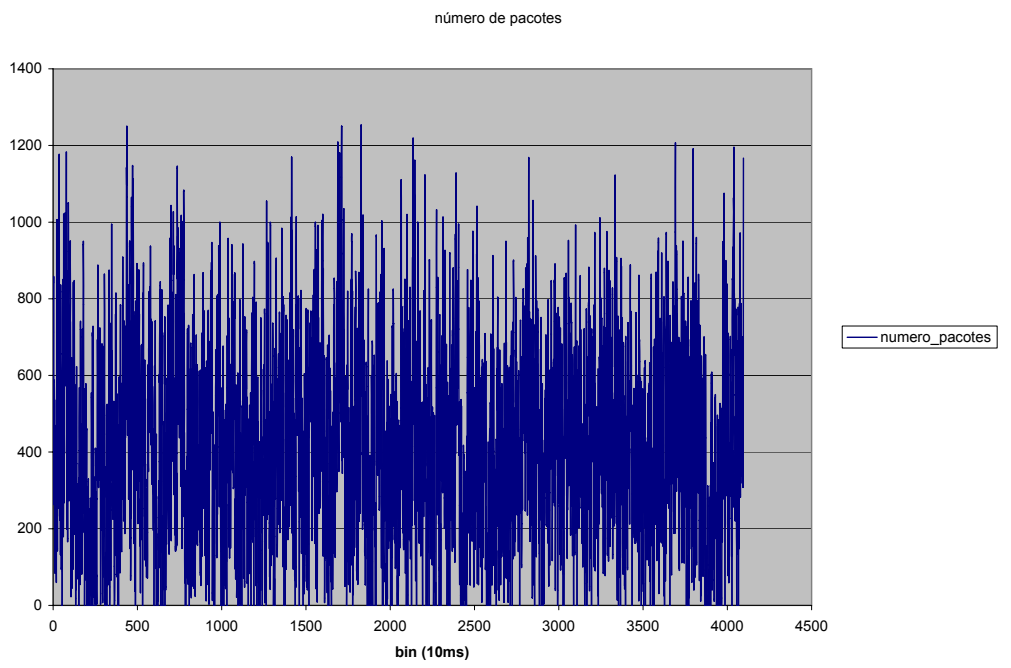

Figura 4.49: Série de pacotes/bin para o modelo fGN com $H=0,8$, $T X_{\text {avg }}=50$ Mbps e método de conversão 2 com pacotes de 150 bytes. 
Configurando o simulador para um período de amostragem de estatísticas de QoS de 100 ms, foram gerados os gráficos em função do tempo para atraso médio do tráfego de interesse (4.50), perda de pacotes do tráfego de interesse (4.51), comprimento médio da fila (4.52), perda de pacotes do tráfego agregado na fila (4.53).

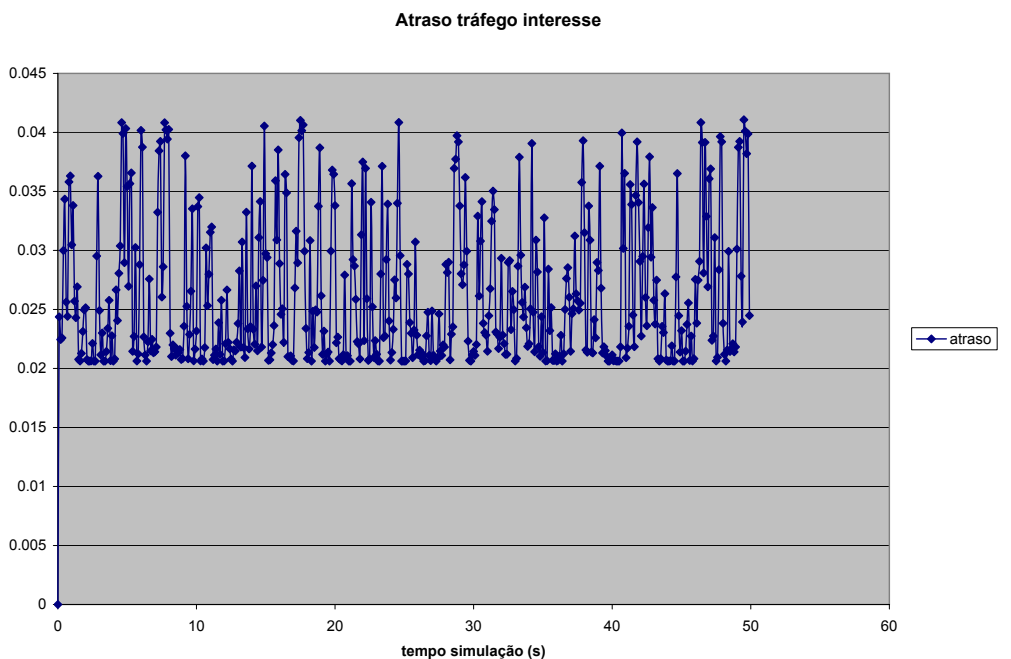

Figura 4.50: Atraso médio para o tráfego de interesse - cenário fGN conversão 2 . 


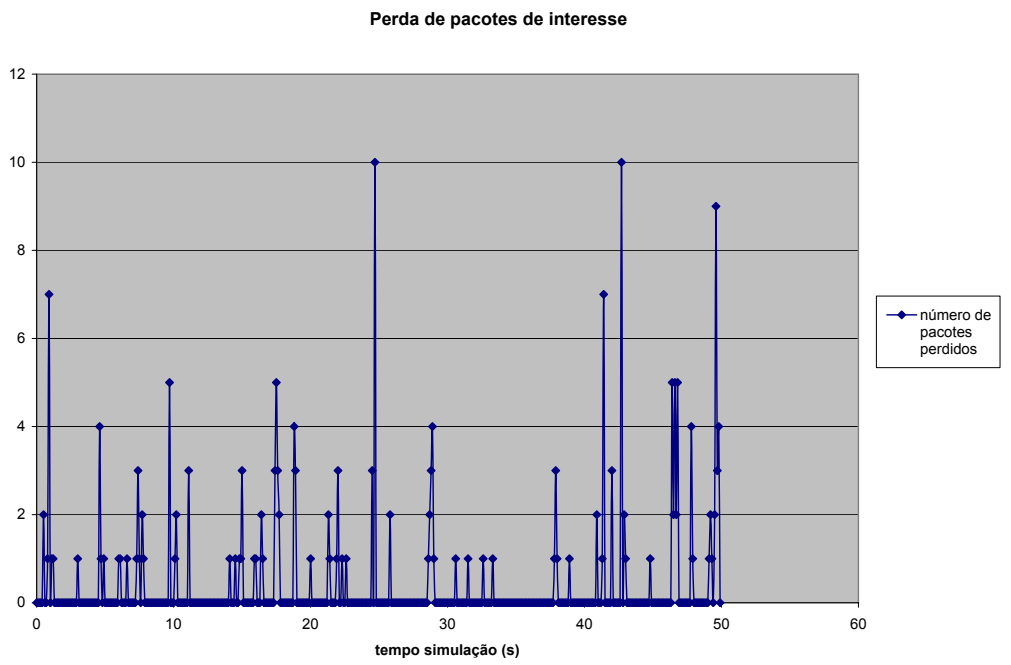

Figura 4.51: Perda de pacotes do tráfego de interesse - cenário fGN conversão 2 .

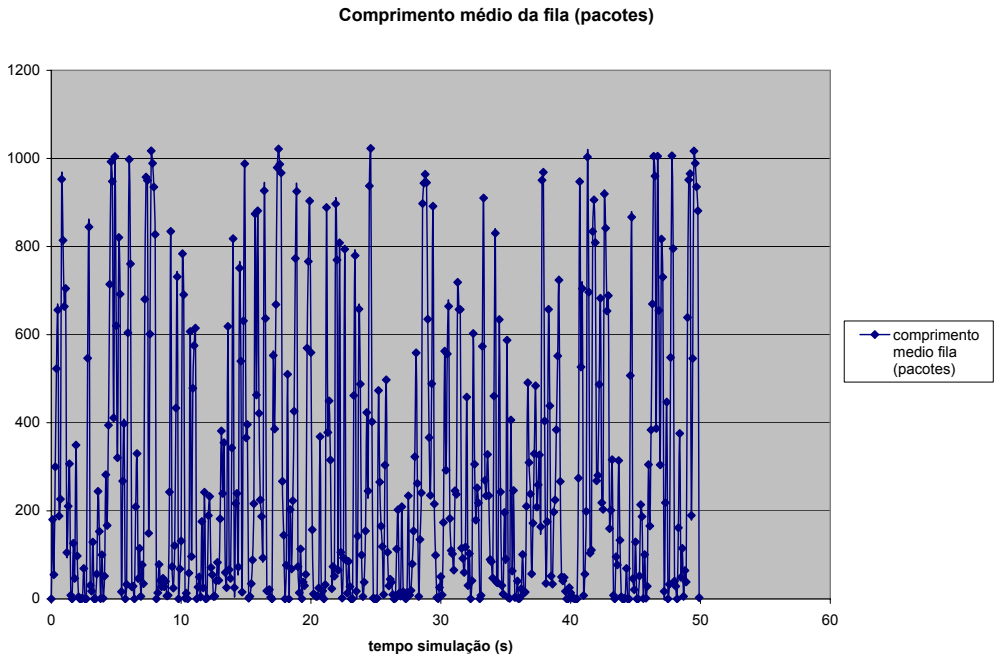

Figura 4.52: Comprimento médio da fila - cenário fGN - conversão 2. 
Perda de pacotes na fila (agregado)

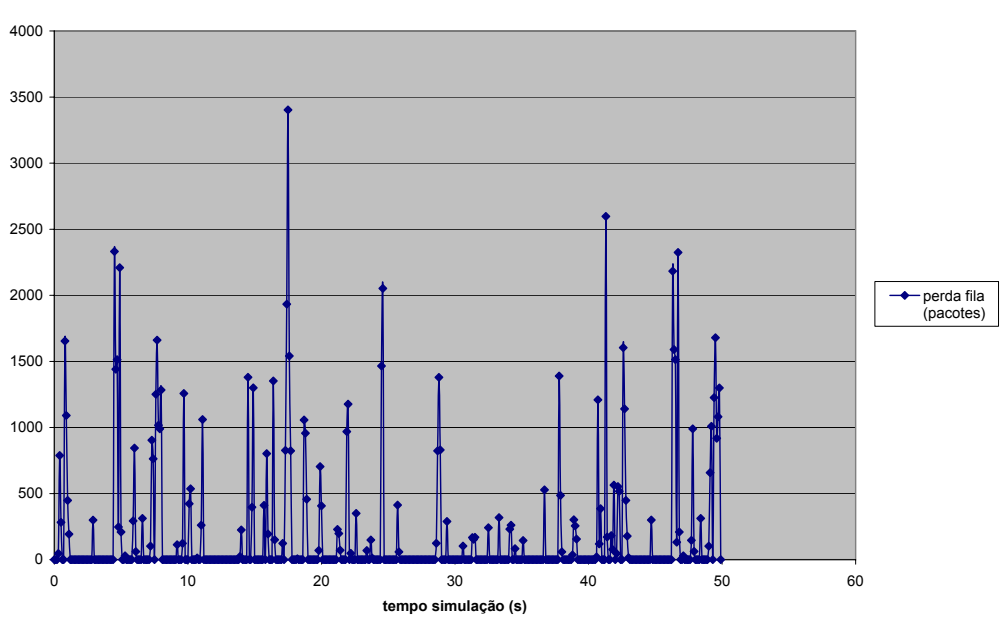

Figura 4.53: Perda de pacotes do tráfego agregado na fila - cenário fGN conversão 2 . 
Como cenário de referência elaborou-se um cenário similar, substituindo-se o tráfego interferente fGN por tráfego interferente Poisson, parametrizado de modo a obter $T X_{\text {avg }}$ equivalente à utilizada com o modelo fGN. Para compatibilizar os parâmetros deste cenário Poisson com o cenário fGN, conversão 2, fixou-se o tamanho dos pacote do tráfego Poisson em 150 bytes.

A Figura 4.54 apresenta os parâmetros utilizados no cenário de simulação de referência, Poisson com $T X_{\text {avg }}=50$ Mbps e tamanho de pacotes de 150 bytes.

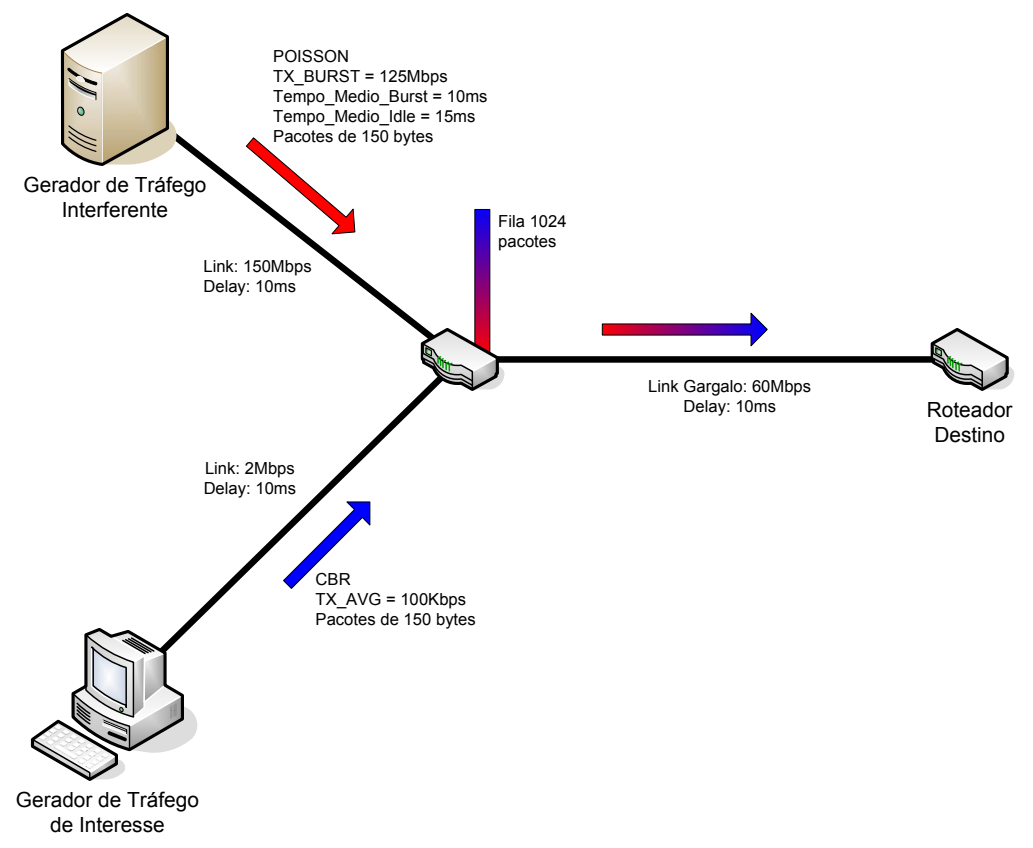

Figura 4.54: Cenário de simulação de referência, Poisson com $T X_{\text {avg }}=50$ Mbps e tamanho de pacotes 150 bytes.

A Tabela 4.23 apresenta os parâmetros de maior interesse para a criação desse cenário de referência.

A Tabela 4.24 apresenta os resultados obtidos para alguns parâmetros de QoS. 
Tabela 4.23: Tabela de parâmetros do cenário de simulação de referência, Poisson com $T X_{\text {avg }}=50 \mathrm{Mbps}$, pacotes de 150 bytes.

\begin{tabular}{||c||c||}
\hline \hline \multicolumn{1}{||c||}{ Parâmetro } & Valor \\
\hline \hline$T X_{\text {avg }}$ do Tráf. Interferente & $50 \mathrm{Mbps}$ \\
\hline \hline Taxa Transmissão em Burst & $125 \mathrm{Mbps}$ \\
\hline \hline Tempo Médio em Burst & $10 \mathrm{~ms}$ \\
\hline \hline Tempo Médio em Idle & $15 \mathrm{~ms}$ \\
\hline \hline Tam. pacotes do Tráf. Interferente & 150 bytes \\
\hline \hline Tam. da Fila & 1024 pacotes \\
\hline \hline Taxa máxima do Link Gargalo & $60 \mathrm{Mbps}$ \\
\hline \hline Taxa Média do Tráf. de Interesse & $100 \mathrm{kbps}$ \\
\hline \hline Tam. pacotes do Tráf. de Interesse & 150 bytes \\
\hline \hline
\end{tabular}

Tabela 4.24: Tabela de parâmetros de QoS para cenário com tráfego interferente baseado no modelo Poisson, $50 \mathrm{Mbps}, 150$ bytes.

\begin{tabular}{||c||c||}
\hline \hline \multicolumn{1}{||c||}{ Parâmetro } & Valor \\
\hline \hline Atraso médio (Tráf. interesse) & $27,19 \mathrm{~ms}(20 \mathrm{~ms}$ prop.) \\
\hline \hline Desvio padrão amostral do atraso & $4,0 \mathrm{~ms}$ \\
\hline \hline Perc. Perda de pacotes (Tráf. interesse) & $9,4 \%$ \\
\hline \hline Comprimento médio da fila & 383,4 pacotes \\
\hline \hline Perda total na fila & 302990 pacotes \\
\hline \hline
\end{tabular}


Configurando o simulador para um período de amostragem de estatísticas de QoS de 100 ms, foram gerados os gráficos em função do tempo para atraso médio do tráfego de interesse (4.55), perda de pacotes do tráfego de interesse (4.56), comprimento médio da fila (4.57), perda de pacotes do tráfego agregado na fila (4.58).

Atraso tráfego interesse

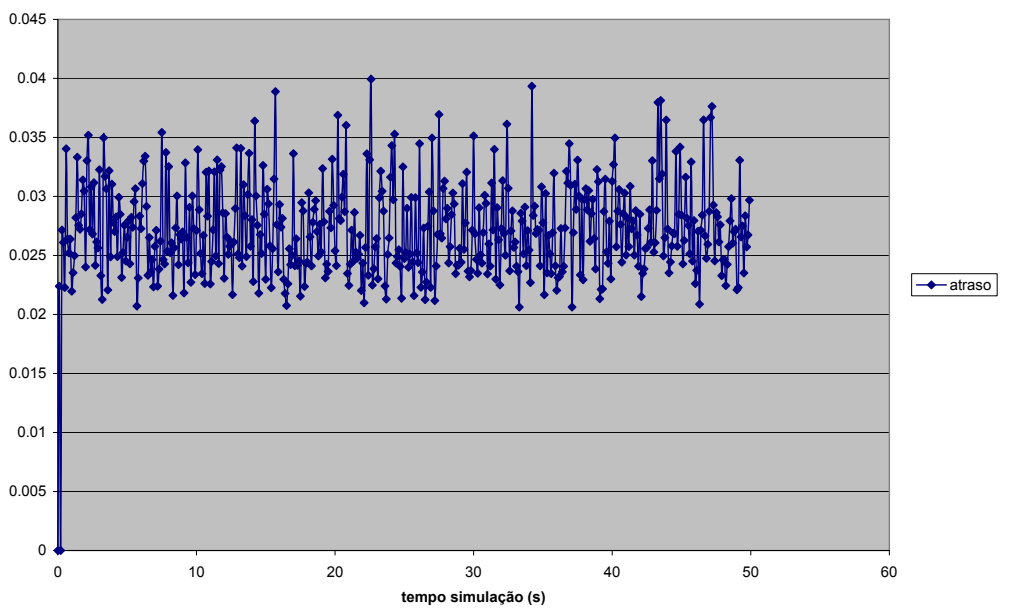

Figura 4.55: Atraso médio para o tráfego de interesse - cenário Poisson 50 Mbps com pacotes de 150 bytes. 


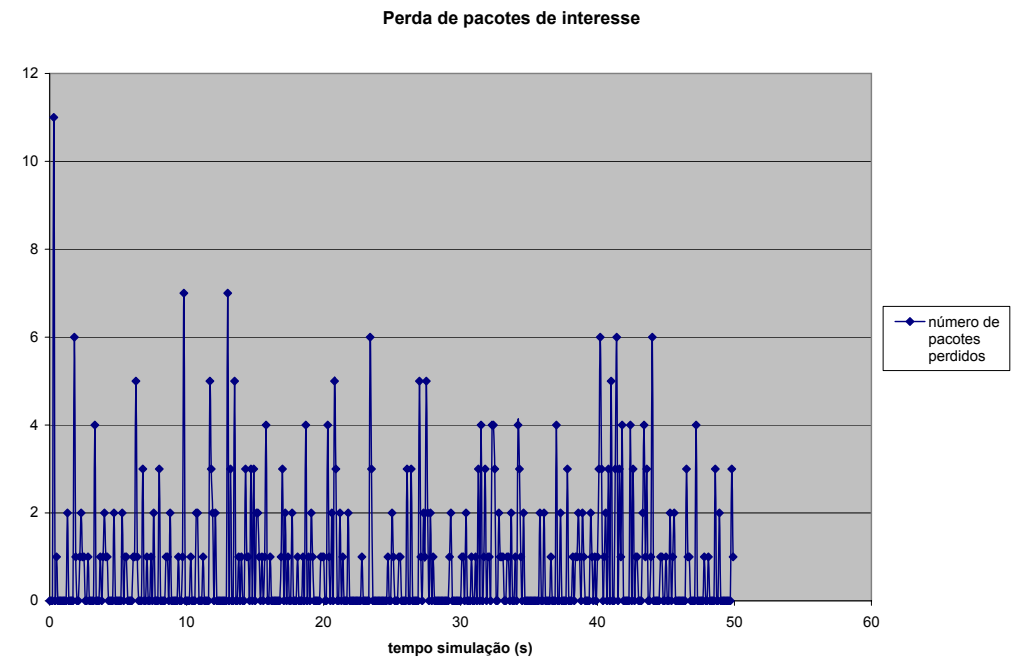

Figura 4.56: Perda de pacotes do tráfego de interesse - cenário Poisson 50 Mbps com pacotes de 150 bytes.

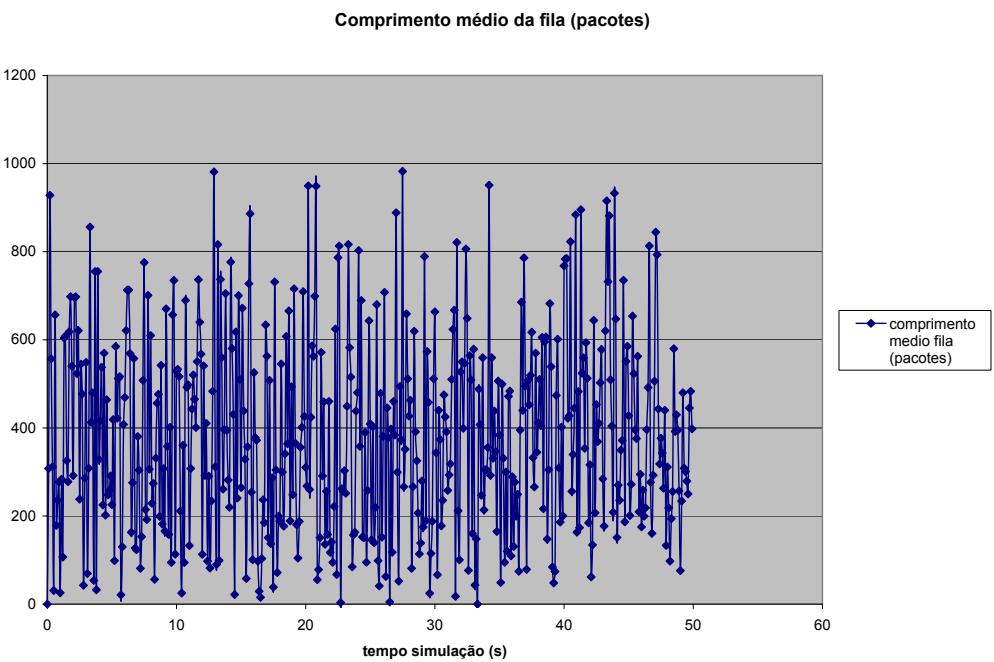

Figura 4.57: Comprimento médio da fila - cenário Poisson - 50 Mbps com pacotes de 150 bytes. 
Perda de pacotes na fila (agregado)

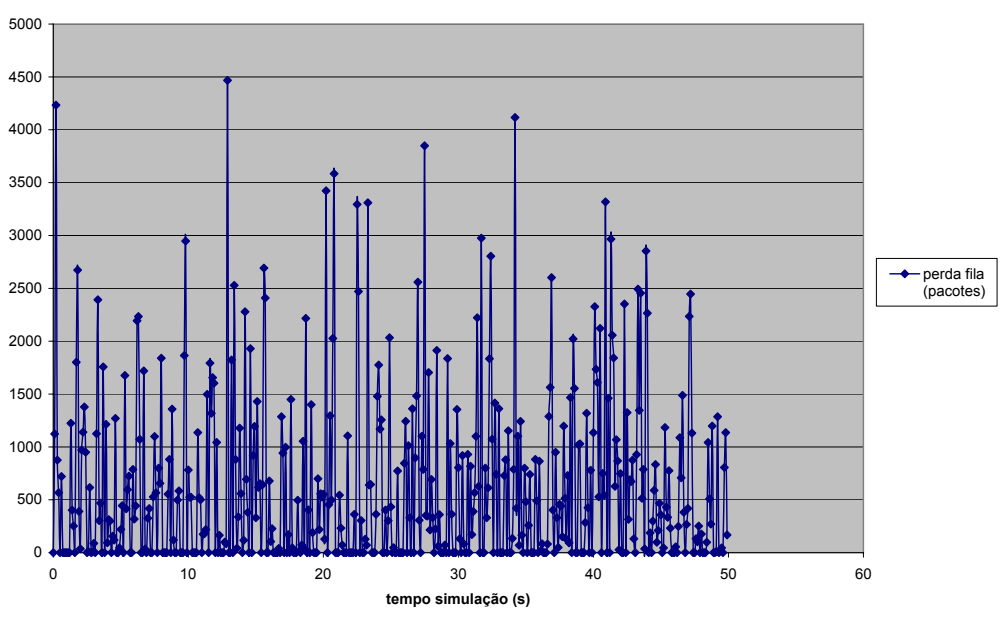

Figura 4.58: Perda de pacotes do tráfego agregado na fila - cenário Poisson 50 Mbps com pacotes de 150 bytes. 


\subsubsection{Consolidação dos resultados de simulação}

A Tabela 4.25 resume os resultados obtidos em cada cenário de simulação. Comparações iniciais somente são significativas entre os cenários de um modelo LRD de conversão específica vs. o respectivo modelo Poisson.

Tabela 4.25: Tabela de consolidação dos parâmetros de QoS para os diversos cenário de simulação.

\begin{tabular}{||c||c||c||c||c||}
\hline \hline Modelo & Atraso & Desvio atraso & $\begin{array}{c}\text { Perda Pacotes } \\
\text { (interesse) }\end{array}$ & $\begin{array}{c}\text { Compr. médio } \\
\text { na fila }\end{array}$ \\
\hline \hline MWM conv 1 & $26,21 \mathrm{~ms}$ & $7,5 \mathrm{~ms}$ & $13,3 \%$ & 4,16 \\
\hline Poisson 1 & $35,5 \mathrm{~ms}$ & $16,1 \mathrm{~ms}$ & $3,4 \%$ & 4,09 \\
\hline \hline MWM conv 2 & $36,25 \mathrm{~ms}$ & $19,2 \mathrm{~ms}$ & $4,1 \%$ & 31,33 \\
\hline Poisson 2 & $36,28 \mathrm{~ms}$ & $14,4 \mathrm{~ms}$ & $2,9 \%$ & 32,93 \\
\hline \hline fGN conv 1 & $28,65 \mathrm{~ms}$ & $6,9 \mathrm{~ms}$ & $2,5 \%$ & 41,10 \\
\hline Poisson 3 & $28,59 \mathrm{~ms}$ & $5,0 \mathrm{~ms}$ & $8,7 \%$ & 45,44 \\
\hline \hline fGN conv 2 & $26,12 \mathrm{~ms}$ & $6,0 \mathrm{~ms}$ & $4,6 \%$ & 285,13 \\
\hline Poisson 4 & $27,19 \mathrm{~ms}$ & $4,0 \mathrm{~ms}$ & $9,4 \%$ & 383,4 \\
\hline \hline
\end{tabular}

Verifica-se nas duas simulações com tráfego agregado MWM, que o percentual de perda de pacotes para o tráfego de interesse foi superior ao percentual obtido nos respectivos cenários com tráfego Poisson. Essa era uma das expectativas de efeito na fila causado pelo tráfego MWM, por tratar-se de um modelo LRD com alta variabilidade. Por outro lado, os resultados de simulação para o tráfego fGN não exibiram esse mesmo comportamento. O percentual de perda de pacotes com o tráfego fGN foi menor que os respectivos cenários com tráfego Poisson. Ainda assim, observa-se que o desvio do atraso é superior nos cenários com tráfego fGN do que o obtido nos respectivos cenários com tráfego Poisson.

Ressalta-se que os efeitos verificados nos resultados de simulação não devem ser generalizados. Trabalhos futuros deverão ser conduzidos para validar que os modelos fGN e MWM realmente reproduzem com precisão as características do tráfego encontrado em redes de dados, qual a faixa apropriada para o parâmetro de Hurst e quais são os níveis adequados de SRD. Além disso, as características dos traces de tráfego Poisson que são utilizados como comparação também podem ser melhor elaboradas. 


\section{Conclusão}

\subsection{Sumário e Contribuições}

Conforme enunciado na Seção 1.1, o objetivo principal deste trabalho é modelar e implementar um gerador de tráfego agregado capaz de reproduzir as características estatísticas encontradas em traces de tráfego reais, tais como, autosimilaridade, LRD e SRD. As séries de tráfego sintéticas produzidas por esse gerador podem ser aplicadas em cenários de simulação ou redes de teste para contribuir na investigação de algoritmos de controle de tráfego, estudo de protocolos de rede, avaliação de desempenho de sistemas sobre carga, entre muitas outras possibilidades.

O gerador de tráfego proposto é segmentado em dois estágios para síntese de séries temporais. Através da transformada wavelet de tempo discreto, implementou-se o estágio de geração de séries temporais do tipo $1 / f$ de maneira semelhante à apresentada por Bäckar. Dois modelos são contemplados: um modelo para síntese de séries Gaussianas LRD que aproxima realizações de um processo fGN, e um modelo não-Gaussiano denominado MWM, proposto por Riedi et. al. Esses modelos de tráfego utilizados são realistas e têm a propriedade de capturar a alta variabilidade do tráfego em várias escalas de tempo.

O segundo estágio de síntese de séries temporais atua sobre a série de saída do primeiro estágio e introduz a característica SRD via filtragem IIR. A DEP de um processo $\mathrm{AR}(4)$ sugere um nível de SRD em uma faixa de médias freqüências que foi aproximado pela resposta em frequiência do filtro arbitrário adotado. Demonstrou-se que o método de dois estágios proposto é bastante flexível e capaz de inserir SRD em realizações de processos do tipo $1 / f$. O resultado obtido será tão bom para aplicações de teletráfego quanto for o projeto do filtro passa-banda para modelar as características SRD presentes em traces de tráfego reais.

Foram efetuadas análises estatísticas das séries obtidas, utilizando momentos estatísticos de $2^{-}$, $33^{-a}$ e $4^{-}$ordens, além de testes estatísticos específicos para séries auto-similares: estimação do parâmetro de Hurst pelo método de Whittle e do 
periodograma. A etapa de análise estatística mostrou-se essencial para certificar que as características estatísticas modeladas em cada estágio são preservadas ao longo do processo de geração de uma série de tráfego.

Para que as séries sintetizadas pelo gerador possam ser aplicadas em simuladores ou redes de teste, é necessário converter as séries temporais para o formato de séries de tráfego (tamanho e instante de envio de pacotes). Duas propostas de conversão são abordadas: envio de chunks em intervalos de tempo equiespaçados e o envio de pacotes de tamanho constante posicionados uniformemente dentro do período de um bin. Essas duas alternativas são implementadas e efetua-se a análise estatística das séries de pacotes resultantes. Verifica-se, desse modo, que ambos os métodos de conversão preservam as propriedades LRD inicialmente sintetizadas nas séries temporais.

Por fim, mostra-se uma maneira de inserir as séries de tráfego sintéticas em cenários de simulação do simulador de redes NS-2. Resultados obtidos para parâmetros de QoS dos cenários com tráfego interferente baseado nos modelos fGN e MWM foram apresentados e preliminarmente comparados com resultados obtidos em cenários cujo tráfego interferente foi gerado com modelo Poisson. Ressalta-se, no entanto, que conclusões definitivas não podem ser traçadas a partir da análise desses cenários iniciais de simulação. Um estudo mais rigoroso envolvendo maior abrangência de parâmetros de simulação e compatibilização entre cenários de simulação para permitir a comparação de resultados de situações semelhantes precisa ser conduzido.

\subsection{Sugestões para Trabalhos Futuros}

Inúmeras extensões podem ser indicadas para esta dissertação. Enumeram-se abaixo algumas sugestões de trabalhos futuros:

1. realizar estudos aprofundados sobre as características de teletráfego em diferentes redes de comunicação, modelando através de evidências empíricas os níveis de LRD e SRD encontrados em traces de tráfego real. As conclusões desses estudos permitirão refinar o resultado do gerador de tráfego sintético;

2. ajustar os coeficientes do filtro IIR para obter resposta em freqüência compatível com os níveis de SRD encontrados em tráfego real;

3. ainda baseado em estudos de teletráfego, elaborar histogramas de tama- 
nho de pacotes e identificar um modelo para a distribuição de tempo entre pacotes com o objetivo de melhorar as propostas de conversão de séries temporais em séries de pacotes;

4. aprimorar as técnicas de análise empregadas neste trabalho, por exemplo através da investigação de estimadores que apresentem bom desempenho para séries mistas SRD e LRD. Um outro exemplo é explorar os estimadores do parâmetro de memória longa baseados em wavelets;

5. incorporar outros modelos de séries temporais através da alteração dos processos que determinam os valores dos coeficientes wavelet e dos coeficientes de aproximação, e alteração do filtro wavelet utilizado na IDWT;

6. averiguar vantagens de uso da Maximal Overlap Discrete Wavelet Transform (MODWT) e Discrete Wavelet Packet Transform (DWPT) na síntese e análise de séries temporais de espectro genérico (SRD e LRD);

7. desenvolvimento de um software ou de uma plataforma dedicada (que inclua hardware e software) para síntese on line de tráfego fractal em redes de teste;

8. explorar adequadamente o espaço de parâmetros de simulação e a definição de cenários a fim de obter resultados comparáveis entre modelos;

9. aplicação das séries de tráfego sintético em estudos de algoritmos de controle de congestionamento. 


\section{Referências}

ABRY, P.; VEITCH, D. Wavelet analysis of long-range dependent traffic. IEEE Transactions on Information Theory, v. 4, n. 1, p. 2-15, 1998.

ARMITAGE, G. Quality of Service in IP Networks: Foundations for a Multi-Service Internet. 1st.. ed. [S.1.]: MTP, 2001.

BAC by Mercury.

http://www.mercury.com/us/products/business-availability-center/, 2006.

BACCALá, L. A. Processamento de Sinais no Dominio Tempo-Freqüência Notas de Aula.

http://www.lcs.poli.usp.br/ baccala, 2003.

BACKäR, J.-A. A Framework for Implementing Fractal Traffic Models in Real Time. Tese (Master Thesis) — SERC, Melbourne, 2000.

BARRA, C. R. Caracterização experimental e por simulação e modelagem da qualidade de serviço obtida na transmissão de áudio e vídeo em tempo real. Tese (Tese de Doutorado) — Escola Politécnica da USP, São Paulo, 2005.

BAUER, M. A. et al. A quality of service management testbed. In: . [S.l.]: IEEE Third International Workshop on Systems Management, 1998.

BERAN, J. Statistics for Long-Memory Processes. [S.l.]: Chapman \& Hall, 1994.

BOX, G. E. P.; JENKINS, G. M.; REINSEL, G. C. Time Series Analysis:

Forecasting and Control. 3rd. ed. [S.1.]: Prentice Hall, 1994.

BROCKWELL, P. J.; DAVIS, R. A. Introduction to Time Series and Forecasting. New York, NY: Springer-Verlag, 1996.

CASELLA, G.; BERGER, R. L. Statistical Inference. 2nd. ed. [S.1.]: Duxbury, 2002 .

DAUBECHIES, I. Orthonormal bases of compactly supported wavelets. Comm. Pure Appl. Math., v. 41, p. 909-996, 1988.

DAUBECHIES, I. Ten Lectures on Wavelets. Philadelphia: SIAM, 1992.

DAVIES, R. B.; HARTE, D. S. Tests for hurst effect. Biometrika, v. 74, p. 95-101, 1987.

EMMA, D.; PESCAPE, A.; VENTRE, G. Analysis and experimentation of an open distributed platform for synthetic traffic generation. In: . [S.l.]: 10th IEEE International Workshop on Future Trends of Distributed Computing Systems, 2004 . 
EMMA, D.; PESCAPE, A.; VENTRE, G. et al. D-itg distributed internet traffic generator. In: . [S.l.]: First International Conference on the Quantitative Evaluation of Systems, 2004.

ERRAMILLI, A.; NARAYAN, O.; WILLINGER, W. Experimental queueing analysis with long-range dependent traffic. IEEE/ACM Transactions on Networking, v. 4, p. 209-223, April 1996.

FALL, K.; VARADHAN, K. The ns Manual. http://www.isi.edu/nsnam/ns/ns-documentation, 2006.

FAN, Z.; MARS, P. Self-similar traffic generation and parameter estimation using wavelet transform. IEEE Global Telecommunications Conference, 1997.

FLANDRIN, P. On the spectrum of fractional brownian motions. IEEE Transactions on Information Theory, v. 35, p. 197-199, 1989.

FLANDRIN, P. Wavelet analysis and synthesis of fractional brownian motion. IEEE Transactions on Information Theory, v. 38, n. 2, p. 910-917, 1992.

FLOYD, S.; PAXSON, V. Difficulties in simulating the internet. IEEE/ACM Transactions on Networking, 2001.

GABOR, D. Theory of communication. J. Inst. Eletr. Eng., v. 93, n. III, p. 429-457, 1946.

GENÇAY, R.; SELÇUK, F.; WHITCHER, B. An Introduction to Wavelets and Other Filtering Methods in Finance and Economics. [S.1.]: Academic Press, 2001.

GINSBURG, D. ATM solutions for enterprise internetworking. [S.l.]: Addison-Wesley, 1999.

GRANGER, C. W. J.; ; JOYEUX, R. An introduction to long-memory time series models and fractional differencing. Journal of Time Series Analysis, v. 1, p. 15-29, Oct. 1980.

HOLLABAUGH, P. C. Embedded Linux - Hardware, Software, and Interfacing. [S.1.]: Addison Wesley, 2002.

HOSKING, J. R. M. Fractional differencing. Biometrika, v. 68, p. 165-176, Oct. 1981.

HOSKING, J. R. M. Modeling persistence in hydrological time series using fractional differencing. Water Resources Research, v. 20, p. 1898-1908, 1984.

JARQUE, C. M.; BERA, A. K. A test for normality of observations and regression residuals. International Statistical Review, v. 55, n. 5, p. 163-172, 1987.

KAISER, G. A Friendly Guide to Wavelets. Boston, MA: Birkhäuser, 1994.

KAPLAN, L. M.; KUO, C.-C. J. Fractal estimation from noisy data via discrete fractional gaussian noise (dfgn) and the haar basis. IEEE Transactions on Signal Processing, v. 12, p. 3554-3562, 1993. 
KHAN, A. A. Practical Linux Programming: Device Drivers, Embedded Systems, and the Internet. [S.l.]: Charles River Media, 2002.

KWEON, S.-K.; CHO, M. gyu; SHIN, K. G. Soft real-time communication over ethernet with adaptive traffic smoothing. IEEE Transactions on Parallel and Distributed Systems, 2004.

LELAND, W.; TAQQU, M.; WILLINGER, W.; WILSON, D. On the self-similar nature of ethernet traffic (extended version). IEEE/ACM Transactions on Networking, v. 2, n. 1, p. 1-15, Feb. 1994.

LIMA, A. B. Proposta de uma Estratégia para o Controle de Admissão de Conexões Baseado em Medições de Tráfego Agregado e Caracterização de Redes IP. Dissertação (Mestrado) — Escola Politécnica da USP, 2002.

LIPAS, M. Análise de escalabilidade de adaptação de conteúdo multimídia através do padrão mpeg-21. Exame de Qualificação apresentado à Escola Politécnica da USP. 2005.

LOADRUNNER by Mercury.

http://www.mercury.com/us/products/performance-center/loadrunner/, 2006.

MALLAT, S. G. A theory for multiresolution signal decomposition: The wavelet representation. IEEE Transactions on Pattern Analysis and Machine Intelligence, v. 11, p. 674-693, 71989.

MANDELBROT, B. B.; NESS, J. V. Fractional brownian motions, fractional noises and applications. SIAM Rev., v. 10, p. 422-437, Feb. 1968.

PARK, K.; WILLINGER, W. et al. Self-Similar Network Traffic and Performance Evaluation. [S.l.]: Wiley-Interscience, 2000.

PAXSON, V. Fast, approximate synthesis of fractional gaussian noise for generating self-similar network traffic. Computer Communication review, v. 27, p. 5-18, Oct. 1997.

PAXSON, V.; FLOYD, S. Wide-area traffic: The failure of poisson modeling. IEEE/ACM Transactions on Networking, v. 3, n. 3, p. 226-244, June 1995.

PERCIVAL, D. B. Simulating gaussian random processes with specified spectra. Computig Science and Statistics, v. 24, p. 534-538, 1992.

PERCIVAL, D. B.; WALDEN, A. T. Spectral Analysis for Physical Applications. New York, NY: Cambridge, 1993.

PERCIVAL, D. B.; WALDEN, A. T. Wavelet Methods for Time Series Analysis. [S.l.]: Cambridge University Press, 2000.

PEREIRA, F. M. Análise de Desempenho da Disciplina de Serviço 'Generalized Processor Sharing' sob Tráfego Auto-Similar. Dissertação (Mestrado) Faculdade de Engenharia Elétrica e de Computação, Unicamp, 2002.

PáSZTOR, A. Packet Sender, version 0.1. Emulab, Australia. [S.l.], 2001.

RIEDI, R.; VéHEL, J. L. Multifractal properties of TCP traffic: a numerical study, Tech. Rep. 3129.

http://www.dsp.rice.edu/riedi/cv_publ_theme.html, 1997. 
RIEDI, R. H.; CROUSE, M. S.; RIBEIRO, V. J.; BARANIUK, R. G. A multifractal wavelet model with application to network traffic. IEEE Transactions on Information Theory, v. 45, n. 3, p. 992-1018, April 1999.

SATO, H. Teletraffic Technologies in ATM Networks. [S.l.]: Artech House, 1994.

SATO, J. R. Processos com Memória Longa Compartilhada. Tese (Dissertação de Mestrado) — IME-USP, São Paulo, 2004.

SCHWARTZ, M. Broadband Integrated Networks. [S.l.]: Prentice Hall, 1996.

SHIMIZU, J. A Multifractal Traffic Generation Method using Wavelet and Volterra Filtering. Sapporo, Japan: [s.n.], October 2004.

SKYPE.

http://www.skype.com/intl/pt/, 2006.

STARK, H.; WOODS, J. W. Probability and Random Processes with Applications to Signal Processing. 3rd. ed. Upper Saddle River, NY: Prentice Hall, 2002.

VEITCH, D.; BäCKAR, J.; WALL, J.; YATES, J.; ROUGHAN, M. On-line Generation of Fractal and Multi-Fractal Traffic. Hamilton, New Zealand: [s.n.], April 2000.

WALL, J. Implementing a tool for converting time series into ATM traffic. Dissertação (Mestrado) — Software Engineering Research Center (SERC), 1999.

ZIVOT, E.; WANG, J. Modeling Financial Time Series with S-PLUS. [S.l.]: Springer, 2003. 